WHC-EP-0873

Revision 0

1.

t i

Engineering Evaluation of

Alternatives:

Managing the Assumed Leak

from Single-Shell Tank 241-T-101

Prepared for the U.S. Department of Energy

Assistant Secretary for Environmental Management

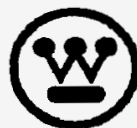

Westinghouse

Hanford Company Richland, Washington

Management and Operations Contractor for the

U.S. Department of Energy under Contract DE-AC06-87RL10930

Approved for public release; distribution is unlimited 


\section{LECAL DISCLAMMER}

This report was prepared as an account of work sponsored by an agency of the United States Government. Neither the United States Government nor any agency thereof, nor any of their employees, nor any of their contractors, subcontractors or their employees, makes any warranty, express or implied, or assumes any legal liability or responsibility for the accuracy, completeness, or any third perty's use or the results of such use of any information, apparatus, product, or process disclosed, or represents that its use would not infringe privately owned rights. Reference herein to any specific commercial product, process, or service by trade name, trademark, manufacturer, or otherwise, does not necessarily constitute or imply its endorsement, recommendation, or favoring by the United States Government or any agency thereof or its contractors or subcontractors. The views and opinions of authors expressed herein do not necessarily state or reflect those of the United States Government or any agency thereof.

This report has been reproduced from the best available copy. Available in peper copy and microfiche.

Available to the U.S. Department of Energy and its contractors from

U.S. Department of Energy

Office of Scientific and Technical Information (OSTI)

P.O. Box 62

Oak Ridge, TN 37831

(615) 576-8401

Available to the public from the U.S. Department of Commerce National Technical Information Service (NTIS)

5285 Port Royal Road

Springfield, VA 22161

(703) $487-4650$

Printed in the United States of Americe

DISCLM-1.CHP (8-95) 
LEGAL DISCLAMER

This report was prepared as an eccount of work sponsored by an agency of the United States Government. Neither the United States Government nor any agency thereof, nor any of their omployees, nor any of their contractors, subcontractors or their employees, makes any warrenty, express or implied, or assumes any legal liebility or responsibility for the

accuracy, completeness, or any third party's use or the results of such use of any information, apparatus, product, or process disclosed, or represents that its use would not infringe privately owned rights. Reference herein to any specific commercial product, process, or service by trade name, tredemark, manufacturer, or otherwise, does not necesserily constitute or imply its endorsement, recommendation, or favoring by the United States Government or any agency thereof or its contractors or subcontractors. The views and opinions of authors expressed herein do not necessarily state or reflect those of the United States Government or any agency thereof.

This report has been reproduced from the best available copy. Available in paper copy and microfiche.

Available to the U.S. Depertment of Energy

and its contractors from

U.S. Department of Energy

Office of Scientific and Technical Information (OSTI)

P.O. Box 62

Oak Ridge, TN 37831

(615) 576-8401

Aveilable to the public from the U.S. Department of Commerce National Technical Information Service (NTIS)

5285 Port Royal Road

Springfield, VA 22161

(703) 487-4650

Printed in the United Statee of America

DISCLM-1.CHP (8-95) 


\title{
Engineering Evaluation of Alternatives: \\ Managing the Assumed Leak from Single-Shell Tank 241-T-101
}

\author{
C. H. Brevick
}

Date Published

February 1996

Prepared for the U.S. Department of Energy

Assistant Secretary for Environmental Management

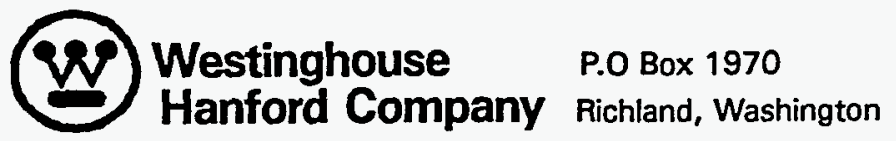

Management and Operations Contractor for the

U.S. Department of Energy under Contract DE-AC06-87RL10930

Approved for public release; distribution is unlimited 


\section{RELEASE AUTHORIZATION}

Document Number: WHC-EP-0873

Document Title: Engineering Evaluation of Alternatives: Managing the Assumed Leak from Single-She11 Tank 241-T-101

Release Date: $\quad 2 / 16 / 96$

This document was reviewed following the procedures described in WHC-CM-3-4 and is:

APPROVED FOR PUBLIC RELEASE

WHC Information Release Administration Specialist:

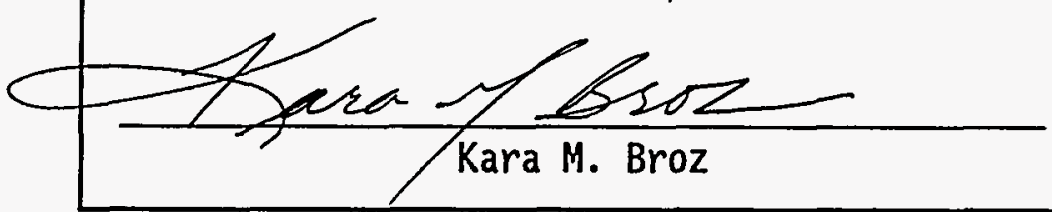


HHC-EP-0873, Rev. 0

\section{LIST OF CONTRIBUTORS}

Name

Claude Denson

Charles Jenkins

Michael

Danielson

Bradley Rarig

Rodney Campbe 71

Thiruchitr

Amba 7 am

Charles Kenoyer

Larry Hal1
Contribution

Project Manager

Principal Author

No-Action Alternative

In-Tank Stabilization

External Tank

Stabilization

Liquid Retrieval

Total Retrieval

\section{Company}

Kaiser Engineers Hanford Company

Kaiser Engineers Hanford Company

Pacific Northwest Laboratory

Kaiser Engineers Hanford Company

Kaiser Engineers Hanford Company

Kaiser Engineers Hanford Company

Kaiser Engineers Hanford Company 
WHC-EP-0873, Rev. 0

\section{ENGINEERING EVALUATION OF ALTERNATIVES \\ MANAGING THE ASSUHED LEAK FROM \\ SINGLE-SHELL TANK 241-T-101}

Prepared by

ICF Kaiser Hanford Company

Richland, Washington

for

Westinghouse Hanford Company
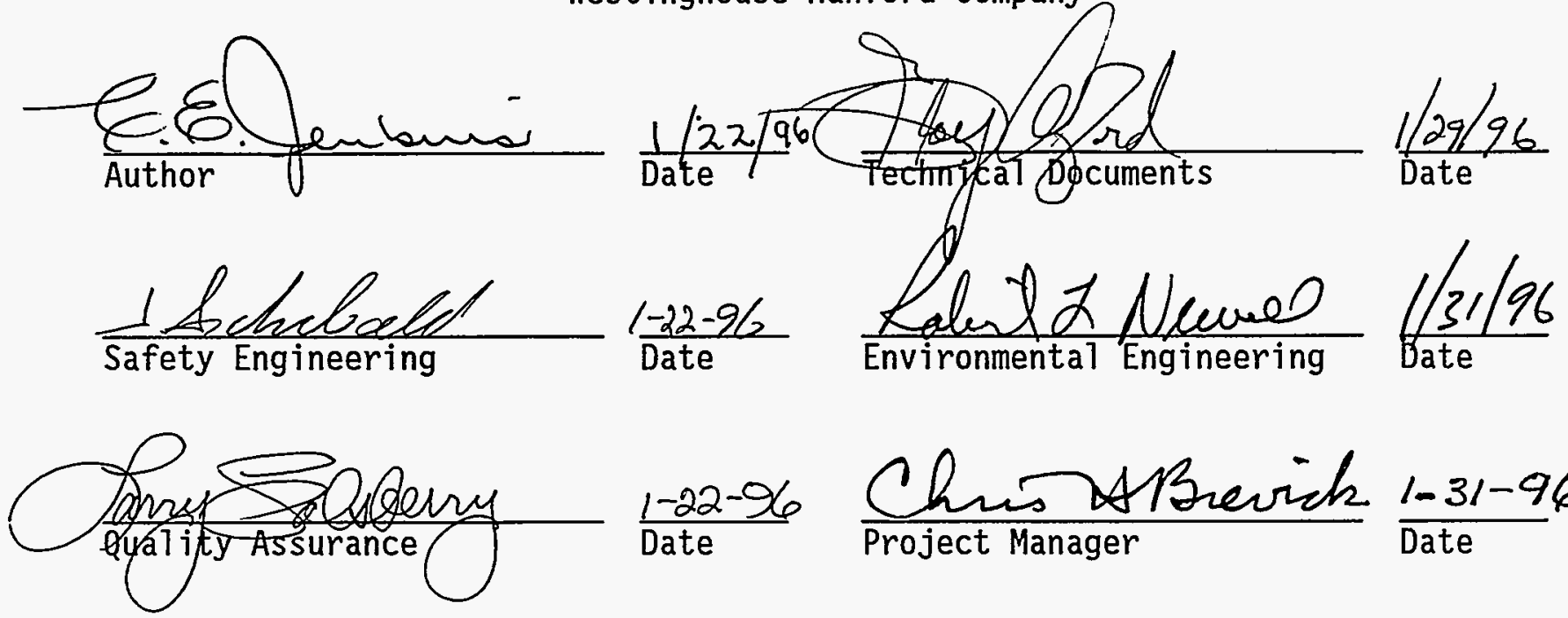

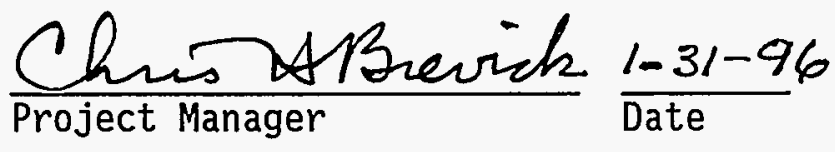

Westinghouse Hanford Company

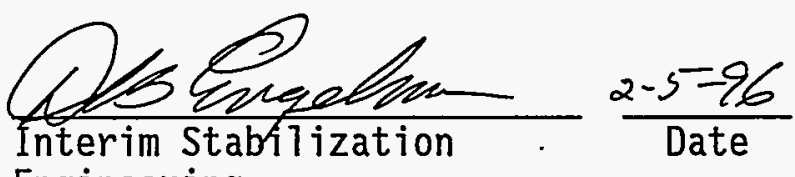

Engineering 


\section{CONTENTS}

1.0 STATEMENT OF PROBLEM . . . . . . . . . . . . 1-1

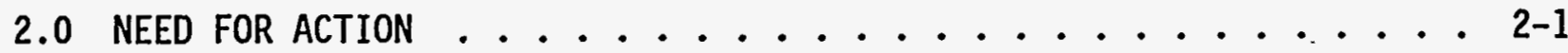

3.0 DESCRIPTION OF ALTERNATIVES ............... 3-1

3.1 NO-ACTION ALTERNATIVE .................. 3-1

3.1.1 Existing SST Option .................. 3-1

3.1 .2 Enhanced SST Option ................ 3-4

3.2 IN-TANK STABILIZATION ALTERNATIVE .......... 3-5

3.2.1 Tank Corrosion Inhibition Options ....... 3-5

3.2 .2 Liquid Absorption ................. 3-6

3.2 .3 Drying Options .................... 3-11

3.2 .4 Stop-Leak . . . . . . . . . 3-14

3.3 EXTERNAL TANK STABILIZATION ALTERNATIVE ......... 3-15

3.3.1 Subsurface Barrier Options . . . . . . . . . 3-15

3.3 .2 Ground Freezing Option ................ 3-23

3.3.3 Deep Soil Mixing ............... 3-25

3.3 .4 Geomembrane Walls .............. 3-25

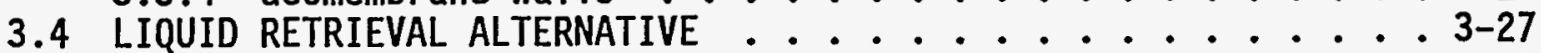

3.4.1 Pump out Option - Existing Pipeline ...... 3-34

3.4.2 Pump Out Option - New Pipeline ......... 3-36

3.4.3 Pump Out Option - Tank Truck/Railcar . . . . . . . 3-39

3.4.4 Pump In Option - Internal BT adder Vesse . . . . . . 3-39

3.5 TOTAL RETRIEVAL ALTERNATIVE ............. 3-41

3.5.1 Unlimited Sluicing Option ................ 3-41

3.5.2 Limited Sluicing 0ption ............... 3-43

3.5.3 Articulated Arm Scarifier . . . . . . . . 3-45

3.5.4 Mining .................... 3-48

4.0 HAZARDS EVALUATION ..................... . . . . .

4.1 CHEMICAL AND RADIOLOGICAL HAZARDS ............ 4-1

4.2 HYDROGEN GAS AND ORGANICS .............. 4-4

4.3 FERROCYANIDE STABILITY .............. . . 4-5

4.4 CRITICALITY .................. . . . . .

4.5 HIGH HEAT $\ldots \ldots$

5.0 ALTERNATIVES SELECTION CRITERIA . . . . . . . . 5-1

5.1 HEALTH SAFETY .............. $5-2$

5.1.1 Public Safety ............... 5-2

5.1 .2 Worker Safety .............. 5-2

5.1.3 Environmental Safety. . . . . . . . . . 5-2

5.2 REGULATORY COMPLIANCE .............. . . . . . .

5.2.1 Washington Administrative Code (WAC), Dangerous Waste

Regulations ............... 5-3

5.2.2 Closure/Post-ciosure Activities . . . . . 5-3

5.3 HASTE SAFETY . . . . . . . . . 5-3

5.3.1 Hydrogen/FTammable Gas Generation ....... 5-3

5.3.2 Ferrocyanide Stability . . . . . . . . . . 5-4

5.3 .3 Criticality ............... 5-4

5.3 .4 Heat Load ............... 5-4

5.4 TANK INTEGRITY ................ . . . . 5-4

5.4.1 Waterl ine corrosion ............ 5-4 
5.4 .2 sCC . . . . . . . . . . . . . . . 5-5

5.4.3 Crevice Corrosion ............... . . 5-5

5.4.4 Concrete Degradation/Cracking . . . . . . . . 5-5

5.4.5 Ease of Maintaining Confinement ......... 5-5

5.5 FUTURE RETRIEVAL AND PROCESSING . . . . . . . . . 5-5

5.5.1 Haste Retrieval ............... 5-5

5.5.2 Soil Retrieval ................ 5-6

5.5.3 Transfer System Integrity . . . . . . . . . . 5-6

5.5.4 Storage Availability ............... . 5-6

5.5.5 Treatment Compatibility ............. . 5-6

5.6 COST ........................ 5-6

5.7 SCHEDULE ....................... . . . . . . . .

5.8 TECHNICAL FEASIBILITY ................ 5-7

5.9 MAINTAINABILITY AND OPERABILITY ............. . 5-7

5.10 SELECTION CRITERIA HEIGHT FACTORS . . . . . . . . 5-7

6.0 COMPARISON OF ALTERNATIVES/OPTIONS ............... . . . 6-1

6.1 COMPARISON OF OPTIONS FOR NO-ACTION . . . . . . . . . 6-2

6.1.1 Health Safety .................. 6-4

6.1.2 Compliance with Laws and Regulations . . . . . . . 6-4

6.1 .3 Waste Safety ................... 6-4

6.1 .4 Tank Safety ................... . 6-5

6.1.5 Future Retrieval and Processing . . . . . . . . 6-5

6.1 .6 Cost ................... 6-5

6.1 .7 Schedule ................ . . 6-6

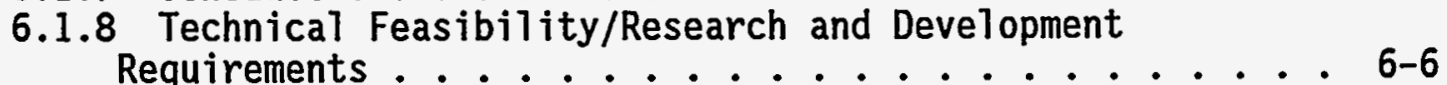

6.1 .9 Maintenance and operations . . . . . . . . . . 6-6

6.2 COMPARISON OF OPTIONS FOR IN-TANK STABILIZATION . . . . . . 6-6

6.2.1 Health Safety .................. . 6-6

6.2.2 Compliance with Laws/Regulations . . . . . . . . . 6-10

6.2.3 Waste Safety ................... 6-10

6.2.4 Tank Safety ................ . 6-11

6.2.5 Future Retrieval and Processing . . . . . . . . 6-12

6.2 .6 Cost ................... 6-15

6.2.7 Schedule ................... 6-15

6.2.8 Technical Feasibility/Research and Development
Requirements . . . . . . . . . . . 6-16

6.2.9 Maintenance and Operations . . . . . . . . . . 6-17

6.3 COMPARISON OF OPTIONS FOR EXTERNAL TANK STABILIZATION . . . . 6-17

6.3.1 Health Safety ................ 6-20

6.3.2 Compliance with Laws/Regulations ........... . 6-21

6.3.3 Waste Safety .................. 6-21

6.3.4 Tank Safety .. . . . . . . . . . . . . 6-21

6.3.5 Future Retrieva1 and Processing .. . . . . . . 6-22

6.3 .6 Cost ................... 6-23

6.3.7 Schedule . . . . . . . . . . . . . . . . 6-23

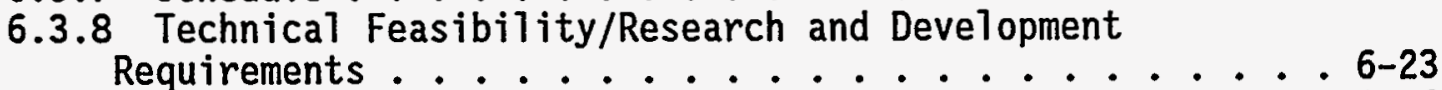

6.3.9 Maintenance and Operations . . . . . . . . . . 6-24

6.4 COMPARISON OF OPTIONS FOR LIQUID RETRIEVAL . . . . . . . . . 6-24

6.4.1 Health Safety .................. 6-24

6.4.2 Compliance with Laws/Regulations . . . . . . . . 6-27

6.4.3 Waste Safety .................. . 6-27

6.4 .4 Tank Safety ................... . . 6-28 
6.4.5 Future Retrieval and Processing ......... 6-28

6.4 .6 cost ..................... 6-29

6.4 .7 Schedule . . . . . . . . . 6-30

6.4.8 Technical Feasibility/Research and Development

Requirements .......... 6- 6-30

6.4.9 Maintenance and Operations ....... 6-30

6.5 COMPARISON OF OPTIONS FOR TOTAL RETRIEVAL SYSTEMS $\ldots . .6-30$

6.5.1 Health Safety .............. 6-.33

6.5.2 Compliance with Law/ReguTations . . . . . . . 6-33

6.5 .3 Waste Safety ............... 6-34

6.5 .4 Tank Safety ................ 6- . . . . . . . . .

6.5.5 Future Retrieval and Processing ........ 6-35

6.5 .6 cost ................ 6- 6-35

6.5 .7 Schedule . . . . . . . . . 6-35

6.5.8 Technical Feasibility/Research and Deve1opment

6.5.9 Maintenance and operations . . . . . . . . 6-36

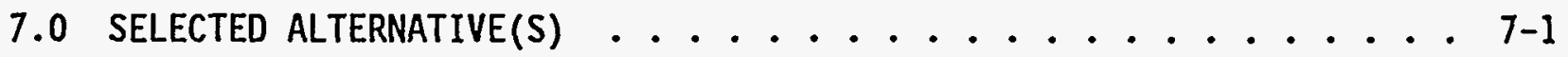

8.0 REFERENCES .......................... 8-1

9.0 GLOSSARY . . . . . . . . . . . . . . . GL-1

10.0 APPENDIX A PRELIMINARY ESTIMATES OF SCHEDULE AND COST FOR SELECTED WASTE MANAGEMENT ALTERNATIVES ....... A-1

SECTION A-1 SCHEDULE DETAILS FOR SELECTED ALTERNATIVES $\ldots \ldots$ SECTION A-2 COST DETAILS FOR SELECTED ALTERNATIVES ....... A-14 


\section{LIST OF FIGURES}

3-1 Tank 241-T-101 . . . . . . . . . . . . 3-2

3-2 Grout Barriers ................. . . . . . . . . . .

3-3 Jet Grout Curtain . . . . . . . . . . . . . 3-18

3-4 Wall and Bio-Polymer Slurry Trench . . . . . . . . 3-20

3-5 Sheet Metal Piling . . . . . . . . . . . . 3-22

3-6 Ground Freeze Barriers . . . . . . . . . . . . 3-24

3-7 Gundle Vertical Barrier System . . . . . . . . . . . 3-26

3-8 Tank 241-T-101 Salt Hell System . . . . . . . . . . . . 3-29

3-9 Salt Well Jet Pump . . . . . . . . . . . . 3-31

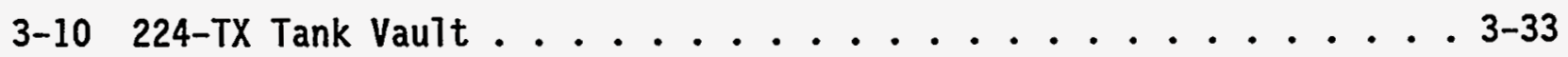

3-11 Existing Transfer Routes .............. 3- . . . . . .

3-12 New/Existing Transfer Route . . . . . . . . . . . 3-37

3-13 Tank Truck Transfer . . . . . . . . . . . . . . . 3-39

3-14 Tank Railcar Transfer . . . . . . . . . . . . . . 3-41

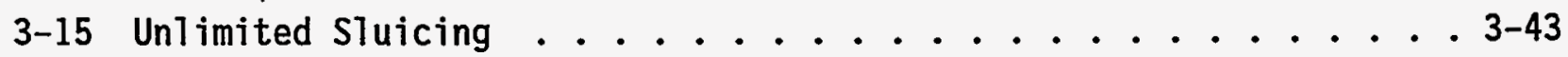

3-16 Limited Sluicing . . . . . . . . . . . 3-45

3-17 Limited Sluicing Assembly . . . . . . . . . . . . 3-46

3-18 Articulated Arm Scarifier System ... . . . . . . 3-49 
WHC-EP-0873, Rev. 0

\section{LIST OF TABLES}

4-1 Watch List Tank Status as of August 1992 . . . . . . . . . . . 4-2

4-2 Composition of Tank 241-T-101 Supernatant (Chemicals) . . . . . 4-3

4-3 Composition of Tank 241-T-101 Supernatant (Radiological) . . . 4-3

4-4 Track Radioactive Component Inventories for Primary Nonfissile Compounds in Tank 241-T-101 .......... . 4-4

4-5 Temperature History of Stabilized Ferrocyanide Tanks . . . . . . 4-6

4-6 Track Radioactive Component Inventories for $\mathrm{Pu}$ and $\mathrm{U}$ Isotopes in Tank 241-T-101 ............ 4-7

5-1 Weight Factor ..................... 5-1

5-2 Score Factor . . . . . . . . . . . . . . . 5-1

5-3 Criteria Height Factors . . . . . . . . . . . . . . 5-8

6-1 Total Weighted Scores for Each Alternative . . . . . . . . . 6-1

6-2 Comparison of Options for No-Action Alternative . . . . . . . 6-3

6-3 Comparison of Options for In-Tank Stabilization Alternatives . . 6-7

6-4 Comparison of Options for External Tank Stabilization A1ternative . 6-18

6-5 Comparison of Options for Liquid Retrieval A1ternatives . . . . . 6-25

6-6 Comparison of Options for Total Retrieval Alternatives . . . . . 6-31 
WHC-EP-0873, Rev. 0

\section{ENGINEERING EVALUATION OF ALTERNATIVES - \\ MANAGING THE ASSUMED LEAK FROM \\ SINGLE-SHELL TANK 241-T-101}

\subsection{STATEMENT OF PROBLEM}

The management program for interim stabilization of single-shell tanks (SST) containing high-level radioactive waste is being reassessed because significant changes have occurred since the last U.S. Department of Energy (DOE) Record of Decision in the 1988 Hanford Defense Haste - Environmental Impact Statement (HDH-EIS) (HDH-EIS 1988). These changes involve new issues in safety, waste disposal technologies and facilities, and DOE direction. Resolutions of issues in these areas are interdependent, therefore, technical plans for interim stabilization of SSTs need to be reexamined and rebaselined.

Decisions to mitigate leakage from SSTs were made by Energy Research and Development Administration (ERDA 1538) in 1975, and by the DOE in 1988. The DOE's decision was documented in the HDH-EIS Record of Decision (Federal Register, Vol 53, No. 72, April 14, 1988) and the Hanford Federal Facility Agreement and Consent Order (Tri-Party Agreement, May 1989). These documents provide the following objectives:

- Removal of Tiquids from SSTs to reduce the potential for future tank Teaks

- Continued storage of residual wastes in SSTs after 1 iquid removal

- Development and evaluation of methods for retrieving, processing, and disposing waste

- Minimization of worker exposure

- Limitation of environmental releases

- Protection of public health.

Selection of disposal technologies for individual SSTs in support of the 1988 and 1989 objectives was delayed, because of the lack of waste characterization information. As more waste characterization information was developed in the 1990s, waste-related safety issues were identified. Therefore, some SSTs were placed on safety watch lists, or an unreviewed safety question list (criticality issue) to ensure safe waste management during resolution of safety issues. In addition, facility and equipment-related technical issues have arisen, i.e., transfer line integrity (the need for double-encased transfer 1 ines), and long-term effects on retrieval from interim stabilization actions (accelerated tank corrosion and waste heating and hardening).

While these waste safety and technical issues were being identified for SSTs, the appropriateness of the disposal technologies selected for doubleshell tanks (DSTs) in the 1988 Record of Decision were challenged. The B-Plant (Hanford's waste pretreatment facility) was shut down, because it 
failed to meet regulatory requirements. The grout disposal method for lowlevel radionuclide and hazardous waste is being reassessed.

In response to safety and technical issues, and challenges to the 1988 Record of Decision, the DOE directed that a new strategy and a new baseline for disposal of tank waste be developed by March 31, 1993. Plans were to include storage, retrieval, transportation, processing, and disposal of all DST and SST waste. A new EIS would be prepared in lieu of a supplemental EIS to the HDW-EIS. This waste retrieval system EIS would address the retrieval and disposal of DST and SST wastes.

Because criticality safety and watch list safety issues were not reviewed, the 1988 interim waste management program was delayed, and is currently being reassessed. Therefore, Tri-Party Agreement milestones M-05-03 (interim stabilization of four tanks during fiscal year 1991), and M-05-04 (interim stabilization of nine tanks during fiscal year 1992) have not been met.

Alternative SST waste management plans are evaluated and ranked because of the interim stabilization program status, and events, that have occurred since 1988. Alternatives span the full range of technologies available for managing tank wastes. This report is focused on Tank 241-T-101, because this tank may have recently leaked. Possible alternatives to pumping 1 iquids from an assumed SST leaker are identified, evaluated, and screened using safety, compliance, and socioeconomic criteria. 


\subsection{NEED FOR ACTION}

One hundred forty-nine SSTs were constructed between 1943 and 1964 to store high-level radioactive wastes. These SSTs, monitoring instrumentation, ventilation, pipelines, and support equipment do not meet current standards and operating requirements. Sixty-seven of the SSTs are believed to have leaked a total of 600,000 to 900,000 gal of waste into the soil since operations began. Single-she11 tanks are projected to fail and began leaking at the rate of one per year.

In response to the Record of Decision and Tri-Party Agreement, a program has been established to interim stabilize a11 SSTs. Interim stabilization of an SST is achieved by reducing the Tiquid content to less than 50,000 gal of drainable interstitial liquid, less than 5,000 gal of supernatant, or a jetpumped flow rate of $0.05 \mathrm{~g} / \mathrm{min}$ has been achieved. This requirement is accomplished either by crystallizing or solidifying the liquid contents or by transferring the liquid to DSTs. Interim stabilization has been accomplished on a11 tanks except 44 SSTs. Tank 241-T-101 is among the remaining SSTs and contains approximately 133,000 gal of waste of which more than 30,000 gal is pumpable liquid.

At mid-year 1992, the 1iquid level gage for Tank 241-T-101 indicated that 6,000 to $9,000 \mathrm{gat}$ had leaked. Because of the liquid level anomaly, tank 241-T-101 was declared an assumed leaker on October 4, 1992. SSTs 1iquid level gages have been historically unreliable. False readings can occur because of instrument failures, floating salt cake, and salt encrustation. Gages frequently self-correct and tanks show no indication of leak. Tank levels cannot be visually inspected and verified because of high radiation fields. High radiation causes frequent failure of television cameras and electrical equipment and increases the difficulty in obtaining photographs. Manual tapes can be used, but their accuracy level does not allow detection of small volume leaks. These measurement uncertainties and the lack of adequate DST space often deiay recovery actions for an assumed leaker SST until accuracy and dependability of the gage can be determined.

The gage in Tank 241-T-101 has largely corrected itself since the midyear 1992 reading. Therefore, doubt exists that a leak has occurred, or that the magnitude of the leak poses any immediate environmental threat. White reluctance exists to use valuable DST space unnecessarily, there is a large safety and economic incentive to prevent or mitigate release of tank liquid waste into the surrounding environment.

During the assessment of the significance of the Tank 241-T-101 1iquid level gage readings, Washington State Department of Ecology determined that Westinghouse Hanford Company (WHC) was not in compliance with regulatory requirements, and directed transfer of the Tank 241-T-101 1iquid contents into a DST. Meanwhile, DOE directed WHC to examine reasonable alternatives/options for safe interim management of Tank 241-T-101 wastes before taking action.

The findings of these examinations are reported in this study. 
WHC-EP-0873, Rev. 0

This page intentionally left blank. 
WHC-EP-0873, Rev. 0

\subsection{DESCRIPTION OF ALTERNATIVES}

The five alternatives that could be used to manage waste from a leaking SST are: (1) No-Action, (2) In-Tank Stabilization, (3) External Tank Stabilization, (4) Liquid Retrieval, and (5) Total Retrieval. The a]ternatives span the full spectrum of recovery actions that could be used to manage SSTs containing liquid and solid wastes. Each alternative contains a number of options that could be used. Detailed descriptions are provided for those options thought to be the most viable, given our current knowledge of the physiochemical properties/parameters associated with SSTs and their wastes. In narrowing the scope of this engineering evaluation, some viable options may have been inadvertently overlooked or eliminated. More in-depth and focused evaluations should rectify that shortcoming. The evaluation is focused on Tank 241-T-101 which is a presumed leaker (1992 event). The a]ternatives are also applicable to 44 SSTs containing appreciable Tiquids that have not been interim stabilized.

\subsection{NO-ACTION ALTERNATIVE}

The No-Action alternative is defined as taking no action in response to a possible leaking SST. Normal maintenance and monitoring activities are continued. Nothing is done to mitigate, control, or stop the leakage nor is the waste retrieved in any fashion.

\subsubsection{Existing SST Option}

Radioactive mixed waste is stored in 149 underground SSTs at Hanford. Sixty-seven of these SSTs are assumed to have leaked. To date, 104 SSTs have been interim stabilized, i.e., the liquid partially pumped out.

Tank 241-T-101, as shown in Figure 3-1, was constructed between 1943 and 1944 and placed in service in December 1944. It is a domed, reinforced concrete structure that has a mild steel liner $(1 / 4$ in. side wa71; 5/16 in. knuckle area and bottom).. A $3 / 8$ in. layer of mastic separates the steel liner from the concrete she 17 . The tank is $75 \mathrm{ft}$ in diameter with a storage capacity of approximately 500,000 gal. Currently, it contains approximately 133,000 gal of waste of which approximately 30,000 gal are 1iquid. Recent liquid level measurements (1992) indicate that the tank may be leaking, a) though gamma logging in adjacent dry wells has not shown increased radioactivity. Since monitoring instruments frequently give false readings, there is currently great uncertainty as to the status of leakage in Tank 241-T-101.

3.1.1.1 Instrumentation/Monitoring. Tank liquid level has been determined by three different methods: Food Instrument Corporation (FIC) gauge, manual tape, and zip cord. The FIC gauge consists of wire-tank wall conductivity measurement excited by a 60 cycle, 24 Vac transformer system. Depth is determined by automatically lowering the tape and bob until contact is indicated by deflection of a current meter (current flows). A calibrated measuring wheel determines the amount of tape unrolled. The manual tape is similar to the FIC design (wire-tank wal1), but is manually reeled out (length markings directly on the side of the tape). A direct current (DC) source of excitation with an ohmmeter is used to indicate contact. Depth must be 
WHC-EP-0873, Rev. 0

Figure 3-1. Tank 241-T-101.

(ER3415/TMBM8).

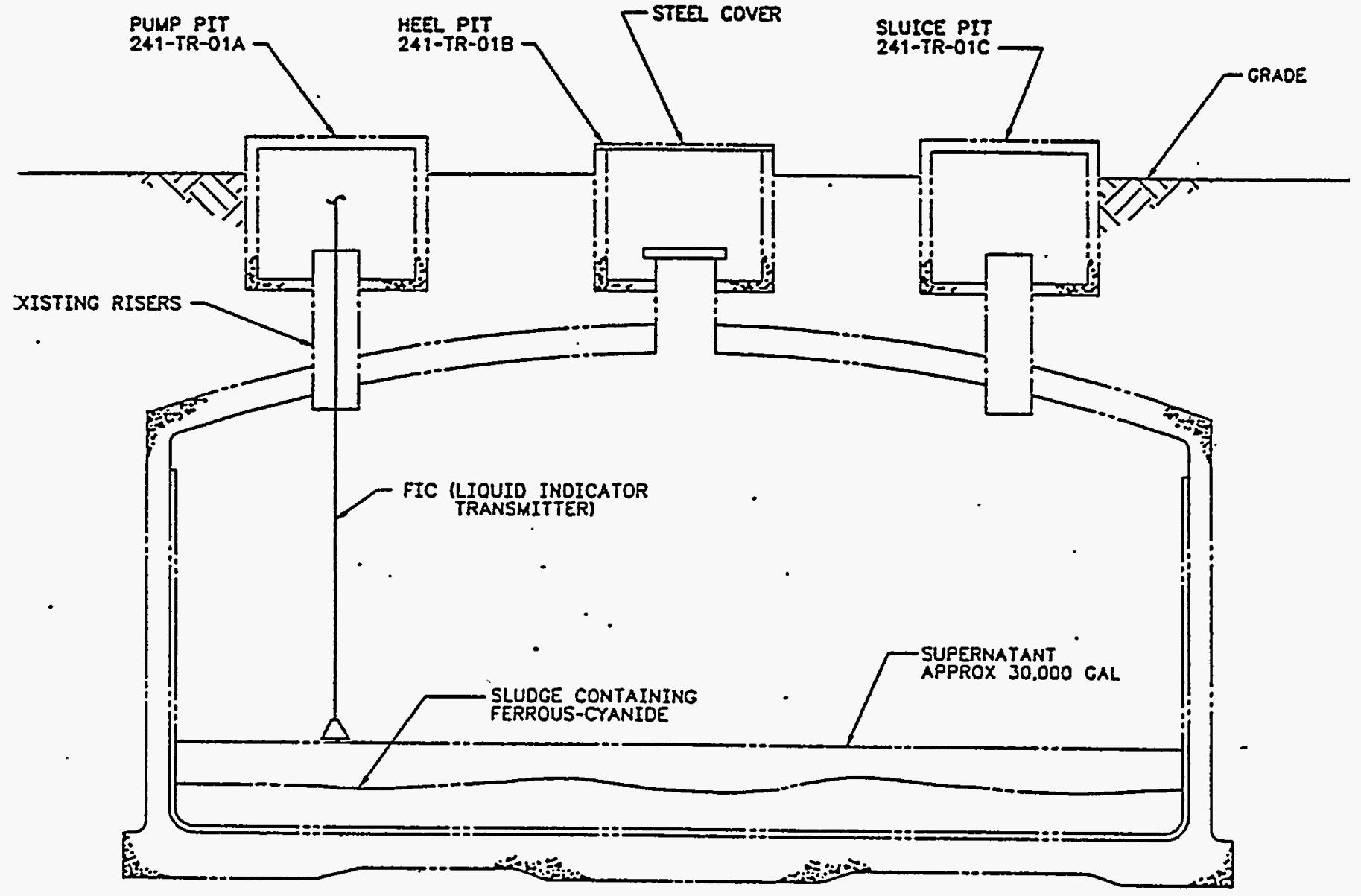

$24 \frac{\text { TANK }}{1-T-101}$ 
WHC-EP-0873, Rev. 0

indexed to some fixed point on the riser. The zip cord is an indexed 2-wire cord that is manualiy lowered until the exposed ends contact liquid to close the circuit. An ohmmeter is used to detect the loss of resistance (current flows) similar to the manual tape system. A complimentary visual observation of the tank surface does not take place when the tapes are lowered to the surface.

Without a complimentary visual observation, reproducible placement of the conductivity gauge cannot take place at the air/solution/solid interface. Both liquid and moist salt are conductive for this type of measurement. For instance, if the surface of the tank solution contains both salt and liquid, a finite conductivity measurement would be recorded when the tapes contacted a chunk of floating salt or stationary salt that may be several inches above the liquid level. Uncertainty of depth of $1 \mathrm{in}$. for a tank $75 \mathrm{ft}$ in diameter would represent a 2,750-gal uncertainty in the volume. The depth measurement, as presently constituted, can give a very uncertain liquid level measurement if salt bergs and/or salt encrustations are forming in a tank.

Another monitoring system is known as liquid observation well (LOW). A LOW is a closed-ended tube inserted to the bottom of the tank. Neutron and gamma-logging permits an indication of the liquid and pore water levels in the waste. Experimental observation has shown that the radiation levels are higher in the liquid than the salt cake. Since liquid seeks a constant level, this method is promising because it discerns both pore water and liquid levels independent of floating salt bergs or salt crust. Unfortunately, liquid level sensitivity is 1.2 in. because the data is logged ten times per foot. The LOW method has not been applied to Tank 241-T-101 because the closed-end tube has not been installed.

3.1.1.2 Steel Liner Corrosion Potential. There have been no efforts to retrieve liner steel plate samples from Hanford SSTs with leaks and conduct corrosion failure analyses of the steel samples. This has not been practical because retrieval and evaluation of radioactive contaminated plate samples are major tasks. Special equipment and procedures would have to be developed. Samples would have to be taken at random and many samples would have to be takèn to obtain a sample that coincided with a tank leak.

At the Savannah River Site (SRS), corrosion failure analyses were conducted for primary steel tank samples retrieved from observed leak locations (E.I. du Pont de Nemours and Company). The steel samples were taken from nonstress-relieved SRS DSTs that developed multiple leaks very soon after filling the caustic waste that included nitrates and nitrites. The failure analyses indicated that stress corrosion cracking (SCC) caused the SRS primary tank leaks. Haste chemistry is one of three basic conditions necessary to cause SCC in waste tank steel plate. The SRS 1aboratory SCC studies determined the waste chemistry variables that promote or inhibit SCC. High $\mathrm{pH}$ levels and nitrite concentrations were found to inhibit SCC. The other two necessary conditions for SCC occurrence are elevated temperature and high tensile stress.

The Hanford SST steel liners are nonstress-relieved. Therefore, based on the SRS study and the waste temperatures and chemistry that exist in Hanford SSTs, SCC in the liners is a hypothesized cause for SST leaks. 
The SRS failure analyses for waste tank steel samples did not confirm uniform, pitting, or crevice corrosion. Photographs have been taken inside Hanford SSTs that show the inside surface of the steel 1iner above the waste surface. Some of these photographs indicate that there could be through-wall corrosion at the waterline, therefore, remedial actions involving the use of liquids in SSTs are likely to cause leaks into the environment from those cracks.

3.1.1.3 Leak Self Healing. The SRS has observed large barnacles and stalactites of salt crystals adjacent to stress corrosion cracks that have breached the tank wall in the annular space of their DSTs. The SRS believes that the slow seepage followed by evaporation and reaction of the alkaline liquid with the surrounding air causes precipitation of a salt cake that closes off the leak (see E.I. du Pont de Nemours and Company).

There has been no observation of a similar plugging phenomenon at Hanford because there is no directly visible annular space in SSTs. There is an asphaltic mastic layer between the steel and concrete, and the concrete is in contact with the backfill. The SRS healing mechanism seems unlikely to be at work in SSTs since it would require contact with the air and evaporation of the liquid. Hanford SSTs in contact with concrete/backfill would have a much slower rate of water mass transport, preventing dry-out and salt precipitation. Hanford tanks that leak and later appear to stop may be more indicative. of the liquid level falling below the level of the crack.

\subsubsection{Enhanced SST Option}

The enhanced SST option refers to improving the leak monitoring instrumentation for the SST. Otherwise, the definition is the same for no-action (see Section 3.1).

3.1.2.1 Instrumentation/Monitoring. There are new methods of measuring depth by a tape that are being studied; the improved FIC system method and the displacer method. The improved FIC method uses modern electronics to repeatedly raise and lower the conductivity probe to search for a constant depth. The displacer uses a weight on a wire which is raised and lowered by modern electronic controllers that will break through a salt crust if it exists. Load on the wire is monitored to determine when the weight has reached the liquid level. Both methods suffer from the same problems mentioned earlier, namely, the need for a confirming visual observation that the sensing heads are in the correct location. Both devices will fit through 4-in. risers.

The most interesting new liquid-level measurement technique is a radar detector that continuously sweeps the surface to determine 1iquid depth in real time. A visual observation is required to confirm that the detector is focused on the liquid rather than on a salt berg or salt layer. A 30.5-cm (12-in.) diameter riser is required for entry into a tank. Recent experience in Tank 101-SY has been inconclusive using the radar detector, but this could be because the dynamic nature of the interface (hydrogen bubbling lifts the Tiquid) and/or salt bergs moving in and out of the radar window.

There are other liquid level measurement systems being evaluated such as acoustic/ultrasonics, gamma probes attuned to $106 \mathrm{Ru}$ decay, neutron probes, 
etc. Ongoing investigations have not yet clearly singled out one measurement system over another because of the diverse and complex waste chemical and radiation environments existing in SSTS.

Liquid-level measurements normally require a visual check to confirm the instrument reading. This cannot routinely be done because radiation prevents visual inspection and interferes with electrical systems such as television cameras. It is important to note that a tank without a free-standing phase of liquid (salt cake sludge fully filled with pore fluid to the top) can still leak. Thus, a surface level measurement may give a false sense of confidence. The LOW method might show the most promise if the sensitivity could be improved by an order of magnitude.

3.1.2.2 Leak Detection Systems. External dry we1ls exist around the tanks; Tank 241-T-101 does not have a lateral dry we11 under the tank as some SSTs do. Existing dry wells can be used to introduce neutron and gamma detecting equipment into the ground. Plumes of leaking waste will carry radioactive contaminants that can be identified by gamma-ray analysis. However, it has not been too successful because leaks from other tanks have raised the background radiation levels. New leaks do not significantly increase the measured radiation levels; consequently, there is usually not adequate sensitivity for monitoring new leak activity.

\subsection{IN-TANK STABILIZATION ALTERNATIVE}

This alternative refers to internal tank methods used to prevent 1iquid from leaking waste into the environment. These methods include preventing the leaks in the first place, trapping the liquid by some method, removing the liquid by drying, or plugging the leaks as they occur.

\subsubsection{Tank Corrosion Inhibition Options}

Corrosion inhibitors may be added to a tank to prevent or inhibit further tank-wall corrosion. The SSTs contain a mixture of solids and liquids which complicates the chemistry of liquid tank wastes and may make the addition of inhibition chemicals difficult to control. Analysis of the tank contents is required to determine what specific chemicals would be needed to add to the liquid waste to inhibit corrosion.

3.2.1.1 Tank Stress Corrosion Cracking Inhibitors. An SRS series of laboratory tests determined the waste chemistry variables which effect SCC of carbon stee] plates used for waste tanks. The caustic and nitrite concentrations are the most important and can be added to control SCC. Accordingly, SRS controls these concentrations in their waste storage tanks for protection from SCC.

It is unlikely that Hanford SST waste chemistry controls for SCC protection similar to those enforced for SRS tanks could be beneficial or practical. The reasons include:

- It would be too late. Historically, at SRS, nonstress-relieved primary tanks experienced multiple SCC leaks very soon after filling (without the current chemistry control). 
- The wastes stored in Hanford SSTs current1y are combinations of solids and some liquid. The chemistry variables have ranges of uncertainty. Therefore, it may be difficult to add this type of chemistry control and effectively inhibit SCC.

Historically, nonstress-relieved tanks failed very quickly in the high $\mathrm{pH}$ waste at SRS. Tank 241-T-101 should be thoroughly stress corrosion cracked by this time since it has all the predetermining factors. The SRS observed hundreds of cracks in their early nonstress-relieved tanks. It is probably too late to gather any benefit from modifying the chemistry in Tank 241-T-101 (assuming, first, that we know what the chemistry is, and secondly, that we can mix the waste).

\section{Advantages}

- Prevents further tank wal1/floor degradation

- Stops new leaks to the environment.

\section{Disadvantages}

- Tank contents must be mixed to properly distribute the inhibitor

- No known means of mixing solids and Tiquids in SSTs

- Does not stop existing leaks.

Application. The waste in the tank would be analyzed to determine its chemical makeup. The proper chemicals to inhibit corrosion would then be determined. These chemicals would be added to the tank and mixed to ensure uniform distribution. The tank contents would still be monitored to ensure that the waste is maintaining its desired properties. If it has changed, chemicals would be added to restore the desired inhibition properties.

3.2.1.2 Liquid Surface Inhibitors. The SRS (David Hobbs) has recognized that the waste/air interface of their high $\mathrm{pH}$ wastes will continuously absorb carbon dioxide from the air. This means that the hydroxide ions will react with carbon dioxide to make carbonates; thereby, tying up the hydroxide and lowering the $\mathrm{pH}$ and making the steel vulnerable to SCC at that location. The SRS periodically analyzes the surface (grab sample by bottle on a string) for $\mathrm{pH}$, nitrite, and nitrate. When needed (surface chemistry has dropped below their specifications), sodium hydroxide (sometimes accompanied with sodium nitrite) is sprayed onto the waste surface to inhibit SCC (E.I. du Pont de Nemours and Company).

The value of this process for Tank 241-T-101 requires knowing whether the failure process leading to leakage is because of ongoing SCC at the waste/air interface or old SCC cracks in the metal that intersect with ongoing cracking in the concrete. A conservative approach would assume that SCC of the metal is still ongoing. Implementation of the method would require analyses of the surface chemistry to establish a baseline.

\subsubsection{Liquid Absorption Options}

Liquid absorption can be used to trap the 1 iquid in the tank by immobilizing it. Diatomaceous earth (DE) and portland cement have been tried at 
Hanford with little success. They are included in this study to demonstrate the application of various options and their impact on the selection criteria.

3.2.2.1 Diatomaceous Earth. Diatomaceous earth acts like a sponge when it is added to Tiquids. Once absorbed, the liquid cannot be removed without adding heat to dry the DE. Solids are more difficult to retrieve from SSTs than liquids. While DE can aid in preventing or mitigating a leak, its use complicates waste retrieval, increases volume solids, and makes waste more difficult to process using existing and planned waste handling and treatment facilities.

Diatomaceous earth has been added to the following six SSTs at Hanford (WHC-EP-0338 draft).

\begin{tabular}{|c|c|c|}
\hline Tank & Amount & $\begin{array}{c}\text { Date diatomaceous } \\
\text { earth added }\end{array}$ \\
\hline $241-\mathrm{BX}-102$ & 95 tons & January 1972 \\
\hline $241-S X-113$ & 41 tons & Apri1 1972 \\
\hline $241-$ TX-116 & 95 tons & November 1972 \\
\hline $241-$ TX-117 & 41 tons & January 1971 \\
\hline $241-T Y-106$ & 27 tons & February 1972 \\
\hline $241-U-104$ & 55 tons & May 1972 \\
\hline
\end{tabular}

Liquids were first pumped from the tanks before the DE was added. This minimized the amount of DE required to absorb liquids. This same approach would 7ikely be used for any future DE additions. If DE were added to a tank, such as Tank 241-T-101, prior to interim stabilization, the large quantity needed to absorb ali the excess liquid would add enormously to the volume to be retrieved and make processing much more difficult.

\section{Advantages}

- Easy to distribute if free liquids have been removed

- Soaks up small pools of liquid well

- Easy to add to the waste.

Disadvantages

- Salt well jet pump not likely to work for retrieval due to $0.127 \mathrm{~cm}$ $(0.05$ in.) openings in the salt well screen

- May contribute to corrosion of the carbon steel wall by removing Tiquid by dioxides and nitrites

- Existing equipment can only transport liquids

- No existing or planned systems to process DE solids 
WHC-EP-0873, Rev. 0

- Experience with hot-ce11 samples from DSTs indicates that if wastes dry out, they are much more difficult to dissolve for transporting and processing. Additions of DE will contribute to this phenomena by removing cooling capability associated with evaporating liquids

- There have been no efforts to date to retrieve DE stabilized tanks. It is not known to what extent DE will complicate future waste retrieval and processing operations

- Overall increase in the volume of waste to be retrieved and disposed.

Application. The DE was injected into the liquid waste using air pressure. One problem encountered during injection was that the DE tended to clump as it became wet, making it difficult to spread evenly through the liquid waste.

Sufficient quantities of DE must be injected into the waste to ensure absorption of the free liquid. As discussed previously, this dry material causes a problem for future retrieval and processing. Present equipment can only handle liquid wastes. Any dry waste would have to be redissolved prior to retrieval. The present vacuum-evaporator crystallizer would have problems processing the retrieved DE wastes to reduce excess liquids. Solids created by adding DE are likely to complicate retrieval/transport and processing operations. This would greatly increase the volume of waste to be handled, processed, and disposed. The dissolving of DE solids produces gels that are hard to transport. Diatomaceous earth is heavy in silicates, which are difficult to process through existing and planned pretreatment facilities.

3.2.2.2 Portland Cement. Portland cement can be added to a tank to absorb some of the liquid waste and form a grout barrier. The cement could be placed where the tank wall and the liquid interface to prevent liquids from leaking out of the tank.

This method has been used in onty Tank 241-BY-105 (WHC-EP-0338 1990). Fifty-seven tons of portland cement were added as part of a demonstration program. The cement did not mix we17. After injecting the portland cement, some of the remaining liquid was pumped out. The mixture blocked the underground transfer lines.

\section{Advantages}

- Relatively inexpensive and readily available for use.

\section{Disadvantages}

- Wi11 plug liquid waste transfer lines

- Does not inhibit tank corrosion

- No existing Hanford equipment for retrieval of solids generated

- No existing Hanford equipment for processing solids generated 
WHC-EP-0873, Rev. 0

- No reliable method exists to mix portland cement with liquid waste in the tank

- Any cement added to the tanks will have to be broken up and removed during solids retrieval

- Potential for explosive gas and/or exothermic reactions to be generated during mixing of liquid waste.

Application. Field personnel indicate that when the portland cement was injected onto a pool of liquid waste, the cement powder simply spread out across the surface of the waste without mixing. The cement powder never mixed well with the liquid to form the desired grout barrier. In trying to remove residual liquid from the tank, the main underground transfer line became blocked by cement. The underground line had to be abandoned and the liquid transported by adding overland transfer lines. Assuming a method is found to mix the 1iquid waste with portland cement, a method for retrieval and processing the solid waste would be required. The solids would need to be broken into small enough pieces (while still in the tank) to permit retrieval and processing. Otherwise, the solids will be in such large pieces (potentially, many cubic feet in volume) that they cannot be removed through any existing tank openings.

The portland cement option could be developed to allow filling of an entire tank without future retrieval. In this option, the entire tank contents would be mixed and solidified and the tank filled with grout and abandoned in-place. The waste would then be considered disposed. A concrete vault could be built around the tank and the environment monitored. This option would eliminate waste retrieval and processing.

\subsubsection{Desiccants/Gels.}

Desiccants. Desiccants placed in a tank could remove the free liquids in the waste. Since a desiccant does not have to physically contact the liquids to remove moisture, it has an advantage over an absorbent that must contact the liquid to absorb it. The desiccant would need to be isolated from the outside atmosphere to ensure that it only collects tank moisture. Whether the desiccant would work we1l to remove the interstitial liquids under and in the salt cake sludge is unknown. The tank contents may need to be mixed to ensure these liquids are exposed to the desiccant. No desiccants have been placed in waste tanks.

\section{Advantages}

- May remove moisture without contacting the waste

- Won't heat waste while removing moisture.

\section{Disadvantages}

- If desiccant is suspended above the waste, ensuring that it does not drop into the waste as moisture is absorbed it would require an internal support structure suspended within the tank

- Handling the desiccant when removed from the tank 
WHC-EP-0873, Rev. 0

- Redissolving any solidified waste for retrieval and processing. Experience with hot cell samples from DSTs indicates that if the samples dry out, they are much more difficult to dissolve

- Ensuring there are no isolated pools of free 1iquid in the waste to leak out

- Potential explosive gas generation when mixing the waste.

Application. If the desiccant is suspended above the liquid level, precautions must be taken to ensure that the moisture picked up in the desiccant does not cause the desiccant to drop into the liquid. Equipment and experience exist that should enable desiccant to be added safety into the tank. Exposure of trapped liquids in the solid waste to the desiccant is an unsolved problem. Waste retrieval would not be directly affected by the desiccant. As waste dries out, however, it becomes more difficult to retrieve. Either new methods of solid-waste retrieval and processing need to be developed or liquid would have to be reintroduced to dissolve the waste for retrieval and processing.

If the desiccant were placed directly in the waste, all of the above would still apply. However, the chemical properties of the desiccant would have to be evaluated to determine what effect they might have on process chemistry and equipment.

Gels. Pacific Northwest Laboratory is currently working on a proposal to develop a media that could be added to the liquid waste to turn it into a gel that would return to a liquid state when mixed, stirred, or pumped. The title of the proposal is "Non-leaking Hydraulic Retrieval: Development and Demonstration of Non-leaking Dissolution and Slurrying Media for Retrieval of Waste from Leaking Tanks." The purpose of this study is to "develop a nonleaking fluid for retrieval of SST waste. It will have a low viscosity when stirred and pumped, but forms a nonflowing gel when left undisturbed." One of the candidate fluids has exhibited the desired thixotropic behavior when mixed with a simulated SST salt cake. Colloidal silica forms a gel when mixed with salts or salt solutions, due to ion exchange between the salt cation and the silinol hydrogen. The strength of the gels were controllable by adjusting the silica solids content, salt concentration and $\mathrm{pH}$. The gelling process was found to be reversible by lowering the pH below 6 .

No gel material has been added to any Hanford waste tanks, although some laboratory testing has been done to demonstrate its feasibility. Numerous activities and issues must be resolved before implementation can take place. The time frame in the milestone summary indicates that development will not be complete until September 30, 1995. If the technology is successful, it will allow hydraulic retrieval of waste which provides a larger cost savings over mechanical retrieval.

\section{Advantages}

- Liquid waste will gel to ensure no leakage from tank even though new wall defects develop

- Retrieval virtually the same as if no media added to waste 
WHC-EP-0873, Rev. 0

- Processing only slightly more difficult with gel.

\section{Disadvantages}

- Tank contents must be mixed to ensure even media distribution throughout the waste

- The increased silicate loading complicates processing

- Under development, with a minimum 2- to 3-year time frame before practical full-scale application

- May enhance corrosion by removing hydroxide and nitrite inhibitors

- Potential for explosive gas generation when mixing liquid waste.

Application. Gel media could be added to the waste using similar technology to that developed for $D E$ and portland cement. A method of mixing must be developed that ensures uniform distribution throughout the waste. If the gel works as described, retrieval would be virtually the same as pumping liquids for interim stabilization. The waste would liquify under the shear introduced by the pump. Processing of waste should remain the same as presently planned, except, there are additional silicates from the gelling media. Operating personnel indicate that silicates are difficult to process through the vacuum evaporator crystaliizer.

\subsubsection{Drying Options}

Drying offers a method for physical removal of tank liquids without changing chemistry or providing external transport to a DST. The methods investigated include heat exchangers, microwave systems, and air drying. A11 these methods evaporate liquids and leave the waste solid.

\subsubsection{Heat Exchangers. The referenced report contains information on a} model system for underground waste storage tanks and a circulator-concentrator (Dunn 1986). The circulator-concentrator system consisted of a 400 gal stainless steel vessel equipped with a circulator of 3-in. internal standard schedule 40 pipe that is 32 in. long. It is vertically suspended 6 in. above the bottom of the tank. Evenly spaced within this circulator are six tubular hairpin 1,500 watt, $240 \mathrm{~V}$ immersion heaters.

In a recent test, these heaters were immersed in simulated waste of Tank 101-BY for 407 hours. Measurements of flowrate velocity of the waste did not reveal any significant changes in the circulation rate as the quantity of solids increased. However, there were difficulties as the concentration increased. Small holes in the air distributor, used for circulation, became plugged from crystal growth. Steam sparging and lancing were required to keep the ports open (total of 14 times during the test).

At 112 hours, the solution reached a concentration sufficient to allow crusting over the surface. As it formed, the crust broke up and sank to the bottom. The salt cake on the circulator top was 8 in. thick when the test ended. The final specific gravity $(\mathrm{sg})$ was 1.670 at $68{ }^{\circ} \mathrm{C}$. When it cooled to 
room temperature, the apparent solids content was $96 \%$ with a sg of 1.495 and a viscosity of 21 centipoise at $33^{\circ} \mathrm{C}$.

A11 measurements and observations indicate that no insurmountable process difficulties would be encountered in plant operations for the circulatorconcentrators unless extended periods of shutdown are required. There was a localization of the remaining liquid after concentration that should simplify addition of cementing agents for any remaining liquid. U1timate disposal of these final liquids would take place in containers filled with cementing agents.

Per discussions with field personnel, this method of waste stabilization was dismissed in the 1975 to 1976 time frame because the vacuum-evaporator crystallizer worked better. In addition, the waste needed to be heated to approximately $240^{\circ} \mathrm{F}$ to boil off the moisture since the process took place at atmospheric pressure rather than at the reduced pressure of the evaporator crystallizer.

\section{Advantages}

- Removes most of the moisture to virtually eliminate leakage

- Haste is mostly crystalline when complete

- Little residual liquid to be disposed.

\section{Disadvantages}

- Waste must be heated to approximately $115.6^{\circ} \mathrm{C}\left(240^{\circ} \mathrm{F}\right)$ to boil off liquids (maximum allowable temperature of ferrocyanide tank is $\left.20{ }^{\circ} \mathrm{C}\left[392^{\circ} \mathrm{F}\right]\right)$

- Increased moisture load on heating, ventilating, and airconditioning (HVAC) equipment

- Drying waste makes it much more difficult to retrieve and process

- Existing retrieval and processing equipment cannot handle solids

- Not an efficient method of evaporation. (Vacuum evaporator/ crystallizer works at $65.5^{\circ} \mathrm{C}$ )

- May increase corrosion by removing inhibitors (hydroxides and nitrites)

- Potential explosive gas generation from additional heat to tank waste

- Design for application in the final storage container.

3.2.3.2 Microwave. Microwave heating shows promise of being capable of completely and finally stabilizing pumped and unpumped tanks to less than $4 \%$ total moisture. The economic incentive for portable microwave use thus can be even greater than wiped $f i 1 m$ evaporation for interstitial liquors because existing piping would not be required, and salt well pumping, transfers or double-shel1 storage would not be required (Berry 1990). The proposed microwave system need not become contaminated; thus, it should be much easier 
to move from tank to tank. It does, however, require a portable exhauster and would require the same size chiller-condenser-deionizer planned for the wiped film evaporation (E.I. du Pont de Memours and Company 1982).

Oak Ridge worked on simulated waste with a $1 / 3$ scale proprietary microwave system. The intent was to evaporate the free water in the waste followed by melting of the salt residues. The cooled melt forms a solid monolith. The final waste volume is much less than the original because the water is removed and the salts are melted residues. They can produce final waste with no free particulates or liquids (White 1990).

The microwave energy heats the waste directly because the oscillating electric fields directly couple to the molecular bonds of the chemicals in the waste, causing frictional heating. The microwave process contains no moving parts and is designed to heat the liquid waste in the final storage container. The direct heating of the microwave energy must be carefully controlled to avoid process upsets such as splattering, arcing, and thermal runaway.

During testing, boiloff liquid occurred at approximately $120^{\circ} \mathrm{C}\left(248{ }^{\circ} \mathrm{F}\right)$. The residual salt melted when the temperature rose to $360^{\circ} \mathrm{C}\left(680^{\circ} \mathrm{F}\right)$.

\section{Advantages}

- Can produce a very dry waste product

- One microwave assembly can be used in numerous tanks

- Microwave unit does not contact the waste and is not contaminated.

\section{Disadvantages}

- Solidified waste is difficult to redissolve for processing

- Waste will need to be heated to approximately $360{ }^{\circ} \mathrm{C}$ to melt the salt residue if the tank is chosen for final storage. (This exceeds the maximum allowable temperature $\left[200^{\circ} \mathrm{C}\right.$ ] for a ferrocyanide tank.)

- In-tank mixing may be required

- Tank contents must be heated to approximately $120^{\circ} \mathrm{C}$. Hot spots easily develop

- A new/modified ventilation system must be developed to condense all the excess moisture vapor developed while boiling the liquid

- Still in development stage. May be years before practical application

- No existing equipment for retrieval or processing solids

- Potential explosive gas generation when heating the waste

- High temperatures may structuraliy damage the concrete tank.

3.2.3.3 Air Drying. Circulating air through the air space above the liquid waste will remove moisture through evaporation. The moisture-laden air is passed through a condenser to remove the excess moisture and prevent damage to 
WHC-EP-0873, Rev. 0

the high-efficiency particulate air (HEPA) filters. Air drying works much slower and at lower temperatures than the other drying techniques.

The air-drying method may require mixing of the tank contents to maximize the removal of moisture. Circulating the air is not likely to remove the moisture entrained in the salt cake. Air circulation has been used to c001 tanks. Cooling dried the waste surface as it removed the heat. The waste surface has been described as desert like. How much the circulating air dried the waste underneath the surface is unknown.

\section{Advantages}

- Method has been used in the past and results in waste surface that looks like a "desert"

- Ventilation system can be readily connected to tank

- Ventilation system does not contact waste

- No requirement for new technology.

\section{Disadvantages}

- No existing equipment to retrieve or process solids

- Tank contents require mixing to get maximum drying

- Isolated pockets of liquid likely to exist even if thorough mixing is done

- This method may enhance corrosion of the tank wall by eliminating the liquid corrosion inhibitors

- Modified ventilation system needed to remove moisture from the air

- Through-wall defect below dried waste may result in leak to the environment

- Once the waste dries, it is difficult to redissolve according to WHC tank operations personnel.

\subsubsection{Stop-Leak Option}

A material similar to that used in a leaking automobile radiator has been proposed for stopping flow from a leaker tank. Stop-leak materials will need to be mixed into the liquid waste, this way it can flow to the liner defect and plug it.

Typical ingredients in commercially available products are sodium silicate, polysaccharide, colloidal clay, smedtite clay, borax, wood flour, bentonite clay, sodium metasilicate, defoamer, corrosion inhibitors, and water.

Advantages 
- Safe for environment and personnet

- Proven process, it works in automobile radiators

- Commercially available, therefore, relatively inexpensive

- Easy to inject

- Quick response to a leaking tank

- Corrosion inhibitor added at the same time as stop leak.

\section{Disadvantages}

- Increased silicate loading

- Requires mixing the waste

- Potential explosive gas generation when mixing heated waste

- Waste must be heated

- Unknown how much media to add and how evenly it will be distributed

- Effects on future processing are unknown.

Application. Injection of the stop-leak media can be done using existing technology. But, a means of thoroughly mixing it in the liquid layer is required to ensure the media gets quickly to the tank defect. Stop-leak does not solidify or thicken the waste and should not affect liquid retrieval methods. But the silicate loading that comes from the media may make processing more difficult. Processing silicates through the evaporator is difficult.

\subsection{EXTERNAL TANK STABILIZATION ALTERNATIVE}

External tank stabilization can retain contaminates at the waste site to significantly lessen the environmental impact of leaking tanks. Stabilization of the soil surrounding the tank with subsurface barriers, without stressing the tank, can prevent migration of the plume to lessen the amount of contaminated soil--an important goal of interim stabilization. A number of innovative in-situ technologies have emerged in recent years for hazardous waste containment. They include grouting, freezing (cryogenic barriers), deep soil mixing, sheet metal piling, and geomembrane walls.

Ground-freezing and ground-cooling technologies can be used to immobilize contaminates around a leaking container. They can act as a barrier to plume migration to prevent further contamination of a site. Geomembrane walls are similar to sheet piling (subsurface barriers) except that the barrier. permeabilities are significantly lower. Membrane and hazardous waste compatibility is important in achieving closure status after remediation. Factors that influence the selection of an appropriate technology include waste characteristics, soil characteristics, and hydroecology. Site-related information and data requirements for a given stabilization technology may be found in the documents referenced.

\subsubsection{Subsurface Barrier Options}

Subsurface barriers can be used to isolate and/or immobilize the waste once outside the tanks. Isolation is achieved by placing a wall or membrane of low permeability between the waste and the environment. Immobilization is a process where leaked waste is converted to a less mobile, more chemically stable form. Subsurface barriers can be grout barriers, siurry walls, or 
sheet piles depending on waste and soil properties and characteristics of the site. Surface encapsulation is one of a broad spectrum of technologies that involve subsurface installation of barriers. It does not treat waste directly but serves to immobilize contaminates. Surface encapsulation involves chemicals that may influence future options for site closure. Surface encapsulation is not addressed in this summary because regulatory guidelines are not formulated to permit their use.

3.3.1.1 Grout Barriers. In the grouting process, fluid additives are injected into soil to form a barrier that reduces the movement of water/contaminates through the site, or increases the strength of a site's natural barriers (see Figure 3-2). Grouting has been frequently used in remedial actions at radioactive waste sites. A drawback to grout barriers is that they are not capable of truly achieving low permeabilities in unconsolidated materials as surrounds the Tank 241-T-101 site. Leaks can occur between pours. Both the grout formulation and the techniques for placement are important factors in whether the grout will perform properly to mitigate migration of contaminants. Theoretically, placement of grout around and underneath the contaminated sites (bottom sealing) is possible; in practice, this has proven to be very difficult and expensive to accomplish. The subsoil strata at tank sites is a mixture of coarse and fine grained sand. Rainfall is low. This suggests that low viscosity grouts placed by injection or jet grouting may be reasonably effective in reducing permeabilities and in preventing migration of contaminants.

Grouts are typically injected with pumps and mixers. Proposals for grouting involve shallow low-pressure injection to seal the voids in the soil and create a barrier to lateral or vertical migration of contaminates.

Materials used can be silicates, acrylate, urethane, and portland cement. Jet grouting is a wide array of techniques to washout cavities in the subsurface soils (see Figure 3-3). With directional drilling, jet grouting can be used to install barriers to prevent vertical migration. Jet grouting uses highpressure water or air jets to create cavities in the soil. The cavities are then refilled with bentonite clay or portland cement mixtures.

Chemicals or cements used in injection and jet grouting can effectively be used to produce an impermeable barrier. Presently, no technique is available to detect any discontinuities between pours/injjections. The grout masses can leave gaps through which contaminates may pass. Jet grouting was proven effective in a wide variety of geologic media (such as fine sand or mixture of silt and sand) where waste/grout interactions are not significant problems. Jet grouting requires specialized equipment that is not normally available localiy. It requires significantly more time to set up and cleanup than injection grouting.

\section{Advantages}

- Forms high strength barrier

- Effective in preventing horizontal migration of contaminants

- Adaptable to use in preventing vertical migration- 
WHC-EP-0873, Rev. 0

Figure 3-2. Grout Barriers.

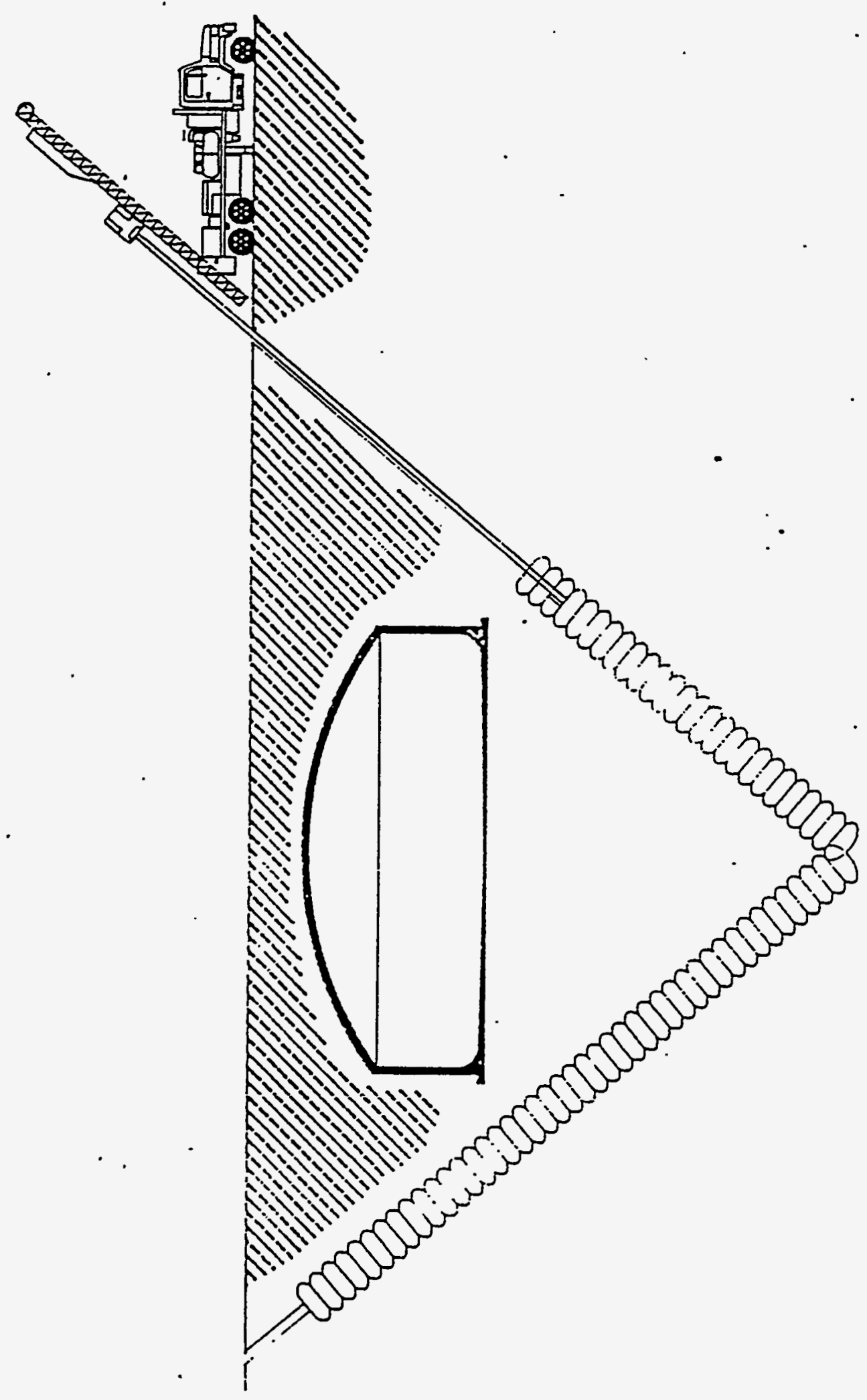


WHC-EP-0873, Rev. 0

Figure 3-3. Jet Grout Curtain.

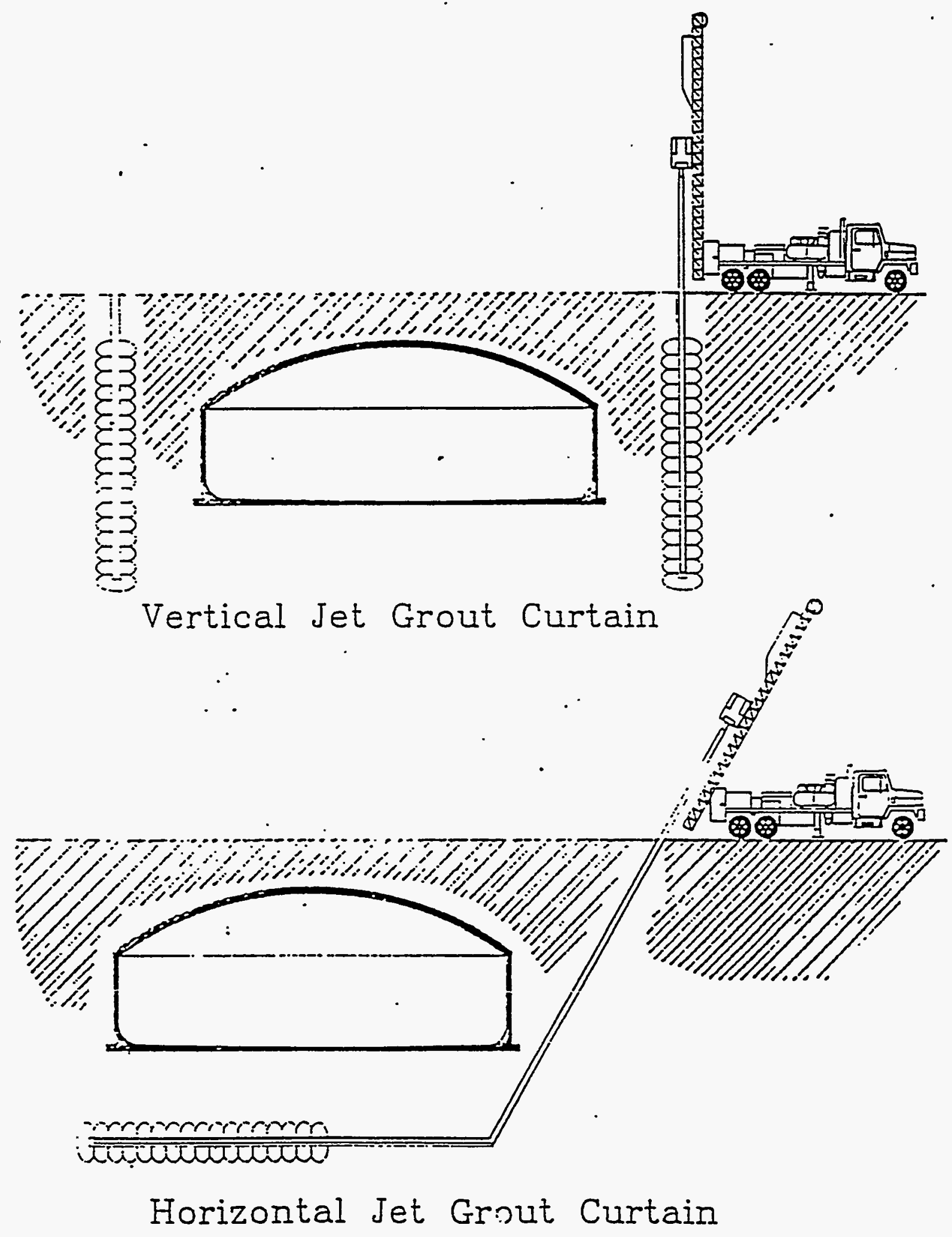


WHC-EP-0873, Rev. 0

- Uses low cost, readily available, ecologically acceptable materials for construction

- Commercially available technique frequently used to prevent migration of radioactive materials

- No hazardous materials associated with technology

- Retrievable if necessary for final disposal and site restoration.

\section{Disadvantages}

- Leak paths may develop between pours

- Leak paths may develop if used in unconsolidated soils and rock

- Grout placement around and beneath contaminated site is difficult and expensive

- Significantly increases the amount of contaminated soil requiring treatment.

3.3.1.2 Slurry Wa11s. Slurry walls (see Figure 3-4) are used to contain waste or contamination and reduce the potential of future migration of contaminants. Slurry walls are constructed in vertical trenches that are excavated while being filled with slurry. The slurry provides a shoring for the trench and forms a barrier preventing fluid losses to the environment. Slurry walls are differentiated by the type of materials used in the slurry mix. Most commonly, an engineered soil mixture is blended with a bentonite clay slurry to form a soil-bentonite slurry wall. Portland cement, bentonite, and water are also frequently blended to form a cement-bentonite slurry wall.

of the major types, soil bentonite walls offer the lowest installation costs, and the broadest range of chemical compatibilities, with relatively low permeability. Cement-bentonite walls offer high strength, low permeability and are suited to restricted areas, such as around tank sites. Large spaces are needed to mix soil-bentonite. Cement-bentonite barriers have higher permeability than soil-bentonite, but are subject to cracking and chemical attack. Soil-bentonite slurry walls are generally favored by regulators because of extremely low permeabilities and a high degree of compatibility with hazardous chemicals.

Slurry walls are mainly employed as a vertical barrier. Bottom sealing is rarely feasible. Deep excavation is usually required to maintain contaminant contro7. Excess soil has to be disposed. It is important that the walls be extended and sealed to a natural barrier confining layer under the contaminated site to prevent seepage underneath the wal1. At the Tank 241-T-101 site, the applicability of slurry walls is 1imited, because of the long distance to a confining layer, and the close proximity of the tanks to each other. However, slurry wa17s used in conjunction with jet grouting may offer a viable, cost-effective option to mitigate tank leakage during waste retrieval operations. 
WHC-EP-0873, Rev. 0

Figure 3-4. Wall and Bio-Polymer S7urry Trench.

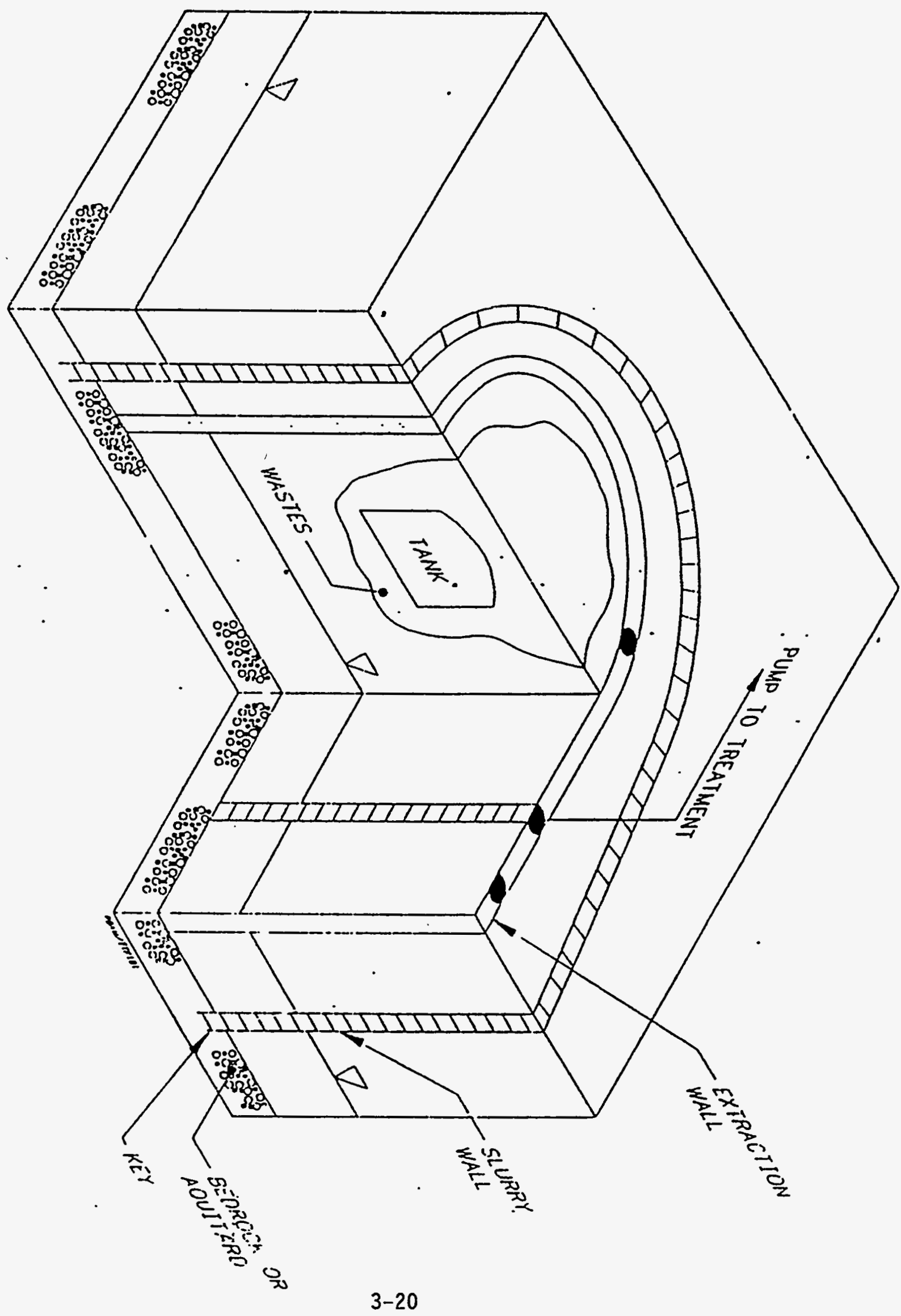


HHC-EP-0873, Rev. 0

\section{Advantages}

- Forms relatively high strength, low permeability barrier

- Low installation and material costs

- Compatible with hazardous chemicals--no hazardous materials associated with technology

- Effective in wide variety of geologic media

- Retrievable if necessary for final disposal and site restoration.

\section{Disadvantages}

- Barrier permeability sensitive to construction materials used

- Not applicable to stopping vertical migration of contaminants

- Specialized equipment and significant setup and cleanup time required

- Significantly increases the amount of contaminated soil requiring treatment

- Excavation activities disturb any contaminated soil present

- Large excavation requirement preclude its use in close proximity to other tanks.

3.3.1.3 Sheet Piles. Sheet piles (see Figure 3-5) are routinely used in the construction industry to prevent intrusion of ground water. Sheet piles are interlocked sheets of steel or concrete panels, driven into the subsurface by hydraulic or pneumatic pile drivers. They provide a continuous barrier. The piles that stabilize the sheets are driven into the ground via a jetting shoe, vibratory hammer, or static emplacement. Steel sheet piles are costeffective, but only a temporary method of retaining the contaminates. They can be installed close to the tanks.

A drawback of sheet piling is the installation problem caused by rocky soils as found in the Hanford tank farms. Damage to or deflection of the piles during installation usually renders the barrier ineffective. Bottom sealing of the containment area is not feasible using this technique.

\section{Advantages}

- A developed commercial technology

- May be installed in close proximity to leaking tank

- Barriers easily removed

- Low material costs. 
WHC-EP-0873, Rev. 0

Figure 3-5. Sheet Metal Piling.

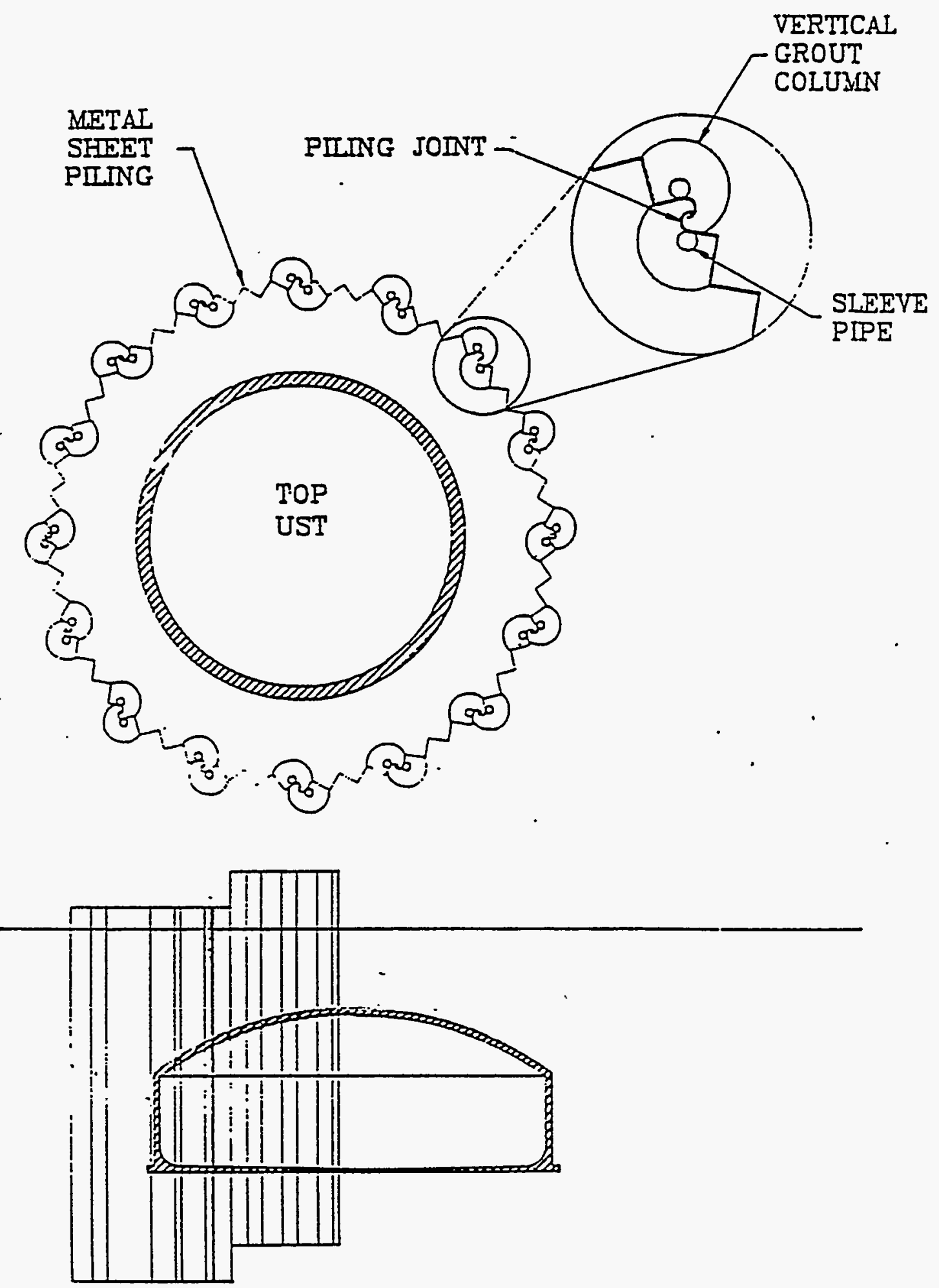


HHC-EP-0873, Rev. 0

Disadvantages

- Sheet piles deflected by rocks, hardened soils, etc., during installation compromises barrier integrity

- Leaks in barrier frequently occur between sheet pilings

- Vibrations from pile driver in close proximity can damage existing piping, equipment, and tanks

- Not applicable to stopping vertical migration of contaminants

- Sheet piling is subject to corrosion

- Significantly increases the amount of contaminated soit requiring treatment.

\subsubsection{Ground Freezing Option}

Artificial ground freezing (see Figure 3-6) involves the installation of freezing loops in the ground and a self-contained refrigeration system that pumps coolant through the loops. By injecting coolant (e.g., ethylene glycol or liquid nitrogen) into the loops, the soil can be cooled below the freezing point. Ground freezing renders the soil practically impermeable. It has high operations and maintenance costs.

Two freezing methods have been used to date: (1) slow-rate freezing in closed-loop systems or (2) rapid-rate freezing in open-loop systems using liquid nitrogen. Open-7oop systems are advantageous because they achieve much lower temperatures $\left(-321^{\circ} \mathrm{F}\right)$ than compressor-type closed-7oop systems that achieve freezing temperatures of $-4^{\circ} \mathrm{F}$.

The primary advantage of the freezing technologies is that they require no chemicals or additives that may restrict future options. Ground freezing has been used in the construction industry to prevent groundwater intrusion. Both vertical and horizonal barriers are possible and the subsurface around the tank can also be included. Because operations and maintenance costs are high, this technique is considered short-term. Ground freezing may induce thermal stresses in tanks nearby and cause stress cracking in the concrete and metal lining. Frozen soils expand and could damage tank structures.

\section{Advantages}

- Isolates tank and prevents further leakage

- Impermeable barrier to horizontal and vertical migration of contaminants

- Commercially available technology

- Effective in all soil media

- Little impact on decontamination and site restoration activities. 
$\downarrow z-\varepsilon$

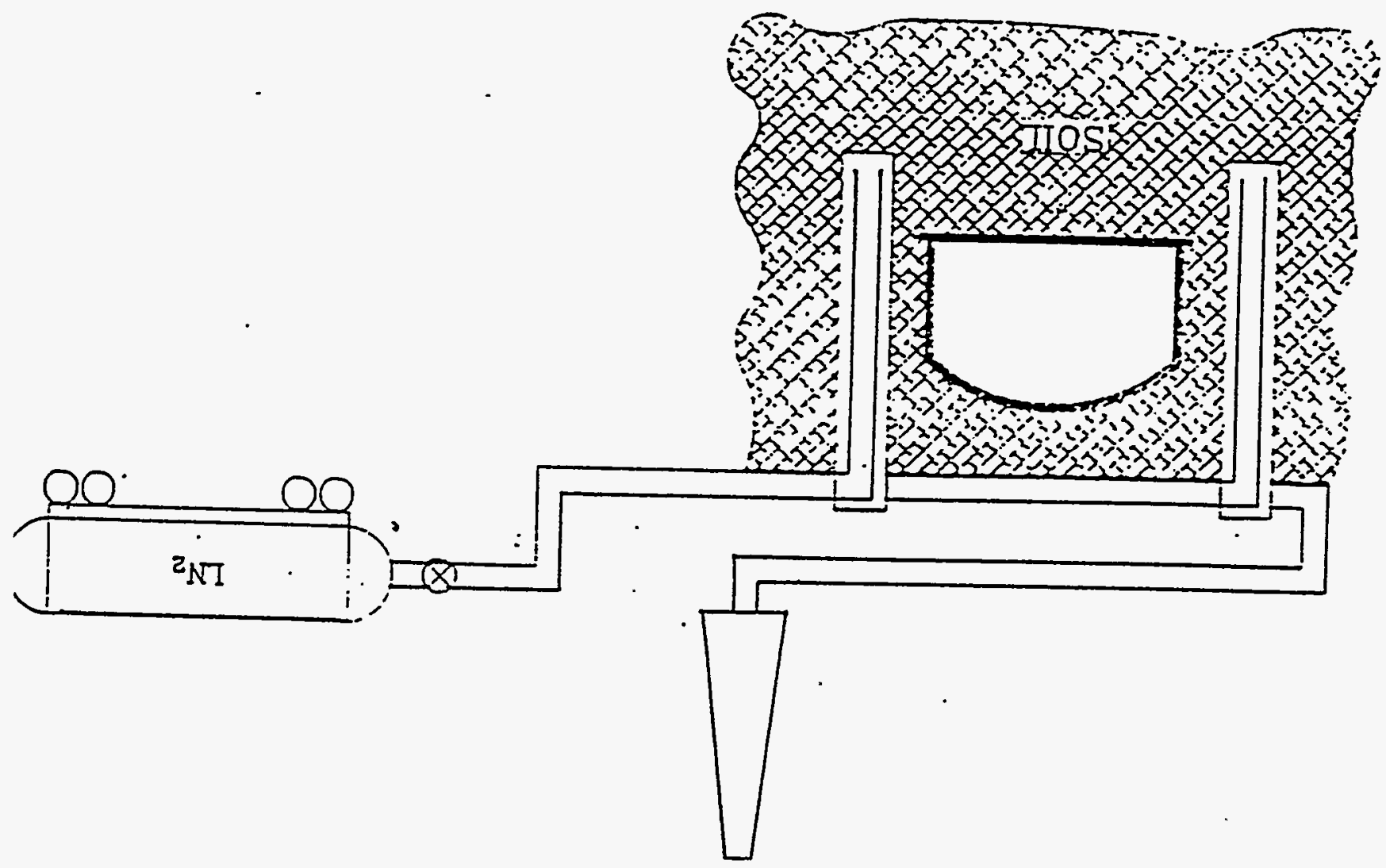

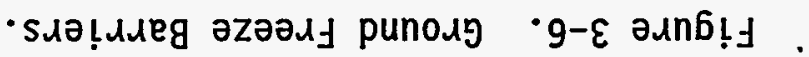

0 • ^əУ ' $\varepsilon \angle 80-\mathrm{d} \exists-\supset H M$ 
WHC-EP-0873, Rev. 0

\section{Disadvantages}

- Expensive to instal1, operate, and maintain

- Freezing soils expand to stress and possibly damage tank structures and underground equipment

- Freezing and thawing soils induce soil heaving and cracking, which permits existing soil contaminants to migrate faster.

\subsubsection{Deep Soil Mixing Option}

In deep soil mixing, augers ( 3 to $5 \mathrm{ft}$ diameter) are used in parallel to drill holes up to $75 \mathrm{ft}$ deep. Grout is mixed with soil on the surface and returned to the hole. Excess spoils are disposed. The technology is widely used in Japan to remediate sites. Its use in the United States has been limited. Unresolved contaminant control and health safety issues would 7ikely preclude its use for the Tank 241-T-101 site.

\section{Advantages}

- Relatively impermeable, long lasting barrier

- Barrier materials readily available at low cost

- Extensively used to immobilize existing contaminated soils in Japan

- Compatible with most hazardous chemicals.

\section{Disadvantages}

- Large soịl piles generated during excavation with a high potential for disturbing contaminated soils

- Area required for excavation and barrier construction may preclude or limit its use in existing tank farms

- Barrier integrity questionable--leaks possible between pours and excavation activities likely to disturb previous pour

- Unresolved technology and health and safety issues associated with this technology. Not approved for use in the U.S.A.

- Not applicable to stopping vertical migration of contaminants.

\subsubsection{Geomembrane Walls option}

Geomembrane walls consists of high-density polyethylene sheets ( $80 \mathrm{mils}$ or greater in thickness) that are interlocked and vibrated into place with a steel insertion plate, much like sheet piling (see Figure 3-7). The interlocks between the sheets incorporate a hydrotite seal made of chlorphene to ensure water tightness. Superior chemical resistance and compatibitity with radioactive materials makes this a viable barrier system. High-density polyethylene (HDPE) liners are an acceptable means of containment for hazardous wastes because of their impermeability and environmental stress characteristics. 
WHC-EP-0873, Rev. 0

Figure 3-7. Gund7e Vertical Barrier System.

(CAD FILE: FIG0I)

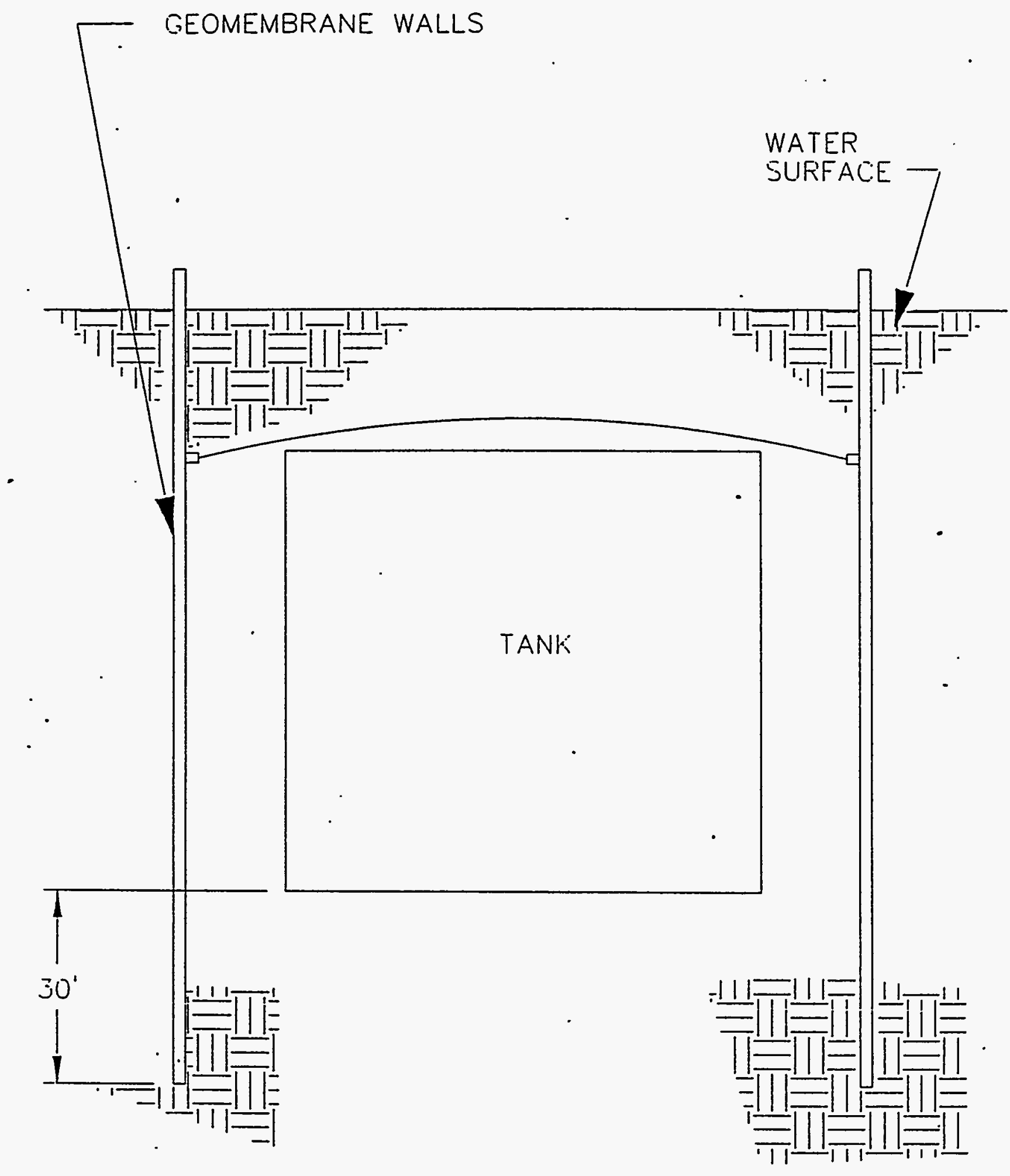


WHC-EP-0873, Rev. 0

The membrane can be installed either by unrolling it in a slurry trench or mounting it onto steel frames and lowering the frames into the slurry mixture. It is common to install panels in slurry walls, installations up to $35 \mathrm{ft}$ deep have been vibrated into place with vibratory hammers. Sandy soil conditions at the tank may permit the panels to be installed to a lower depth.

Geomembrane walls are exclusively marketed by Gundle Lining System, Inc., as Gundwal1 Exterior Barrier Systems. As a in situ stabilization system, Gundwall is an emerging technology in the U.S. The system involves no additional chemicals to the soil and suitability is high for the arid environment. Stabilization by geomembrane walls involves no significant public or worker safety risks, except that it requires heavy equipment for installation. Because of the success of geomembrane liners as a barrier system for hazardous wastes, acceptability with regulators should be high and would help in eventual closure/postclosure of the Site. Though the system will prevent horizontal migration of contaminants, vertical movements are not restricted. The method imposes no constraints to waste retrieval, storage, or transfer of tank contents. Geomembrane walls coupled with vertical and horizontal jet grout curtains may deserve a large scale demonstration at this site.

\section{Advantages}

- Long lasting, impermeable barrier to horizontal migration of contaminants

- Compatible with hazardous chemicals and radionuclides

- Technology commercially available

- Installation flexible and relatively easy in sand soils

- Retrievable if necessary for final site closure.

\section{Disadvantages}

- Barrier susceptible to leaks between membranes if not carefully installed

- Heavy equipment required for installation

- Not applicable for stopping vertical migration of contaminants

- Technology relatively new in the U.S.A.

- Permits significant amounts of soils to potentially become contaminated and require treatment.

\subsection{LIQUID RETRIEVAL ALTERNATIVE}

The liquid retrieval alternative is defined as removal of tank supernate and pumpable interstitial liquids from solid wastes.

Supernates are typically removed by a submersible pump. Removal of the interstitial liquid contained in the waste solids is achieved by a process 
called salt well jet pumping. The residual liquid left in the tank after this process is largely held in the solids by physical and chemical forces. The amount available to drain through a breach in the tank, if the breach is below the remaining solids, is small.

The quickest way to emergency pump is by using a submersible pump followed by a jet pump. The submersible pump is capable of pumping 10 to $30 \mathrm{gal} / \mathrm{min}$. The jet pump is capable of pumping between 0.05 and $4.0 \mathrm{gal} / \mathrm{min}$. The submersible pump discharges the liquid in a short time. The pump can quickly reduce the driving force behind the leak to minimize the impact from liquids leaking into the environment. In some cases, jet pumping may be the only pumping option. This occurs when the liquid is interstitially dispersed with in the solids.

The common process facilities and equipment needed for the pumping of Tank 241-T-101 are:

- Pump Pit, Salt We11, Screen, and Submersible/Jet Pump Assembly--The equipment and installations required for pumping are (1) a pump pit, (2) a salt well screen, (3) a submersible/jet pump assembly, (4) flushing assembly, (5) flex-hose jumpers, and (6) associated controls.

- Pump Pit--The dome of an SST is built with several risers of different diameters, one of which protrudes into the pump pit. A pump pit is a concrete structure located above the tank dome near the center of the tank with a drain in the bottom that empties into the tank. The pumping system is housed within the pump pit with portions of it extending into the riser and tank.

- Salt We1l Screen--The salt well system is a 10 in. diameter salt well casing consisting of a stainless steel salt well screen welded to a Schedule 40 carbon steel pipe (reference drawing $\mathrm{H}-2-38587$ ). The casing and screen are to be inserted into the $30.5 \mathrm{~cm}(12-\mathrm{in}$. tank riser located in the pump pit. The stainless steel screen portion of the system will extend through the tank waste to near the bottom of the tank. The salt well screen portion of the casing is a $10 \mathrm{ft}$ length of 300 Series, 10 in. diameter, stainless steel pipe with screen openings (slots) of $0.050 \mathrm{in}$. Because the waste level is at less than $4 \mathrm{ft}$, the salt well screen will extend above the tank waste. Therefore, the salt well is open to the tank's atmosphere (see Figure 3-8). The function of the salt well screen is to allow liquids to flow in while minimizing the size and amount of solids impacting the pump.

- Submersible Jet Pump Assembly--The submersible pump is to be mounted to a 2 in. transfer pipe extending up through the tank and the adapter flange to the pump pit. From the adapter flange, the waste will be routed through a horizontal discharge flange. The discharge flange will be connected by a process jumper to the wall nozzle and, finally, to the waste transfer line. A flex-hose jumper will tie into the process jumper to provide flushing capabilities. 
WHC-EP-0873, Rev. 0

Figure 3-8. Tank 241-T-101 Salt We1l System.

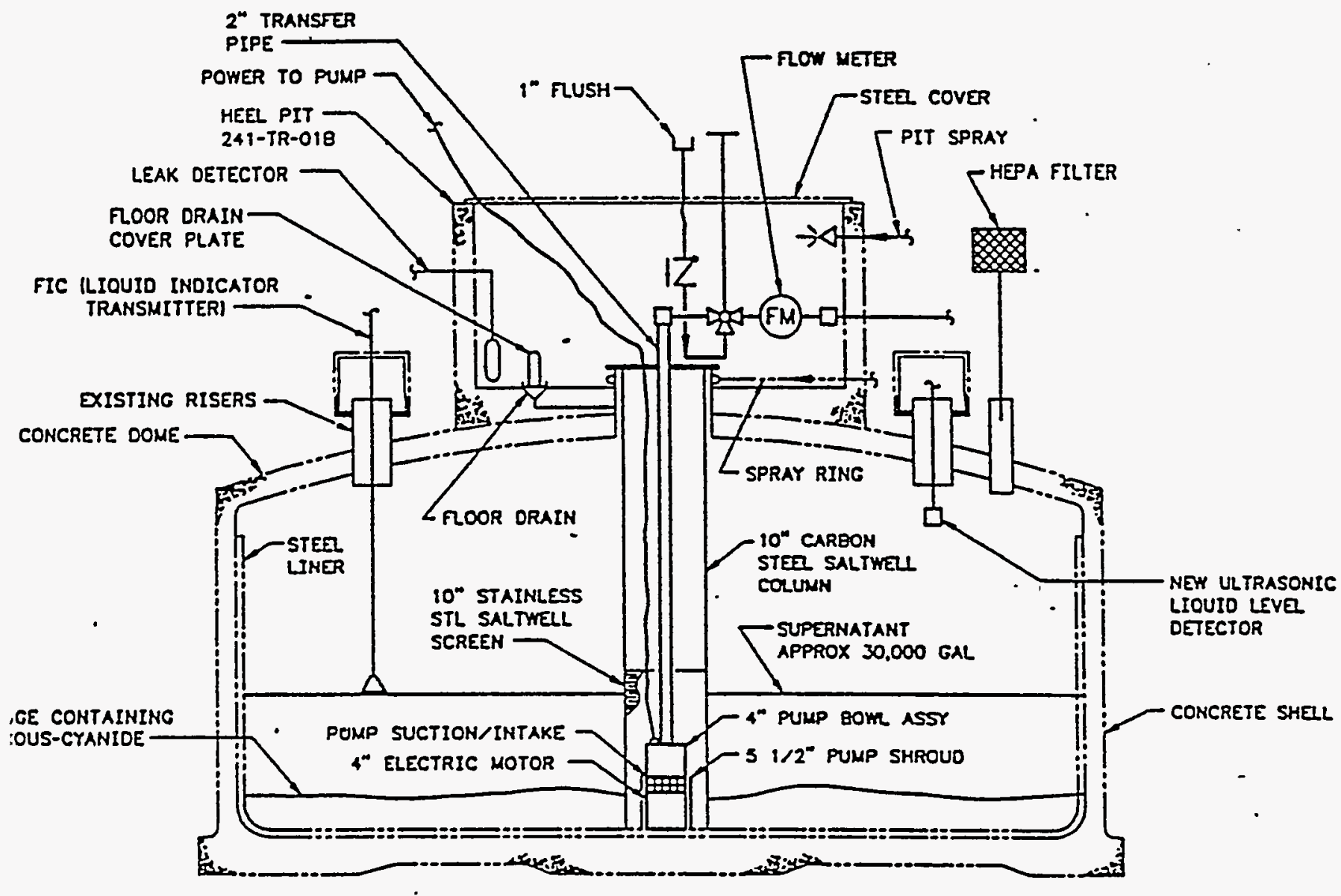

TANK 241-T-101 
The submersible pump assembly needed to pump liquid from the salt well screen into the pump pit has a 5-horsepower motor driven by 480 volt, 3-phase power (reference drawing H-2-73896). The motor is located below the pump intake and is submersed in the liquid. The pump is rated at $40 \mathrm{gal} / \mathrm{min}$ at $39.624 \mathrm{~m}$ (130 ft) total dynamic head, for liquid with a specific gravity of 1.7 . The pump motor is cooled by the liquid being pumped. To aid liquid flow past the motor, the pump has a flow director shroud (see Figure 3-8).

Important instrument and control systems include leak detection and submersible pump controls including safety interlocks. The interlocks that shut down the pumps include loss of pump outlet pressure, excess pressure in the flush leg, leak detection in the pump pit, area radiation detection, leak detection in the double-contained receiver tank (DCRT), and DCRT at maximum operating level. An additional interlock associated with the pump itself is a thermal overload device designed to shut off the pump in the event the pump temperature increases from pumping air or stoppage by excessive sludge.

The jet pump system includes (1) a jet assembiy with foot valve mounted to the base of two pipes that extend from the top of the well to near the bottom of the well casing inside the salt well screen, (2) a centrifugal pump to supply power fluid to the downhole jet assembly, (3) flexible or rigid transfer jumpers, (4) a flush line, and (5) a flowmeter (see Figure 3-9). The jumpers contain piping, valves, and pressure and 1 imit switches. Instrumentation and control devices are located within the pump pit.

The centrifugal pump and jet assembly are needed to pump the interstitial liquid from the salt well screen into the pump pit, nominally a $12.192 \mathrm{~m}(40 \mathrm{ft})$ elevation rise. The centrifugal pump, rated at approximately $30 \mathrm{gal} / \mathrm{min}$ at $30 \mathrm{psig}$, pressurizes power fluid to the jet assembly located in the salt well screen. The power fluid passes through a nozzle in the jet assembly and acts to convert fluid pressure head to velocity head, thereby reducing the pressure in the jet assembly chamber. The reduction in pressure allows the interstitial liquid to enter the jet assembly chamber and mix with the power fluid. Velocity head is converted to pressure head above the nozzle, lifting power fluid, and interstitial liquid to the pump pit. Pumping rates vary from 0.05 gal to about 4 gal/min. Reference drawing H-2-73990 depicts a jet pump system.

Raw water is used to fill the salt well jet pump system 1oop and prime the pump for operation. A recirculation loop permits the prime on the pump to be maintained at very low pumping rates. The energy produced by the pump's operation can heat the recirculated liquid about $30^{\circ} \mathrm{F}$ above tank temperatures.

Jet pump system controls include limit switches and safety interlocks. The interlocks that shut down the pump include (1) loss of pump outlet pressure, (2) excess pressure in the flush 1eg, (3) high pressure in the circulation loop, (4) leak detection in the pump pit, (5) area radiation detection, (6) leak detection in the DCRT, and (7) DCRT at maximum operating level. 
Figure 3-9. Salt Wel1 Jet Pump. (ER3415/TMBM4)

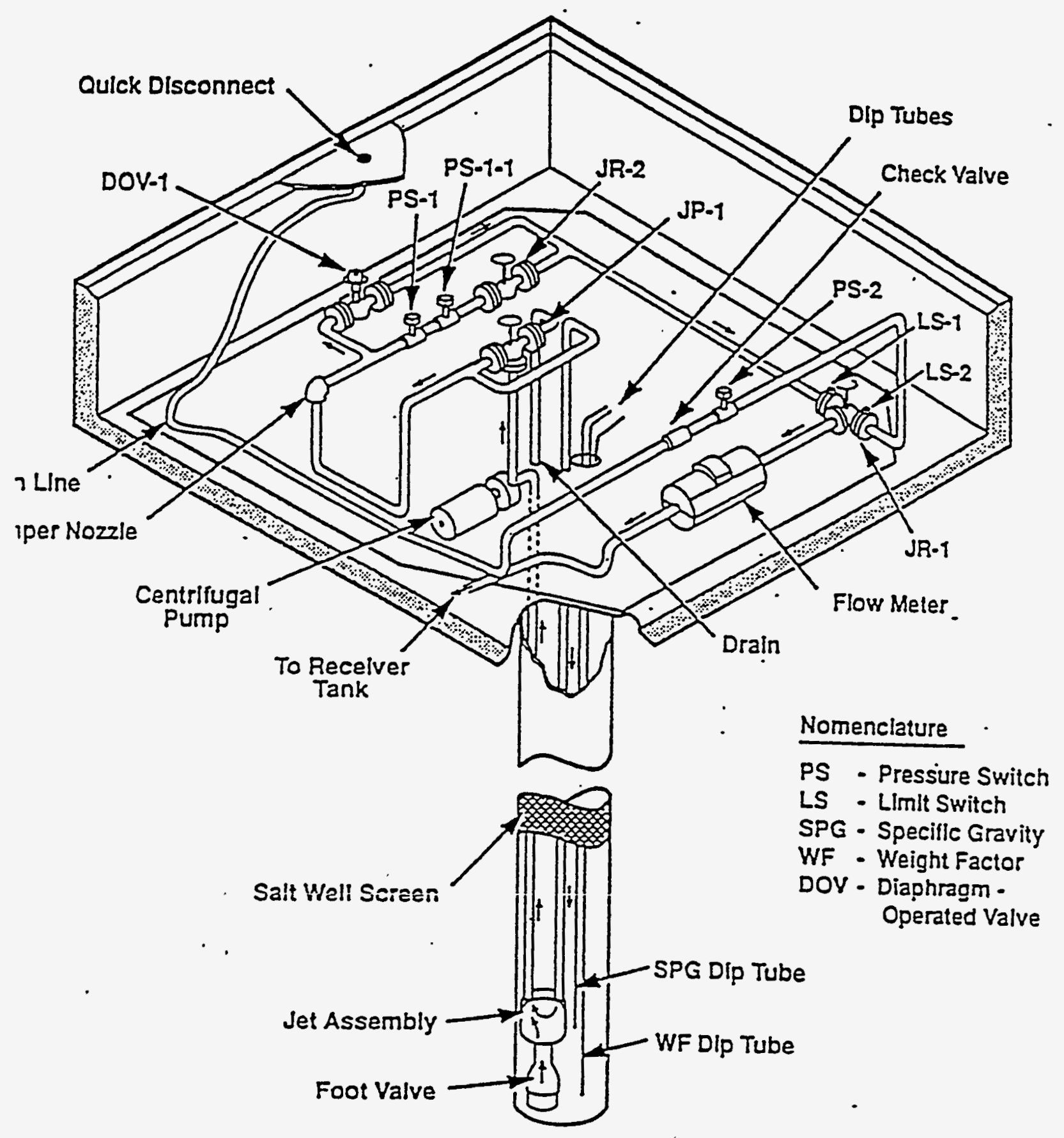


- Double-Contained Receiver Tank (Tank 244-TX)--The salt well waste from Tank 241-T-101 will initially go to the DCRT underground Tank 244-TX. Tank 244-TX is a 25,000 gal cylindrical tank. The tank is positioned with its axis horizontal in the lower section of the reinforced concrete vault. Above the tank vault, and connected to it are a pump pit and a filter pit. An instrument enclosure is above the tank vault, but not connected to it.

The pump pit contains transfer and agitator pumps and jumper connections with valves to the transfer lines. The filter pit contains a ventilation system equipped with HEPA filters. The tank vault contains the receiver tank and sump well. Associated instrumentation is contained in the instrument pit (see Figure 3-10).

The ventilation system maintains the receiver vesse 7 and annulus under negative pressure with respect to the atmosphere to prevent the release of radioactive materials in case of a tank breach. Supply air is taken into the tank annulus through a coarse filter and a HEPA filter. The exhaust system pulls air from the annulus intake and the inner tank through a coarse filter and two stages of HEPA filters.

Safety considerations and controls on the ventilation system provide dampers and valves for regulation/isolation, measurement of differential pressure across the filters, continuous radioactive particulate monitoring and record sampling of exhaust air, and continuous flow measurement of exhaust air.

The leak detectors in the DCRT sumps are interlocked with the primary pumps to shut down if there is a leak in the DCRT. Leak detectors are also installed in the filter pits or filter housing.

To minimize the sedimentation of solids from liquor in the piping systems, the capability of water dilution is provided in the DCRT. In Tank 244-TX, rotating spray nozzles are installed inside the tank to aid in tank flushing. Also, sluice jets and flow from a pump agitator provide a way to resuspend solids, and keep them in slurry form.

- Double-She11 Waste Storage Tank--The transfer continues from Tank 244-TX to Tank 241-SY-102 after verification of compatibility by sampling and analyzing samples. Sample results from both sending and receiving tank after comparison to the Tank Farm Waste Compatibility Program, HHC-SD-HM-OCD-015, must show there is no compatibility problem. If sample analysis determines that Tank 241-T-101 in the 200 West Area contains complexed waste, a compatible receiver tank in that area may not be available.

- Associated Instrumentation and Controls--Leak detection is provided in each pump pit in the transfer system. Leak detection in each pit is interlocked to shut down the transfer pump. A flashing light and an audible alarm, located on top of the pump control station outside the pump pit area, alert tank farm operators of a shutdown condition. 
HHC-EP-0873, Rev. 0

Figure 3-10. 224-TX Tank Vault. (ER3415/TMBM3)

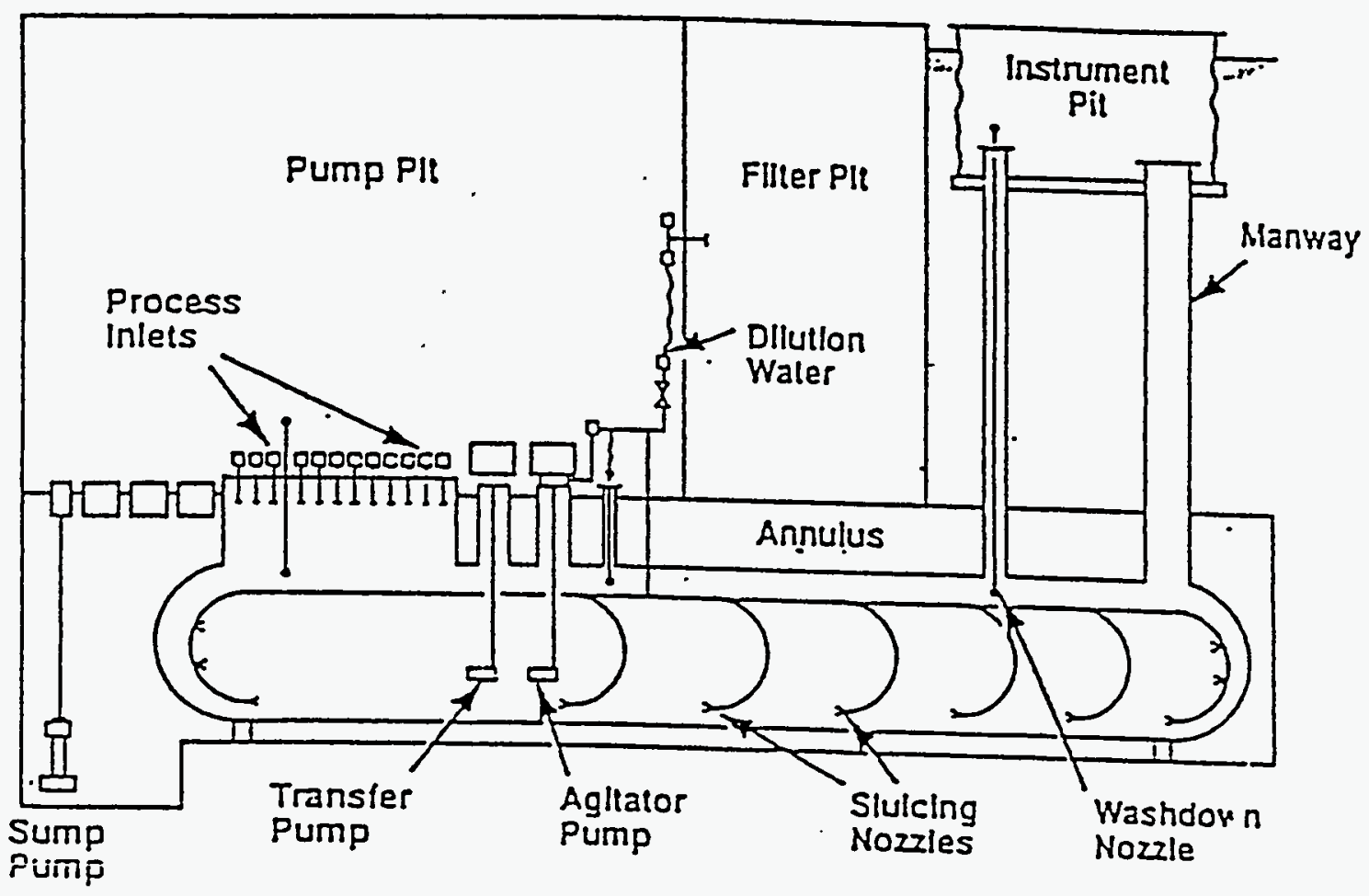

244-TX TANK VAULT 
WHC-EP-0873, Rev. 0

Before pumping, the following existing or new devices would be required:

Tank 241-T-101

- New ultrasonic liquid level monitoring system (optional).

- New in-tank photography or a closed-circuit television (CCTV) system.

- New raw water supply for priming jet pump, flushing jumpers, and transfer 1 ines.

- An available source of power shall be identified that is compatible with the pump to be used.

- Move the existing emergency pumping equipment trailer to the tank farm when the jet pump is used. The trailer is equipped with operational instrumentation, pump control station, power cable, air compressor and pump pit leak detection as described in WHC-SD-WM-AP-005, SST Leak Emergency Pumping Guide.

- Transfer Piping--The transfer piping options are 1isted in the following subsections.

\subsubsection{Pump Out Option - Existing Pipeline}

Tank 241-T-101 has several existing buried carbon steel pipelines ranging in size from $5.08 \mathrm{~cm}$ ( 2 in.) to $15 \mathrm{~cm}$ ( 6 in.) in diameter.

The $5.08 \mathrm{~cm}$ ( 2 in.) lines are direct buried (in soil) and were installed in 1980 . The $8 \mathrm{~cm}$ ( 3 in.) and $15 \mathrm{~cm}$ ( 6 in.) 1ines are in concrete encasements that were installed in 1952 .

Leak detection is provided in each pit in the transfer system, and is interlocked to automatically shut down the pump upon leak detection. A flashing light and an audible alarm alert tank farm operators to the shutdown condition. This system is located on top of the pump control station outside the pump pit area.

These existing pipelines are not heat traced, and only the southern part that connects to Tank 244-TX is insulated. The pipelines are sloped downward in the direction of flow for drainage.

3.4.1.1 Pipeline $\mathrm{SN}-6012$. This transfer route uses existing buried piping from Tanks 241-T-101 to 244-TX as shown in Figure 3-11.

The northern and southern part of the pipe route is $5.08 \mathrm{~cm}$ (2 in.) Schedule 40 carbon steel welded pipe direct buried with $1 \mathrm{~m}(3 \mathrm{ft})$ of ground cover to provide shielding, and was constructed in 1980. The middle portion is $15 \mathrm{~cm}$ ( 6 in.) Schedule 80 carbon steel pipe buried in a concrete encasement, and constructed in 1952. 
Figure 3-11. Existing Transfer Routes. (ER3415/TMBM5)

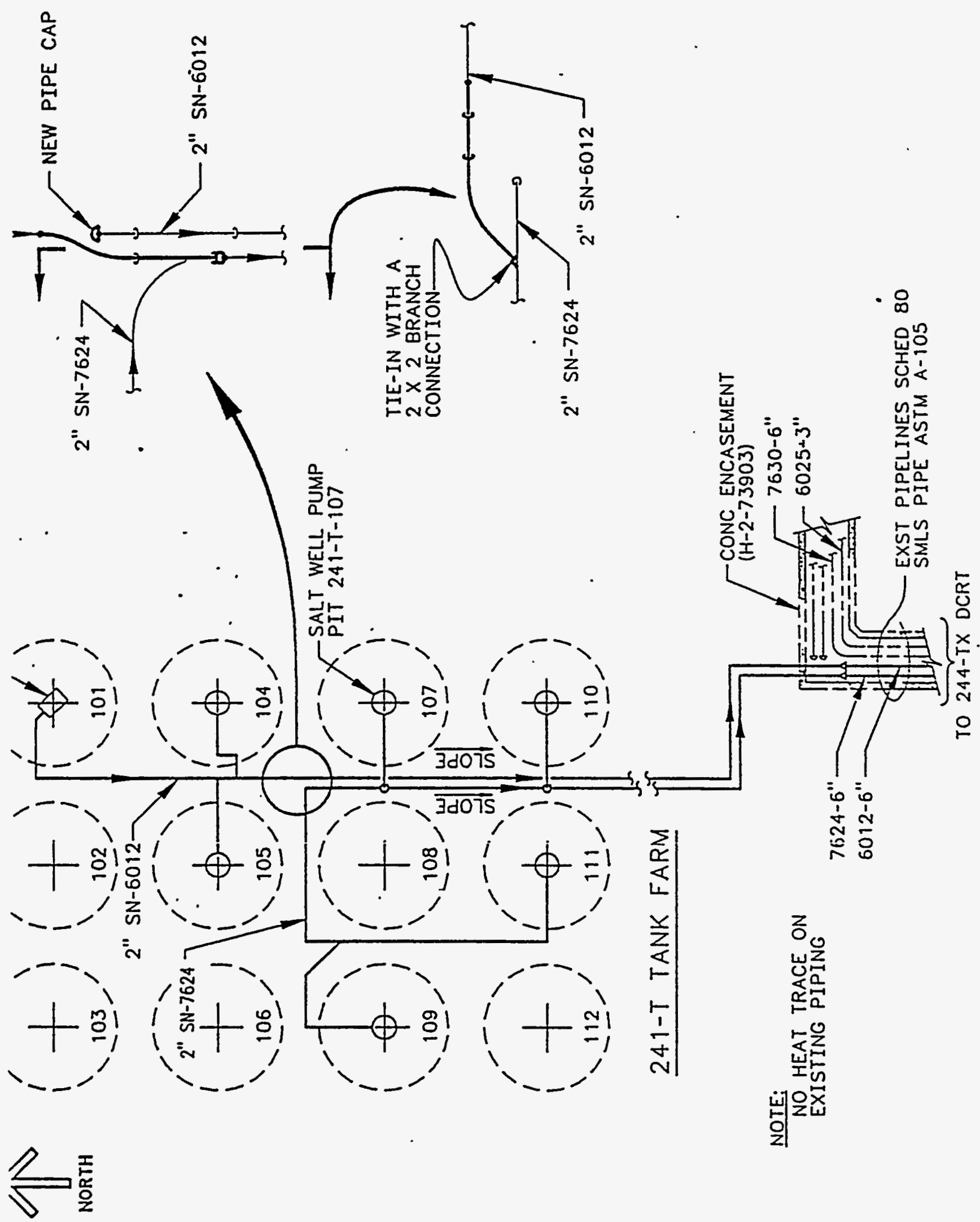


The design life of the salt well pumping transfer lines was 5 years. They are now more than 10 years old. The 7 ines must be pressure tested before use, and every 6 month during use, to ensure against leaks. The pipeline integrity was verified in 1992 with a hydrostatic test pressure of $200 \mathrm{lb} / \mathrm{in}^{2}$.

Since the transfer 7 ine is a three-pronged manifold system from the $T-101, T-104$, and $T-105$ pump pits to the joint transfer line (SN-6012) going to Tank 244-TX, leak detection is provided in each pump pit, T-101, T-104, T-105, and at Tank 244-TX (see Figure 3-11).

3.4.1.2 Combination of Pipeline Segments. This transfer route would be used if a section of pipeline $5.08 \mathrm{~cm}$ ( 2 in.) $\mathrm{SN}-6012$ (reference subsection 3.4.1.1) failed.

This route requires pipeline $5.08 \mathrm{~cm}$ (2 in.) SN-6012 from Tank 241-T-101 be tied into line $5.08 \mathrm{~cm}$ (2 in.) SN-7624 that routes to Tank 244-TX as shown in Figure 3-11.

The northern and southern part of the pipe route is $5.08 \mathrm{~cm}$ (2 in.) Schedule 40 carbon steel pipe direct buried, and constructed in 1980 . The middle portion is $15 \mathrm{~cm}$ ( 6 in.) Schedule 80 carbon steel pipe buried in a concrete encasement, and constructed in 1952. 150 psig.

The pipeline integrity was verified in 1980 by hydrostatic testing at

\subsubsection{Pump Out Option - New Pipeline}

When a tank is identified as an assumed leaker and a pipeline from the tank to a DCRT, or DST does not exist, or does exist, and has failed, a new pipeline with encasement is required.

The new 1 ine will be pressure-testable and equipped with a leak detection system. The new pipeline would be routed from Tank 241-T-101 heel pit TR-01B to the closest useable line in T-Tank Farm that is approximately $61 \mathrm{~m}$ (200 ft.) If a useable line does not exist, the new pipeline would be routed approximately $488 \mathrm{~m}(1,600 \mathrm{ft})$ to the $244-\mathrm{TX}$ receiver vault as shown in Figure 3-12.

3.4.2.1 Pipeline Below Grade. A new pipeline would be installed below grade in an existing tank farm.

\section{Advantages}

- Earth cover provides shielding

- Does not impede accessibility of personnel or equipment

- Line can be sloped to drain in one direction

- Complies with past transfer methods

- Complies with Taws/regulations.

Disadvantages 
WHC-EP-0873, Rev. 0

- Not conducive to emergency pumping time restraints (excessive time required for designing, procuring, fabricating, installing, and testing) 
WHC-EP-0873, Rev. 0

Figure 3-12. New/Existing Transfer Route. (ER3415/TMBM7)

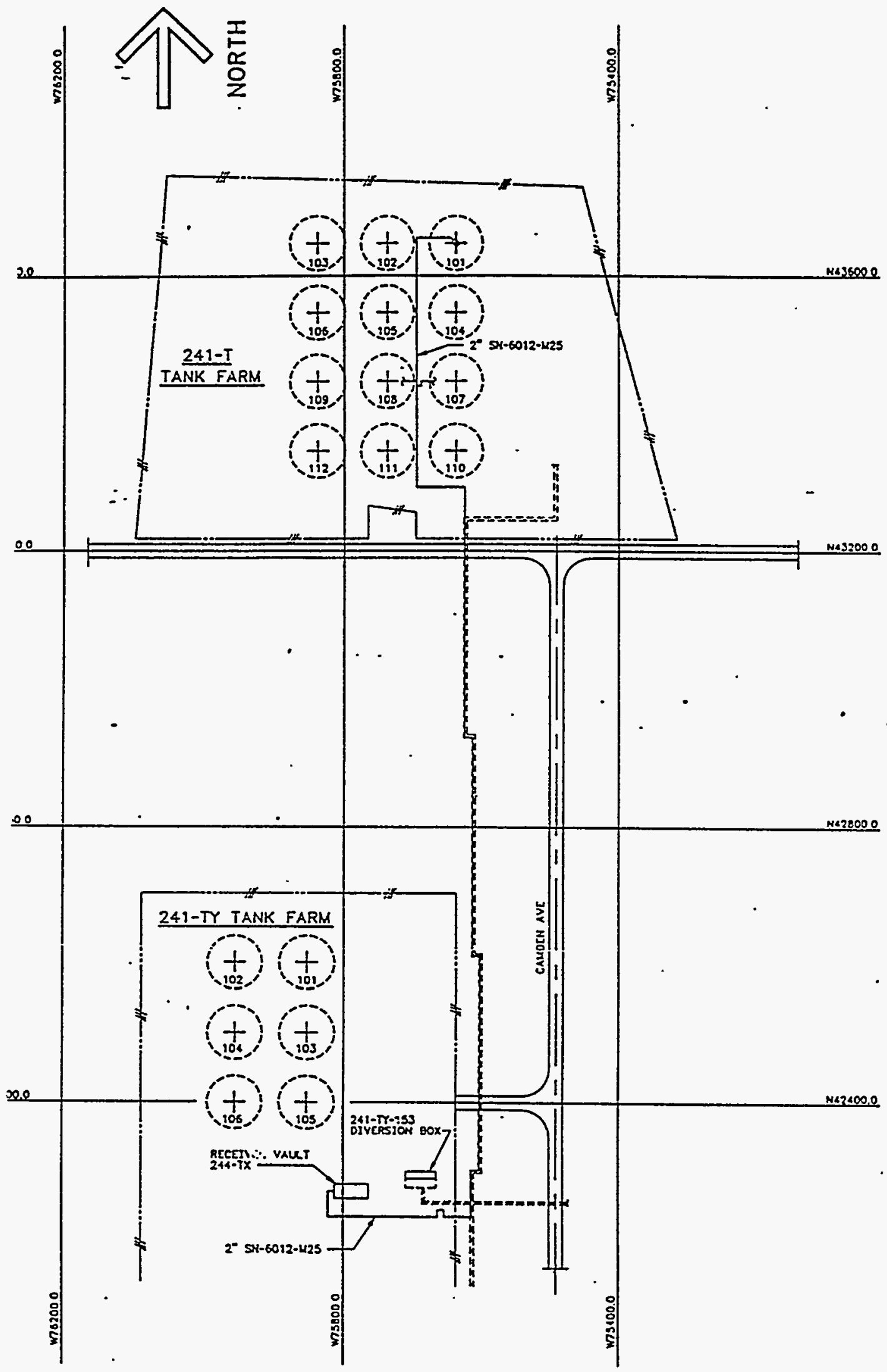


WHC-EP-0873, Rev. 0

- Contaminated soil may be encountered during excavation

- Excavation will expose other buried obstacles that may affect the design

- Limited accessibility for inspection and/or repair.

3.4.2.2 Pipeline Above Grade. Install a new pipeline on grade and add an earth berm as required for shielding or install a temporary double-contained piping system above grade.

An addendum to safety analysis report (SAR) SD-WM-SAR-034 must be prepared to evaluate the aboveground transfer.

\section{Advantages}

- Requires less time to install than a below grade line

- Cost is less than a below grade line

- Reduced chance of encountering soil contamination

- Inspection and repair accessibility

- Complies with laws/regulations

\section{Disadvantages}

- Impedes access of equipment and personnel

- Line must be sloped to drain to both ends

- Leak detection required at both ends of the transfer line

- The transfer line will have a high point (air entrapment)

\subsubsection{Pump Out Option - Tank Truck/Railcar}

Pumping supernate and drainable interstitial liquid from solid wastes in Tank 241-T-101 into a tank truck, or tank railcar, would use the equipment listed for Tank 241-T-101, and Heel Pit 241-TR-01B (reference section 3.4). Flow measurement and control would also be required in the remote pipe jumper.

The transfer piping from the heel pit to the tank truck or railcar is described in Subsection 3.4.2.2, as a temporary double contained piping system.

The tank liquid would be sampled and analyzed along with core samples for tank characterization before pumping.

An addendum to SAR SD-HM-SAR-034 would be prepared to evaluate this type of transfer.

3.4.3.1 Tank Truck. The 3,000-gal capacity tank truck and trailer can be driven into the tank farm fenced area and parked adjacent to Tank 241-T-101 on a loading containment apron, as shown in Figure 3-13. The containment apron will drain back to the Tank 241-T-101 in the event of a spil1. The drain will be plugged when not in use. After loading, the waste will be delivered to the 244-AR unloading facility in the 200-East Area. The waste can be transferred from the 244-AR unloading facility through existing buried, encased pipe lines to a number of DSTs. 


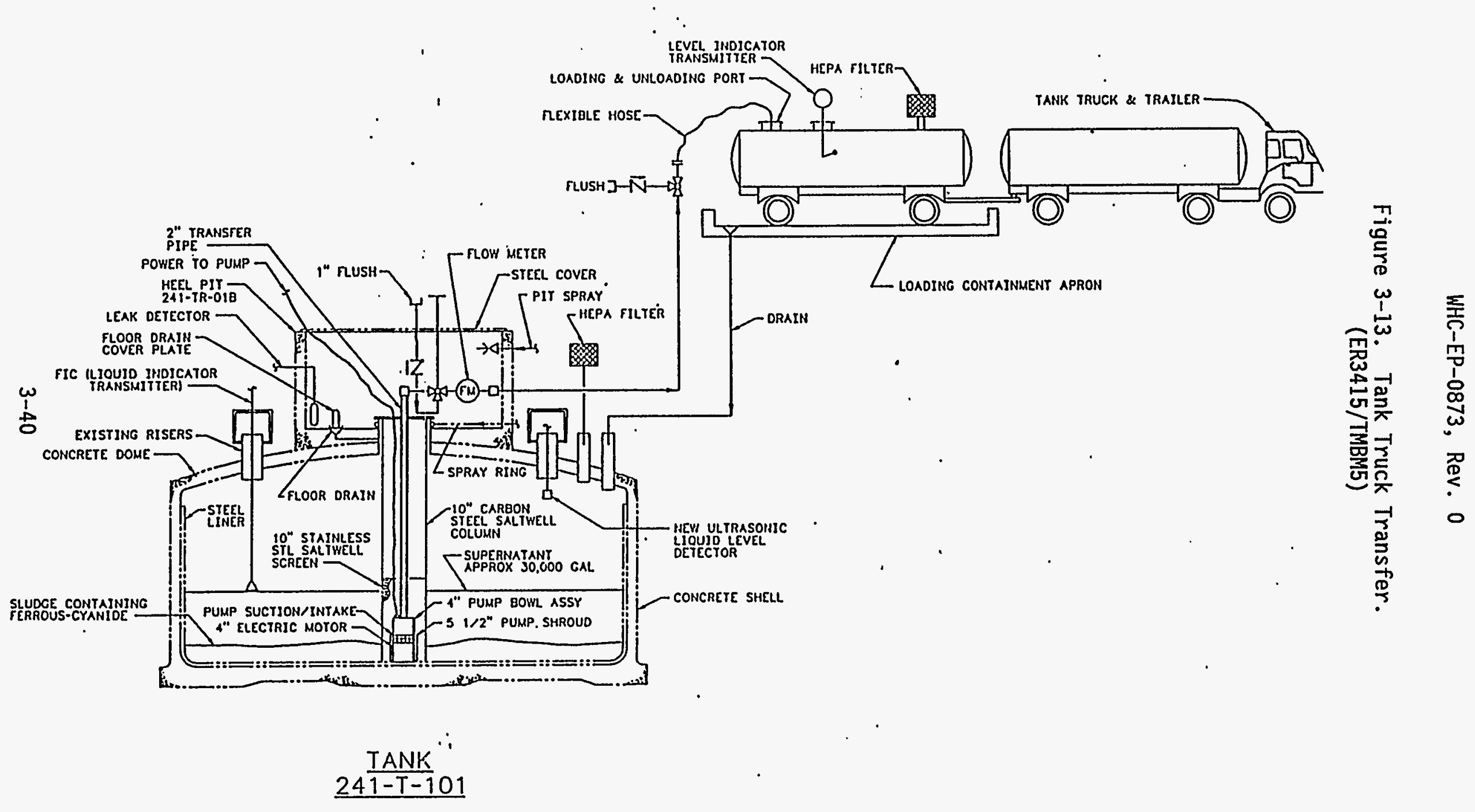


WHC-EP-0873, Rev. 0

The trailer wiil be equipped with:

- A HEPA filter to remove any particulates from the air

- Level indicator transmitter interlocked with transfer pump to effect a shutdown on high-level condition

- Loading port with rupture disc and pressure relief valve

- UnToading port

- Shielding.

3.4.3.2 Tank Railcar. There is a railroad track approximately $900 \mathrm{ft}$ on the east and west sides of T-Tank Farm. The tank railcar with a capacity of approximately 15,000 gal could be positioned at one of the track and filled via a new pipeline from Tank 241-T-101 as shown in Figure 3-14.

The tank railcar equipment, filling, transporting, and unloading will be similar to the tank truck and trailer described in Subsection 3.4.3.1.

Future decommissioning and cleanup of a11 tanks in Tank Farm T, TX, and TY could justify building a railroad spur along the west side of the tank farms.

\subsubsection{Pump In Option - Internal Bladder Vesse1}

If Tank 241-T-101 or a similar SST were found to be leaking, a resilient material bladder with a sump pump attached to it could be placed in the bottom of the tank through a new or existing tank riser. The sump pump would then be energized to transfer the supernate into the bladder vessel. The supernate would be temporarily contained and the leak alleviated. At an appropriate time, the bladder vessel could be pumped out and the bladder vessel removed.

Tank 241-T-101 has $30.5 \mathrm{~cm}$ (12 in.) diameter risers near the tank edge opposite each other and one $30.5 \mathrm{~cm}$ (12 in.) diameter riser on the center that could be used to insert three 10,000 gal capacity bladder vessels with sump pumps. Alternatively, if a $30.5 \mathrm{~cm}$ (12 in.) riser is 1 arge enough to accommodate the insertion of a single 30,000 gal capacity bladder, the center riser would be used. Technology for the bladder vessel has not been developed for wastes similar to those at Hanford. They have been used extensively in the petrochemical industry.

\subsection{TOTAL RETRIEVAL ALTERNATIVE}

Total retrieval of contents from within Tank 241-T-101 shall be defined as removing as much of the existing Tiquids and salt cake/sludge as practical. The selected total retrieval system will be required to dislodge/mix tank contents before pumping the slurry/sludge mixture via new encased lines to an approved double-she11 storage tank. Currently, the proposed retrieval systems are thought to be the most viable to accomplish total retrieval. 
WHC-EP-0873, Rev. 0

Figure 3-14. Tank Railcar Transfer.

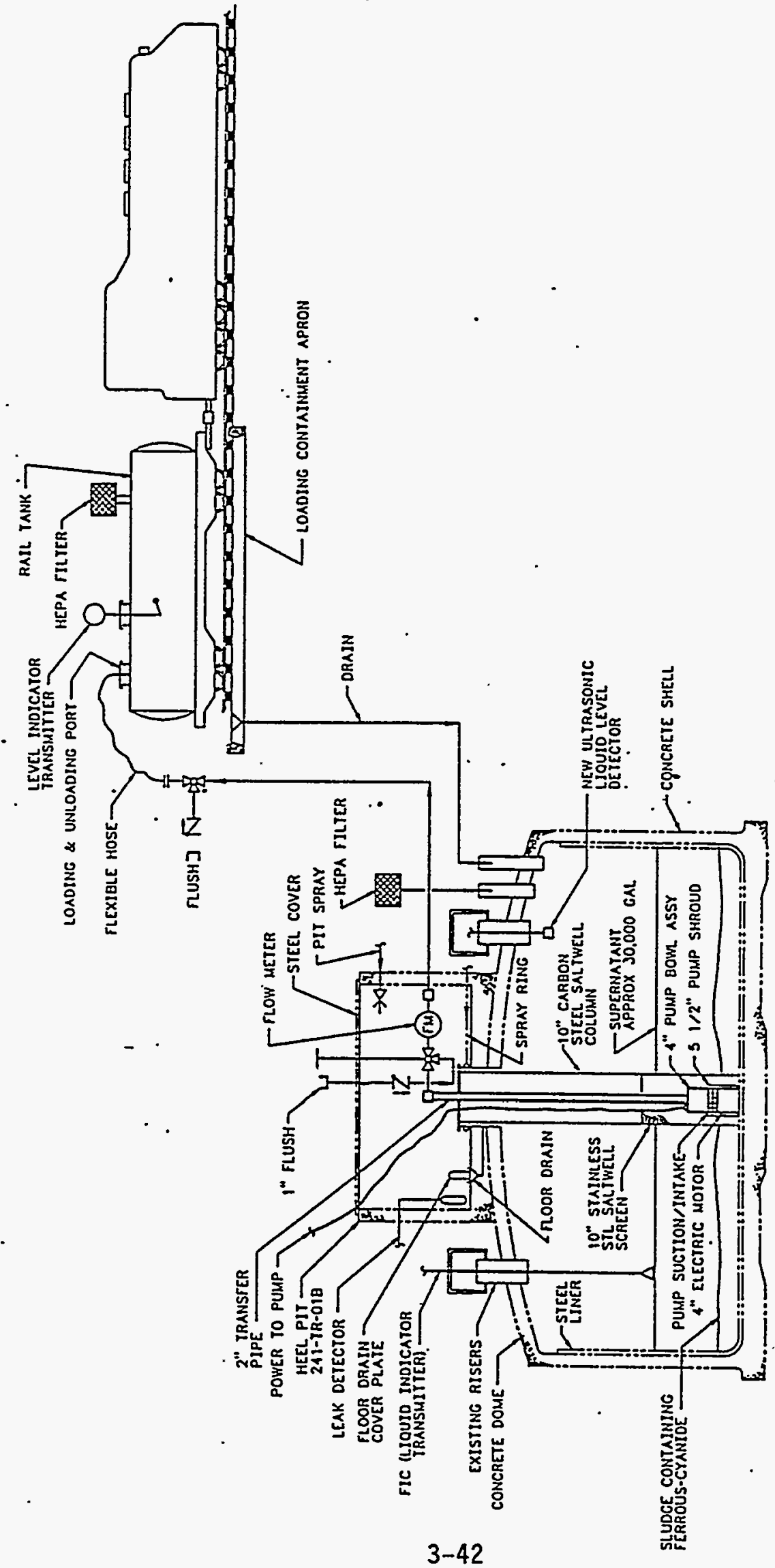

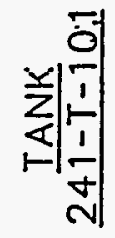




\subsubsection{Un1imited STuicing Option}

The unlimited sluicing (10w pressure - high volume) retrieval system consists of a pump and a sluicing nozzle to dislodge and mix solids followed by pumping of the suspended solids by a sludge/slurry pump. Unlimited sluicing is similar to the past practice used to remove wastes from Hanford SSTs. Sufficient water would be added by the sluicer to suspend the intank sludge.

Description of Unlimited STuicing. In this system, a sluicing pump will deliver 350 to $400 \mathrm{gal} / \mathrm{min}$ of liquid at a pressure of $175 \mathrm{lb} / \mathrm{in}^{2}$ to a 1 -in. diameter nozzle. Note: with a liquid velocity in excess of 100 miles/hour leaving the sluicing nozzle, the liquid stream should dislodge and suspend the in-tank sludge. The sluicing nozzle assembly will be inserted into the tank and move in a horizontal and vertical pattern to cover the entire tank bottom. A sludge/slurry pump will pump 350 to $400 \mathrm{gal} / \mathrm{min}$ of slurry through a new encased pipe transfer 7 ine to a double-sheli receiver/lag storage tank (see Figure 3-15).

The slurry will be allowed to settle in the receiver/lag storage tank and the decanted supernate shall be recycled back through the sluicer assembly located on Tank 241-T-101. Note: using the recycled supernate will minimize the need to add liquids to the sluicing operation.

\section{Advantages}

- Untimited sluicing techniques are well known and a proven Hanford technology

- Sluicing is adaptable to the specific needs of Tank 241-T-101 sludge clean out

- The new unlimited sluicer could be installed in the existing $30.5 \mathrm{~cm}$ (12 in.) riser R-3 located in Sluice Pit 241-TR-01C

- A new sludge/slurry pump could be installed in the existing $30.5 \mathrm{~cm}$ (12 in.) riser R-10 Tocated in Heel Pit 241-TR-01B

- A new remote two-camera CCTV system could be installed in the existing $30.5 \mathrm{~cm}$ (12 in.) risers $\mathrm{R}-6$ and $\mathrm{R}-2$.

- Existing small Tank 241-T-101 risers may need minor modifications to accept new instruments required to monitor and control the unlimited sluicing retrieval system

- The new unlimited sluicing equipment is reusable and can be readily transported and installed for use in other SSTs.

\section{Disadvantages}

- The existing heel pit 241-TR-01B may require structural upgrades to permit installation of a new sludge/slurry pump (e.g., new cover blocks, shielding plugs, metal pit liner, and pit reconfiguration 


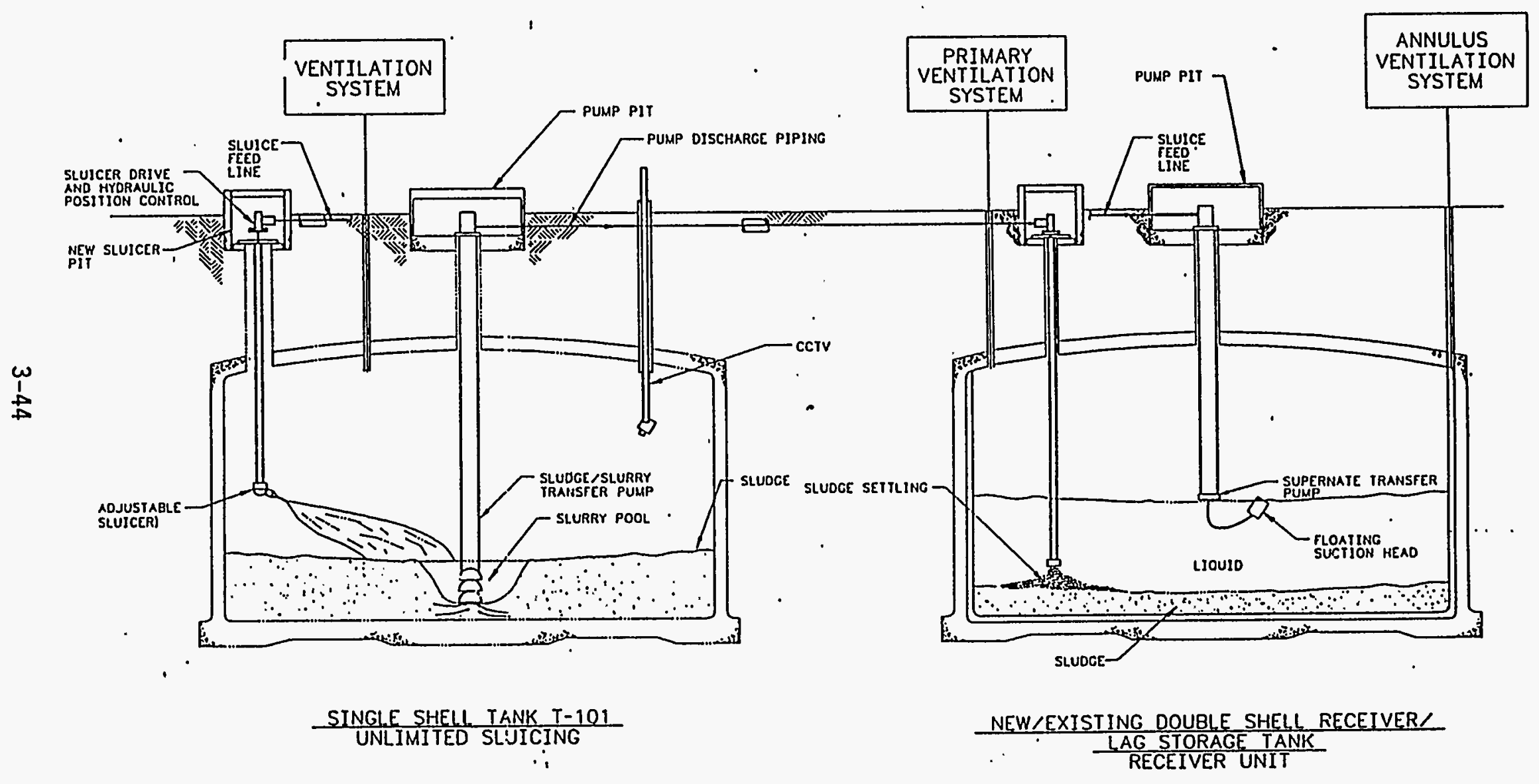

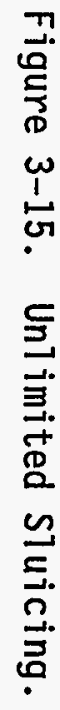

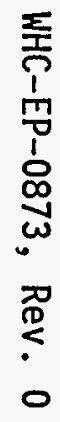

$\stackrel{0}{5} 0$ 
HHC-EP-0873, Rev. 0

- Existing equipment pits on Tank 241-T-101 to be reused for the installation of unlimited sluicing equipment need to be modified for installation of a $3,000 \mathrm{lb} / \mathrm{in}^{2}$ decontamination system

- The existing sluice pit 241-TR-01C may require structural upgrades to permit installation of a new unlimited sluicing assembly (e.g., new cover blocks, shielding plugs, metal pit liner, and pit reconfiguration)

- Sluicer technologies are inefficient for removing sludge. Large volumes of liquid (as much as 100:1) are needed to move, mix, and recover SST solids with a low-pressure, high-volume sluicer

- Large capacity double-contained receiving tanks are required to settle sludge/slurry and decant supernate for recycle back to Tank 241-T-101

- A "compliant" recycle/return system is required between Tank 241-T-101 and one or more sludge/slurry double-contained receiving tanks.

\subsubsection{Limited Sluicing Option}

Limited sluicing (high pressure - low volume) is a variation of the past practiced sluicing method, i.e., the intent to minimize the amount of additional water added to the tank to dislodge solids while preventing highpressure water from harming the tank walls or other internal fixtures. This is accomplished by carrying out the sluicing operation in a controlled manner. Several sluicing nozzles are placed in close proximity to the sludge and the direction of the water spray is controlled so that dislodged sludge and water are directed toward the center of the tank. Sluicing in this manner creates a slurry pool at the center of the tank that is then pumped out to the designated storage tank. An articulated robot arm concept is shown in Figure 3-16.

The system would use four sluicing arms placed 90 degrees apart in new 46 $\mathrm{cm}$ (18 in.) risers. The detailed concept is depicted in Figure 3-17. One cutting nozzle and eight sweeping nozzles are on each sluicing arm. Each sluicing head is positioned by a boom. The nozzle has full altitude control. The boom fore section would have an extension and retraction portion. A screw-jack drive system would move the boom and nozzle carriage up and down. The direction of the nozzle is controlled hydraulically, with both programmed automatic sweep or manual control of the nozzle. The siudge/slurry pump would be sized to fit through the $12 \mathrm{in}$. opening in the tank's heel pit (241-TR-018) at the center of the tank.

Once pumped out of the tank, the sludge/slurry would be mixed with additional liquids, if required, to permit pump transfer by pipe. The sludge/slurry pump outlet would be connected by a jumper to a dilution feed line, and a new pipe-in-pipe transfer line. 
WHC-EP-0873, Rev. 0

Figure 3-16. Limited S7uicing.
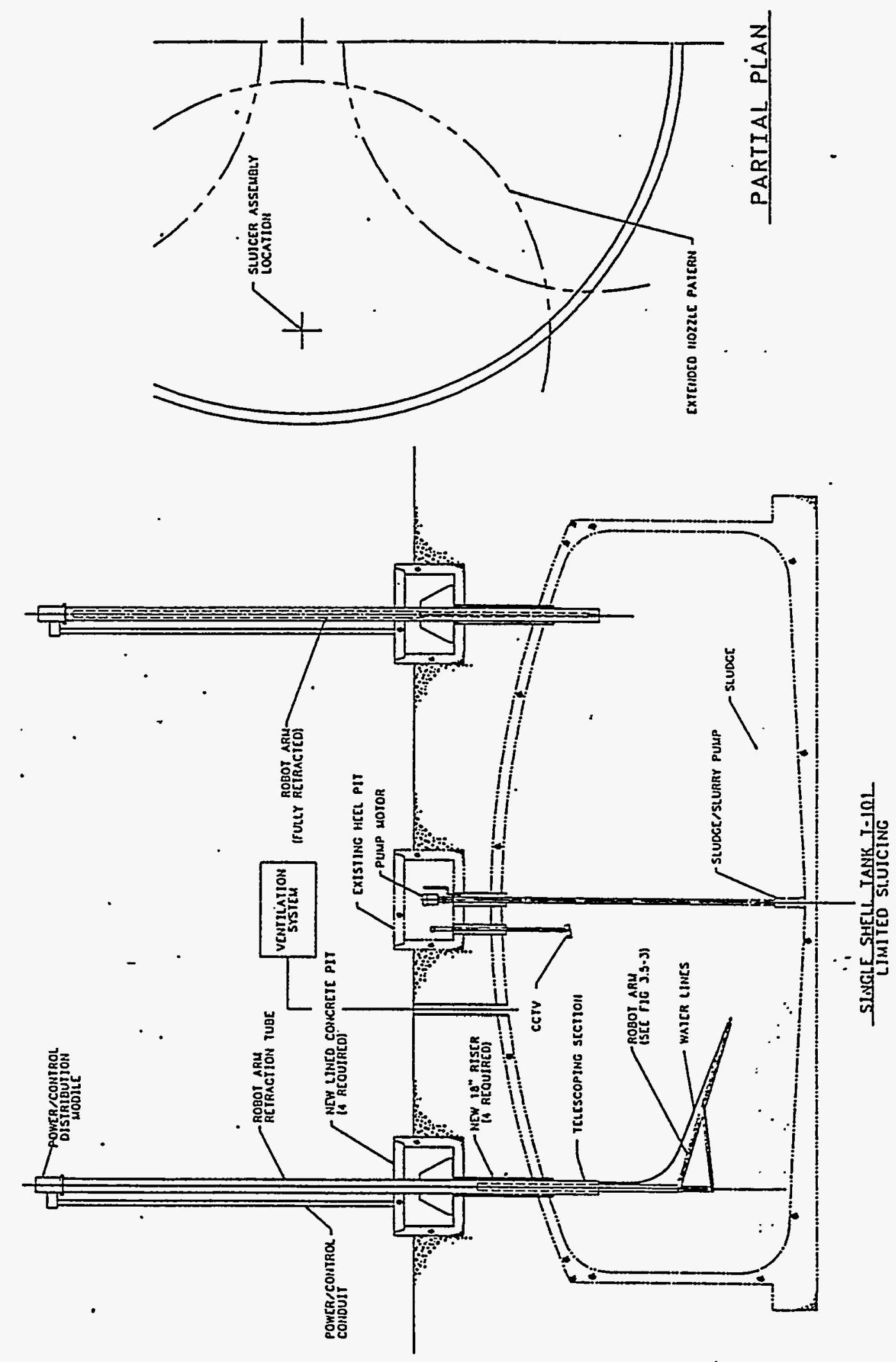
WHC-EP-0873, Rev. 0

Figure 3-17. Limited S7uicing Assembly.

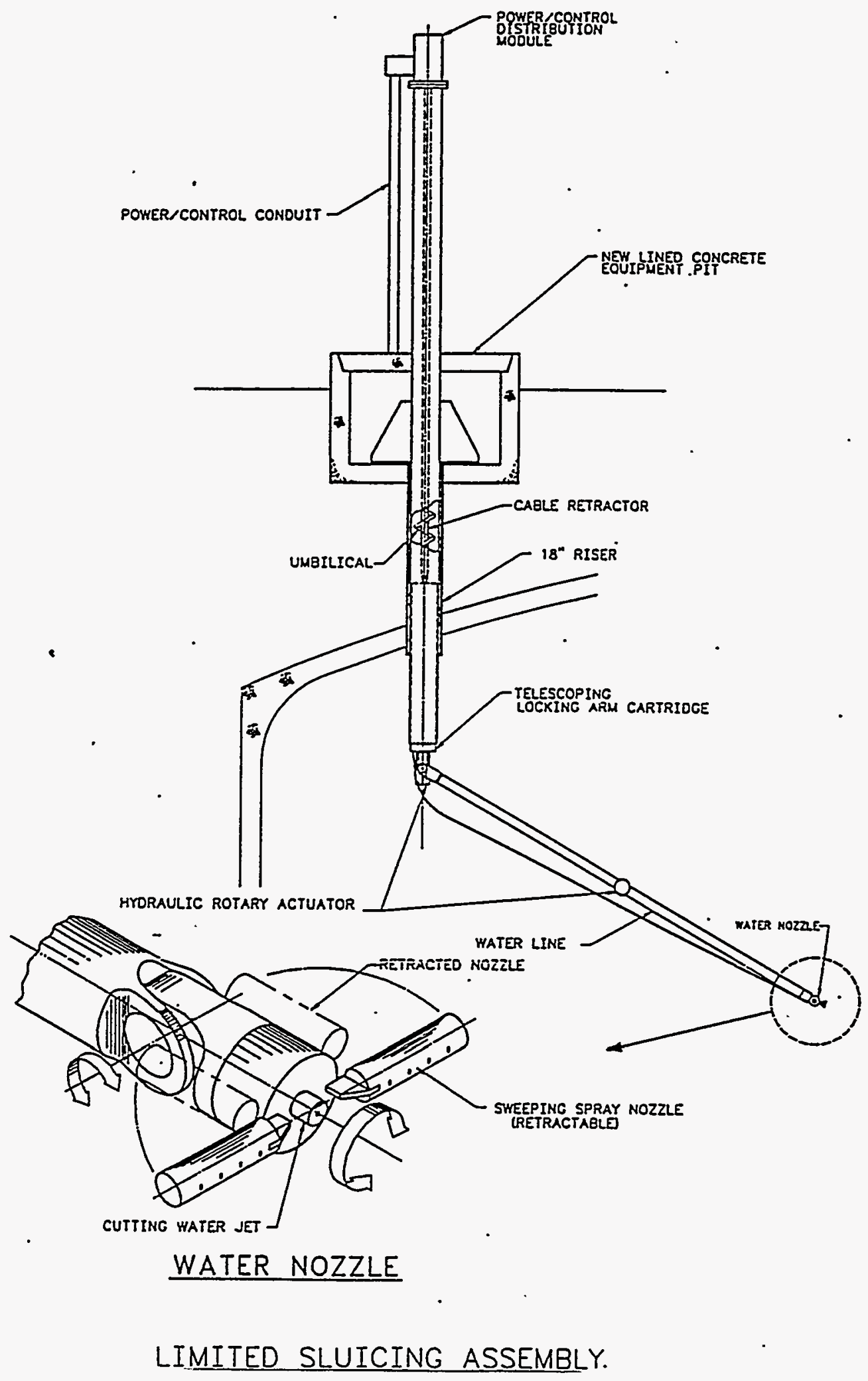


The slurry is then pumped through a new pipe-in-pipe transfer line to a double-shell receiver/lag storage tank. Untike past sluicing methods, the supernate 1 iquids from the receiver/1ag storage tank cannot be reused because of erosion/corrosion effects on the sluicing nozzles.

Advantages

- Limited sluicing is adaptable to the specific needs of Tank 241-T-101 sludge cleanout

- This system minimizes the amount of water added to Tank 241-T-101 for sludge retrieval operation

- A new sludge/slurry pump could be installed in the existing $30.5 \mathrm{~cm}$ (12 in.) riser $R-10$ located in heel pit 241-TR-01B

- Existing sma11 Tank 241-T-101 risers may need only minor modifications to accept new instruments required to monitor and control the limited sluicing system operation

- The new limited sluicing equipment is reusable and can be readily transported and installed for use in other SSTs

- A new remote CCTV two-camera system could be installed in the existing $30.5 \mathrm{~cm}$ (12 in.) risers $\mathrm{R}-6$ and $\mathrm{R}-2$.

\section{Disadvantages}

- Four new $46 \mathrm{~cm}$ (18 in.) risers will need to be installed through the existing Tank 241-T-101 concrete dome

- Lined concrete equipment pits need to be constructed over each of the new $46 \mathrm{~cm}$ (18 in.) risers to enclose limited sluicing equipment. Each new equipment pit requires a $3,000 \mathrm{lb} / \mathrm{in}^{2}$ decontamination system

- Existing equipment pits on Tank 241-T-101 to be reused for the installation of retrieval systems equipment need to be modified for the installation of a $3,000 \mathrm{lb} / \mathrm{in}^{2}$ decontamination system

- The existing heel pit 241-TR-01B may require structural upgrades to permit installation of a new sludge/slurry pump (e.g., new cover blocks, shielding plugs, metal pit liner, and pit reconfiguration)

- For Tank 241-T-101, an accumulator tank and transfer lines do not exist to permit implementation of this concept.

\subsubsection{Articulated Arm Scarifier}

The articulated arm scarifier is an untried waste retrieval concept that is based on a commercial water scarifier design. Commercial scarifiers are used to remove paving materials from roadways and bridge decks. A key feature of this concept is a high-pressure multijet sluicer that is housed in two hemispherical shells with an annular space between them to allow for the 
inflow of air. The low-volume, high-pressure water jets dislodge and mix the sludge. Suction provided by an air lift system removes the sludge/slurry mixture as soon as it is formed.

The use of this type of air conveyance system has not been demonstrated for use on sludge wastes having an uneven surface. A large R\&D effort would be required to prove the system, therefore, this system is not yet considered a viable option for the removal of SST sludge wastes.

The articulated arm scarifier consists of a $1 \mathrm{~m}$ ( $3 \mathrm{ft})$ diameter dome or shell containing eight water jet nozzles and the intake for the air conveyance system (Barnes 1991). The outer shell provides an air channel to feed the pneumatic intake even when the module is submerged. The module is mounted on an articulated robotic arm that can move in any direction desired within the tank. The concept is illustrated in Figure 3-18.

The high-pressure, 10w-volume water jet nozzles with flow rates from $6 \mathrm{gal} / \mathrm{min}$ at $20,000 \mathrm{lb} / \mathrm{in}^{2}$ up to $1 / 2 \mathrm{gal} / \mathrm{min}$ at $55,000 \mathrm{lb} / \mathrm{in}^{2}$ would sluice and mix the sludge. Each nozzle is fed separately with clean water from a highpressure supply unit located above the tank. The water jets dislodge and blow the sludge into a high-velocity air path created by the air conveyance system. The suspended sludge/slurry inside the sluicing module is pneumatically transported out of the module and pumped to a new process building where the air will be separated from the sludge/slurry. Since the supernate has already been removed, the sludge/slurry will be mixed with additional liquids as required (approximately $30 \%$ solids) to permit transfer by pipe-in-pipe to a double-shell receiver/lag storage tank.

A11 equipment needed to operate the arm and jets is located in a utility module. The utility module transmits hydraulic power and electricity to a distribution module. The distribution module serves as the interface point from the utility module to the scarifier and robotic arm via the retrieval tower. The retrieval tower functions as the arm transport, arm storage, and arm support for activities inside the tank.

\section{Advantages}

- This system minimizes the amount of water added to a tank

- Neither the scarifier nor the air conveyance system have moving parts

- This system can break up and mix very hard materials/sludges not amenable to removal by other sluicer technologies

- The scarifier will not erode the walls and floor of the tank unless desired

- Equipment associated with the system lends itself to modular design, and use in more than one SST.

\section{Disadvantages}

- The system is not available commercially. It must be designed, fabricated, tested and developed 


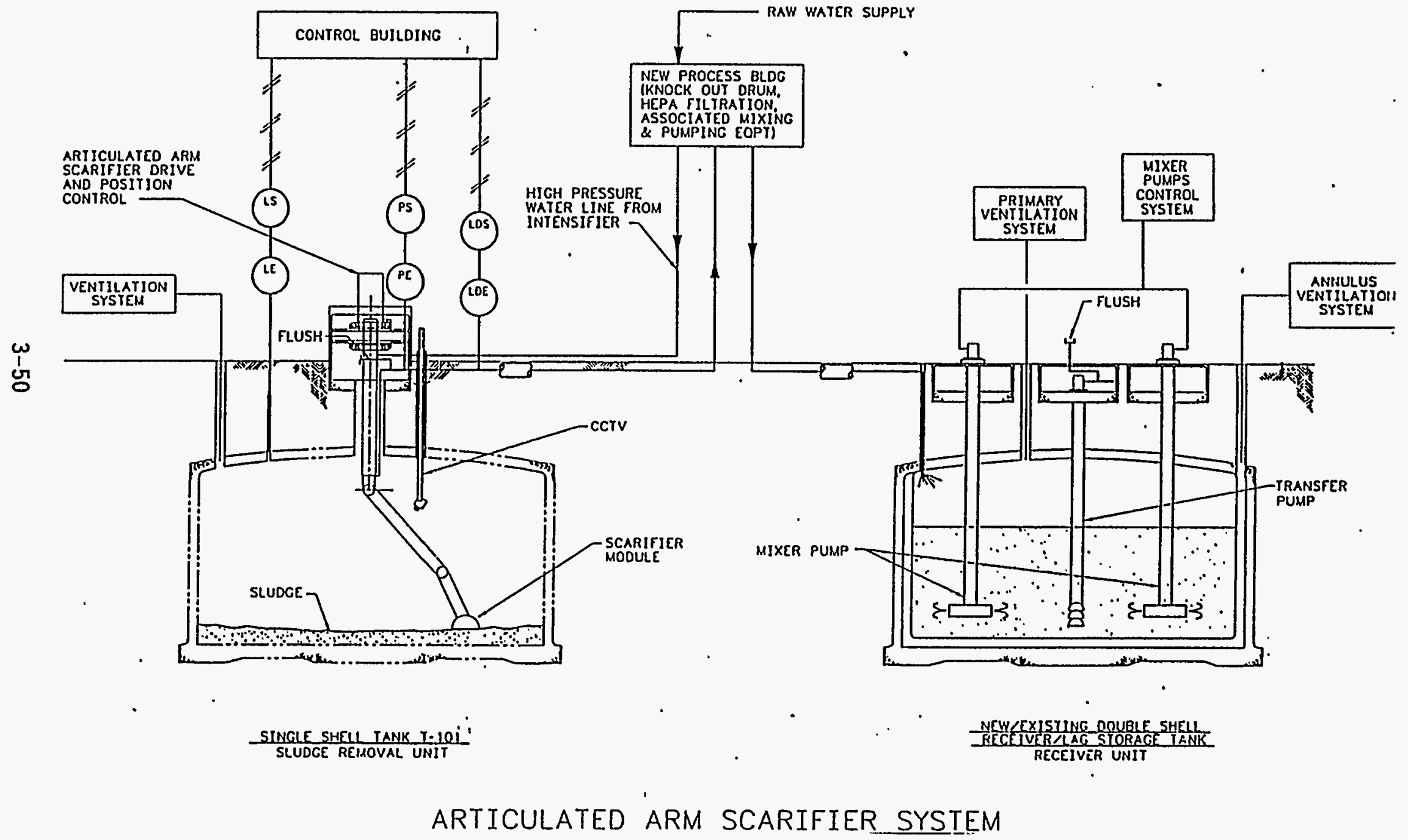

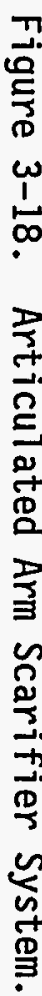

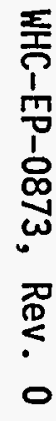


- An untested, large positive displacement air conveyance system would be required to transport the waste to the surface

- A $1 \mathrm{~m}(4 \mathrm{ft})$ to $2 \mathrm{~m}(6 \mathrm{ft})$ diameter hole would be required in the Tank 241-T-101 dome to install this system (Barnes 1991).

\subsubsection{Mining}

There are a number of physical mining concepts that have been considered in the past for retrieval of solid wastes from SSTs. Most studies have concluded that physical mining is not a feasible concept. Safety issues, research and development, maintenance and operations drive life cycle costs so high that they are dismissed from further consideration.

An engineering study for retrieval of Tank 241-C-106 wastes demonstrates the magnitude of the impacts from certain proposed mining concepts (Barnes 1991). The following concepts were studied:

- Mechanical dredge (tethered systems)

- Direct retrieval - air mining (robotic arm)

- Mechanical extraction (robotic arm)

- Direct pumping of siudge (robotic arm) 
WHC-EP-0873, Rev. 0

This page intentionally left blank. 
WHC-EP-0873, Rev. 0

\subsection{HAZARDS EVALUATION}

Existing SSTs have exceeded their design Tife. Little is known about the physical conditions of the tank structures or the physicochemical characteristics of the stored waste. Fresh radioactive waste has not been introduced into the tanks since the 1980s.

Some of the tanks have several safety concerns. Single-shell tanks that meet Priority 1 safety issues have been categorized according to the safety concern and placed on a watch list (see Table 4-1). Priority 1 tanks are defined as ones containing most of the necessary conditions that could lead to worker onsite or public radiation exposure through an uncontrolled release of fission products. Tanks that are placed on the watch list contain one or more of the following features:

- Organic-nitrate or total organic carbon greater than $3 \%$ in weight ( $10 \%$ weight sodium acetate equivalent)

- Ability to produce, entrap, and periodically release flammable gas

- Ferrocyanide ion content greater than 1,000 g-mole

- Heat load that exceeds $40,000 \mathrm{Btu} / \mathrm{hr}$, and requires active cooling for temperature maintenance.

Tank 241-T-101 is on the ferrocyanide tank watch 7 ist.

\subsection{CHEMICAL AND RADIOLOGICAL HAZARDS}

Waste quantities in the tanks are based on estimated levels by the computerized tracking program known as Track Radioactive Components (TRAC). The TRAC data is questionable because it is based mainly on historical records with few backup samples. More sampling is needed to obtain a better knowledge of the tank waste characteristics. Some chemical and radiological concentrations in Tank 241-T-101 are known from supernatant samples taken in August 1989, see Tables 4-2 and 4-3 (Vail 1992). These samples contained 69\% water in weight, had a specific gravity of 1.2 , and a $\mathrm{pH}$ of 13.3 .

The principal radionuclides of concern are 90Sr, 99Tc, 137Cs, and transuranics 239Pu, 240Pu, and 241Am. Hazardous materials include toxic elements, nitrites, nitrates, hydroxides, and organics. Currently, there is no watch list for toxic vapor releases; however, RL considers the problem of dome space toxic vapors to be a priority concern (Kummer et al.). Toxic elements that may be a problem include constituents such as heavy metals, chromium, cadmium, arsenic, and mercury. The primary chemical elements/ compounds for Tank 241-T-101 are listed in Table 4-4. 
WHC-EP-0873, Rev. 0

Table 4-1. Watch List Tank Status as of August 1992.

\begin{tabular}{|c|c|c|c|c|}
\hline & $\begin{array}{c}\text { Hydrogen/ } \\
\text { flammable gas }\end{array}$ & - Ferrocyanide & Organic salts & High heat \\
\hline 1 & $101-A$ & 102-BX & $103-B$ & $104-A$ \\
\hline 2 & $101-A X$ & $106-B X$ & $103-C^{1}$ & $105-A$ \\
\hline 3 & $103-A X$ & $110-B X$ & $102-S^{*}$ & $105-C$ \\
\hline 4 & $102-S^{*}$ & $111-B X$ & $106-S X^{*}$ & $106-C$ \\
\hline 5 & $111-S$ & 101-BY & 105-TX & 107-SX \\
\hline 6 & $112-S$ & 103-BY & $118-\mathrm{TX}^{*}$ & $108-S X$ \\
\hline 7 & $101-S^{*}$ & 104-BY & $106-U$ & $109-S X^{* 1}$ \\
\hline 8 & $102-S X$ & $105-B Y$ & $107-U$ & $110-S X$ \\
\hline 9 & $103-S X$ & 106-BY & & $111-S X$ \\
\hline 10 & $104-S X$ & 107-BY & & 112-SX \\
\hline 11 & $105-S X$ & 108-BY & & 114-SX \\
\hline 12 & $106-S X^{*}$ & $110-B Y$ & & \\
\hline 13 & $109-S X^{*}$ & $111-\mathrm{BY}$ & & \\
\hline 14 & $110-\mathrm{T}$ & 112-BY & & \\
\hline 15 & $103-U$ & $108-C$ & & \\
\hline 16 & $105-U$ & $109-C$ & - & \\
\hline 17 & $108-U$ & $111-C$ & & \\
\hline 18 & $109-U$ & $112-C$ & & \\
\hline 19 & $103-\mathrm{AN}^{+}$ & $101 \div T$ & & \\
\hline 20 & $104-\mathrm{AN}^{+}$ & $107-T$ & & \\
\hline 21 & $105-\mathrm{AN}^{+}$ & $118-T^{*}$ & & \\
\hline 22 & $101-S Y^{+}$ & 101-TY & & \\
\hline 23 & $103-S Y^{+}$ & 103-TY & & \\
\hline 24 & & 104-TY & & \\
\hline
\end{tabular}

*These tanks appear on two lists.

tDouble-she1l tanks.

${ }^{1}$ Tank 103-C has separable organic layer on surface of waste.

${ }^{2}$ Tank 109-SX has hydrogen potential because Tanks 101 through 106-SX vent through it.

Data taken from "Operations Specifications for Watch List Tanks," 0SD-T-151-00030. 
HHC-EP-0873, Rev. 0

Table 4-2. Composition of Tank 241-T-101 Supernatant (Chemicals).

\begin{tabular}{|c|c|c|}
\hline Component & As Is, g/1 & Filtered, g/l \\
\hline $\mathrm{NO}_{2}$ & -- & 22.85 \\
\hline $\mathrm{NO}_{3}$ & -- & 160.6 \\
\hline $\mathrm{OH}$ & -- & 3.65 \\
\hline Al & 0.316 & 0.034 \\
\hline $\mathrm{CO}_{3}$ & 39.72 & - \\
\hline $\mathrm{SO}_{4}$ & 13.16 & -- \\
\hline $\mathrm{PO}_{4}$ & 4.48 & -- \\
\hline$F$ & $<1.09$ & -- \\
\hline $\mathrm{Cl}$ & 1.08 & -- \\
\hline TOC & -- & - \\
\hline$P$ & 1.07 & - \\
\hline$K$ & 0.53 & - \\
\hline $\mathrm{Na}$ & 59.08 & -- \\
\hline $\mathrm{Cr}$ & 1.53 & -- \\
\hline B & 0.012 & -- \\
\hline $\mathrm{Ca}$ & 0.007 & -- \\
\hline
\end{tabular}

Data from "Justification for Continued Operation of Hanford High Leve] Waste Tanks, "Correspondence number 9257718, WHC-SD-SQA-CSA-20355, Rev. 0.

Table 4-3. Composition of Tank 241-T-101 Supernatant (Radiological).

\begin{tabular}{|l|c|c|}
\hline \multicolumn{1}{|c|}{ Components } & As is $(\mathrm{g} / \mathrm{L})$ & Filtered $(\mathrm{g} / \mathrm{L})$ \\
\hline${ }^{239,240} \mathrm{Pu}$ & 0.000004 & 0.0000025 \\
\hline${ }^{241} \mathrm{Am}$ & $<10^{-7}$ & $<10^{-7}$ \\
\hline${ }^{89,90} \mathrm{Sr}$ & $<10^{-6}$ & -- \\
\hline${ }^{99} \mathrm{Tc}$ & 0.0063 & -- \\
\hline${ }^{137} \mathrm{Cs}$ & 0.001 & -- \\
\hline
\end{tabular}

Data from "Justification for Continued Operation of Hanford High Leve1 Haste Tanks," Correspondence Number 9257718, WHC-SD-SQA-CSA-20355, Rev. 0. 
Table 4-4. Track Radioactive Component Inventories for Primary Nonfissile Compounds in Tank 241-T-101.

\begin{tabular}{|c|c|}
\hline Component & Total moles \\
\hline $\mathrm{Al}$ & $1 . \mathrm{E}+06$ \\
\hline $\mathrm{C}_{6} \mathrm{H}_{5} \mathrm{O}_{7}$ & $3 . \mathrm{E}+05$ \\
\hline $\mathrm{CO}_{2}$ & $9 . \mathrm{E}+06$ \\
\hline $\mathrm{F}$ & $2 . \mathrm{E}+05$ \\
\hline $\mathrm{Fe}$ & $4 . \mathrm{E}+04$ \\
\hline $\mathrm{K}$ & $1 . \mathrm{E}+05$ \\
\hline $\mathrm{NO}_{2}$ & $1 . \mathrm{E}+05$ \\
\hline $\mathrm{NO}_{3}$ & $1 . \mathrm{E}+07$ \\
\hline $\mathrm{Na}$ & $3 . \mathrm{E}+07$ \\
\hline $\mathrm{OH}$ & $2 . \mathrm{E}+05$ \\
\hline $\mathrm{PO}_{4}$ & $2 . \mathrm{E}+06$ \\
\hline $\mathrm{SO}_{4}$ & $3 . \mathrm{E}+05$ \\
\hline
\end{tabular}

Data from "Justification for Continued Operation of Hanford High Level Waste Tanks," Correspondence number 9257718, HHC-SD-SQA-CSA-20355, Rev. 0.

\subsection{HYDROGEN GAS AND ORGANICS}

Current7y, 18 SSTs and 5 DSTs are on the hydrogen/flammable gas watch list (see Table 4-1). Hydrogen/flammable gas buildup in the tanks can lead to a radioactive material release to the environment because of over pressurization or explosion. The best example of over pressurization is Tank 101-SY. This tank periodically releases built-up hydrogen gas over a short period of time in sufficient concentrations to support combustion. Depending upon the rate of gas release and volume, the tank may also become pressurized. An explosion could result if an ignition source were present at the peak of release. Currently, hydrogen is not a problem in Tank 241-T-101; however, 7ittle is known about how the hydrogen is produced, so it cannot be dismissed.

Eight tanks are on the organic salts watch list. Two of these contain hydrogen/f7ammable gas and one contains ferrocyanide (see Table 4-1). Organic salt tanks have potentially explosive organic chemicals. Organics in the tank, flammable gases, and ferrocyanide-nitrate mixtures are sources of deep safety concern. However, an explosion is deemed unlikely because of relatively low tank temperatures at present and the high ignition temperature required to initiate a reaction. Major safety issues involve tanks that contain mostly solids. If solids dry out, any high organic concentrations could be heated to high temperatures by radioactive decay to create an 
exothermic condition. This could further raise the temperatures in the tank to the ignition point of other chemicals such as ferrocyanides. Ultimately, this could result in release of high-level waste (HLH) because of tank pressurization. Two options for dealing with the hazards of organic tanks are:

1. Prove or demonstrate that an explosion is highly unlikely

2. Remove or destroy the hazardous waste constituents.

Tank 241-T-101 is not included on the organic watch 1ist.

\subsection{FERROCYANIDE STABILITY}

Ferrocyanide was originally added to waste to precipitate radioactive nitrate constituents from the liquid for the purpose of gaining additional storage space during the 1950s (Kummer 1992b). Tanks on the ferrocyanide list contain 1,000 g-mole or more of ferrocyanide. There are currently 24 tanks listed as ferrocyanide tanks, one is also 1isted as an organic tank (see Table 4-1). Ferrocyanide can be oxidized by nitrate. This oxidation results in the release of thermal energy that can lead to an explosion, pressurization of the tank, and ejections of hazardous and radioactive materials into the atmosphere and surrounding environment. Options that are being considered to deal with or limit the hazards of ferrocyanide tanks are:

- Demonstrate that the possibility of a runaway chemical reaction is remote. Therefore, only surveillance of the tank is needed

- Maintain and monitor tank's water content to cool the waste and prevent an explosion

- Remove the waste and destroy the ferrocyanide as proposed in project $\mathrm{W}-236 \mathrm{~B}$, initial pretreatment module.

Tank temperatures at Hanford do not exceed $93{ }^{\circ} \mathrm{C}$. A ferrocyanide induced pressurization event could take place under certain conditions. Conditions include a temperature of $285{ }^{\circ} \mathrm{C}$, dryness, and proper chemical mixtures and concentrations. Tank temperatures have actually been decreasing at $2{ }^{\circ} \mathrm{C}$ per year due to radioactive decay. A recent investigation of the watch-list ferrocyanide tanks found incorrect characterization data. Tanks 241-T-101, $B X-106, B X-110$, and $B X-111$ were apparently incorrectly placed on the 1ist of ferrocyanide tanks. These tanks contain less than the required amount of ferrocyanide to be on the watch 7ist. Tank 241-T-101 has not been formally removed from the ferrocyanide tank watch 1 ist. The temperature of Tank $241-\mathrm{T}-101$ was $21^{\circ} \mathrm{C}\left(70^{\circ} \mathrm{F}\right)$ in August 1992. Highest yearly temperature for stabilized ferrocyanide tanks are shown in Table 4-5.

\subsection{CRITICALITY}

Since many of the HLH tanks at Hanford contain more than the minimum fissile material necessary to cause a criticality event, a criticality must be considered for each. Criticality is a self-sustained atomic reaction and is possible under optimal conditions in the tanks. The fissile material 
Table 4-5. Temperature History of Stabilized Ferrocyanide Tanks.

\begin{tabular}{|c|c|c|c|c|c|c|c|c|c|c|c|c|c|}
\hline \multirow{2}{*}{ Tank } & \multicolumn{13}{|c|}{ Highest yearly temperatures ( $\left.{ }^{\circ} \mathrm{F}\right)$} \\
\hline & 180 & '81 & '82 & '83 & $' 84$ & $' 85$ & '86 & ' 87 & ' 88 & $' 89$ & 190 & $91^{\prime}$ & $92^{\prime}$ \\
\hline BY-101 & & 75 & 96 & 72 & 84 & & & & & & 76 & 76 & 75 \\
\hline BY-104 & 170 & 145 & 164 & 145 & 143 & 158 & 145 & 149 & 136 & 148 & 130 & 129 & 129 \\
\hline BY-107. & & & & & & & & & & & 86 & 94 & 97 \\
\hline BY -108 & 117 & 96 & 119 & 118 & & 97. & & & & & 103 & 102 & 92 \\
\hline BY -110 & 139 & 132 & 118 & 147 & 148 & 140 & 145 & 139 & 133 & 136 & 135 & 120 & 122 \\
\hline BY-111 & & & & & & 978 & & & & & 87 & 83 & 87 \\
\hline BY-112 & & 93 & & & & 93 & & & & & 84 & 82 & 83 \\
\hline$T X-118$ & & & 100 & 108 & 85 & 89 & & & & & 78 & 78 & 77 \\
\hline TY-101 & 80 & 62 & 78 & 68 & & & & 68 & 79 & & 71 & 71 & 71 \\
\hline TY-103 & 69 & 75 & & 64 & & & 65 & & & & 69 & 69 & 67 \\
\hline
\end{tabular}

Shaded areas indicate that the tank was jet pumped.

*Tank BY-107 was jet pumped in 1979.

Data from "Safety Assessment for Interim Stabilization of Ferrocyanide Tanks," WHC-SD-WM-SAD-018, Rev. 0.

of greatest criticality concern at Hanford is plutonium. Plutonium fissile concentrations of at least $3.0 \mathrm{~g} / 1$ over a large.volume of the tank waste are needed for criticality. Criticality requires a plutonium mass of at least $4.0 \mathrm{~g} \mathrm{Pu} / 1$. The greatest plutonium concentration reported in tanks is $0.038 \mathrm{~g} / 1$ in Tank 107-C. Because of a void of plutonium, a criticality is extremely unlikely to occur in Tank 241-T-101, even if the Tiquid is pumped from the tank. The concentrations shown in Table 4-6 are based on TRAC data and, therefore, are questionable.

\subsection{HIGH HEAT}

Currently, 11 tanks are 1isted as high-heat tanks (see Table 4-1). Only one of these tanks, 106-C is on the watch list. High-heat tanks have a heat load greater than $40,000 \mathrm{Btu} / \mathrm{hr}$, and require survei11ance. Water is added to regulate the temperatures in tanks $105-C$ and $106-C$. If the water is removed from a tank during interim stabilization, there could be an increase in the thermal resistivity of the salt cake and a corresponding increase in the total tank temperature. Higher temperatures may result from ferrocyanide and nitrate mixtures reacting, and further increase the temperature. Salt well jet pumping has shown no long-term temperature increase in ferrocyanide tanks such as Tank 241-T-101. In fact, a downward temperature trend has been noticed in ferrocyanide Tanks BY-104 and BY-110 with the highest temperatures (see Table 4-5). The decrease in tank temperature is attributed to removal of $137 C s$ in liquids and to the nuclear decay inside the tank. Tank 241-T-101 is not currently listed as a high-heat tank. Tank 241-T-101 has a fairly normal temperature with a maximum $70^{\circ} \mathrm{F}$ temperature in August 1992; this is s7ight7y above the ground temperature. 
WHC-EP-0873, Rev. 0

Table 4-6. Track Radioactive Component Inventories for $\mathrm{Pu}$ and $\mathrm{U}$ Isotopes in Tank 241-T-101.

\begin{tabular}{|c|c|c|c|}
\hline Component & $\begin{array}{c}\text { Concentration in sludge } \\
(\mathrm{g} / \mathrm{T})\end{array}$ & $\begin{array}{c}\text { Total quantity** } \\
\text { moles }\end{array}$ & $\begin{array}{c}\text { Total quantity* } \\
(\mathrm{kg})\end{array}$ \\
\hline${ }^{239} \mathrm{Pu}$ & 0.0043 & $7 . \mathrm{E}+00$ & 1.67 \\
\hline${ }^{240} \mathrm{Pu}$ & 0.00012 & $2 . \mathrm{E}-01$ & 0.048 \\
\hline${ }^{241} \mathrm{Pu}$ & 0.00000 & $4 . \mathrm{E}-03$ & 0.001 \\
\hline${ }^{233} \mathrm{U}$ & 0.00000 & $9 . \mathrm{E}-06$ & 0.000 \\
\hline${ }^{235} \mathrm{U}$ & 12.0 & $2 . \mathrm{E}+04$ & 4700.0 \\
\hline${ }^{238} \mathrm{U}$ & 1831.0 & $3 . \mathrm{E}+06$ & 714000.0 \\
\hline
\end{tabular}

"This includes all liquid and all solids.

Data from "Justification for Continued Operation of

Hanford High Level Waste Tanks, "Correspondence number 9257718, WHC-SD-SQA-CSA-20355, Rev. 0. 
WHC-EP-0873, 'Rev. 0

This page intentionally left blank. 
HHC-EP-0873, Rev. 0

\subsection{ALTERNATIVES SELECTION CRITERIA}

Selection criteria are established in the section for evaluating the potential advantages and disadvantages associated with implementing a given interim waste management strategy for Tank 241-T-101. Criteria was selected that can readily be evaluated using engineering judgement and experience and can be understood to significantly impact or influence the selection process. The criteria are not all inclusive or detailed in scope. They represent a wide range of safety and socioeconomic issues that permit the screening of potential candidate technologies for acceptability. Alternatives passing the initial screening will be analyzed further to select those deemed to have the greatest possibility for successful implementation.

The selection criteria are health, safety, regulatory compliance, waste safety, tank integrity, future retrieval and processing, cost, schedule, technical feasibility, maintainability, and operability. Each is weighted from 1 to 5 to reflect its relative importance to other criteria in the decision making process. A weight of 5 had the highest importance and 1 the lowest.

Table 5-1. Weight Factor.

\begin{tabular}{|l|c|}
\hline \multicolumn{1}{|c|}{ Importance } & Weight factor \\
\hline Low & 1 \\
Low/medium & 2 \\
Medium & 3 \\
Medium/high & 4 \\
High & 5 \\
\hline
\end{tabular}

Score factors are also given for each of the selection criteria within each alternative and option. Numerical scores of 0 to 5 reflect the estimated impact on the selection criteria.

Table 5-2. Score Factor.

\begin{tabular}{|l|c|}
\hline \multicolumn{1}{|c|}{ Impact } & Score \\
\hline None & 0 \\
Light & 1 \\
Light/moderate & 2 \\
Moderate & 3 \\
Moderate/heavy & 4 \\
Heavy & 5 \\
\hline
\end{tabular}

An option's impact score multiplied by the importance weight determines its weighted score. This weighted score indicates how the alternative performs. The higher the impact score, the less favorable the alternative/ option. 
WHC-EP-0873, Rev. 0

\subsection{HEALTH SAFETY}

Health safety concerns include public safety, worker safety, and environmental impacts. Safety concerns are given the highest subjective weight factors, i.e., 5 .

\subsubsection{Public Safety}

Environmental releases to air, soil, and ground water that potentialiy could affect the public are considered. Short-term releases from activities associated with the alternative/option are examined to determine their potential impact on the public health. Long-term releases of radionuclides and hazardous chemicals are not considered because they are associated with the final disposal site.

5.1.1.1 Short Term - Chronic. The short-term or chronic radionuclides and chemical releases from normal operations of facility equipment and transportation are examined for each alternative/option. The evaluation is based on an estimate of the integrated population dose (manirems) from all activities associated with the alternative/option.

5.1.1.2 Short Term - Acute. Short-term or acute releases result from plant and transportation accidents. Short-term acute releases are estimated based on the potential for accidental release of large quantities of hazardous materials from activities associated with the alternative/option. The score includes estimates of the fraction of total inventory released as well as probability of occurrence.

\subsubsection{Worker Safety}

Worker safety involves estimating potential health impacts from industrial accidents and from routine radiation doses. Industrial accidents are based on total manhours estimated to be involved in the alternative/ option. The worker radiation dose is based on total manhour estimates and estimated exposure to radioactive waste during operation and transport activities.

The total man-rems for worker radiation doses are based on total estimated manhours required for the project and on the potential for exposure to elevated levels of radioactivity from handling and transportation activities.

\subsubsection{Environmental Safety}

The potential for release and the relative magnitude of the release of hazardous and radioactive materials are evaluated for a given alternative/ option. The resulting harm or insult to the environment is assessed and ranked. 
WHC-EP-0873, Rev. 0

\subsection{REGULATORY COMPLIANCE}

How an alternative/option is judged to comply with current regulations/laws is evaluated. Regulatory compliance is estimated to be of slightly less importance than safety and was given a weight factor of 4 .

\subsubsection{Washington Administrative Code (WAC), Dangerous Waste Reguilations}

The ability to meet HAC 173-303, "Dangerous Waste Regulations" (Ecology 1993) is the principle regulatory concern. The current action to achieve compliance for leaking SSTs is to pump the liquid contents to a double-contained, receiver/storage tank (ultimately to a DST). Each alternative/option is measured against this approved method or its ability to stabilize an SST and prevent/stop leaks. There is no WAC requirement to pump a nonleaking tank.

\subsubsection{Closure/Post-Closure Activities}

The impact of an alternative/option upon the ability to clean the site to background levels, i.e., regulatory closure/post-closure activities, is evaluated in this subsection. For example, options that cause soil contamination or contaminate large amounts of equipment would significantly impact closure/post-closure activities. Alternatives/options are rated on the perceived effort required to clean the site/contaminated equipment to background levels.

\subsection{WASTE SAFETY}

There are several unresolved waste safety related issues associated with the retrieval of SST wastes. The effect on solid waste of the removal of water and hydroxide solutions has not been adequately determined. Water removal and the heating and drying of waste can decrease the ability of the waste to cool. The possibility for thermal runaway reactions between oxidants (nitrates) and organics/ferrocyanide significantly increases as moisture is removed or heat is added to tank solids. The most significant unresolved waste safety issues are discussed in the following subsections.

\subsubsection{Hydrogen/Flammable Gas Generation}

There are a number of HLW tanks that have the potential to generate flammable gas (hydrogen, organics, and/or nitrous oxide). A possibility exists for a fire in these tanks and release of radioactive/hazardous material to the environment if an ignition source is provided. An unfiltered release could occur in the event of an overpressurization of the tank ventilation system during periodic gas venting. The possibility for this condition to occur during waste retrieval operations is examined. 
WHC-EP-0873, Rev. 0

\subsubsection{Ferrocyanide Stability}

Twenty-four SSTs may contain enough ferrocyanide precipitates to be a safety concern. Ferrocyanide compounds can react and detonate if conditions are right. Among these conditions are sufficient ferrocyanide chemical concentrations and elevated temperatures. Dryness coupled with hot spots could elevate tank waste temperatures to produce exothermic reactions of present organic wastes $\left(220\right.$ to $250^{\circ} \mathrm{C}$ ) or ferrocyanide compounds $\left(285^{\circ} \mathrm{C}\right)$. The possibility for such a reaction is evaluated for each alternative/option.

\subsubsection{Criticality}

Analytical results from tank core samples consistently show fissile material concentrations that are at least an order of magnitude lower than the $1 \mathrm{~g} / 1$ allowed by the criticality prevention specification. However, few tanks have been sample-cored. A safety criticality concern exists about the effect of removing supernate from the tanks because supernate is a moderator. The potential impact of actions taken to implement an alternative/option is evaluated with respect to creating a criticality event within a given tank.

\subsubsection{Heat Load}

Any drying of salt cake/sludge is expected to increase thermal resistivity. This resistivity can affect the ability of tank waste to cool, and hot spots could be created. If organics/ferrocyanide compounds are present in sufficient quantities, an exothermic reaction could occur causing tank pressurization and loss of containment. High sludge temperatures may cause structural damage to the tank resulting in a possible dome collapse and exposure of waste to the environment.

\subsection{TANK INTEGRITY}

The SSTs have exceeded their original design life. Available information on the physical condition of the tank structure is Timited. Monitoring equipment is unreliable. The steel liners on approximately half the SSTs may have already leaked. Tanks low in hydroxide are considered most vulnerable because hydroxide is known to inhibit corrosion of mild steel. Potential structural safety concerns and impacts associated with SST waste storage and removal operations that could influence the selection of a waste retrieval technology are addressed below. Tank integrity concerns are given a weight factor of 3 .

\subsubsection{Waterline Corrosion}

No waterline attack has been observed at the SRS or at Hanford. If the waste solution has a high $\mathrm{pH}$ and contains nitrites, waterline corrosion is not thought to p7ay a major role in creating leaks in SSTs. However, histories of waste storage and waste chemistries in SSTs are complex. Waterline corrosion may be a factor in SSTs that originally stored bismuth-phosphate waste solution from old T-Plant and B-Plant operations or which contained insufficient hydroxides and nitrites. Waterline corrosion should have little 
HHC-EP-0873, Rev. 0

or no impact on Tank 241-T-101 safety, because of the corrosion inhibiting properties of the current wastes.

\section{4 .2 SCC}

Stress corrosion cracking of the steel liner is the cause of previous leaks from the nonstress relieved tanks at SRS. ATso, this is probably the cause of the SST leaks at Hanford. The SCC could have started soon after liquid water was routed into the SSTs. Crack growth may be a continuing phenomena that gradually enlarges the leakage path.

\subsubsection{Crevice Corrosion}

No crevice corrosion attack has been observed at the SRS or Hanford Site. This failure mechanism is not considered to have any impact on tank safety. It is included to show completeness in the evaluation.

\subsubsection{Concrete Degradation/Cracking}

Stress corrosion cracking of the steel liner will permit the waste to come into contact with the concrete wall. Hestinghouse Hanford Company has investigated the potential for failure of the concrete over a period of years and has concluded that the concrete has not been significantly degraded by either elevated temperatures or chemicals in the waste. Currently, SSTs are believed to be structurally sound.

\subsubsection{Ease of Maintaining Confinement}

A number of the options considered in this study will require additional $30.5 \mathrm{~cm}$ (12 in.) or larger risers to be added to the tank 1id. These penetrations will complicate waste containment activities significantly, and will increase HVAC requirements to maintain confinement. These penetrations may also require structural analysis to ensure that the dome has adequate strength to support the overburden and equipment associated with the added penetrations and operations.

\subsection{FUTURE RETRIEVAL AND PROCESSING}

Alternatives and options are evaluated for potential impact on future retrieval, transport, storage, and waste processing operations. Actions that may potentially compromise, severely impact, or complicate retrieval, transport, storage, or waste treatment are identified and rated for each option. Major operations that could be individually affected are listed in the following subsections.

\subsubsection{Waste Retrieval}

Existing and planned Hanford facilities are designed to handle and transfer liquids. Waste retrieval involves the sluicing or mixing of present 
solids with liquids to permit the transfer of the liquid and slurry via pumps through existing and future transfer lines to storage and processing systems. The advantages of liquid retrieval transport versus air transport and physical mining of hazardous materials are numerous. Principle advantages involve safety, cost, mature technology, maintainability, ease of shielding for radioactivity, and a system in existence on the Site. Options are evaluated on the basis of the potential impact on future waste retrieval and processing operations. Judgement is made on whether the option increases or decreases waste retrievability and recovery.

\subsubsection{Soil Retrieval}

Alternatives and options are evaluated for their potential to contaminate soil and thereby require retrieval and future treatment of large volumes of soil. Options deemed to have a high potential to contaminate soil are given a high score as to their impact on future retrieval and processing operations.

\subsubsection{Transfer System Integrity}

The potential impact of the proposed option on existing and future waste transfer systems is evaluated. Whether the options facilitate transport and handling, or complicate it and conflict with existing and planned waste transfer systems are evaluated. Options are judged on their compatibility with existing and planned transfer, and waste storage/processing facilities.

\subsubsection{Storage Availability}

Alternatives and options are evaluated on their potential impact on current waste storage volumes. Options likely to significantly add to the waste volume to be handled, stored, and processed are deemed to have a high impact. Options causing little or no growth in the volume of waste to be retrieved are rated lower. The need for additional storage space significantly impacts other selection criteria such as cost, schedule, and safety.

\subsubsection{Treatment Compatibility}

Alternatives/options are evaluated on their compatibility with existing and planned waste treatment operations for tank waste. Options that render the wastes more difficult to treat and process into final disposal form are given higher impact scores than those options that are compatible with the planned HLW treatment facilities (glassification of radioactive/toxic waste; grouting of chemical wastes).

\section{$5.6 \operatorname{COST}$}

Alternatives and options are evaluated and ranked with respect to each other based on their potential cost. Costs are primarily based on engineering experience; however, some cost data was available. Included in the cost assessment are considerations of existing systems and facilities and 
WHC-EP-0873, Rev. 0

compatibility with planned waste retrieval, handling, storage, treatment, and disposal activities. Prudent trade offs between safety, compliance, schedules, technical feasibility, and costs are assumed in making relative cost estimates.

\subsection{SCHEDULE}

Alternatives and options are evaluated to determine if the Tri-Party Agreement milestone schedule can be met and the relative timeframe necessary to complete the option. The options considered to require the most time to achieve were given the highest impact score. The schedule is given a weight factor of 3 .

\subsection{TECHNICAL FEASIBILITY}

Alternatives and options are evaluated and rated as to their technical maturity in this section. Options were ranked and rated with respect to each other on the basis of the research and development (R\&D) effort thought to be required to bring them to maturity. Engineering judgement and experience was used to assess the amount of $R \& D$ effort required.

\subsection{MAINTAINABILITY AND OPERABILITY}

The degree of difficulty in maintaining and operating an alternative and option is considered in this part of the selection criteria. Options are rated and then ranked with respect to each other and to the perceived degree of difficulty required to operate and maintain the facilities/processes involved in the option. Options having a complex technology, i.e., requiring facilities, large amounts of equipment, chemicals, etc., are deemed to heavily impact maintenance and operations. Maintainability and operability is given a weight factor of 3 .

\subsection{SELECTION CRITERIA WEIGHT FACTORS}

Engineering judgement and experience was used to determine the relative importance of each selection criterium. Health and waste safety concerns were given the highest weight by the eight-member evaluation team. Regulatory compliance was also considered extremely important. The selection criteria are not truly independent of one another. Safety can always be increased by adding cost and schedule at an increasingly lower benefit to cost ratios. Likewise, other selection criteria may be altered up or down to the detriment or enhancement of other criteria. In performing this preliminary screening, the evaluation team assumes that a balanced approach will be used to trade-off potential benefits and costs, and that this evaluation will identify the most promising of the potential technologies for retrieval of SST wastes and, in particular, that of Tank 241-T-101.

The impact importance (weight factor) given for each of the selection criteria is provided in Table 5-3. 
WHC-EP-0873, Rev. 0

Table 5-3. Criteria Weight Factors.

\begin{tabular}{|l|c|}
\hline \multicolumn{2}{|c|}{ Weight factors given for selected criteria } \\
\hline \multicolumn{1}{|c|}{ Criteria } & Weight factor \\
\hline Health Safety & 5 \\
Compl iance with Regulations/Laws & 4 \\
Waste Safety & 5 \\
Tank Safety & 3 \\
Future Retrieval/Processing & 3 \\
Cost & 2 \\
Schedule & 3 \\
Technical Feasibility & 2 \\
Maintenance/Operations & 2 \\
\hline
\end{tabular}




\subsection{COMPARISON OF ALTERNATIVES/OPTIONS}

Scoring of the options within an alternative is discussed in this chapter and compared in Table 6-1. Key basis for this evaluation are DOE's commitments to totally and safely retrieve, process and dispose of tank wastes and cleanup the Hanford Site where practicable.

Consideration was given to a full spectrum of possible methods for managing or recovering stored tank wastes, including doing nothing (noaction), to total recovery of tank wastes (total retrieval). The evaluation is focused on the front end of the waste management program, i.e., retrieval or continued storage. Each option within the alternatives is scored from 0 to 5 for each criterion to indicate the option's adverse impact upon that criterion. The most adverse score is 5 . This score is weighted according to the relative importance of each criterion by multiplying the option's score by the criterion's weight. The more important criteria are given higher weights (see Section 5.10). The sum of all these weighted scores indicates the options total impact upon all criteria and is used to rank the alternatives and options. The alternative and option with the lowest impact score is the preferred waste management method.

Table 6-1. Total Heighted Scores for Each Alternative.

\begin{tabular}{|c|c|c|c|c|c|}
\hline Option No. & No Action ${ }^{a}$ & $\begin{array}{c}\text { In-Tank } \\
\text { Stabilization }\end{array}$ & $\begin{array}{c}\text { External } \\
\text { Tank Stabilizationc }\end{array}$ & $\underset{\text { Retrieval }}{\text { Liquid }}$ & $\begin{array}{c}\text { Total } \\
\text { Retrieval }\end{array}$ \\
\hline 1 & 135 & 116 & 100 & 10 & 55 \\
\hline 2 & 142 & 142 & 100 & 19 & 74 \\
\hline 3 & -- & 180 & 134 & 29 & 122 \\
\hline 4 & -- & 88 & 130 & 49 & -- \\
\hline 5 & -- & 154 & -- & -- & -- \\
\hline 6 & -- & 199 & -- & - & -- \\
\hline 7 & -- & 154 & $\cdots$ & - & -- \\
\hline 8 & -- & 113 & -- & -- & -- \\
\hline
\end{tabular}

$a_{\text {No-action options (see Section } 3.1 \text { ). }}$.

1. Existing monitoring system, 2. Enhanced (improved monitoring system).

b In-tank stabilization options (see section 3.2).

1. Tank wall inhibitors, 2. Diatomaceous earth, 3. Portland cement 4. Desiccants/gels, 5. Heat exchangers, 6. Hicrowave, 7. Air drying, 8. Stop leak.

${ }^{C}$ External tank stabilization options (see section 3.3 ).

1. Geomembrane walls/jet grouting, 2. slurry walls/jet grouting, 3. Sheet piling, 4. Ground freezing.

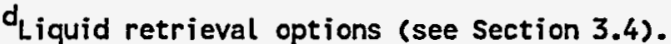

1. Existing pipeline (below grade), 2. New pipeline (below or above grade), 3. Tank truck/railcar, 4. Internal bladder.

e Total retrieval options (see Section 3.5 ).

1. Unl imited sluice (low pressure-high volume), 2. Limited sluice (high pressure-low volume),

3. Articulated arm scarifier. 
A panel of eight experts was used to establish criteria and criteria weights, collect information from presentations by cognizant engineers on each alternative, and to make final judgement on the scioring recommending by these engineers.

Tank 241-T-101 was selected for analys is because this tank is presumed to be a new (mid-1992) leaker containing approximately 30,000 gal of supernatant and requiring recovery action. It is one of the 44 SSTs that have not been interim stabilized.

The summed, weighted scores for the alternatives and options evaluated are shown in Table 6-1. The liquid retrieval alternative least impacted the evaluation criteria and is the preferred alternative. The total retrieval alternative also scored relatively low and should be considered if DST space were available because the alternative also eliminates solid waste. Safety, regulatory compliance, site cleanup, and feasibility uncertainties heavily impact the no-action, in-tank stabilization and external tank stabilization alternatives and options making them considerably less desirable.

Alternatives that involve immediate retrieval and containment of liquids and solid wastes from a leaking SST appear to impact selection criteria the least. Weighted scores for long-term health safety, regulatory compliance, schedule, clean-up, and technical feasibility issues favor existing technologies that ensure containment and minimize releases to the environment. The liquid retrieval alternative, option 1 (pump out - through existing pipeline to an existing DST) has the least immediate impact upon Tank 241-T-101 because systems to implement this option exist and DST space is available. Other liquid retrieval options are fairly easily implemented, but have higher impacts because these options require more effort and time for implementation. The total retrieval alternative offers the additional long-term advantage of solid-waste removal and clean-out. Because DOE is committed to totally cleaning out SSTs, there is no front-end advantage to delay. The SSTs will continue to degrade and leak and will become increasingly more difficult to safely manage and modify. The disadvantages of total retrieval are that potential leaks to the environment can occur during retrieval and that little DST space is available to permit near-term implementation of this alternative.

In-tank stabilization alternative, option 4, may stop a leak until retrieval operations are more opportune but this option is an unproven technology. In-tank stabilization alternative, option 1 , is not a viable option because corrosion inhibitors will not stop leaks.

Although the external tank stabilization alternative had significantly higher impacts than retrieval alternatives, the external tank stabilization a]ternative will confine wastes that have leaked into the environment. External tank stabilization methods could be used to restrict released waste from contaminating additional soil or to confine liquid releases from a failed SST.

\subsection{COMPARISON OF OPTIONS FOR NO-ACTION}

Table 6-2 1ists scores for the no-action alternative options. Safety and compliance issues made the impacts for both options scores high and unfavorable to implement. In the following sections, the reasons and considerations for the scores are given. 
WHC-EP-0873, Rev. 0

Table 6-2. Comparison of Options for No-Action Alternative.

\begin{tabular}{|c|c|c|c|c|c|c|}
\hline \multirow{2}{*}{\multicolumn{2}{|c|}{ Selected criteria (impacts) }} & \multirow{2}{*}{$\begin{array}{l}\text { Weight } \\
(1-5)\end{array}$} & \multicolumn{2}{|c|}{ Option 1} & \multicolumn{2}{|c|}{ Option 2} \\
\hline & & & $\begin{array}{l}\text { Score } \\
(0-5)\end{array}$ & $\begin{array}{l}\text { Weighted } \\
\text { score }\end{array}$ & $\begin{array}{l}\text { Score } \\
(0-5)\end{array}$ & $\begin{array}{l}\text { Weighted } \\
\text { score }\end{array}$ \\
\hline 6.1 .1 & Health Safety & 5 & & & & \\
\hline 6.1 .1 .1 & Public Safety & & 5 & 25 & 5 & 25 \\
\hline 6.1 .1 .2 & Worker Safety & & 0 & 0 & 2 & 10 \\
\hline 6.1 .1 .3 & Enviromental Safety & & 5 & 25 & 5 & 25 \\
\hline 6.1 .2 & Compliance with Laws/Regulations & 4 & & & & \\
\hline 6.1 .2 .1 & WAC $173-303$ Codes & & 5 & 20 & 3 & 12 \\
\hline 6.1.2.2 & Closure/Post-Closure Activities & & 5 & 20 & 3 & 12 \\
\hline 6.1 .3 & Haste Safety & 5 & & & & \\
\hline 6.1 .3 .1 & Hydrogen/Flammable Gas Generation & & 0 & 0 & 0 & 0 \\
\hline 6.1 .3 .2 & Ferrocyanide Stability & & 1 & 5 & 1 & 5 \\
\hline 6.1 .3 .3 & Criticality & & 0 & 0 & 0 & 0 \\
\hline 6.1 .3 .4 & Heat Load & & 0 & 0 & 0 & 0 \\
\hline 6.1 .4 & Tank Safety & 3 & & & & \\
\hline 6.1 .4 .1 & Waterline Corrosion & & 0 & 0 & 0 & 0 \\
\hline 6.1 .4 .2 & Stress Corrosion Cracking & & 5 & 15 & 5 & 15 \\
\hline 6.1 .4 .3 & Crevice Corrosion & & 0 & 0 & 0 & 0 \\
\hline 6.1 .4 .4 & Concrete Degradation/ Cracking & & 2 & 6 & 2 & 6 \\
\hline 6.1 .4 .5 & Ease of Maintaining Confinement & & 0 & 0 & 0 & 0 \\
\hline 6.1 .5 & Future Retrieval and Processing & 3 & & & & \\
\hline 6.1 .5 .1 & Haste Retrieval & & 0 & 0 & 0 & 0 \\
\hline 6.1 .5 .2 & Soil Retrieval & & 5 & 15 & 5 & 15 \\
\hline 6.1 .5 .3 & Transfer Systems Integrity & & 0 & 0 & 0 & 0 \\
\hline 6.1 .5 .4 & Storage Availability & & 0 & 0 & 0 & 0 \\
\hline 6.1 .5 .5 & Treatment Compatibility & & 0 & 0 & 0 & 0 \\
\hline 6.1 .6 & Cost & 2 & 2 & 4 & 3 & 6 \\
\hline 6.1 .7 & Schedule & 3 & 0 & 0 & 0 & 0 \\
\hline 6.1 .8 & $\begin{array}{l}\text { Technical Feasibility/Research and } \\
\text { Development Requirements }\end{array}$ & 3 & 0 & 0 & 3 & 9 \\
\hline 6.1 .9 & Maintenance and Operations & 2 & 0 & 0 & 1 & 2 \\
\hline & Total (weighted score) & & & 135 & & 142 \\
\hline Options: & & Score: & & & & \\
\hline $\begin{array}{l}\text { 1. Exis } \\
\text { 2. Enhal }\end{array}$ & $\begin{array}{l}\text { ng SST systems } \\
\text { ed (improved) SST systems }\end{array}$ & $\begin{array}{l}0=\text { Ho } \\
5=\text { Higl }\end{array}$ & $\begin{array}{l}\text { pact } \\
\text { impact }\end{array}$ & & & \\
\hline
\end{tabular}


WHC-EP-0873, Rev. 0

\subsubsection{Health Safety}

Health safety issues discussed in Section 5.1 are applied to the no-action alternative options.

6.1.1.1 Public Safety. The score for options 1 and 2 is 5 because a leak allows the entry of radioactive materials from Tank 241-T-101 into the environment.

6.1.1.2 Worker Safety. The score for option 1 is 0 because of the status quo condition. The score for option 2 is 2 because of the potential for worker exposure.

6.1.1.3 Environmental Safety. The score for options 1 and 2 is 5 because a leak from Tank 241-T-101 into surrounding soil would continue.

\subsubsection{Compliance with Laws and Regulations}

Compliance with existing 7 aws and regulations is evaluated (see Section 5.2). The option's impact upon future closure and post-closure activities is also evaluated.

6.1.2.1 WAC 173-303. The score for option 1 is 5 because materials leaking from the tank into the soil violates WAC 173-303. The score for option 2 is 3 because new instrumentation would confirm leakers sooner and permit earlier recovery actions.

6.1.2.2 Closure and Post-Closure Activities. The score for option 1 is 5 because leakage to surrounding soit has already occurred. This leakage complicates site and closure cleanup. The score for option 2 is 3 because less soil would be contaminated if there was better monitoring.

\subsubsection{Waste Safety}

Reduction of tank liquid wastes can have a safety impact on the remaining waste (see Section 5.3). Waste can dry out and heat increases the possibility of exothermic chemical reactions, criticality, and flammable gases. 0ther side effects such as corrosion and stress cracking of steel and deterioration of concrete can also occur.

6.1.3.1 Hydrogen and Flammable Gas Generation. The score for both options is 0 because the occurrence of this scenario in Tank 241-T-101 is unlikely.

6.1.3.2 Ferrocyanide Stability. The score for both options is 1 because the occurrence of ferrocyanide reactions is unlikely.

6.1.3.3 Criticality. The score for both options is 0 because the occurrence of criticality in Tank 241-T-101 is unlikely.

6.1.3.4 Heat Load. The score for both options is 0 because the occurrence of heat load in Tank 241-T-101 is unlikely. 
HHC-EP-0873, Rev. 0

\subsubsection{Tank Safety}

The integrity of the tank and the mild steel liner are important safety considerations. The effect of physicochemical processes that compromise tank structural integrity (see Section 5.4) are evaluated.

6.1.4.1 Waterline Corrosion. The score for both options is 0 because waterline corrosion has not been observed at Hanford and SRS for alkalinenitrite/nitrate wastes.

6.1.4.2 SCC. The score for both options is 5 because SCC is the hypothesized cause of SST steel liner failure and neither option mitigates this type of failure.

6.1.4.3 Crevice Corrosion. The score for both options is 0 because crevice corrosion has not been observed to date.

6.1.4.4 Concrete Degradation/Cracking. The score for both options is 2 because cracks in the steel tank permit the waste solution to contact the concrete. This contact could accelerate the concrete cracking.

6.1.4.5 Ease of Maintaining Confinement. The score for both options is 0 because the present confinement system is not modified by tank dome penetrations.

\subsubsection{Future Retrieval and Processing}

The potential impact of each option on future retrieval and processing operations is considered. Considerations include waste and soil retrieval, transfer system integrity, storage availability, and treatment compatibility.

6.1.5.1 Waste Retrieva1. The score for both options is 0 because waste retrieval does not exist for either option.

6.1.5.2 Soil Retrieval. The score for both options is 5 because leaks to the environment are not prevented. Leaks contribute significantly to the amount of contaminated soils that must be retrieved and processed.

6.1.5.3 Transfer System Integrity. The score for both options is 0 because transportation of wastes is not conducted for either option.

6.1.5.4 Storage Availability. The score for both options is 0 because a storage requirement does not exist. Hastes remain in the tank or leak to the surrounding soils.

6.1.5.5 Treatment Compatibility. The score for both options is 0 because treatment is not provided for either option.

\section{1 .6 Cost}

The score for option 1 is 2 because soil waste retrieval and processing will increase costs. The score for option 2 is 3 because the total cost effect for Tank 241-T-101 is unknown. Potential cost savings related to 
WHC-EP-0873, Rev. 0

earlier detection and removal of contaminated soil would be offset by instrument development costs.

\subsubsection{Schedule}

The scores for both options are 0 because the no-action alternative does not require any activity.

\subsubsection{Technical Feasibility/Research and Development Requirements}

The score for option 1 is 0 because the status quo would be continued. The score for option 2 is 3 because considerable R\&D effort could be required to develop dependable and accurate liquid level monitoring instrumentation.

\subsubsection{Maintenance and Operations}

The score for option 1 is 0 because the status quo would be continued. The score for option 2 is 1 because the new monitoring instrumentation would require increased maintenance.

\subsection{COMPARISON OF OPTIONS FOR IN-TANK STABILIZATION}

Table 6-3 lists scores for the in-tank stabilization alternative options. Safety and compliance issues made the impacts for the majority of in-tank stabilization option's score high and unfavorable to implement. In the following sections the reasons and considerations for the scores are given.

\subsubsection{Health Safety}

Health safety concerns as discussed in Section 5.1 are applied to the in-tank stabilization options.

\subsubsection{Public Safety.}

- Option 1--The score for option 1 is 3 because leaks would continue. Continued leakage would allow contamination of the environment and groundwater.

- Options 2 and 3--The score for options 2 and 3 is 1 . The addition of DE or portland cement would have no adverse effect on the public. However, new risers may have to be installed on the tank.

Penetration of the tank dome by these risers pose a remote threat to the public in the event of a mishap.

- Option 4--The score for option 4 is 0 because the addition of desiccants or gels to the tank would prevent leaks. Prevention of leaks would prevent contamination of the environment and groundwater. 
TabTe 6-3. Comparison of Options for In-Tank Stabilization Alternatives. (2 sheets)

\begin{tabular}{|c|c|c|c|c|c|c|c|c|c|c|c|c|c|c|c|c|c|}
\hline \multirow{2}{*}{ Selected criteria (impacts) } & \multirow{2}{*}{$\begin{array}{l}\text { Weight } \\
(1-5)\end{array}$} & \multicolumn{2}{|c|}{ Option 1} & \multicolumn{2}{|c|}{ Option 2} & \multicolumn{2}{|c|}{ Option 3} & \multicolumn{2}{|c|}{ Option 4} & \multicolumn{2}{|c|}{ Option 5} & \multicolumn{2}{|c|}{ Option 6} & \multicolumn{2}{|c|}{ Option 7} & \multicolumn{2}{|c|}{ Option 8} \\
\hline & & $\begin{array}{l}\text { Scoro } \\
(0-5)\end{array}$ & $\left|\begin{array}{c}\text { Weighted } \\
\text { score }\end{array}\right|$ & $\begin{array}{l}\text { Score } \\
|0-5\rangle\end{array}$ & $\begin{array}{c}\text { Woighted } \\
\text { score }\end{array} \mid$ & $\begin{array}{l}\text { Score } \\
(0-5)\end{array}$ & $\left|\begin{array}{c}\text { Woighted } \\
\text { score }\end{array}\right|$ & $\begin{array}{l}\text { Score } \\
(0.5)\end{array}$ & $\begin{array}{l}\text { Woightod } \\
\text { scoro }\end{array}$ & $\begin{array}{l}\text { Score } \\
(0-5)\end{array}$ & $\begin{array}{c}\text { Woighted } \\
\text { score }\end{array}$ & $\begin{array}{l}\text { Score } \\
(0-5)\end{array}$ & $\begin{array}{c}\text { Woighted } \\
\text { scoro }\end{array}$ & $\begin{array}{c}\text { Scoro } \\
(0-5)\end{array}$ & $\begin{array}{l}\text { Woighted } \\
\text { score }\end{array}$ & $\begin{array}{c}\text { Scoro } \\
(0-5)\end{array}$ & $\begin{array}{c}\text { Woighted } \\
\text { score }\end{array}$ \\
\hline 6.2.1 Hoalth Safety & 5 & & & & & & & & & & & & & & & & \\
\hline 6.2.1.1 Publlc Safety & & 3 & 15 & 1 & 5 & 1 & 5 & 0 & 0 & 3 & 15 & 3 & 25 & 3 & 15 & 1 & 5 \\
\hline 6.2.1.2 Workor Safety & & 1 & 5 & 2 & 10 & 2 & 10 & 2 & 10 & 3 & 15 & 3 & 15 & 3 & 15 & 2 & 10 \\
\hline 6.2.1.3 Environmental Safety & & 4 & 20 & 1 & 5 & 1 & 5 & 0 & 0 & 4 & 20 & 4 & 20 & 4 & 20 & 1 & 5 \\
\hline $\begin{array}{ll}\text { 6.2.2 } & \text { Compliance with } \\
& \text { Laws/Regulations }\end{array}$ & 4 & & . & & & & & & & & & & & & & & \\
\hline 6.2.2.1 WAC 173-303 & & 5 & 20 & 5 & 20 & 5 & 20 & 5 & 20 & 5 & 20 & 5 & 20 & 5 & 20 & 5 & 20 \\
\hline 6.2.2.2 Closure/Post-Closuro Activitios & & 2 & 8 & 3 & 12 & 5 & 20 & 2 & 8 & 2 & 8 & 2 & 8 & 2 & 8 & 1 & 4 \\
\hline 6.2.3 Wasto Safoty & 5 & & & & & & & & & & & & & & & & \\
\hline $\begin{array}{l}\text { 6.2.3.1 Hydrogen/Flammable Gas } \\
\text { Generation }\end{array}$ & & 0 & 0 & $\mathbf{0}$ & 0 & 0 & 0 & 0 & 0 & 0 & 0 & 0 & $\mathbf{0}$ & 0 & 0 & 0 & 0 \\
\hline 6.2.3.2 Forrocyanide Stability & & 0 & 0 & 0 & 0 & 0 & 0 & 0 & 0 & 1 & 5 & 3 & 15 & 1 & 5 & 0 & 0 \\
\hline 6.2.3.3 Criticality & & 0 & 0 & 0 & 0 & 0 & 0 & 0 & 0 & 0 & 0 & 0 & 0 & 0 & 0 & 0 & 0 \\
\hline 6.2.3.4 Heat Load & & 0 & 0 & 0 & 0 & 1 & 5 & 0 & 0 & 0 & 0 & 4 & 20 & 0 & $\mathbf{0}$ & 2 & 10 \\
\hline 6.2.4 Tank Integrity & 3 & & & & & & & & & & & & & & & & \\
\hline 6.2.4.1 Waterline Corrosion & & 0 & $\mathbf{0}$ & 0 & 0 & 0 & 0 & 0 & 0 & 0 & 0 & 0 & 0 & 0 & 0 & 0 & $\mathbf{0}$ \\
\hline 6.2.4.2 Stross Corrosion Cracking & & 2 & 6 & 0 & 0 & 0 & 0 & 0 & 0 & 2 & 6 & 2 & 6 & 2 & 6 & 3 & 9 \\
\hline 6.2.4.3 Crevico Corrosion & & 0 & 0 & 0 & 0 & 0 & 0 & 0 & 0 & $\mathbf{0}$ & 0 & 0 & 0 & 0 & 0 & 0 & 0 \\
\hline 6.2.4.4 Concrete Degradation/Cracking & & 2 & 6 & 0 & 0 & 0 & 0 & 0 & 0 & 2 & 6 & 3 & 9 & 2 & 6 & 1 & 3 \\
\hline $\begin{array}{l}\text { 6.2.4.5 Ease of Maintaining } \\
\text { Confinement }\end{array}$ & & 4 & 12 & 4 & 12 & 4 & 12 & 2 & 6 & 3 & 9 & 3 & 9 & 3 & 9 & 3 & 9 \\
\hline 6.2.5 Future Retrieval and Processing & 3 & & & & & & & & & & & & & & & & \\
\hline 6.2.5.1 Waste Retrieval & & 0 & 0 & 4 & 12 & 5 & 15 & 1 & 3 & 4 & 12 & 4 & 12 & 4 & 12 & 0 & 0 \\
\hline
\end{tabular}


Table 6-3. Comparison of Options for In-Tank Stabilization Alternatives. (2 sheets)

\begin{tabular}{|c|c|c|c|c|c|c|c|c|c|c|c|c|c|c|c|c|c|c|}
\hline & \multirow{2}{*}{ Selected criteria (impacts) } & \multirow{2}{*}{$\begin{array}{l}\text { Weight } \\
(1-5)\end{array}$} & \multicolumn{2}{|c|}{ Option 1} & \multicolumn{2}{|c|}{ Option 2} & \multicolumn{2}{|c|}{ Option 3} & \multicolumn{2}{|c|}{ Option 4} & \multicolumn{2}{|c|}{ Option 5} & \multicolumn{2}{|c|}{ Option 6} & \multicolumn{2}{|c|}{ Option 7} & \multicolumn{2}{|c|}{ Option 8} \\
\hline & & & $\begin{array}{l}\text { Score } \\
(0-5)\end{array}$ & $\begin{array}{c}\text { Weighted } \\
\text { score }\end{array} \mid$ & $\begin{array}{l}\text { Score } \\
(0-5)\end{array}$ & $\begin{array}{c}\text { Welghted } \\
\text { score }\end{array} \mid$ & $\begin{array}{l}\text { Score } \\
(0-5)\end{array}$ & $\left|\begin{array}{c}\text { Woighted } \\
\text { score }\end{array}\right|$ & $\begin{array}{l}\text { Score } \\
(0-5)\end{array}$ & $\begin{array}{l}\text { Woighted } \\
\text { score }\end{array}$ & $\begin{array}{l}\text { Score } \\
(0-5)\end{array}$ & $\begin{array}{c}\text { Woighted } \\
\text { score }\end{array}$ & $\begin{array}{l}\text { Scoro } \\
(0-5)\end{array}$ & $\begin{array}{l}\text { Woighted } \\
\text { score }\end{array}$ & $\begin{array}{l}\text { Score } \\
(0-5)\end{array}$ & $\begin{array}{l}\text { Weighted } \\
\text { score }\end{array}$ & $\begin{array}{l}\text { Scoro } \\
(0-5)\end{array}$ & $\begin{array}{c}\text { Welghted } \\
\text { scoro }\end{array}$ \\
\hline 6.2 .5 .2 & Soil Retrioval & & 5 & 5 & 1 & 3 & 1 & 3 & 2 & 6 & 4 & 12 & 4 & 12 & 4 & 12 & 3 & 9 \\
\hline 6.2 .5 .3 & Transfer Systems Integrity & & 0 & 0 & 5 & 15 & 5 & 15 & 1 & 3 & 1 & 3 & 1 & 3 & 1 & 3 & 0 & 0 \\
\hline 6.2.5.4 & Storago Availability & & 1 & 3 & 5 & 15 & 5 & 15 & 0 & 0 & 0 & 0 & 0 & 0 & 0 & 0 & 0 & 0 \\
\hline 6.2.5.5 & Treatment Compatibility & & 0 & 0 & 4 & 12 & 5 & 15 & 3 & 9 & 0 & 0 & 0 & 0 & 0 & 0 & 3 & 9 \\
\hline 6.2 .6 & Cost & 2 & 1 & 2 & 3 & 6 & 5 & 10 & $\mathbf{3}$ & 5 & 2 & 7 & 4 & 8 & 2 & 4 & 2 & 4 \\
\hline 6.2 .7 & Schedulo & 3 & 0 & $\dot{0}$ & 3 & 9 & 5 & 15 & 3 & 9 & 2 & 6 & 3 & 9 & 2 & 6 & 1 & 3 \\
\hline 6.2 .8 & $\begin{array}{l}\text { Technical Feasibility/Research } \\
\text { and Development Requirements }\end{array}$ & 3 & 0 & 0 & 2 & 6 & 5 & 15 & 2 & 6 & 3 & 9 & 4 & 12 & 3 & 9 & 3 & 9 \\
\hline \multirow[t]{2}{*}{6.2 .9} & Maintenance and Operations & 2 & 2 & 4 & 0 & 0 & 0 & 0 & 1 & 2 & 2 & 4 & $\mathbf{3}$ & 6 & 2 & 4 & 2 & 4 \\
\hline & Total (weighted score) & & & 116 & & 142 & & 180 & & 88 & & 154 & & 199 & & 154 & & 113 \\
\hline & $\begin{array}{l}\text { Options: } \\
\text { 1. Tank wall inhibitors } \\
\text { 2. Diatomaceous earth } \\
\text { 3. Portland cement } \\
\text { 4. Desiccants/gols } \\
\text { 5. Heat exchangers } \\
\text { 6. Microwave } \\
\text { 7. Air drying }\end{array}$ & & & & & & & & & & & & & & & & & \\
\hline
\end{tabular}

8. Stop leak

Score:

$0=$ No impact

$5=$ High impact 
- Options 5, 6, and 7--The score for options 5, 6, and 7 is 3 because drying would proceed so slowly that a leak to the environment would continue. Continued leakage would allow contamination of the environment and groundwater.

- Option 8--The score for option 8 is 1 because waste will continue to leak for several days after addition of the stop-leak. Continued leakage would allow contamination of the environment and groundwater.

\subsubsection{Worker Safety.}

- Option 1--The score for option 1 is 1 because cleanup of contaminated soils would expose the workers to radioactivity and toxic waste. This exposure would be minor because the leak in Tank 241-T-101 is smal1.

- Options 2, 3, and 4--The score for options 2, 3, and 4 is 2 because tank dome penetrations would be required for installation of equipment and because work would be performed in close proximity to the tank. Exposure to radioactivity, toxic waste, and accidents would increase correspondingly.

- Options 5, 6, and 7--The score for options 5, 6, and 7 is 3 because tank dome penetrations would be required for risers, equipment, and HVAC modifications and because work would be performed in close proximity to the tank. Exposure to radioactivity, toxic waste, and accidents would increase correspondingly. This exposure would be significantly greater than for options $1,2,3$, and 4 .

\subsubsection{Environmental Safety.}

- Option 1--The score for option 1 is 4 because corrosion inhibitors are unlikely to stop leaking of the tank liquids.

- Options 2 and 3--The score for options 2 and 3 is 1 because DE and portland cement are unlikely to stop leakage.

- Option 4--The score for option 4 is 0 because gel and desiccant are expected to stop leakage into the environment.

- Options 5, 6, and 7--The score for options 5, 6, and 7 is 4 because drying would proceed so slowly that a leak to the environment would continue. Continued leakage would allow contamination of the environment.

- Option 8--The score for option 8 is 1 because waste will continue to leak for several days after addition of stop leak. Continued leakage would allow contamination of the environment. Leaks would be smaller than for options $1,5,6$, and 7 . 


\subsubsection{Compliance with Laws/Regulations}

Compliance with existing 1 aws and regulations is evaluated (see Section 5.2). Impact of the option upon future closure and post-closure activities is also evaluated.

6.2.2.1 WAC 173-303. The score for all options is 5 because none of the options are in compliance with WAC-173-303, which requires that leaking tanks be emptied of liquids.

\subsubsection{Closure/Post-Closure Activities.}

- Option 1--The score for option 1 is 2 because corrosion inhibitors may make remediation actions more difficult and allow more soil to be contaminated.

- Option 2--The score for option 2 is 3 because the increased waste volumes from the addition of DE will make closure more difficult.

- Option 3--The score for option 3 is 5 because the time needed for retrieval and processing would be lengthened and waste left in place would require monitoring for a long time. Closeout would be extremely difficult if the waste had to be retrieved or processed.

- Option 4--The score for option 4 is 2 because the addition of desiccants and gels would increase requiring disposal waste volumes requiring disposal.

- Options 5, 6, and 7--The score for options 5, 6, and 7 is 2 because the amount of contaminated soil will be increased.

- Option 8--The score for option 8 is 1 because the amount of contaminated soil will be increased.

\subsubsection{Waste Safety}

Reduction of tank liquids can have a safety impact on the remaining waste (see Section 5.3). Waste can dry out and heat up; this increases the possibility for exothermic chemical reactions, criticality, and flammable gases. Other side effects such as corrosion and stress cracking of steel and concrete can also occur.

6.2.3.1 Hydrogen/Flammable Gas Generation. The score for all options is 0 because there is little possibility of hydrogen and other flammable gas generation.

\subsubsection{Ferrocyanide Stability.}

- Options $1,2,3,4$, and 8--The score for options $1,2,3,4$, and 8 is 0 because ferrocyanide stability will be unaffected.

- Options 5 and 7--The score for options 5 and 7 is 1 because drying may concentrate the ferrocyanide increasing the likelihood of ignition in the presence of elevated temperatures. 
- Option 6--The score for option 6 is 3 because drying may concentrate the ferrocyanide increasing the likelihood of ignition in the presence of elevated temperatures. The occurrence of this event would be more likely under option 6 than under options 5 and 7 .

6.2.3.3 Criticality. The score for all options is 0 because there are no criticality concerns.

\subsubsection{Heat Load.}

- Options $1,2,4,5$, and 7--The score for options $1,2,4,5$, and 7 is 0 because heat load will not be generated.

- Option 3--The score for option 3 is 1 because the amount of generated heat load will be minimal.

- Option 6--The score for option 6 is 4 because the amount of generated heat load will be significant.

- Option 8--The score for option 8 is 2 because the generated heat load will be greater than under option 3 , but significantly less than under option 6.

\subsubsection{Tank Safety}

The impact of implementing the option's effect upon the processes that compromise tank structural integrity is evaluated (see section 5.4).

6.2.4.1 Waterline Corrosion. The score for all options is 0 because waterline corrosion is not considered to be a cause of leaks.

\subsubsection{SCC.}

- Option 1--The score for option 1 is 2 because a corrosion inhibitor will slow, but not stop, SCC.

- Options 2, 3, and 4--The score for options 2, 3, and 4 is 0 because the absorption of Tiquids by DE, portland cement, desiccants, and gels should el iminate further SCC.

- Options 5, 6, and 7--The score for options 5, 6, and 7 is 2 because SCC should gradually decrease and eventually end as waste is dried. However, areas where corrosion has occurred may provide paths for leaching if the tank is used for long-term storage.

- Option 8--The score for option 8 is 3 because stop-leak may have some corrosion inhibitors.

6.2.4.3 Crevice Corrosion. The score for al1 options is 0 because crevice corrosion is not considered to be a cause of leaks. 


\subsubsection{Concrete Degradation and Cracking.}

- Option 1--The score for option 1 is 2 because corrosion inhibitors would prevent leaks.

- Option 2, 3, and 4--The score for options 2, 3, and 4 is 0 because liquids would be absorbed; therefore contact with concrete and the resulting concrete degradation would be prevented.

- Options 5 and 7--The score for options 5 and 7 is 2 because concrete degradation and cracking should decrease as waste is dried.

- Option 6--The score for option 6 is 3 because concrete degradation and cracking should decrease as waste is dried. Microwave equipment may increase the heat load on the concrete.

- Option 8--The score for option 8 is 1 because the stop-leak prevents leaks that could comprise tank concrete. However, some leakage is required to implement this option.

\subsubsection{Ease of Maintaining Confinement.}

- Option 1--The score for option 1 is 4 because new penetrations of the tank dome would be required for the installation of mixing equipment.

- Options 2 and 3--The score for options 2 and 3 is 4 because new penetrations of the tank dome would be required for the installation of equipment.

- Option 4--The score for option 4 is 2 because additional penetrations of the tank dome would be required for the installation of equipment. The number and size of penetrations would not be as great as for options 2 and 3.

- Options 5, 6, and 7--The score for options 5, 6, and 7 is 3 because penetrations of the tank dome would be required for the installation of the heat exchanger, microwave, air-drying, and HVAC equipment. The number of penetrations needed would be greater than for options 1,2 , and 3 , but fewer than for option 4 .

- Option 8--The score for option 8 is 3 because this option is similar to option 4 except that more mixing equipment would be required.

\subsubsection{Future Retrieval and Processing}

The impact of each option on future retrieval and processing operations has been considered. Considerations included waste and soil retrieval, transfer system integrity, storage availability, and treatment compatibility.

\subsubsection{Waste Retrieval.}

- Option 1--The score for option 1 is 0 because the inhibitor will not impact retrieval of tank wastes. 
- Option 2--The score for option 2 is 4 because the addition of DE will significantly increase the difficulty of waste retrieval. Existing used retrieval equipment is designed to handle liquid waste. Either equipment would have to be designed and procured for removal of solid waste or waste would have to be redissolved.

- Option 3--The score for option 3 is 5 because the addition of portland cement would significantly increase the difficulty of waste retrieval. Existing retrieval equipment is designed to handle liquid waste. Heavy-duty equipment would have to be developed to break the cement into small pieces for removal through existing tank openings. Equipment would have to be designed and developed to process the solid waste after it is broken up.

- Option 4--The score for option 4 is 1 because the addition of desiccants and gels would increase the difficulty of waste retrieval. Either the waste would have to be liquified for pumping or a new method would have to be developed for removing the waste from the tank.

- Options 5, 6, and 7--The score for options 5, 6, and 7 is 4 because retrieval of solidified waste would be more difficult. Either solidified waste would have to be redissolved or a method of retrieving solid waste would have to be developed.

- Option 8--The score for option 8 is 0 because stop-leak will not affect retrieval, but it will make processing marginally more difficult because it contains silica.

\subsubsection{Soil Retrieval.}

- Option 1--The score for option 1 is 5 because confidence is lacking in the ability of corrosion inhibitors to stop or prevent leaks. Large amounts of soil would be contaminated.

- Options 2 and 3--The score for options 2 and 3 is 1 because DE and portland cement would stop a leak quickly if placed close to the leak. However, placement would be imprecise. Until the liquid is absorbed or the leak stopped, waste would continue to contaminate the soil.

- Option 4--The score for option 4 is 2 because desiccants and gels would require time to be effective. Desiccants will not stop an existing leak quickly. In addition, a gel would require placement near the defect to be effective.

- Options 5, 6, and 7--The score for options 5, 6, and 7 is 4 because al1 three methods would take considerable drying time to stop the leak. Soil would continue to become contaminated.

- Option 8--The score for option 8 is 3 because stop leak would require time to be effective. The soil would continue to become contaminated. 


\subsubsection{3 $3^{\circ}$ Transfer System Integrity.}

- Option 1--The score for option 1 is 0 because the liquid transfer system would not be affected by the addition of corrosion inhibitors.

- Option 2--The score for option 2 is 5 because the transfer system is not designed to handle the solid waste produced by DE. The waste would have to be dissolved or transported by another method.

- Option 3--The score for option 3 is 5 because the existing transfer system would have to be abandoned and a new solid-waste retrieval system deve7oped.

- Option 4--The score for option 4 is 1 because no difficulty is anticipated in converting gel water to liquid form for transferral to processing.

- Options 5, 6, and 7--The score for options 5, 6, and 7 is 1 because the dried waste could not be transferred using the existing liquid transport system. Either a new solid waste transport system would have to be developed or the waste would have to be redissolved and liquified.

- Option 8--The score for option 8 is 0 because stop-leak will not adversely impact the transfer system. The transfer system would have to be monitored and modified for the abrasive effects of the silica.

\subsubsection{Storage Availability.}

- Option 1--The score for Option 1 is 1 because adding corrosion inhibitors would have little effect on DST storage space requirements. Storage requirements for contaminated soils would likely increase.

- Options 2 and 3--The score for options 2 and 3 is 5 because the storage areas for the waste would have to be significantly enlarged to accommodate the increased waste volume from DE and portland cement.

- Options 4, 5, 6, 7, and 8--The score for options 4, 5, 6, 7, and 8 is 0 for the same reasons as option 1 , except that options $4,5,6$, 7 , and 8 would have slightly less impact than option 1.

\subsubsection{Treatment Compatibility.}

- Option 1--The score for option 1 is 0 because the treatment process would be unaffected by the corrosion inhibitor.

- Option 2--The score for option 2 is 4 because the treatment process is not compatible with the solid waste generated by the addition of $D E$. The DE would have to be removed or dissolved before treatment. 
HHC-EP-0873, Rev. 0

- Option 3--The score for option 3 is 5 because a method to treat the waste after mixing with the cement does not exist. A method to either treat or dissolve the solid waste would need to be developed.

- Option 4--The score for option 4 is 3 because silicate loading by the gelling compound would make treatment more difficult.

- Options 5, 6, and 7--The score for options 5, 6, and 7 is 0 because dried nitrate and nitrite wastes can be redissolved in water.

Current waste treatment processes should be unaffected by drying the waste.

- Option 8--The score for option 8 is 3 because modifications to the treatment process would be required to accommodate silica.

\subsubsection{Cost}

- Option 1--The score for option 1 is 1 because the time and manpower - required for applying the inhibitor, testing, and additional monitoring would increase the cost.

- Option 2--The score for option 2 is 3 because the volume of waste would be increased, retrieving and processing would be more difficult, and the schedule would be lengthened.

- Option 3--The score for option 3 is 5 because the schedule would be lengthened, retrieval and processing would be more difficult, and equipment would have to be designed and purchased.

- Option 4--The score for option 4 is 3 because significant research and development costs are anticipated. The gelling media may have a high cost and the treatment process may have to be significantly modified to handle the silica loads imposed by the gels.

- Options 5 and 7--The score for options 5 and 7 is 2 because high operations and maintenance costs would occur. Haste would have to be redissolved for retrieving and processing: Some modifications would have to be made to the HVAC system.

- Option 6--The score for option 6 is 4 because the microwave drying system is in the development stage. New risers and HVAC would have to be added. The schedule to bring microwave technology to maturity, although uncertain, is likely to be long.

- Option 8--The score for option 8 is 2 because processing will increase in difficulty.

\subsubsection{Schedule}

Efforts to stabilize tank waste contents may impact the schedule for disposal and site closure. Considerations of these impacts are provided below. 
- Option 1--The score for option 1 is 0 because the schedule for disposal and final closure would not be effected by the addition of an inhibitor.

- Option 2--The score for option 2 is 3 because the schedule would have to be lengthened to accommodate the increased waste volume and the difficulty in retrieving and processing DE waste.

- Option 3--The score for option 3 is 5 because the increase in waste volume and the difficulty in retrieving waste would lengthen the schedule.

- Option 4--The score for option 4 is 3 because the retrieving and processing time would be increased. In addition, research and development efforts for a gelling media would cause a delay.

- Options 5 and 7--The score for options 5 and 7 is 2 because dissolution of solid wastes would length the schedule.

- Option 6--The score for option 6 is 3 because dissolution of solid wastes would lengthen the schedule. Dissolution under option 6 is expected to be slightly more difficult than under options 5 and 7 .

- Option 8--The score for option 8 is 1 because processing of waste containing silica would be more difficult; therefore, more time would be required.

\subsubsection{Technical Feasibility/Research and Development Requirements}

This selection criteria evaluates the feasibility of technical requirements for accomplishing in-tank stabilization and the amount of research required to accomplish the option.

- Option 1--The score for option 1 is 0 because the contents of the tank need only be analyzed to determine the amount of inhibitors needed.

- Option 2--The score for option 2 is 2 because research and development would be required to develop methods to inject DE into the waste to ensure adequate absorption of the liquid.

- Option 3--The score for option 3 is 5 because new equipment would have to be developed to inject the portland cement and mix the waste.

- Option 4--The score for option 4 is 2 because research is needed to determine the effects of a desiccant on the waste if the desiccant were immersed in the waste. The gelling media will need research and development.

- Options 5 and 7--The score for options 5 and 7 is 3 because the microwave drying system needs further development. If the solid 
waste were retrieved and treated, a method to either dissolve the waste or break the waste up for treatment would have to be developed.

- Option 6--The score for option 6 is 4 because microwave technology requires significant research before it may be used at Hanford in a waste tank.

- Option 8--The score for option 8 is 3 because the effects of the stop-leak upon the waste and the amount needed have to be ascertained.

\subsubsection{Maintenance and Operations}

- Maintenance and operations are required to accomplish an option. The option's maintenance and operation impacts on the criteria are listed below.

- Option 1--The score for option 1 is 2 because the corrosion inhibitor will increase maintenance and operations to ensure proper inhibitor concentrations.

- Option 2--The score for option 2 is 0 because DE would not interfere with maintenance and operations.

- Option 3--The score for option 3 is 0 because portland cement would not affect maintenance and operations.

- Option 4--The score for option 4 is 1 because desiccants and gels may increase maintenance and operations.

- Option 5--The score for option 5 is 2 because drying of the waste would increase normat maintenance and operations. Addition activities would be required to maintain and operate new drying and HVAC equipment.

- Option 6--The score for option 6 is 3 because the microwave drying system would significantly increase maintenance and operations.

- Option 7--The score for option 7 is 2 because air drying would have little effect upon maintenance and operation activities for the tank. Maintenance and operations would be expanded to accommodate new air-drying equipment.

- Option 8--The score for option 8 is 2 because the stop-leak option should have 1ittle effect upon maintenance and operations. Mixer equipment with heating capability would require additional maintenance.

\subsection{COMPARISON OF OPTIONS FOR EXTERNAL TANK STABILIZATION}

Table 6-4 lists scores for the external tank stabilization alternative options. Weighted scores are fairly high for environmental safety, compliance, and future retrieval and process criteria. These high scores 
Table 6-4. Comparison of Options for External Tank Stabilization Alternative. (2 sheets)

\begin{tabular}{|c|c|c|c|c|c|c|c|c|c|}
\hline \multirow[b]{2}{*}{ Selected criteria (impacts) } & \multirow{2}{*}{$\begin{array}{l}\text { Wolght } \\
(1-5)\end{array}$} & \multicolumn{2}{|c|}{ Option 1} & \multicolumn{2}{|c|}{ Option 2} & \multicolumn{2}{|c|}{ Option 3} & \multicolumn{2}{|c|}{ Option 4} \\
\hline & & $\begin{array}{l}\text { Score } \\
(0.5)\end{array}$ & $\begin{array}{l}\text { Welghted } \\
\text { score }\end{array}$ & $\begin{array}{l}\text { Score } \\
(0-5)\end{array}$ & $\begin{array}{l}\text { Wolghted } \\
\text { score }\end{array}$ & $\begin{array}{l}\text { Score } \\
(0-5)\end{array}$ & $\begin{array}{l}\text { Wolghted } \\
\text { score }\end{array}$ & $\begin{array}{l}\text { Score } \\
(0-5)\end{array}$ & $\begin{array}{c}\text { Weighted } \\
\text { score }\end{array}$ \\
\hline 6.3.1 Health Safoty & 5 & & & & & & & & \\
\hline 6.3.1.1 Public Safety & & 0 & 0 & 0 & 0 & 3 & 15 & 2 & 10 \\
\hline 6.3.1.2 Worker Safety & & 1 & 5 & 1 & 5 & 1 & 5 & 2 & 10 \\
\hline 6.3.1.3 Environmental Safety & & 2 & 10 & 2 & 10 & 3 & 15 & 3 & 15 \\
\hline 6.3.2 Compliance With Laws/Regulations & & & & & & & & & \\
\hline 6.3.2.1 WAC 173-303 Codes & 4 & 5 & 20 & $\mathbf{6}$ & 20 & 5 & 20 & $\mathbf{5}$ & 20 \\
\hline 6.3.2.2 Closure/Post-Closure Activities & & 4 & 16 & 4 & 16 & 4 & 16 & 4 & 16 \\
\hline 6.3.3 Waste Safety & 5 & & & & & & & & \\
\hline 6.3.3.1 Hydrogen/Flammable Gas Generation & & 0 & 0 & 0 & 0 & 0 & 0 & 0 & 0 \\
\hline 6.3.3.2 Ferrocyanide Stability & & 0 & 0 & 0 & 0 & 0 & 0 & 0 & 0 \\
\hline 6.3.3.3 Criticality & & $\mathbf{0}$ & 0 & 0 & 0 & $\mathbf{0}$ & 0 & 0 & 0 \\
\hline 6.3.3.4 Heat Load & & $\mathbf{0}$ & 0 & 0 & 0 & 0 & 0 & 0 & 0 \\
\hline 6.3.4 Tank Safety & 3 & & & & & & & & \\
\hline 6.3.4.1 Waterline Corrosion & & 0 & 0 & 0 & 0 & 0 & 0 & 0 & 0 \\
\hline 6.3.4.2 Stross Corrosion Cracking & & 0 & 0 & 0 & 0 & 0 & $\mathbf{0}$ & 0 & 0 \\
\hline 6.3.4.3 Crevice Corrosion & & 0 & 0 & 0 & 0 & 0 & $\mathbf{0}$ & 0 & 0 \\
\hline 6.3.4.4 Concrete Degradation/Cracking & & 0 & 0 & 0 & 0 & 0 & $\mathbf{0}$ & $\mathbf{0}$ & 0 \\
\hline 6.3.4.5 Ease of Maintaining Confinement & & 0 & $\mathbf{0}$ & 0 & $\mathbf{0}$ & 0 & $\mathbf{0}$ & 0 & 0 \\
\hline 6.3.5 Future Retrieval and Processing & 3 & & & & & & & & \\
\hline 6.3.5.1 Waste Retrieval & & 0 & 0 & 0 & $\mathbf{0}$ & 0 & $\mathbf{0}$ & $\mathbf{o}$ & 0 \\
\hline
\end{tabular}


Table 6-4. Comparison of Options for External Tank Stabilization Alternative. (2 sheets)

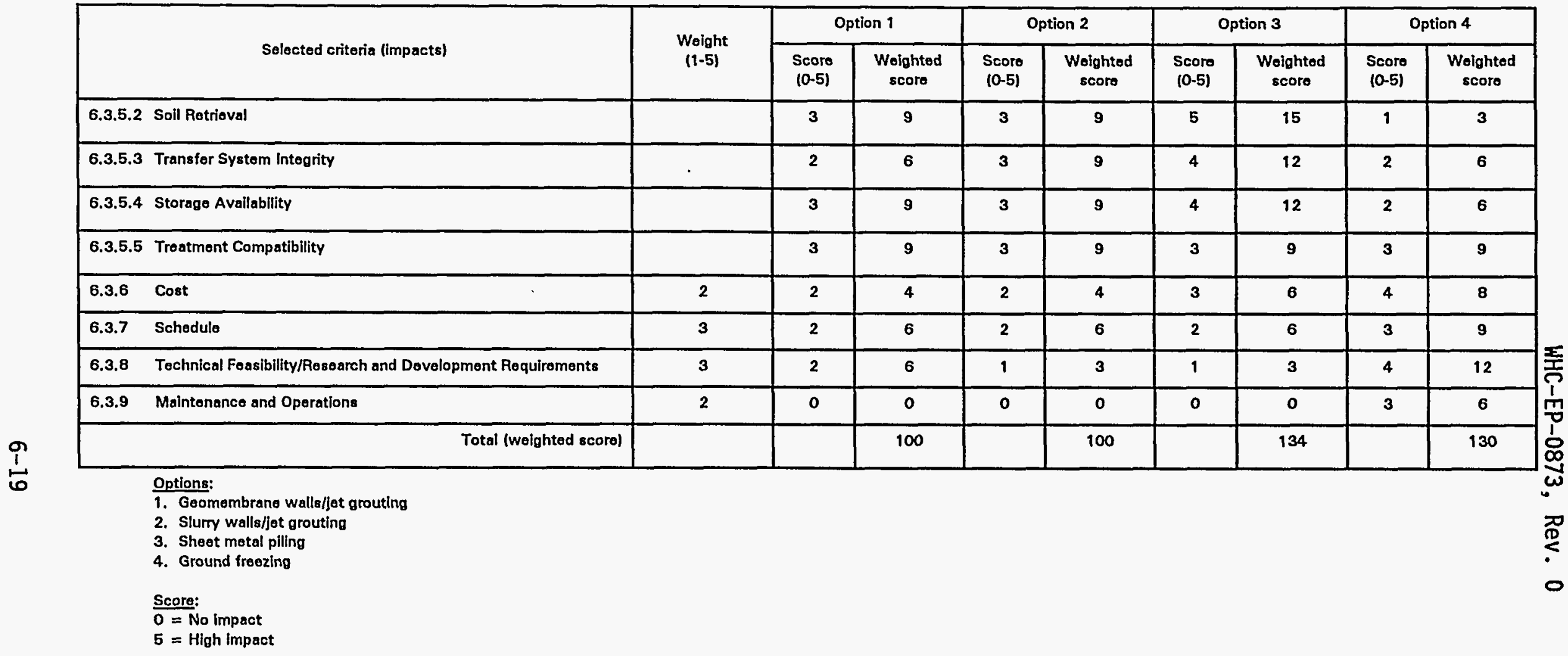


indicate that the external tank stabilization alternative would be undesirable to implement for a leaking SST. Geomembrane walls and slurry walls in combination with jet grouting appear to be viable methods of external stabilization where containment of contaminants from past leaks is desired. The adverse impacts and costs from ground freezing appear to outweigh its advantages based on the criteria examined in this study. The ability to move in close to the contamination source is a highly desirable feature of this technique. If external stabilization is required for future tank operations, further research and a field demonstration of geomembrane walls in conjunction with jet grouting is recommended. In the following sections, the reasons and considerations for the scores are given.

\subsubsection{Health Safety}

Health safety concerns as discussed in Section 5.1, are applied to the external tank stabilization. Barriers are created to contain the spread of contamination from leaks. Adverse impacts to safety are only partially mitigated.

\subsubsection{Public Safety.}

- Options 1 and 2--The score for options 1 and 2 is 0 because geomembrane walls/jet grouting and slurry walls/jet grouting are routinely used in the hazardous waste remediation industry to confine hazardous materials. Exposure of the public to Tank 241-T101 releases would be minimal and easily contained.

- Option 3--The score for option 3 is 3 because sheet metal pilings are routinely used in the construction industry to prevent groundwater intrusion into a construction site. The rocky soils surrounding the tanks would complicate placement of the pilings and metal sheeting. Bottom sealing is not feasible. The metal sheets are subject to electrolytic corrosion. As a result, the possibility for loss of containment and exposure of the public is significant.

- Option 4--The score for option 4 is 2 because the behavior of contaminants in frozen soil is not known and the risk of refrigerant equipment failure is significant.

\subsubsection{Horker Safety.}

- Options 1, 2, and 3--The score for options 1, 2, and 3 is 1 because geomembrane walls/jet grouting, slurry walls/jet grouting, and sheet metal piling are passive containment systems after installation. Installation procedures have been developed over the years to ensure worker safety.

- Option 4--The score for option 4 is 2 because ground freezing is a continuous operation that requires constant monitoring and maintenance. Refrigerant technologies have been safely and routinely used for years in industry, but represent a higher risk for workers than the passive containment options. 
HHC-EP-0873, Rev. 0

\subsubsection{Environmental Safety.}

- Options 1 and 2--The score for options 1 and 2 is 2 because geomembrane walls/jet grouting and slurry walls/jet grouting would not prevent spread of contamination between the tank and the vertical and horizontal barriers.

- Option 3--The score for option 3 is 3 because sheet metal piling would not prevent the spread of contamination between the tank and the vertical barrier. A bottom seal cannot be installed to prevent continued migration of contaminants toward groundwater.

- Option 4--The score for option 4 is 3 because the risk of refrigerant equipment failure is significant. Lengthy downtimes could allow the soil to thaw and the contamination to spread.

\subsubsection{Compliance with Laws/Regulations}

Barrier option scores are high because barriers do not stop or remove the leaking contamination source and they allow contamination of soil up to the barriers. To be effective and to ensure compliance with laws and regulations, barriers would need to be in place before containment loss and a means devised to remove or stop the contamination from leaking into the environment.

6.3.2.1 HAC 173-303. The score for all options is 5 because WAC 173-303 requires that liquids from a leaking tank be removed and that the leaking tank be taken out of service or enough liquid be removed to allow examination and determination that the leak has stopped. Implementation of these options would not prevent continued leakage and soil contamination.

6.3.2.2 Closure and Post-Closure Activities. The score for all options is 4 because large amounts of contaminated soil would need to be retrieved and processed. Contaminated hardware and equipment would also require disposal.

\subsubsection{Waste Safety}

The score for all options is 0 because none of the options would affect the contents of the tank safety of the waste. During construction, safety measures would have to be taken to ensure the structural integrity of the tank.

\subsubsection{Tank Safety}

The score for all options is 0 because none of the options would affect the integrity of the tank structure. Safety measures would have to be taken to ensure that construction activities do not impact the tank structure. 
HHC-EP-0873, Rev. 0

\subsubsection{Future Retrieval and Processing}

The potential impact of each option on future retrieving and processing operations is considered. Considerations include impacts on waste and soi 1 retrieval, transfer system integrity, storage availability, and treatment compatibility.

6.3.5.1 Waste Retrieval. The score for all options is 0 because waste retrieval from tanks would not be effected. The amount of liquid requiring retrieval would be reduced by the amount of before leakage.

\subsubsection{Soil Retrieval.}

- Options 1 and 2--The score for options 1 and 2 is 3 because vertical and horizontal migration of leaked contaminants would be prevented. The amount of contaminated soil requiring recovery and treatment is significant.

- Option 3--The score for option 3 is 5 because horizontal migration of Teaked contaminants would be prevented, but vertical migration would continue. The amount of contaminated soil requiring recovery and treatment is significantly higher than the amount under options 1 and 2 .

- Option 4--The score for option 4 is 1 because the soit surrounding the tank and some tank wastes would be frozen to stop leaks and contaminant migration. Considerably less soil would be contaminated than under other barrier options. Soil could be thawed just before recovery to limit plume migration.

\subsubsection{Transfer System Integrity.}

- Option 1--The score for option 1 is 2 because installation of geomembranes around the tank and its utilities have the potential to affect waste transfer operations.

- Option 2--The score for option 2 is 3 because shrinkage and settlement of the slurry walls may damage transfer piping.

- Option 3--The score for option 3 is 4 because sheet metal piles could damage or sever pipelines if the sheet metal is deflected during installation.

- Option 4--The score for option 4 is 2 because installation of the pipes to freeze the soil will not impact the transfer system integrity. However, the transfer system pipes could be damaged during freezing of the soil.

\subsubsection{Storage Availability.}

- Options 1 and 2--The score for options 1 and 2 is 3 because contamination of large amounts of soil would be allowed. These additional wastes would require storage, processing, and disposal. Large volumes of soils generated from installation of walls would also be generated. 
- Option 3--The score for option 3 is 4 for the same reasons as options 1 and 2 , except that the potential to vertically contaminate soil is greater under option 3.

- Option 4--The score for option 4 is 2 because ground freezing would confine the waste to the soil immediately surrounding the tank. This additional soil waste would impact the storage availability somewhat less than the other barrier options.

6.3.5.5 Treatment Compatibility. The score for all options is 3 because all four options allow soil contamination in varying degrees. Existing and planned treatment systems do not appear to be compatible with large amounts of solid soil wastes.

\subsubsection{Cost}

- Options 1 and 2--The score for options 1 and 2 is 2 each because a11 barrier options have a high capital cost investment to stage and insta17. The amount of contaminated soil that would require retrieval, treatment, and disposal is particularly high. Both options are in current use and have proven highly effective for selected applications where protection of a sensitive ecological system is required.

- Option 3--The score for option 3 is 3 for the same reason as options 1 and 2. In addition, sheet metal piling would be difficult to install correctly in the rocky soils at Hanford.

- Option 4--The score for option 4 is 4 for the same reasons as options 1 and 2 . In addition, ground freezing would have higher capital and operational costs than other barrier options.

\subsubsection{Schedule}

- Options 1, 2, and 3--The score for options 1,2 , and 3 is 2 because a11 barrier options take a significant amount of time to prepare and instal1. The technologies are proven, but adoptability in a tankfarm environment could take years.

- Option 4--The score for option 4 is 3 because ground freezing would require installation of piping, refrigeration machinery, and associated utilities near the tank. Studies would be required to ensure freezing does not negatively impact tanks, tank utilities, and waste transfer piping.

\subsubsection{Technical Feasibility/Research and Development Requirements}

- Option 1--The score for option 1 is 2 because geomembrane walls use installation techniques similar to those for sheet piles. Membranes have been accepted for hazardous waste impoundment systems. Geomembrane walls as a subsurface barrier are new in the United States but the technique is used extensively in Europe. 
- Option 2--The score for option 2 is 1 because the use of slurry walls is an established method for confinement for wastes at superfund sites.

- Option 3--The score for option 3 is 1 because sheet metal pilings are commonly used during construction to prevent water intrusion.

- Option 4--The score for option 4 is 4 because ground freezing is an emerging technology. The methods and procedures required to work in close proximity to other tanks and utilities require study. The freezing of soil, tanks, tank utilities, and tank wastes require careful analysis to determine impacts.

\subsubsection{Maintenance and Operations}

- Options 1, 2, and 3--The score for options 1, 2, and 3 is 0 because no additional maintenance and operation would be required for geomembrane walls, slurry walls, and sheet metal pilings. They become passive systems once installed.

- Option 4--The score for option 4 is 3 because ground freezing requires daily maintenance to keep the system operational. If the system leaked or shut down, the soil would thaw and migration of soil contaminants would resume.

\subsection{COMPARISON OF OPTIONS FOR LIQUID RETRIEVAL}

Scores are listed in Table 6-5 for the Liquid Retrieval options. The Tow total weighted scores for options 1 and 2 suggest that these two options could easily be implemented with little adverse impact on the selection criteria. In the following sections, the reasons and considerations for the scores are given.

\subsubsection{Health Safety}

Health safety concerns include public safety, worker safety and environmental impacts.

6.4.1.1 Public Safety. The score for all options is 0 because the safety of the public would not be adversely impacted by these options. The only impact on public safety would be road closures during transportation of radioactive Tiquid from Tank 241-T-101 located in 200-West Area to 244-AR unloading facility in 200-East Area during off-peak hours. Road closures would restrict public access but the impact would be minimal.

\subsubsection{Worker Safety.}

- Options 1 and 2--The score for options 1 and 2 is 0 because pipeline transfers confine îquid wastes whereby workers would be protected from exposure to radioactivity and toxic materials. 
Table 6-5. Comparison of Options for Liquid Retrieval Alternatives. (2 sheets)

\begin{tabular}{|c|c|c|c|c|c|c|c|c|c|}
\hline \multirow{2}{*}{ selected criteria (impacts) } & \multirow{2}{*}{$\begin{array}{l}\text { Woight } \\
(1-5)\end{array}$} & \multicolumn{2}{|c|}{ Option 1} & \multicolumn{2}{|c|}{ Option 2} & \multicolumn{2}{|c|}{ Option 3} & \multicolumn{2}{|c|}{ Option 4} \\
\hline & & $\begin{array}{l}\text { Score } \\
(0-5)\end{array}$ & $\begin{array}{l}\text { Weighted } \\
\text { score }\end{array}$ & $\begin{array}{l}\text { Score } \\
(0.5)\end{array}$ & $\begin{array}{l}\text { Weightod } \\
\text { scoro }\end{array}$ & $\begin{array}{l}\text { Score } \\
(0-5)\end{array}$ & $\begin{array}{l}\text { Weighted } \\
\text { score }\end{array}$ & $\begin{array}{l}\text { Score } \\
(0-5)\end{array}$ & $\begin{array}{l}\text { Weighted } \\
\text { score }\end{array}$ \\
\hline 6.4.1 Health Safoty & 5 & & & & & & & & \\
\hline 6.4.1.1 Public Safoty & & $\mathbf{0}$ & 0 & 0 & 0 & 0 & $\mathbf{0}$ & 0 & $\mathbf{0}$ \\
\hline 6.4.1.2 Worker Safoty & & 1 & 5 & 1 & 5 & 2 & 10 & 2 & 10 \\
\hline 6.4.1.3 Environmental Safoty & & 0 & 0 & 0 & 0 & $\mathbf{0}$ & 0 & 0 & 0 \\
\hline 6.4.2 Compllance with Laws/Regulations & 4 & & & & & & & & \\
\hline 6.4.2.1 WAC 173-303 & & 0 & 0 & 0 & 0 & $\mathbf{0}$ & 0 & 0 & 0 \\
\hline 6.4.2.2 Closuro/Post-Closure Activities & & 0 & 0 & 1 & 4 & 1 & 4 & 1 & 4 \\
\hline 6.4.3 Wasto Safoty & 5 & & & & & & & & \\
\hline 6.4.3.1 Hydrogen/Flammable Gas Genoration & & 0 & 0 & 0 & $\mathbf{0}$ & 0 & 0 & $\mathbf{0}$ & 0 \\
\hline 6.4.3.2 Ferrocyanide Stability & & 1 & 5 & 1 & 5 & 1 & 5 & 1 & 5 \\
\hline 6.4.3.3 Criticality & & 0 & 0 & 0 & 0 & 0 & $0^{\prime}$ & $\mathbf{0}$ & 0 \\
\hline 6.4.3.4 Heat load & & 0 & 0 & o & 0 & 0 & 0 & $\mathbf{0}$ & 0 \\
\hline 6.4.4 Tank Integrity & 3 & & & & & & & & \\
\hline 6.4.4.1 Waterlino Corrosion & & 0 & 0 & $\mathbf{o}$ & 0 & 0 & 0 & 0 & 0 \\
\hline 6.4.4.2 Stress Corrosion Cracking & & 0 & 0 & $\mathbf{0}$ & 0 & 0 & 0 & 0 & 0 \\
\hline 6.4.4.3 Crovice Corrosion & & 0 & 0 & 0 & 0 & 0 & 0 & $\mathbf{0}$ & 0 \\
\hline 6.4.4.4 Concrete Degradatlon/Cracking & & 0 & 0 & 0 & 0 & 0 & 0 & $\mathbf{0}$ & 0 \\
\hline 6.4.4.5 Ease of Maintalning Confinement & & 0 & 0 & 0 & 0 & 0 & 0 & 2 & 6 \\
\hline 6.4.5 Future Retrieval and Processing & 3 & & & & & & & & \\
\hline 6.4.5.1 Waste Retrieval & & $\mathbf{o}$ & 0 & 0 & 0 & 0 & 0 & 1 & 3 \\
\hline
\end{tabular}


Table 6-5. Comparison of Options for Liquid Retrieval Alternatives. (2 sheets)

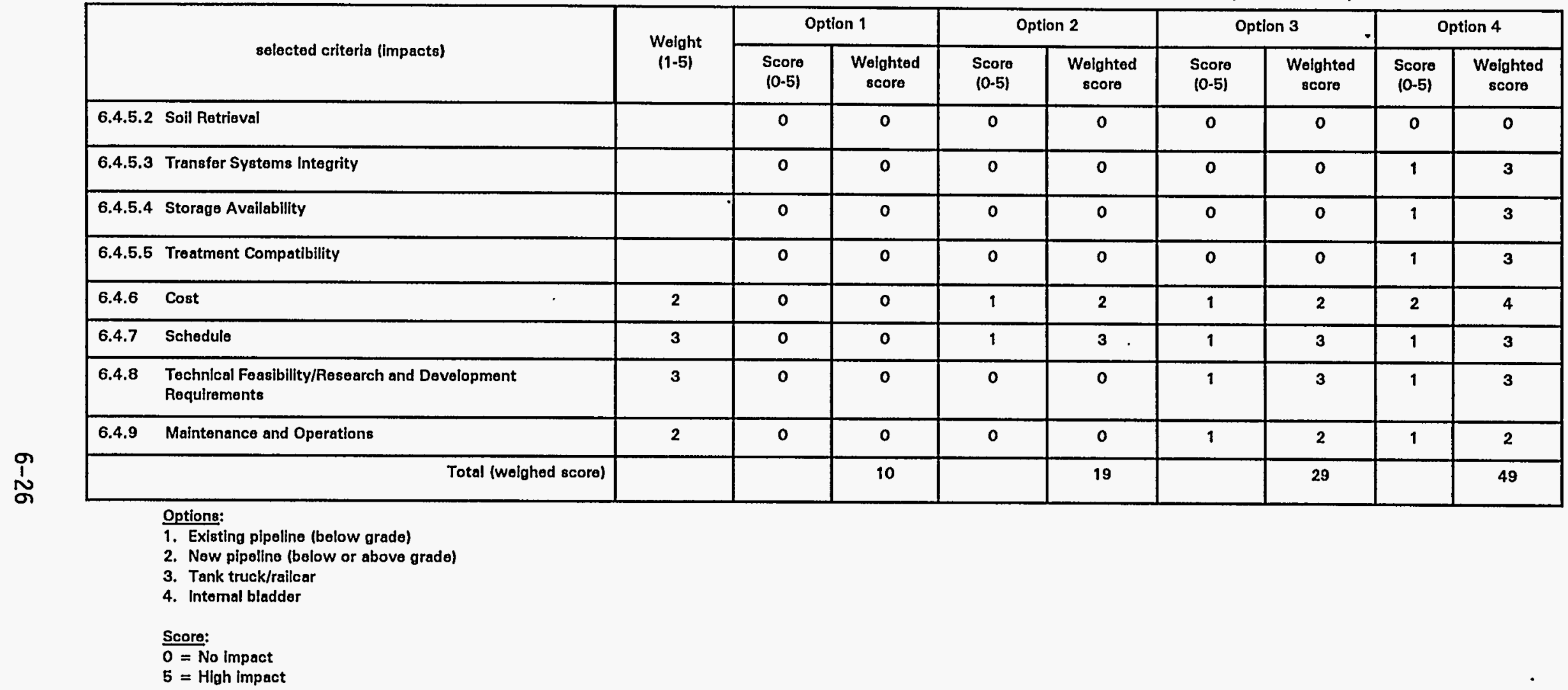

$=$ High impact 
HHC-EP-0873, Rev. 0

- Option 3--The score for option 3 is 2 because worker radiation exposure would increase during transfer by; truck or train to the 244-AR building and during maintenance.

- Option 4--The score for option 4 is 2 because activity would increase around the tank during insertion of the bladder and sump pump. In addition, installation of a larger riser may be required. Workers would be exposed to radiation, toxic wastes, and construction accidents during work on the tank.

6.4.1.3 Environmental Safety. The score for all options is 0 because the potential for release to the environment is very low. Transfers are closely monitored to prevent breach of confinement. In option 3 , waste is transported by truck or rail with a risk assessment less than $10^{-6}$ release accidents/year.

\subsubsection{Compliance with Laws/Regulations}

Compliance with current regulations and laws is evaluated as discussed in Section 5.2.

\subsubsection{WAC 173-303.}

- Options 1, 2, and 3--The score for options 1,2 , and 3 is 0 because pumping of the tank's liquid contents to a double-contained receiver/storage tank complies with WAC-173-303.

- Option 4--The score for option 4 is 0 because transferal of the liquid from the leaking tank into a nonleaking bladder for later transfer to a double-contained receiver/storage tank complies with WAC 173-303.

\subsubsection{Closure/Post-Closure Activities.}

- Option 1--The score for option 1 is 0 because use of existing equipment and pipelines would require no additional decontamination or decommissioning activities.

- Options 2, 3, and 4--The score for options 2, 3, and 4 is 0 because new materials and equipment used under this option would require removal and decontaminating before disposal.

\subsubsection{Waste Safety}

Several unresolved waste safety issues are associated with the retrieval of SST wastes. The full effect of water and hydroxide solution removal has not been determined. Hater removal and the heating and drying of waste can decrease the ability of the waste to cool. The possibility for thermal runaway reactions between oxidants such as nitrates and organics/ferrocyanide significantiy increases as moisture is removed or heat added.

6.4.3.1 Hydrogen/Flammable Gas Generation. The score for all options is 0 because there is no possibility of this condition occurring within Tank 241-T-101 during the liquid retrieval operations. 
WHC-EP-0873, Rev. 0

6.4.3.2 Ferrocyanide Stability. The score for all options is 1 because the possibility of increased ferrocyanide concentration exists when the liquid is pumped and the sludge is left in the tank to dry.

6.4.3.3 Criticality. The score for all options is 0 because pumping would have no effect upon the criticality of the waste.

6.4.3.4 Heat Load. The score for all options is 0 because heat generated during the pumping operation will have minimal effect on the overall tank temperature.

\subsubsection{Tank Safety}

The SSTs have exceeded their original design life. Available information on the physical integrity and condition of the tank structures is limited. Monitoring equipment is unreliable. The steel liners on approximately half of the SSTs have already leaked. Tanks low in hydroxide are considered most vulnerable because hydroxide is known to inhibit corrosion of mild steel.

6.4.4.1 Waterline Corrosion. The score for all options is 0 because waterline attack has not been observed at the SRS or Hanford Site.

6.4.4.2 SCC. The score for all options is 0 because removal of the liquids will reduce or eliminate the SCC of the steel liner.

6.4.4.3 Crevice Corrosion. The score for all options is 0 because no crevice corrosion attack has been observed at SRS or Hanford Site.

6.4.4.4 Concrete Degradation/Cracking. The score for all options is 0 because contact between liquid waste and concrete would be prevented.

\subsubsection{Ease of Maintaining Confinement.}

- Options 1, 2, and 3--The score for options 1, 2, and 3 is 0 because these options would leave no effect on the ease of maintaining confinement.

- Option 4--The score for option 4 is 2 because installation of a larger riser would involve light to moderate confinement risk.

\subsubsection{Future Retrieval and Processing}

Alternatives and options are evaluated for potential impact on future retrieval, transportation, storage and waste processing operations. Actions that may impact transportation, storage, and waste treatment are identified and rated.

\subsubsection{Waste Retrieval.}

- Options 1, 2, and 3--The score for options 1,2 , and 3 is 0 because there was no effect on waste retrieval. 
- Option 4--The score for option 4 is 1 because future retrieval would require removal of 1 iquid, bladders, and sump pumps before the sludge could be removed.

6.4.5.2 Soil Retrieval. The score for all options is 0 because removal of liquids would eliminate tank leakage and resulting soil contamination.

\subsubsection{Transfer System Integrity.}

- Options 1, 2, and 3--The score for options 1, 2, and 3 is 0 because there was no effect on transfer system integrity.

- Option 4--The score for option 4 is 1 because it allows the bladder to be pumped out through the existing transfer system.

\subsubsection{Storage Availability.}

- Option 1, 2, and 3--The score for options 1, 2, and 3 is 0 because the amounts of flush water added to the waste volume would be insignificant.

- Option 4--The score for option 4 is 1 because the amounts of flush water added to the storage volume would be small. However, the amount is greater than under options 1,2, and 3.

\subsubsection{Treatment Compatibility.}

- Options 1, 2, and 3--The score for options 1, 2, and 3 is 0 because these options will not change the existing treatment requirements.

- Option 4--The score for option 4 is 1 because the bladder and associated sump pump become solid waste after liquid retrieval. Although it does not directly affect the future tank waste treatment processes, it adds to the volume of contaminated solid waste that must be disposed.

\subsubsection{Cost}

- Option 1--The score for option 1 is 0 because the use of existing pipeline would not require procurement and installation of equipment.

- Option 2--The score for option 2 is 1 because a new pipeline would be required.

- Option 3--The score for option 3 is 1 because procurement and installation of aboveground pipeline and procurement of a tank truck would be required. Additionally, modification to the railcar and possible modifications to the 244-AR unloading station would be required. An SAR addendum to SD-HM-SAR-034 and permitting would need to be prepared. 
WHC-EP-0873, Rev. 0

- Option 4--The score for option 4 is 2 because research, design, testing, procurement, and installation of bladder tanks, sump pumps, and associated risers would be required.

\subsubsection{Schedule}

- Option 1--The score for option 1 if 0 because the time required to install the pumping system and perform 1iquid transfers is minimal.

- Options 2 and 3--The score for options 2 and 3 is 1 because the time required to construct a new pipeline or railroad.

- Option 4--The score for option 4 is 1 because the option requires time to investigate and implement.

\subsubsection{Technical Feasibility/Research and Development Requirements}

- Options 1 and 2--The score for options 1 and 2 is 0 because these options represent the current method of liquid transfer.

- Option 3--The score for option 3 is 1 because R\&D is required for determining modifications needed to meet environmental, health, and safety requirements.

- Option 4--The score for option 4 is 1 because bladder vessels have been used in the petrochemical industry. Some development is required to adapt the bladder to the physical parameters of Tank 241-T-101.

\subsubsection{Maintenance and Operations}

- Options 1 and 2--The score for options 1 and 2 is 0 because maintenance and operational requirements are the same as current and past tank farm activities.

- Option 3--The score for option 3 is 1 because increased maintenance would be required for the tank truck or the railcar and the unloading facility. Operations would have increased responsibility during transporting and unloading the liquid.

- Option 3--The score for option 4 is 1 because additional tank monitoring by operations and maintenance of equipment for an extended time period would be required until the bladder is pumped out.

\subsection{COMPARISON OF OPTIONS FOR TOTAL RETRIEVAL SYSTEMS}

Table 6-6 contains scores for the total retrieval options. The low total weighted score for option 1 indicates that this option is the best option. In the following sections, the reasons and considerations for the scores are given. 
Table 6-6. Comparison of Options for Total Retrieval A7ternatives. (2 sheets)

\begin{tabular}{|c|c|c|c|c|c|c|c|}
\hline \multirow{2}{*}{. Selected criteria (impacts) } & \multirow{2}{*}{$\begin{array}{c}\text { Weight } \\
(1-5)\end{array}$} & \multicolumn{2}{|c|}{ Option 1} & \multicolumn{2}{|c|}{ Option 2} & \multicolumn{2}{|c|}{ Option 3} \\
\hline & & Score $(0.5)$ & $\begin{array}{l}\text { Woighted } \\
\text { score }\end{array}$ & $\begin{array}{l}\text { Scoro } \\
(0-5)\end{array}$ & $\begin{array}{l}\text { Woighted } \\
\text { score }\end{array}$ & $\begin{array}{l}\text { Scoro } \\
(0-5)\end{array}$ & $\begin{array}{l}\text { Weighted } \\
\text { score }\end{array}$ \\
\hline 6.5.1 Health Safaty & 5 & & & & & & \\
\hline 6.5.1.1 Public Safoty & & 1 & $\mathbf{5}$ & 1 & 5 & 3 & 15 \\
\hline 6.5.1.2 Worker Safoty & & 3 & 15 & 4 & 20 & 5 & 25 \\
\hline 6.5.1.3 Environmental Safoty & & 0 & $\mathbf{0}$ & $\mathbf{0}$ & 0 & 0 & $\mathbf{0}$ \\
\hline 6.5.2 Compliance with Laws/Regulations & 4 & & & & & & \\
\hline 6.5.2.1 WAC 173-303 & & 0 & 0 & 0 & 0 & 0 & 0 \\
\hline 6.5.2.2 Closuro/Post-Closure Activities & & 1 & 4 & 1 & 4 & 2 & 8 \\
\hline 6.5.3 Waste Safoty & 5 & & & & & & \\
\hline 6.5.3.1 Hydrogen/Flammablo Gas Generation (radiation lovols/organics) & & 0 & 0 & 0 & 0 & 0 & 0 \\
\hline 6.5.3.2 Ferrocyanide Stability & & 0 & 0 & 0 & 0 & 1 & 5 \\
\hline 6.5.3.3 Criticality & & 0 & 0 & 0 & 0 & $\mathbf{0}$ & 0 \\
\hline 6.5.3.4 Heat Load & & 0 & 0 & 0 & 0 & 0 & 0 \\
\hline 6.5.4 Tank Safety & 3 & & & & & & \\
\hline 6.5.4.1 Waterline Corrosion & & 0 & 0 & 0 & 0 & 0 & 0 \\
\hline 6.5.4.2 Stress Corrosion Cracking & & 2 & 6 & 2 & 6 & 3 & 9 \\
\hline 6.5.4.3 Crevice Corrosion & & 0 & 0 & 0 & $\mathbf{0}$ & 0 & D \\
\hline 6.5.4.4 Concrete Degradation/Cracking & & 0 & 0 & 0 & 0 & 0 & 0 \\
\hline 6.5.4.5 Ease of Maintaining Confinement & & 1 & 3 & 3 & 9 & 5 & 15 \\
\hline 6.5.5 Future Retrioval and Processing & 3 & & & & & & \\
\hline 6.5.5.1 Waste Retrieval & & 0 & 0 & 0 & 0 & 0 & 0 \\
\hline
\end{tabular}


Table 6-6. Comparison of Options for Total Retrieval Alternatives. (2 sheets)

\begin{tabular}{|c|c|c|c|c|c|c|c|c|}
\hline \multirow{2}{*}{\multicolumn{2}{|c|}{ Selected criteria (impacts) }} & \multirow{2}{*}{$\begin{array}{l}\text { Woight } \\
(1-5)\end{array}$} & \multicolumn{2}{|c|}{ Option 1} & \multicolumn{2}{|c|}{ Option 2} & \multicolumn{2}{|c|}{ Option 3} \\
\hline & & & Score $(0-5)$ & $\begin{array}{l}\text { Wolghted } \\
\text { score }\end{array}$ & $\begin{array}{l}\text { Score } \\
(0-5)\end{array}$ & $\begin{array}{l}\text { Weighted } \\
\text { score }\end{array}$ & $\begin{array}{l}\text { Scoro } \\
(0-5)\end{array}$ & $\begin{array}{l}\text { Weighted } \\
\text { score }\end{array}$ \\
\hline 6.5.5.2 s & Soll Retrieval & & o & 0 & 0 & 0 & 0 & 0 \\
\hline 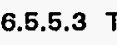 & Transfer System Integrity & & $\mathbf{0}$ & o & 0 & 0 & 0 & 0 \\
\hline 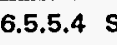 & Storage Avallability & & $\mathbf{0}$ & $\mathbf{0}$ & 0 & 0 & 0 & 0 \\
\hline 6.5.5.5 T & Troatment Compatibility & & 0 & $\mathbf{o}$ & 0 & 0 & 0 & 0 \\
\hline 6.5.6 c & Cost & 2 & 3 & 6 & 4 & 8 & 5 & 10 \\
\hline 6.5.7 & Schodule & 3 & 1 & 3 & 3 & 9 & 4 & 12 \\
\hline 6.5 .8 & Technlcal Feasibility/Research and Dovelopment Requirements & 3 & 3 & 9 & 3 & 9 & 5 & 15 \\
\hline 6.5 .9 & Maintenance and Operations & 2 & 2 & 4 & 2 & 4 & 4 & 8 \\
\hline & Total (weighted score) & & & 55 & & 74 & & 122 \\
\hline & $\begin{array}{l}\text { Options: } \\
\text { 1. Unlimited sluice (low prossure-high volume) } \\
\text { 2. Limited stuice (high pressure-low volumo) } \\
\text { 3. Artlculated arm scarifler } \\
\text { Score: } \\
=\text { = No impact } \\
5=\text { High impact }\end{array}$ & & & & & & & \\
\hline
\end{tabular}

0 No impact 
WHC-EP-0873, Rev. 0

\subsubsection{Health Safety}

Health safety concerns include public safety, worker safety and environmental impacts.

\subsubsection{Public Safety.}

- Options 1 and 2--The score for options 1 and 2 is 1 because waste transfer occurs in a confined system such as pipe-in-pipe transfer lines.

- Option 3--The score for option 3 is 3 because the design of the air conveyance and support ventilation system for option 3 is unproven and represents a moderate potential risk to the public in the event of equipment failure.

\subsubsection{Worker Safety.}

- Option 1--The score for option 1 is 3 because major modifications or the replacement of existing concrete pits would be required. In addition, several existing tank risers may need modifications to accept new instrumentation and CCTV. The potential risks to workers during these activities is moderate.

- Option 2--The score for option 2 is 4 because the potential risks to worker safety during the installation of four $18 \mathrm{in.} \mathrm{diameter} \mathrm{risers}$ and related tank modifications is moderate to heavy.

- Option 2--The score for option 3 is 5 because installation of a 6-ft diameter opening in the SST dome and construction of a large pit over the dome opening are required. Modifications to Tank 241-T-101 are also required to accommodate the new instrumentation and CCTV. The potential risks to workers during these activities is significant.

6.5.1.3 Environmental Safety. The score for all options is 0 because none of the options are expected to significantly impact the environment. Accidents and leaks would be detected before significant releases to the environment occur. Some small leaks could occur to the environment during sluicing of the tank. Leaks during sluicing should be minimal for Tank 241-T-101 because the amount of waste contained by this tank is small.

\subsubsection{Compliance with Law/Regulations}

Regulatory compliance has less importance than safety. Compliance with current regulations and laws is evaluated as discussed in Section 5.2.

6.5.2.1 WAC 173-303. The score for all options is 0 because a11 three options comply with WAC 173-303.

\subsubsection{Closure/Post-Closure Activities.}

- Options 1 and 2--The score for options 1 and 2 is 1 because sluicing systems would be removed and recycled prior to closure activities. 
HHC-EP-0873, Rev. 0

Some minimal decontamination and decommission activities would be required at the completion of sluicing operations.

- Option 3--The score for option 3 is 2 because decontamination and decommissioning would require more effort than other options.

\subsubsection{Waste Safety}

Waste safety concerns for Tank 241-T-101 include hydrogen/flammable gas generation, ferrocyanide stability, criticality, heat load impacts, and are evaluated as described in Section 5.2.

6.5.3.1 Hydrogen/Flammable Gas Generation. The score for all options is 0 because there is little likelihood of this condition occurring within Tank 241-T-101 during retrieval operations.

\subsubsection{Ferrocyanide Stability.}

- Options 1 and 2--The score for options 1 and 2 is 0 because the sluicing and diluting action will not alter the stability of the ferrocyanide during retrieval operations.

- Option 3--The score for option 3 is 1 because there would be a potential for a temperature increase in the salt cake after the liquids have been removed. This could set off an exothermic chemical reaction which could effect ferrocyanide stability.

6.5.3.3 Criticality. The score for all options is 0 because there would be little likelihood of this condition existing within Tank 241-T-101 during retrieval operations.

6.5.3.4 Heat Load. The score for all options is 0 because little heat would be added to Tank $241-T-101$ during retrieval operations.

\subsubsection{Tank Safety}

The SSTs have exceeded their original design 1ife. Available information on the physical integrity of the tank structures is limited. Monitoring equipment is unreliable. The steel liners of approximately half of the SSTs have already leaked. Tanks low in hydroxide are considered most vulnerable because hydroxide is known to inhibit corrosion of mild steel.

6.5.4.1 Waterline Corrosion. The score for all options is 0 because the proposed retrieval systems would not result in waterline corrosion.

\subsubsection{SCC.}

- Options 1 and 2--The score for options 1 and 2 is 2 because highpressure sluicing may aggravate ongoing SCC in the tank liner.

- Option 3--The score for option 3 is 3 for the same reason as options 1 and 2 except that the aggravation of the steel liner by option 3 would be more aggressive. 
6.5.4.3 Crevice Corrosion. The score for all options is 0 because the proposed retrieval systems would not result in crevice corrosion.

6.5.4.4 Concrete Degradation/Cracking. The score for all options is 0 because options would not contribute significantly to concrete degradation or cracking. The tank would be ready for decommissioning so that concrete degradation and cracking would be irrelevant.

\subsubsection{Ease of Maintaining Confinement.}

- Option 1--The score for option 1 is 1 because confinement concerns are light when using existing tank risers for installation of equipment.

- Option 2--The score for option 2 is 3 because penetration of the dome would be required for construction of an 18 in. diameter riser.

- Option 3--The score for option 3 is 5 because penetration of the dome would be required for construction of a $6 \mathrm{ft}$ diameter opening.

\subsubsection{Future Retrieval and Processing}

The score for all options is 0 because total retrieval would be accomplished whereby future concerns would be obviated.

\subsubsection{Cost}

The scores for options 1, 2, and 3 are 3, 4, and 5, respectively. Scores are based on cost information in WHC-SD-W139-ES-001, Rev. 0.

\subsubsection{Schedule}

The scores for options 1, 2, and 3 are 1, 3, and 4, respectively. Scores are based on engineering judgements of each options ability to meet Tri-Party Agreement milestones and on the relative time frame necessary to complete the option.

\subsubsection{Technical Feasibility/Research and Development Requirements}

- Options 1 and 2--The score for options 1 and 2 is 3 because major development and testing of new remotely operated sluicing assemblies would be required. The new sludge/slurry pump assembly would require minor development for remote service prior to installation.

- Option 3--The score for option 3 is 5 because an unproven retrieval system is involved. Extensive development and testing of the remotely operated articulated arm scarifier assembly and air conveyance support equipment would be required. 
WHC-EP-0873, Rev. 0

\subsubsection{Maintenance and Operations}

- Options 1 and 2--The score for options 1 and 2 is 2 because maintenance and operation requirements would be light to moderate by comparison to current and past tank farm activities.

- Option 3--The score for option 3 is 4 because the maintenance and operation requirements would be moderate to heavy by comparison to current and past tank farm activities. 
WHC-EP-0873, Rev. 0

\subsection{SELECTED ALTERNATIVE(S)}

The preferred alternative is liquid retrieval. Options 1 and 2 had the least impact upon the selection criteria. Results strongly suggest that if DST space is available, and the liquid transport system operable, Tank 241-T-101 liquid contents should be transferred as soon as practicable to a DST to prevent further contamination of the environment. The evaluation results imply that other SSTs containing appreciable liquid should also be pumped out as soon as safely practicable to avoid the same safety, compliance, and cleanup impacts found for Tank 241-T-101.

Existing environmental regulations and DOE's pending commitments to retrieve and process all SST and DST wastes and to clean the site to background levels further reinforce the findings of the evaluation. The total retrieval alternative looks quite favorable because it solves the total HLW tank waste problem in one action. Transport, storage, and process systems are not yet in place at Hanford to permit the implementation of this alternative (options 1 and/or 2) in the immediate future. As a result, the total. retrieval alternative cannot be implemented in sufficient time to mitigate a leaker SST. Its potential benefits will have to wait until the back end of waste management system is completed.

In summary, the following alternatives/options were found worthy of further evaluation for Tank 241-T-101 or other liquid-bearing SSTs. The listing is given in order of descending merit.

1. Liquid Retrieval Alternative

- Option 1, pump out - using existing piping

- Option 2, pump out - using new piping

- Option 3, pump out - tank truck/railcar

- Option 4, pump out - internal bladder

2. Total Retrieval Alternative

- Option 1, unlimited sluicing

- Option 2, limited sluicing

3. In-Tank Stabilization Alternative

- Option 4, gels

4. External Tank Stabilization A7ternative

- Option 1, geomembrane walls/jet grouting

- Option 2, slurry wa11s/jet grouting

- Option 3, sheet piling

- Option 4, ground freezing

The external tank stabilization alternative is included because it offers a way to control/contain the spread of contamination through soils from either past tank leaks or future leaks from waste retrieval actions. This alternative was not found to be a viable alternative in this evaluation.

Based on the engineering evaluation of alternatives, findings and preliminary estimates of schedule and costs were developed for the liquid retrieval, total retrieval, and external tank stabilization alternatives to permit comparisons. These estimates are found in Appendix A. 
WHC-EP-0873, Rev. 0

This page intentionally left blank. 


\subsection{REFERENCES}

Barnes, G. A., et a1, September 1991, "Engineering Study for Partial Retrieval of Tank 241-C-106," HHC-SD-H139-ES-002, Rev. 0, Hestinghouse Hanford Company, Richland, Hashington.

Berry, J. B. et. a7., February-March 1990, "Engineering Development of Processing Methods for Remotely Handled Transuranic Sludge at ORNL," Haste Management "90", Tucson, Arizona.

Boomer, K. D., et aT, November 5, 1992, "Tank Waste Engineering Study," HHC-EP-0405 Rev. 0, Hestinghouse Hanford Company, Richland, Washington.

Carothers, K. G. and Cunningham, L. T., November 1, 1991, "Tank Farm Waste Compatibility Program," WHC-SD-WM-OGD-015, Hestinghouse Hanford Company), Richland, Hashington.

Dunn, J., December 1986, "ITS Circulator Studies," BNHL-CC--923, Pacific Northwest Laboratory, Richland, Washington.

E. I. du Pont de Nemours and Company, Apri1-June 1982, "Composite Quarterly Technical Report, Long-Term High-Leve1-Waste Technology, "DP-82-157-2, Savannah River Laboratory, Aiken, South Carolina.

Freeman, H. M., 1989, "Standard Handbook of Hazardous Waste Treatment and Disposal," McGraw Hill Book Company, New York, New York.

Futton, J. C., October 25, 1992, "Justification for Continued Operation-Organic Tank 241-C-103," letter 9257935 to R. E. Gerton, Westinghouse Hanford Company, Richland, Washington.

Fulton, J. C., December 10, 1992, Waste Tank Safety Programs "Get We11" Issue Paper, letter to H. D. Horman, Hestinghouse Hanford Company, Richland, Washington.

Gerton, R. E., September 1, 1992, "Justification for Continued Operation of Hanford High Level Waste Tanks," letter 9256354 to President, Hestinghouse Hanford Company, Richland, Washington.

Godfrey, S. D., 1992, "Operating Specifications for Watch List Tanks," 0SD-T-151-00030, Rev. A-1, Westinghouse Hanford Company, Richland, Washington.

Gundel Lining Systems Inc., December 1992, "Use of High Density Polyethylene Barrier System in the Containment of Contaminants," Marketing Brochure, Houston, Texas.

Hanton, B. M., November 1992, "Tank Farm Surveillance and Waste Status Summary Report for August 1992," HHC-EP-0182-53, Westinghouse Hanford Company, Richland, Washington.

Hanson, G. L., et a1, 1981, "Safety Analysis Report, Stabilization of SingleShell Waste Storage Tanks by Salt Hell Jet Pumping," SD-WM-SAR-034, Rev. 0 , Rockwe 71 Hanford Operations, Richland, Washington. 
JBS Associates, Inc., 1984, "Slurry Trench Construction for Pollution Migration Control," EPA-540/2-84-001, U. S. Department of Commerce, National Technical Information Service, Springfield, Virginia.

JBS Associates, Inc., 1985, "Leachate Plume Management," EPA/540/2-85-004, U.S. Department of Commerce, National Technical Information Service, Springfield, Virginia.

Kreig, S.A., et al, June 1990, "Single Shel1 Tank Waste Retrieval Study," WHC-EP-0352, Westinghouse Hanford Company, Richland, Washington.

Krummer, M., et a1, September 30, 1992, "Near Term Study of Interim Stabilization of Non-Watch List Tanks," WHC-SD-WM-RPT-044 Rev. 0, Westinghouse Hanford Company, Richland, Washington.

Krummer, M., September 29, 1992, "Safety Assessment for Interim Stabilization of Ferrocyanide Tanks," WHC-SD-WM-OSAD-018 Rev. 0, Westinghouse Hanford Company, Richland, Washington.

Lo, J. C., 1991, "Single-She11 Tank Leak Emergency Response Guide," WHC-SD-WM-AP-005, Westinghouse Hanford Company, Rich7 and, Washington.

Marishman, D., et a1, 1988, "Freezing a Temporary Roadway for Transport of a 3,000 Ton Dragline," isbn 61918243, Freeze Wa11 Inc., 5th International Symposium on Ground Freezing, Rotterdam, Netherlands.

McLaughlin, T. J., et a1, September 10, 1992, "Interim Subsurface Barrier Technologies Workshop Report," for Westinghouse Hanford Company by Bovay Northwest Inc.

Quayle, T. A., October 1992, "Quarterly Briefing Book on Environmental and Waste Management Activities," HHC-SP-0434-16, Westinghouse Hanford Company, Richland, Washington.

The Hazardous Haste Consultant, Vol. 9, Issue 1, 1991, "Technology/EconomicsFrozen Soil Containment Walls Isolate Hazardous Wastes."

U.S. Environmental Protection Agency, 1990, "Handbook on In-Situ Treatment of Hazardous Waste-Contaminated Soils," Risk Reduction Engineering Laboratory, Cincinnati, Ohio.

U.S. Environmental Protection Agency, 1987, "Handbook: Responding to Discharge of Sinking Hazardous Substances, Hazardous Waste Engineering Research Laboratory," Cincinnati, Ohio.

U.S. Environmental Protection Agency, 1992, "Slurry Walls" (Engineering Bulletin), EPA/540/S-92/008, Office of Emergency and Remedial Response, Washington D.C.

Vai1, T. S., October 21, 1992, "Transmittal of the Amended Justification for Continued Operations to support Stabilization Activities in 102-BY, 109-BY, 107-C, 110-C, and 101-T," letter 9257718 to R. E. Gerton, Westinghouse Hanford Company, Richland, Washington. 
White, T. L., et al, December 1990, "First Results of In-Can Microwave Processing Experiments for Radioactive Liquid Wastes at the Oak Ridge National Laboratory," CONF-900466-54, Oak Ridge National Laboratory, Oak Ridge, Tennessee.

Carothers, K. G., et a1, November 1991, "Tank Farm Haste Compatibility Program," WHC-SD-WM-OCD-015, Hestinghouse Hanford Company, Richland, Washington.

U.S. Environmental Protection Agency, 1986, "Project Summary: Grouting Techniques in Bottom Sealing of Hazardous Waste Soils, "Hazardous Waste Engineering Research Laboratories, Cincinnati, Ohio.

Boomer, L. D., et. al, June 1990, "Functional Requirements Baseline for the Closure of Single-She11 Tanks," WHC-EP-0338 Draft, Westinghouse Hanford Company, Richland, Washington.

ERDA, 1975, "Final Environmental Impact Statement on Waste Management Operations, Hanford Reservation," ERDA-1538 (two volumes), Energy Research and Development Administration, Washington, D.C.

DOE, December 1987, "Disposal of Hanford Defense High-Level, Transuranic and Tank Wastes," DOE/EIS-0113, Volume 1, Final Environmental Impact Statement.

\section{Referenced Hanford Drawings}

Drawing H-2-73896, "Submersible Pump"

Drawing H-2-73990, "Saltwe11 Pump Assembly"

Drawing H-2-38587, "Saltwel1 Screen" 
WHC-EP-0873, Rev. 0

This page intentionally left blank. 
WHC-EP-0873, Rev. 0

\subsection{GLOSSARY}

\section{ABBREVIATIONS AND ACRONYMS}

CCTV closed-circuit television

DCRT double-contained receiver tank

$D E$ diatomaceous earth

DOE

DST

EIS

FIC

HDW

HEPA

HLW

HVAC

LOW

SAR

SCC

sg

SRS

SSTS

TRAC

WAC

U.S. Department of Energy double-shell tank

Environmental Impact Statement

Food Industry Corporation

Hanford Defense Waste

high-efficiency particulate air

high-level waste

heating, ventilating, and air-conditioning

Tiquid observation we11 safety analysis report

stress corrosion cracking

specific gravity

Savannah River Site

single-she11 tanks

track radioactive components

WHC Washington Administrative Code Westinghouse Hanford Company 
WHC-EP-0873, Rev. 0

This page intentionally left blank.

GL-2 


\subsection{APPENDIX A}

\section{PRELIMINARY ESTIMATES OF SCHEDULE AND COST FOR SELECTED WASTE MANAGEMENT ALTERNATIVES}

Preliminary estimates of schedule and costs were made for the preferred alternatives that were selected in this engineering evaluation of alternatives and for the external tank stabilization alternative. The summary results are shown in Table A-1. The results confirm that the fastest, most economical way to manage a leaking waste tank is to pump the liquids as soon as possible to a safe double-shell tank. Liquid wastes should be transferred to double-shell tanks as rapidly and safely possible to avoid the heavy safety, ecological and regulatory compliance (cleanup) impacts associated with leaks to the soil.

Schedule and cost details for each alternative and option are shown in Sections $A-1$ and $A-2$. 
WHC-EP-0873

Rev. 0

TABLE A-1 SUMMARY OF SCHEDULE AND COSTS FOR SELECTED ALTERNATIVES

\begin{tabular}{|c|c|c|c|}
\hline Aiternatioto & gentorn & 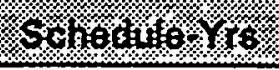 & $4005+645$ \\
\hline \multicolumn{4}{|l|}{ Liquid Retrieval } \\
\hline - Pump out - using existing piping & 1 & 0.67 & 2.4 \\
\hline - Pump out - using new pipe & 2 & 4.0 & 8.3 \\
\hline - Pump out -- using tank truck & 3 & 2.5 & 6.5 \\
\hline - Pump out - using railcar & $3 A$ & 2.58 & 13.2 \\
\hline - Pump out -- using internal bladders & 4 & 4.1 & 8.4 \\
\hline \multicolumn{4}{|l|}{ Total Retrieval } \\
\hline - Unlimited sluicing & 1 & 7.67 & 121.7 \\
\hline Limited sluicing & 2 & 7.75 & 108.9 \\
\hline \multicolumn{4}{|l|}{ External Tank Stabilization } \\
\hline - Geomembrane walls/Jet grouting & 1 & 4.5 & 16.2 \\
\hline Slurry Walls/Jet grouting & 2 & 4.58 & 16.1 \\
\hline Ground freezing & 3 & 4.92 & 26.3 \\
\hline
\end{tabular}


Liquid Retrieval Option 1 (Existing Piping) A-4

Liquid Retrieval Option 2 (New Piping) A-5

Liquid Retrieval Option 3 (Tank Car) A A-6

Liquid Retrieval Option 3A (Railcar) A-7

Liquid Retrieval Option 4 (Bladder) A-8

Total Retrieval Option 1 (Unlimited Sluicing) A-9

Total Retrieval Option 2 (Limited Sluicing) A-10

External Tank Stabilization (Geomembrane Walls/Jet Grouting) A-11

External Tank Stabilization (Slurry Walls/Jet Grouting) A-12

External Tank Stabilization (Ground Freezing) A-13 


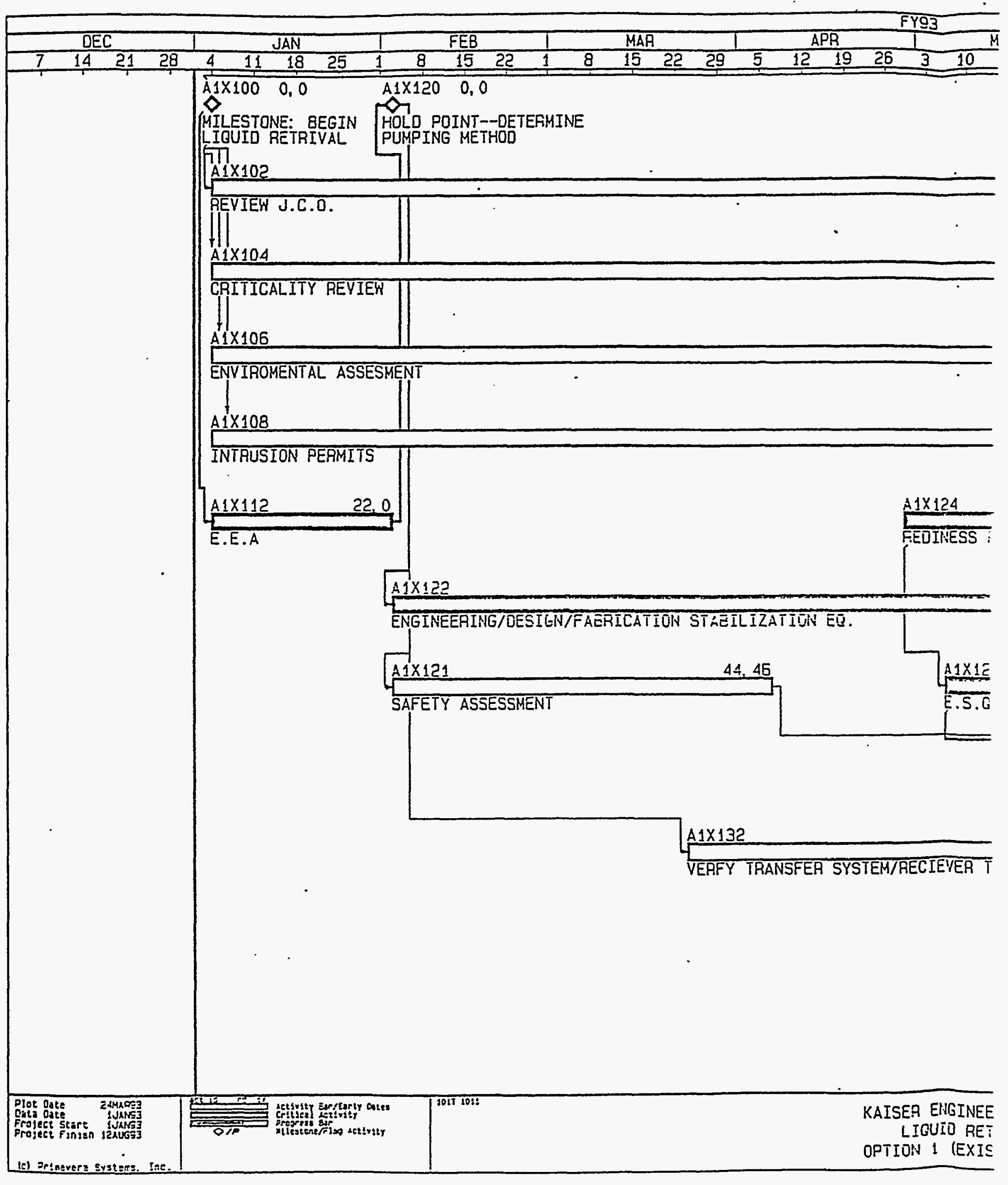




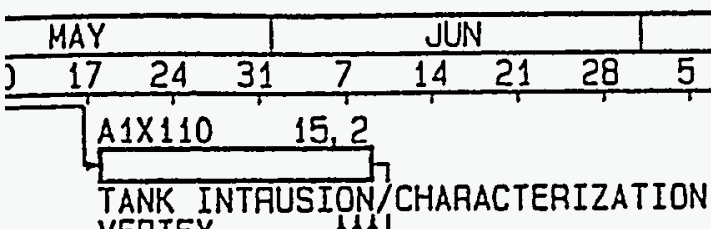

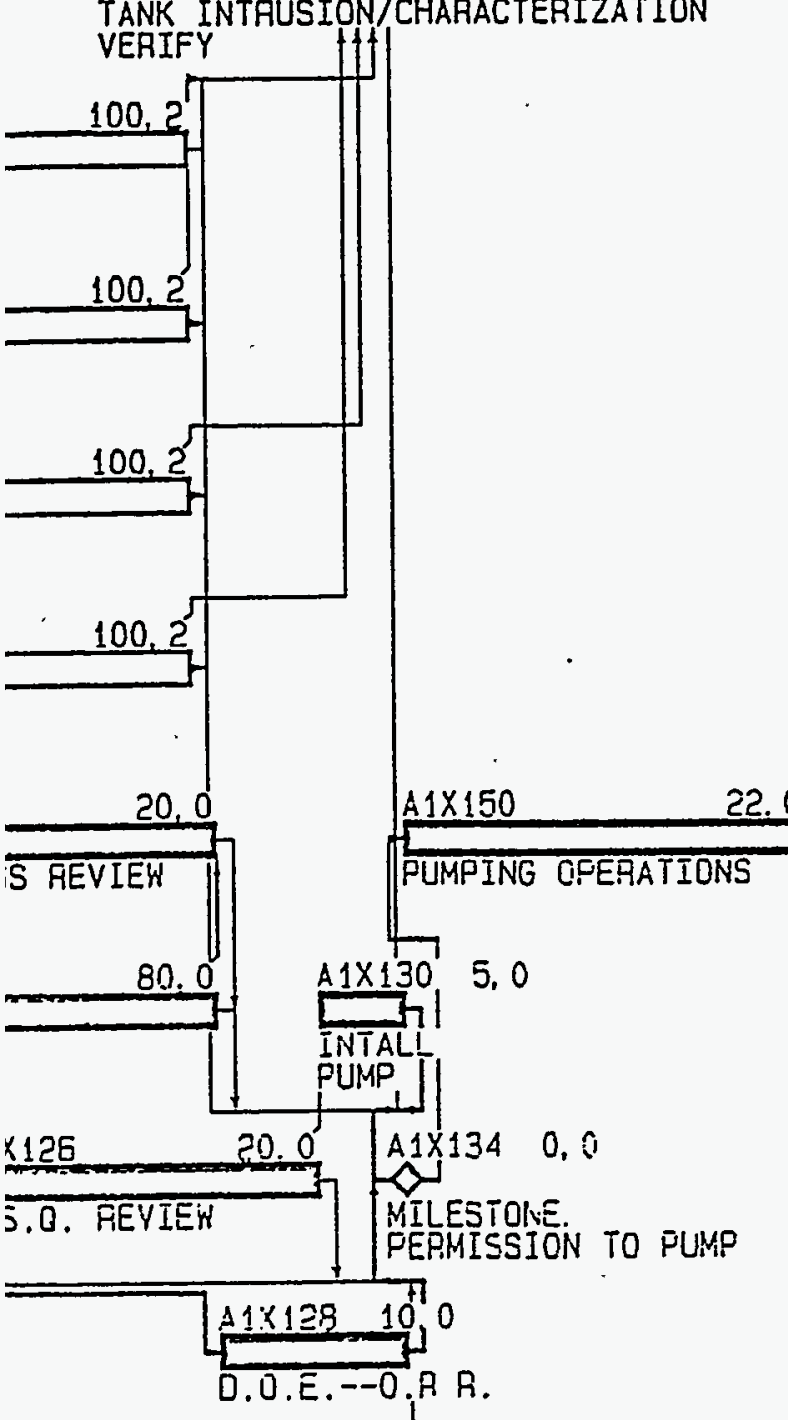

55,1

$\overline{\text { R TANK }}$

2:1T!9!.EEA. 1963 A-4 03/93 ifEV. 1)
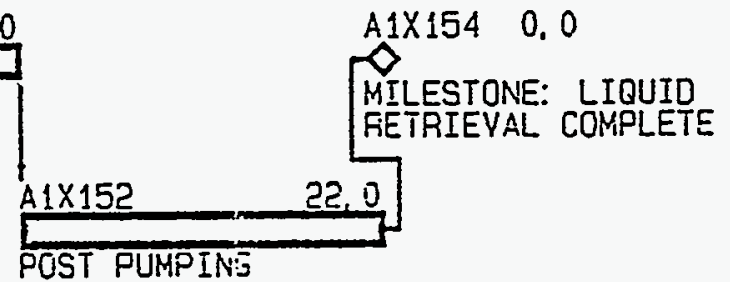

OFERATIONS 


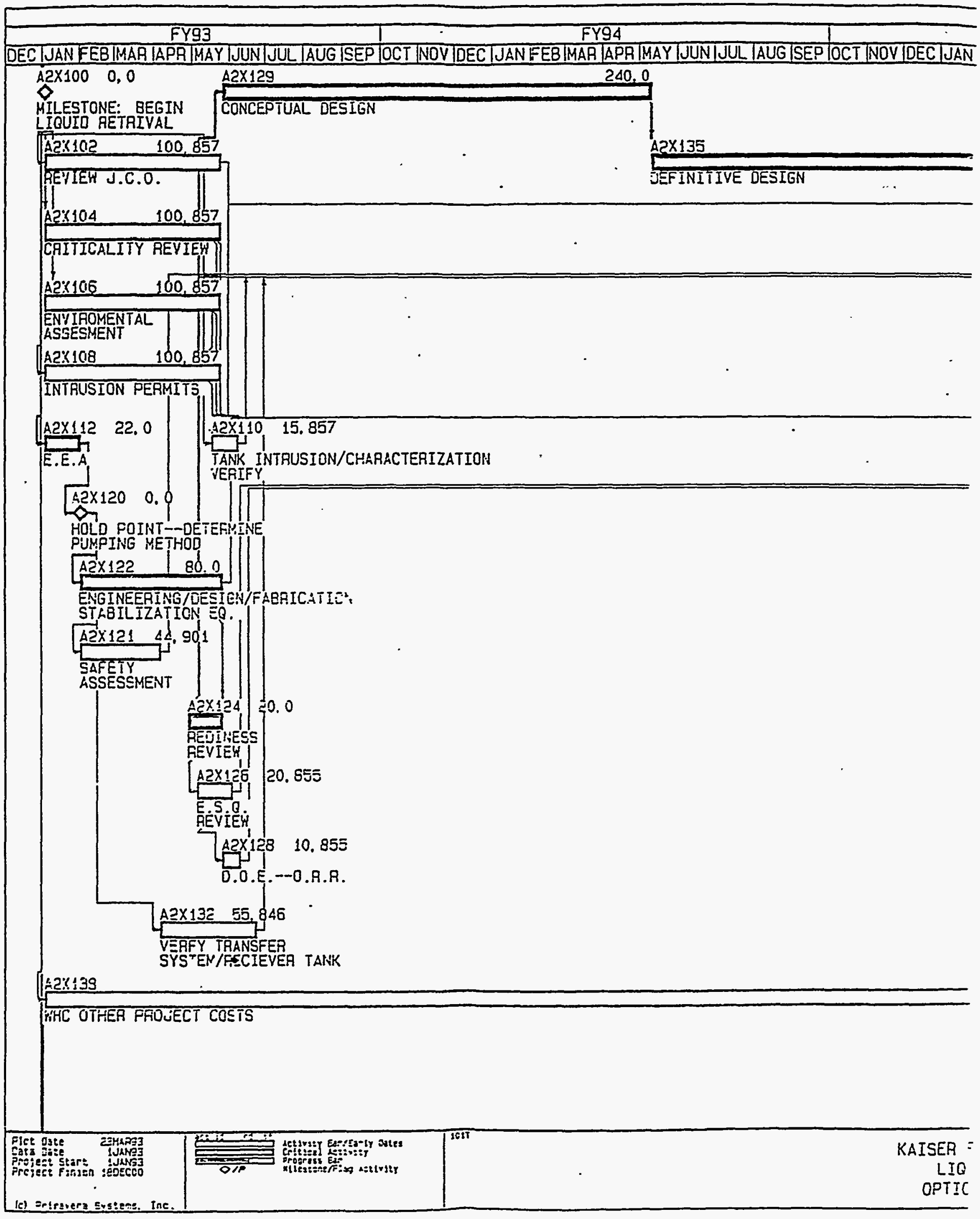


FY95

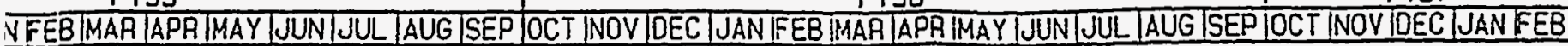
A2X136

ENGINEERING INSPECTION

380.0

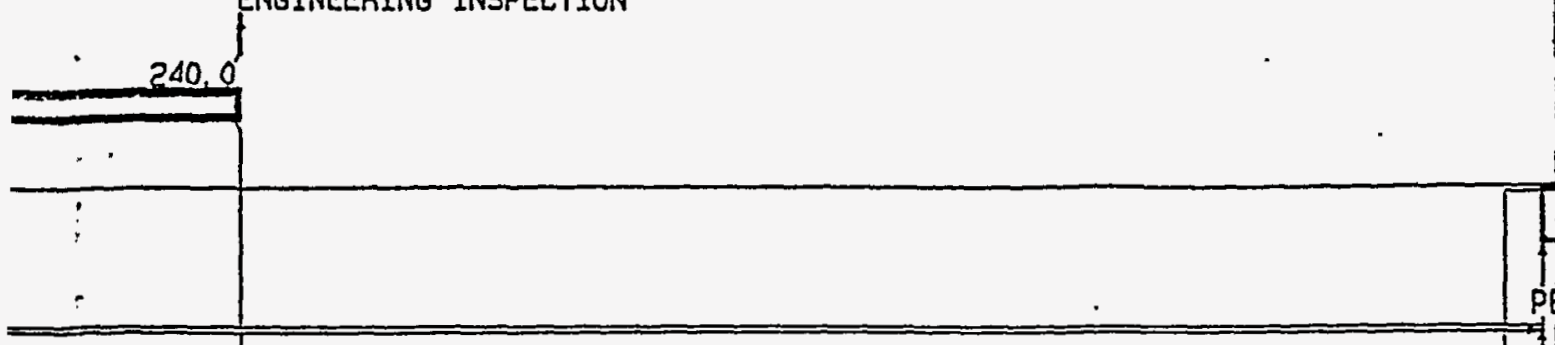

$A 2 \times 130 \quad 5.0$

h INTALL

AटX $134 \quad 0.0$

MILESTONE: PEAMISSION TO PUMP

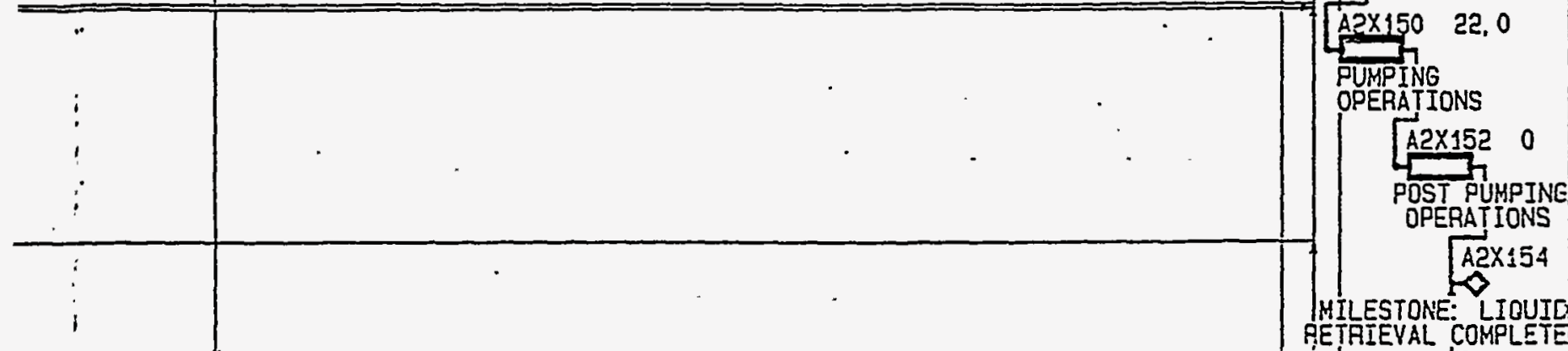
A2X137 360,20

CONSTAUCTION 


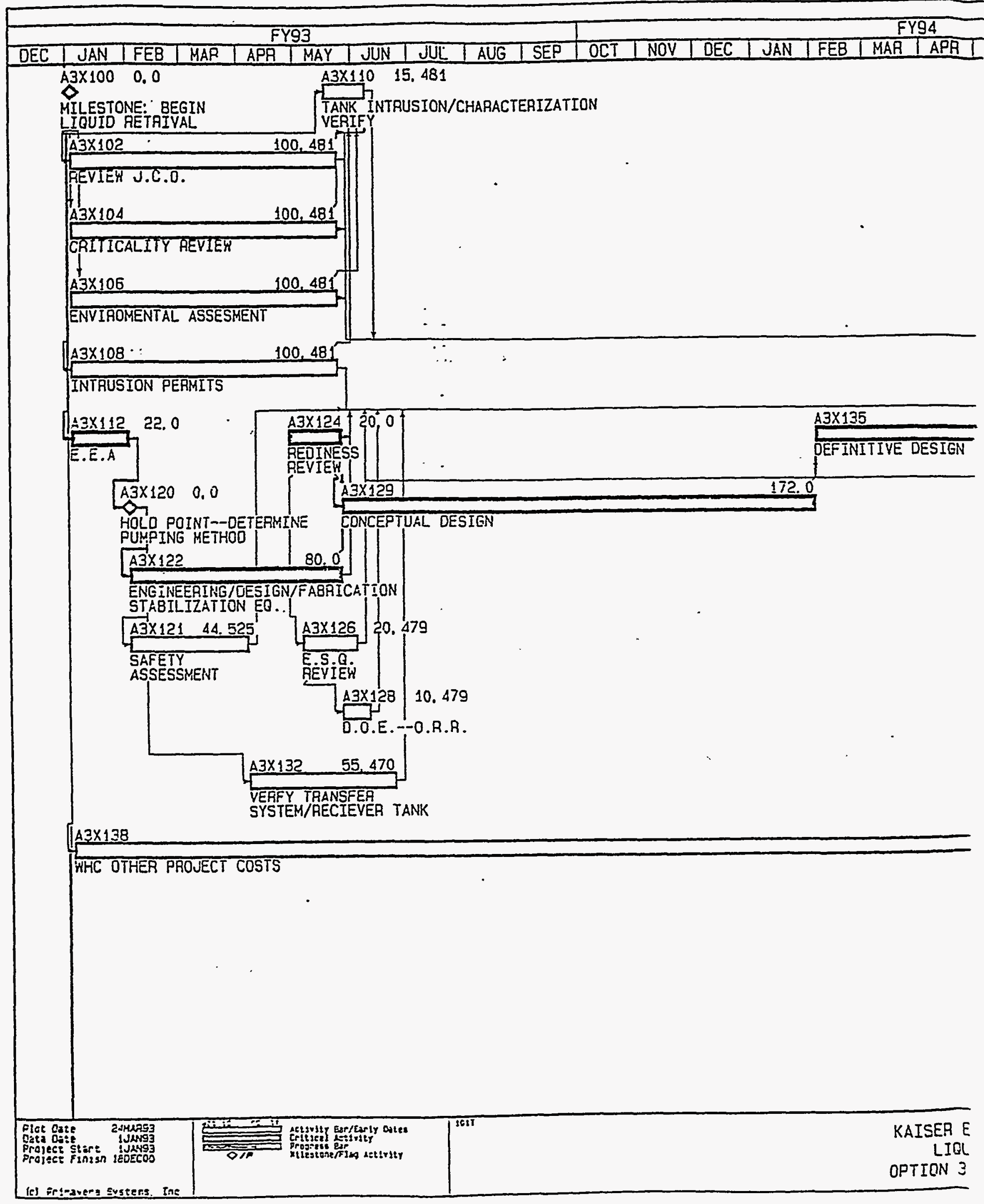




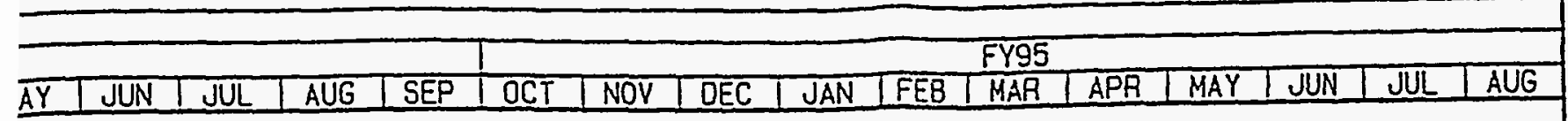

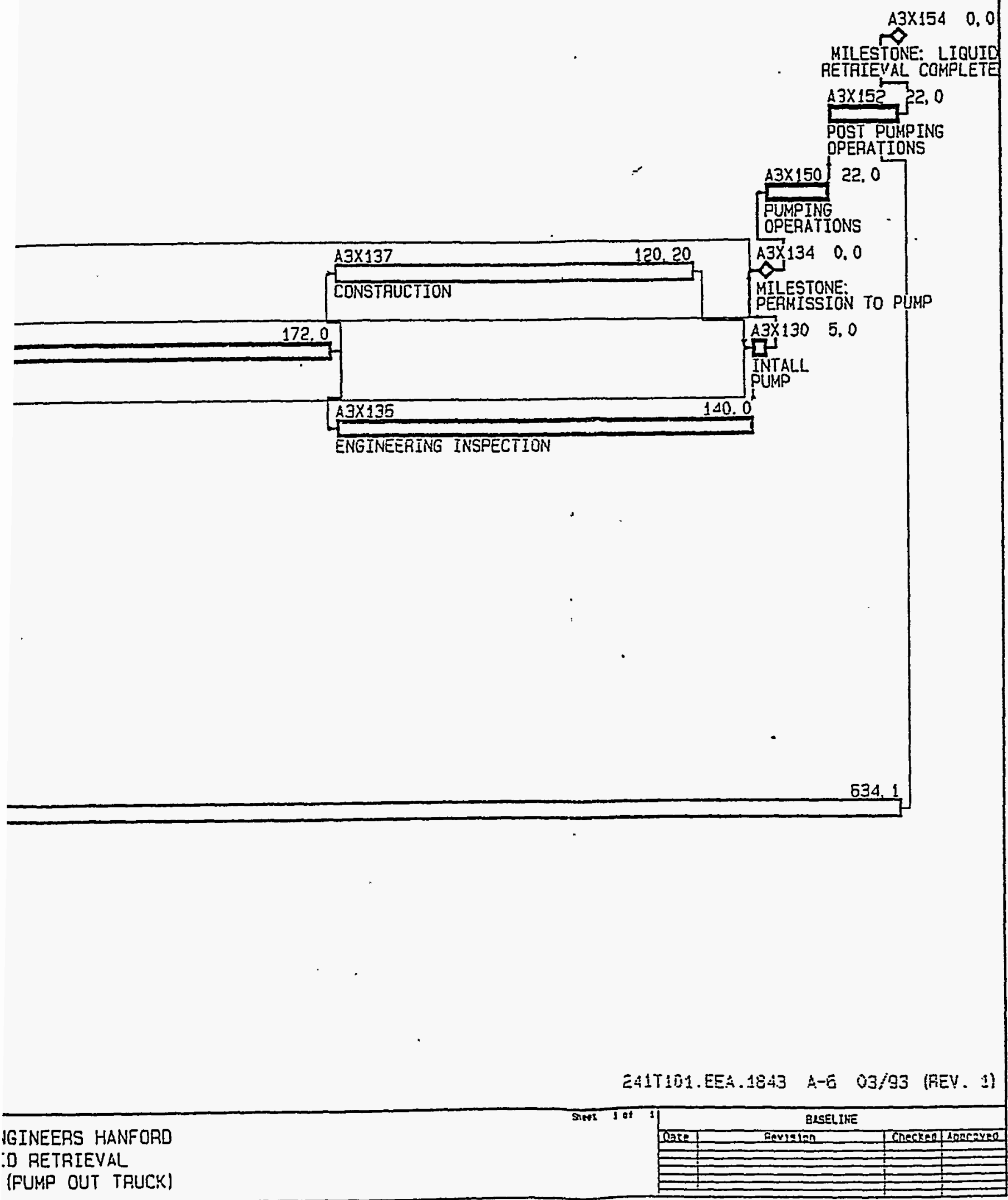


FY93

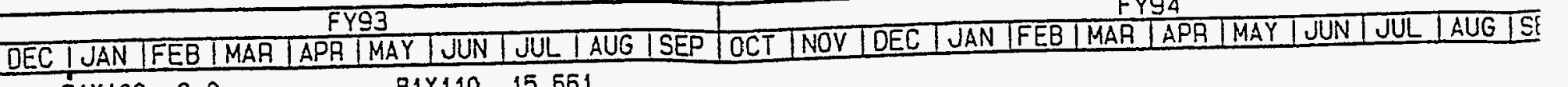
BIX100 0.0 B1X110 15.661

MILESTONE: BEGIN TANK INTAUSION/CHARACTERIZATION

LIOUID RETAIVAL

B

AEVIEW J.C.O.

$81 \times 104$

CAITICALITY AEVIEK

.

$81 \times 106$

100.66 VERIFY

ENVIROMENTAL ASSESMENT

$81 \times 108$

100,661

INTAUSION PEAMITS

$81 \times 11$

22. 0

100,661

E.E.A

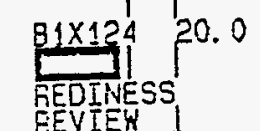

E1X:20

$81 \times 120$

HOLO POINT--DETEAMIN

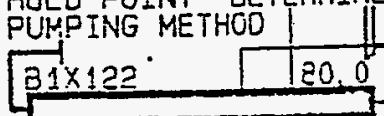

ENG INEERING/LESIGN/FAERICATIOH'

STAEILIZATION EO.

\begin{tabular}{ll}
$81 \times 121 \quad 44.705$ \\
\hline
\end{tabular}

$81 \times 120$

SAFETY

3.129

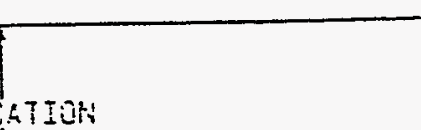

ASSESSMENT

CONCEPTUAL DESIGH

ESSMENT

$\left\{\begin{array}{r}1 \times 126 \\ -320.559\end{array}\right.$

E.S.Q.

GEVIEW

61X 28

10. 859

$91 \times 132 \quad 55.650$

D.O.E. - O.R.R.

VERFY TRANSFEA

SYSTEM/FECIEYER TANK

$81 \times 138$

WHC OTHER PROJECT COSTS

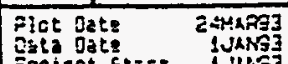

Frajezt s:z: 2 indsy

roject fin:sh :exzcos

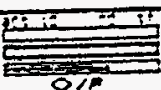




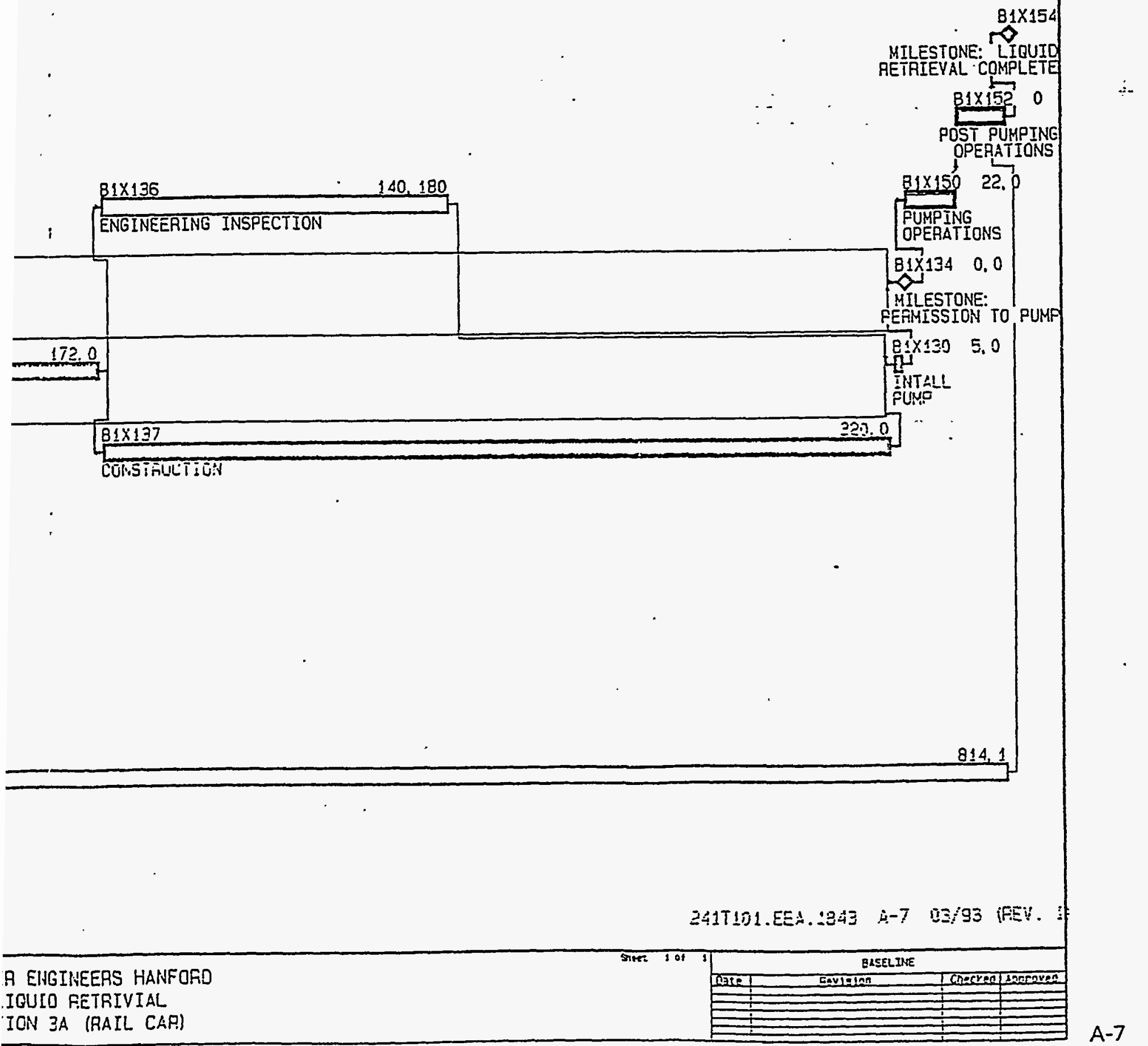


FY93 FY94

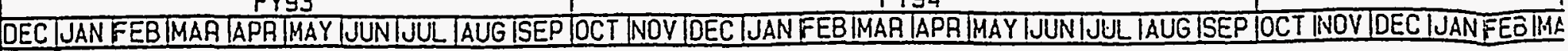
A $4 \times 1000$,

$\Delta$

MILESTONE: BEGIN

LIQUID RETRIYAL

A4X 138

HHC OTHER PROJECT COSIS

A

REVIEW J.C.O. 100,857

II

A $\times 104$ A4X129

240,0

CONCEPTUAL DESIGN

CONCEPTUAL DESIGN
$A 4 \times 135$

DEFINIIIVE DESIGN

CAIIICALITY REVIEY

A4X106

100,857

ENVIROMENTAL

ASSESMENT

A4X108

100,857

INTRUSION PERMITS

1

$14 \times 112 \quad 22.0$

57

E.E.A

A4X120

87

HOLD PRINT-OETERISISE

PLYFING METHO

$14 \times 122$

L

ENGINEETING/CEEIGH/FLEFICATIOU

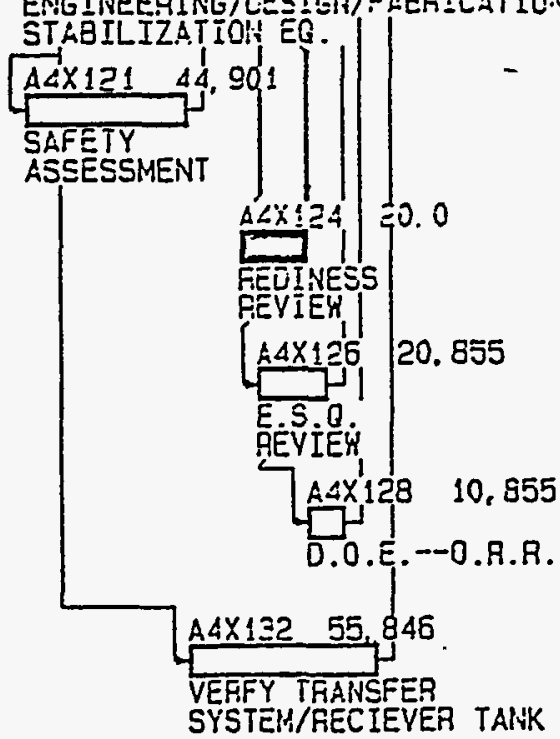

$4 . \bar{X} 110 \quad 15.857$

TANK INTAUSION/CHARACTERIZATION

VERIFY. 


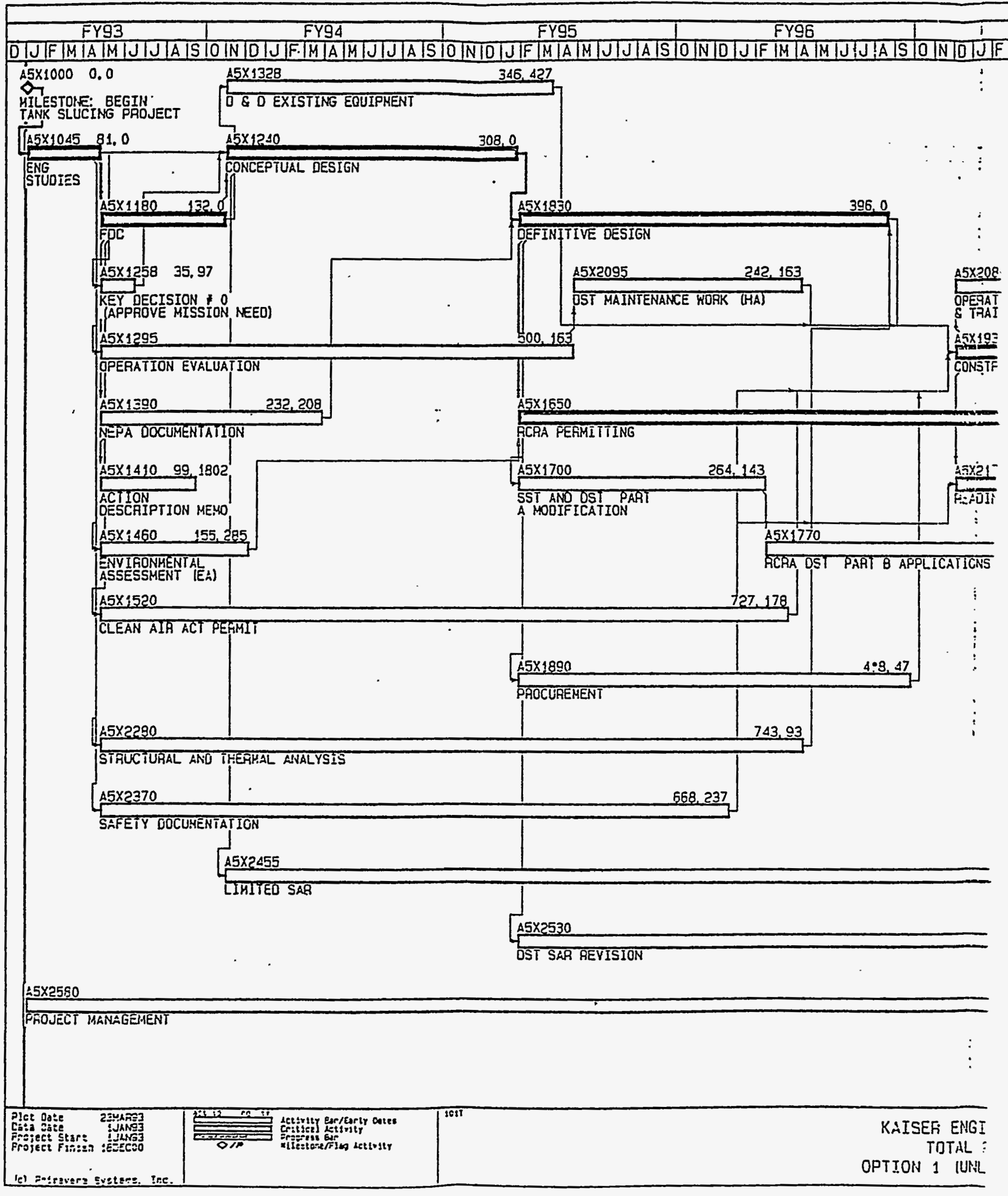




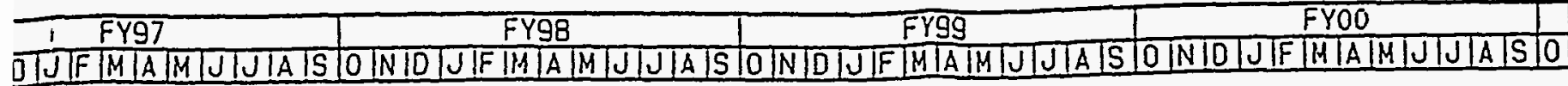

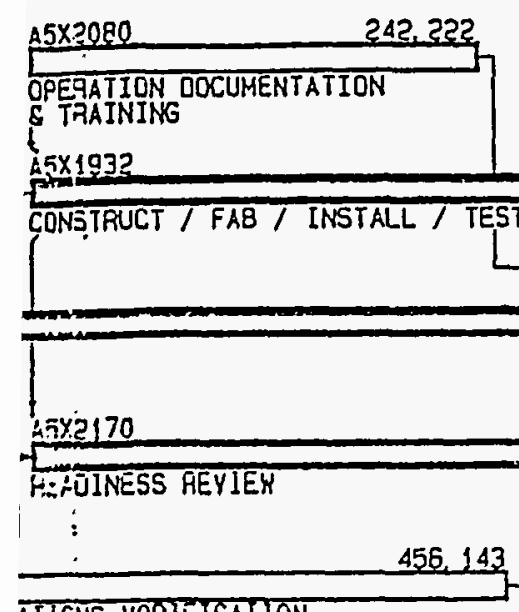

TIICNS MOOIFICATION

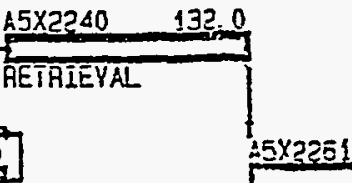


FY93

FYO4

FYS5

FY96

FYg7

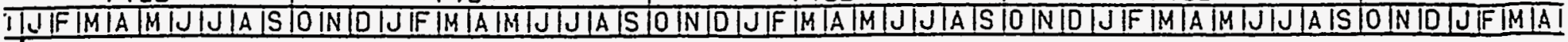
AБX1000 0.0

HILESTONE: GEGIN

TAANK SLUCLNG FADJECT

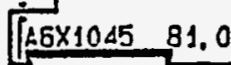

STUDIES

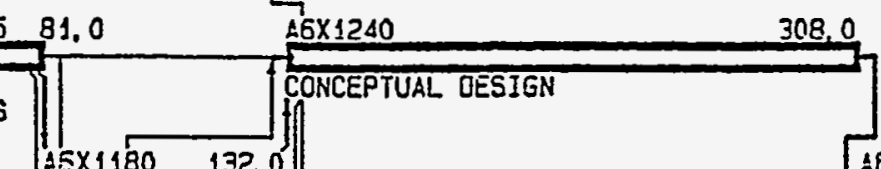

$15 \times 1180 \quad 132.0$

А6X1830

DEFINITIVE DESIGN

A6xi258 35.97

KEY DECISION *

(APPROVE MISSION NEED)

A6x1205

$A 6 \times 1328$

\begin{tabular}{|l|l|}
\hline A6Xj390 & 232.208 \\
\hline
\end{tabular}

NEPA GOCUMENTATION

AEX1410 g9, 182

ACTION

DEESCRIPTION MEMO

$60 \times 1460 \quad 155.270$

ETIVITONRENTAL

HEx $\times 1520$

CLEAN AIR ACT FEFHIT

A6 $20095 \cdot 245,116$

DST MAINTENANCE WORK (HA)

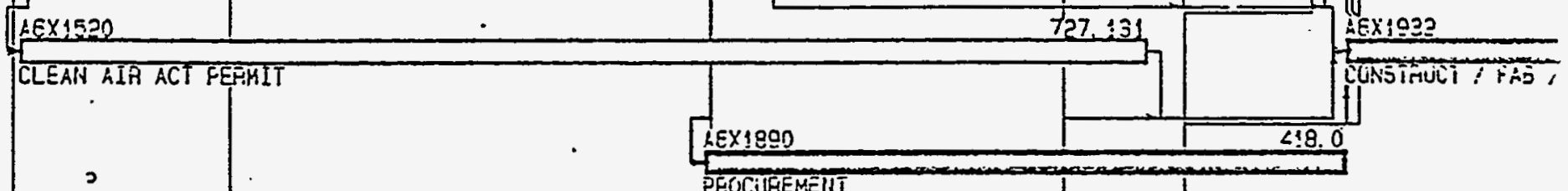

4 A $2 \times 2380$

PFOCUFEMEIIT

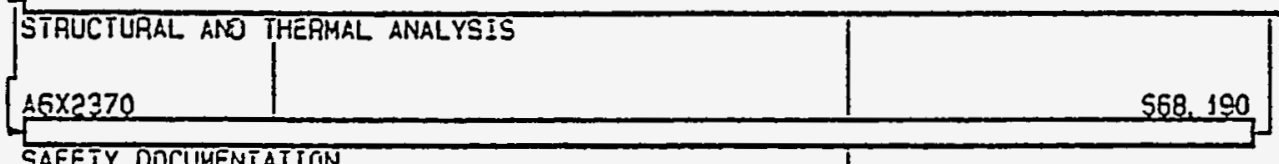

SAFETY DOCUMENTATION

$A$ EX2455

LIMITED SAR

$A E \times 2530$

DST SAR REYISION

$66 \times 2580$

PROJECT MANAGEMENT

Plot Gate 23rafg

Cot: Date

Frolect Star: ijunga

on

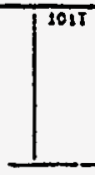

KAISER ENGINEE

TOTAL RETF

(e) In!raverz Evstase. tre.

OPTION 2 (LIMIT 
FY93

FY95

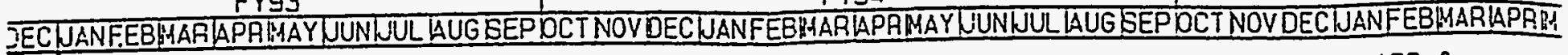

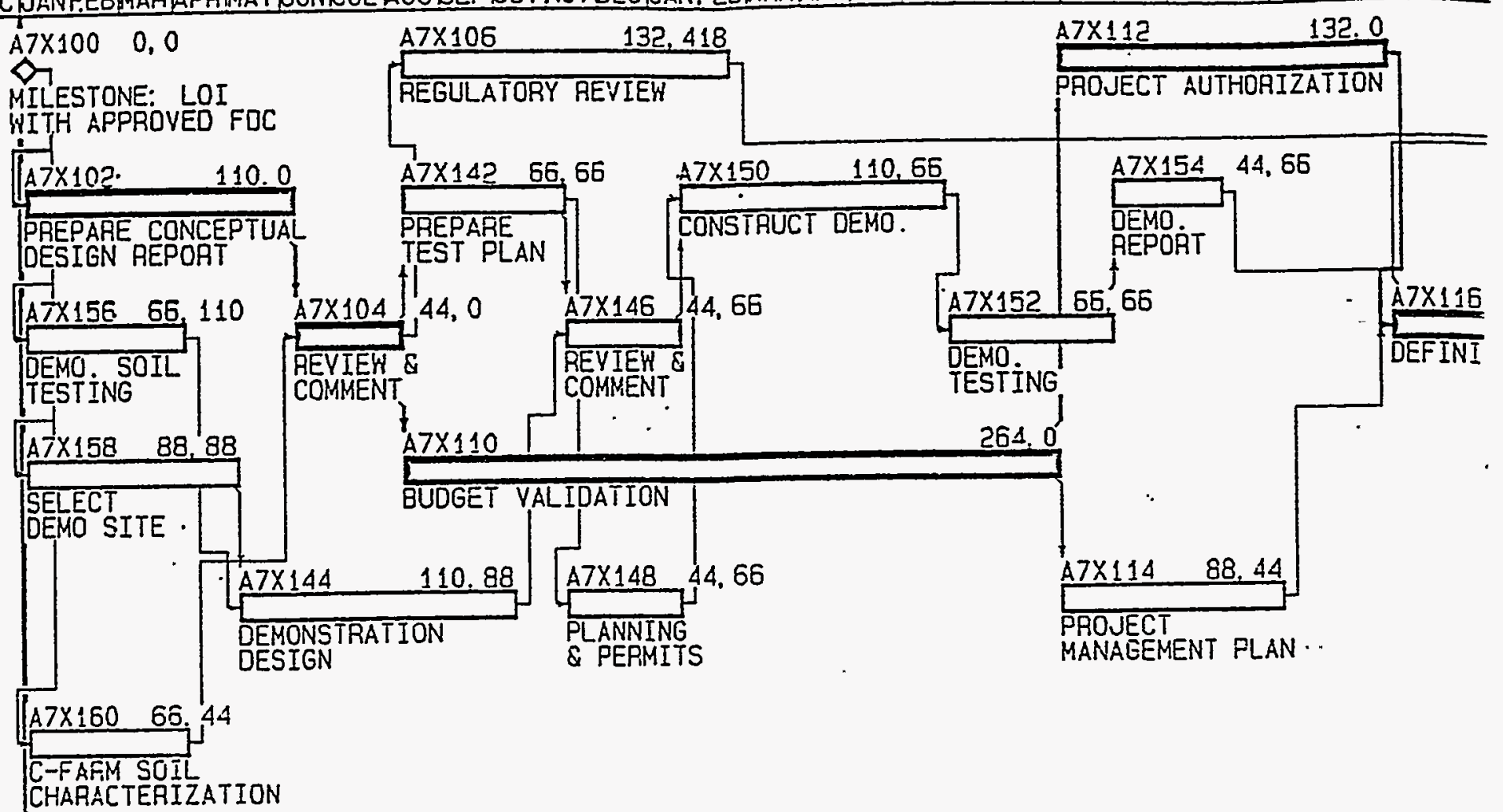

CHARACTERIZATION 
\begin{tabular}{l|ll}
\hline FY93 & $\cdots$ & FY94
\end{tabular}

FY95

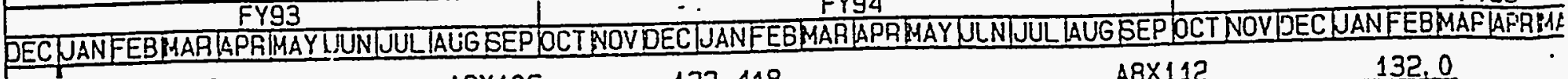

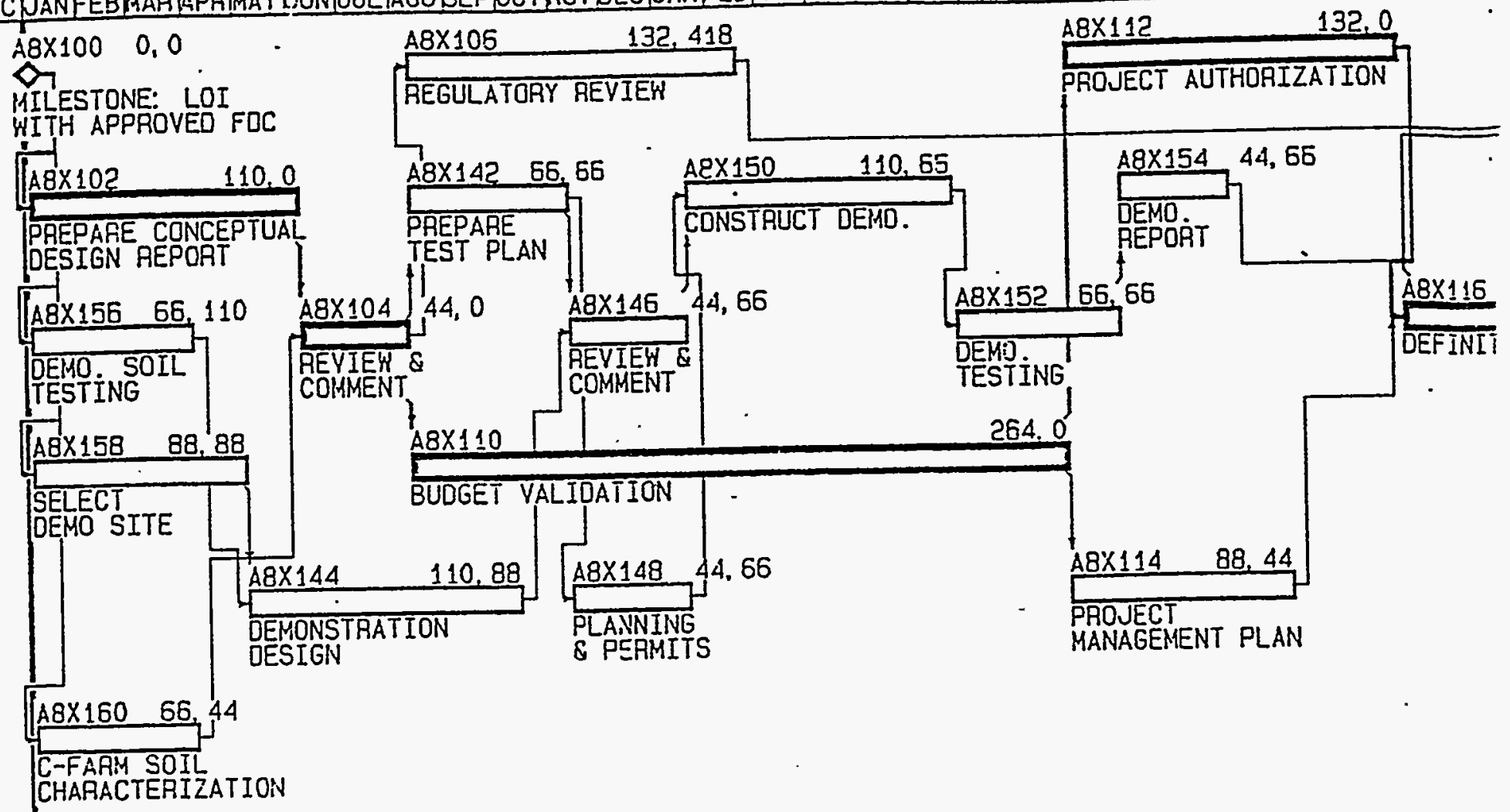




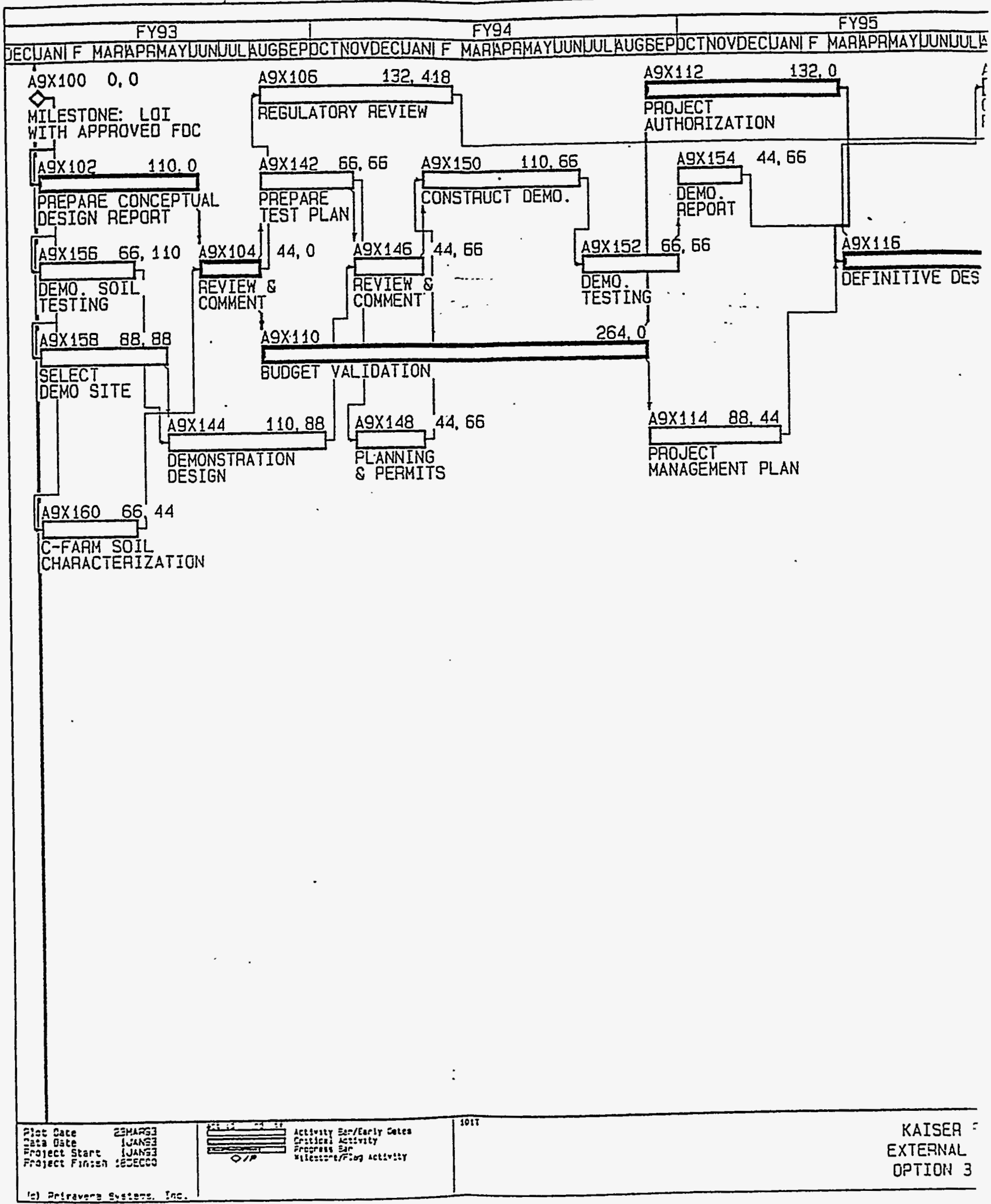




\section{$\because$}

\section{A9X118 22, 54}

CONSTAUCTIBILITY F.EVIEW 
COST DETAILS FOR SELECTED ALTERNATIVES

OPTION \#1 Pump Out -- Existing Piping A-15

OPTION \#2 Pump Out - New Piping A-22

OPTION \#3 Pump Out -- Tank Truck $\quad$ A-29

OPTION \#3A Pump Out - Railcar $\quad$ A-36

OPTION \#4 Pump Out -- Bladder • . A-43

OPTION \#1 Unlimited Sluicing . A-50

OPTION \#2 Limited Sluicing A-64

OPTION \#1 Geomembrane Walls/Jet Grouting . $\quad$ A-77

OPTION \#2 Slurry Walls/Jet Grouting $\quad$ A-86

OPTION \#3 Ground Freezing A-95 
KAISER ENGIHEERS HANFORD HESTINGHOUSE HANFORD COMPANY JOB HO. ER3415/241.T

FILE NO. 24 ITA
* IEST - IHIERACIIVE ESTIMATING * * ALTERNATIVES FOR SINGLE SHELL TANK 241-T-101 STUDY ESTIMATE - OPTION \#I PUMP OUT-EXISTING PIPING DOE_RO1 - PROJECT COST SUMMARY
PAGE 1 OF 7

DATE $03 / 22 / 93 \quad 09: 48: 38$

BY GDR

\begin{tabular}{|c|c|}
\hline$=====$ & 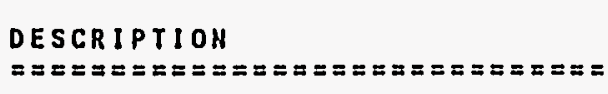 \\
\hline 000 & ENG I NEER ING \\
\hline 700 & SPECIAL EQUIP/PROCESS SYSTEMS \\
\hline 900 & HḦC "OTHER COST" \\
\hline
\end{tabular}

PROJECT TOTAL

\begin{tabular}{|c|c|c|c|}
\hline $\begin{array}{l}\text { ESCALATED } \\
\text { TOTAL COST } \\
======= \pm==\end{array}$ & $\begin{array}{l}\text {. } x^{\mathrm{COI}} \\
===2=\end{array}$ & $\begin{aligned} & \text { IGENCY } \text { TOTAL } \\
&== \pm=\approx= \pm===\end{aligned}$ & $\begin{array}{c}\text { TOTAL } \\
\text { DOLLARS } \\
===\approx E==z===\end{array}$ \\
\hline 610,000 & 20 & 120,000 & 730,000 \\
\hline 360,000 & 20 & 70,000 & 430,000 \\
\hline $1,020,000$ & 20 & 200,000 & $1,220,000$ \\
\hline$+10,000$ & & $+10,000$ & $+20,000$ \\
\hline
\end{tabular}

$1,200,000$

20

400,000

$2,400,000$

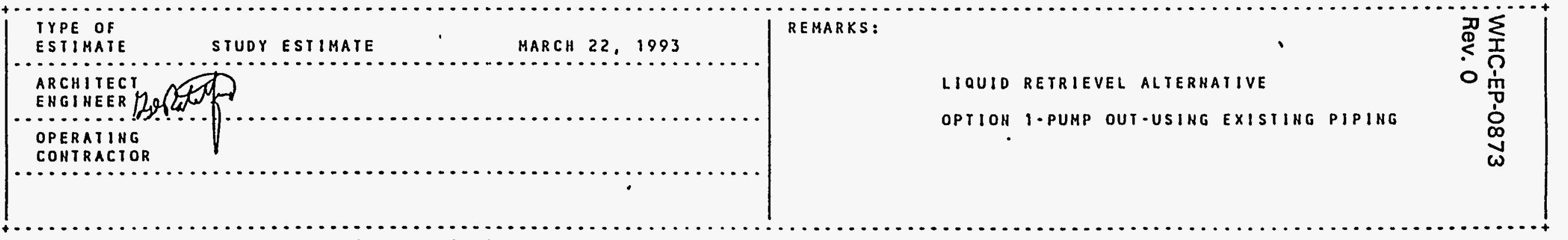

(ROUNDED/ADJUSTED TO THE NEAREST "10,000/100,000" - PERCEHTAGES HOT RECALCULATED IO REFLECT ROUHDING) 
KAISER ENGINEERS HANFORD

HESTINGHOUSE HANFORD COMPANY

JOB NO. ER3415/241-T

FILE NO. 241 TAI

HBS DESCRIPTION

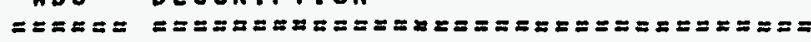

112000 HHC ENGINEERIHG

SUBTOTAL 1 ENGIHEERING

330002 HHC CONSTRUCTION

SUBTOTAL 33 CONSTRUCTIOH-O/C

SUBTOTAL 3 CONSTRUCTIOH

500001 WHC "OTHER PROJECT COST"

SUBTOTAL 5 OTHER.PROJECT COST

PROJECT TOTAL
* IEST - INTERACTIVE ESTIMATING * *

ALTERNATIVES FOR SIHGLE SHELL TANK 249-T-10

STUDY ESTIMATE - OPTION \#I PUMP OUT-EXISIING PIPING DOE ROZ - HORK BREAKDOHN STRUCTURE SUMMARY
PAGE 2 OF 7

DATE 03/22/93 09:48:42

BY GDR

\begin{tabular}{|c|c|c|c|c|c|c|c|c|}
\hline $\begin{array}{l}\text { ESTIMATE } \\
\text { SUB TOTAL } \\
==\approx=\approx==\approx\end{array}$ & $\begin{array}{l}\text { OHSITE } \\
\text { INDIRECTS } \\
==\approx==\approx=\approx\end{array}$ & $\begin{array}{c}\text { SUB } \\
\operatorname{TOYAL} \\
=======\end{array}$ & $==\approx \begin{array}{l}\text { ESCA } \\
X \\
===\end{array}$ & $\begin{array}{l}\text { LATION } \\
\text { TOTAL } \\
=======\end{array}$ & $\begin{array}{c}\text { SUB } \\
\operatorname{rOTAL} \\
=z==z===\end{array}$ & $\begin{array}{c}\text { CONT } \\
\% \\
=x===\end{array}$ & $\begin{array}{l}\text { I HGENCY } \\
\text { TOTAL } \\
========\end{array}$ & $\begin{array}{c}\text { TOTAL } \\
\text { DOLLARS } \\
========\end{array}$ \\
\hline 607100 & 20 & 607120 & 0.00 & 0 & 607120 & 20 & 121424 & 728544 \\
\hline 607100 & 20 & 607120 & 0.00 & 0 & 607120 & 20 & 121424 & 728544 \\
\hline 356500 & 20 & 356520 & 0.00 & 0 & 356520 & 20 & 71304 & 427824 \\
\hline 356500 & 20 & 356520 & 0.00 & 0 & 356520 & 20 & 71304 & 427824 \\
\hline 356500 & 20 & 356520 & 0.00 & 0 & 356520 & 20 & 71304 & 427824 \\
\hline 1015900 & 20 & 1015920 & 0.00 & 0 & 1015920 & 20 & 203184 & 1219104 \\
\hline 1015900 & 20 & 1015920 & 0.00 & 0 & 1015920 & 20 & 203184 & 1219104 \\
\hline
\end{tabular}

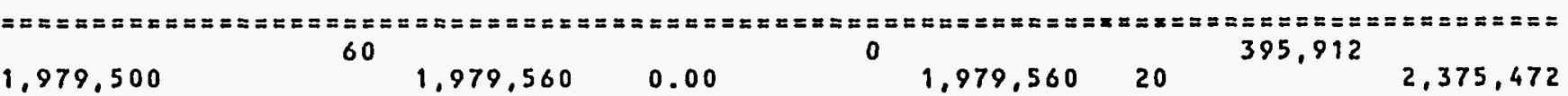


KAISER ENGIHEERS HANFORD

WEST INGHOUSE HANFORD COMPAHY

JOB NO. ER3415/241-T

FILE NO. 24 ITA
* * IEST - INTERACTIVE ESTIMATIHG * *

ALTERNATIVES FOR SINGLE SHELL TANK 241-T-101 STUDY ESTIMATE - OPTION \#I PUMP OUT-EXISTING PIPING DOE RO3 ESTIMATE BASIS SHEET
PAGE 3 OF 7

$03 / 22193 \quad 07: 25: 26$

1. DOCUMENTS AHD DRAHINGS

$==================$

DOCUMENTS: HANAGING THE ASSUMED LEAK FROM SINGLE-SHELL TANK 241-T-101, DATEO FEBRUARY 1993.

DRAHINGS: SKETCHES

2. MATERIAL PRICES .

$======== \pm== \pm=$

UHIT COSTS REPRESENT CURRENT PRICES FOR SPECIFIED MATERIAL.

3. LABOR RATES

$=E=\Sigma=\approx=\Sigma==z$

CURRENT KEH BASE CRAFT RATES, AS ISSUED BY KEH FINANCE (EFFECTIVE 10-01-92), INCLUDE FRINGE BENEFITS, LABOR INSURANCE, TAXES AND TRAVEL HHERE APPLICABLE, PER HANFORD SITE STABILIZATION AGREEMENT: APPENDIX A (EFFECTIVE Q- 2 -9I). NON CRAFT HOURLY RATES ARE BASED ON THE I993 FISCAL YEAR BUDGET LIOUIDATION RATES AS ISSUED BY KEII FIHANCE (EFFECTIVE IO-OI-92).

4. GENERAL REQUIREMENT'S/TECHNICAL SERVICES/OVERHEADS

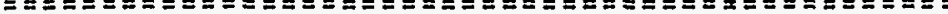

A.) ONSITE CONSTRUCTION FORCES GENERAL REQUIREMENTS, TECHNICAL SERVICES AND CRAFT OVERHEAD COSTS ARE INCLUDED AS A COMPOSITE PERCENTAGE BASED ON TIIE KEH ESTIMATING FACTOR/BILLING SCHEDULE, REVISION 14, DATED OCTOBER OI, 1992. THE TOTAL COMPOSITE PERCENTAGE APPLIED TO ONSITE CONSTRUCTION FORCES LABOR, FOR THIS PROJECT, IS 93\% FOR SHOP WORK AND $134 \%$ FOR FIELO WORK, HHICH IS REFLECTED IN THE "OH\&P/B\&I" COLUMN OF THE ESTIMATE DETAIL.

B.) COST TO COMPLETE AHD. COST TO DATE HERE PROVIDED BY HESTINGHOUSE HANFORD COMPANY AND INCLUDE ALL OVERHEAD MARKUPS.

5. ESCALATION

$== \pm====2$

ESCALATION PERCENTAGES HERE CALCULATED BY THE HANFORO MATERIAL \& LABOR ESCALATION STUDY, DATED FEBRUARY IQ92.

6. ROUNDING

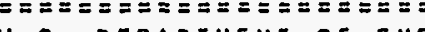

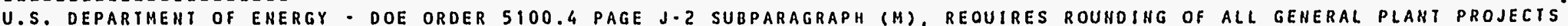

(GPPIS) AND LINE ITEM (LI) COST ESTIMATES. REFERENCE: DOE 5100.4, FIGURE 1-11, DATED 10-31-84.

7. REMARKS

$=====$

A.) COST DOES NOT INCLUDE REMOVAL OF EGUIPMENT AFTER TRANSFER.

B.) ESCALATION WAS NOT INCLUDED DUE TO PROJECT HILL BE FINISHED IN 1993.

C.) COST FOR ENGINEERING, CONSTRUCTION. AHD PROJECT OTHER COSI HAS FURNISHED BY WESTINGHOUSE. 
KAISER EHGIHEERS HANFORD HESTIHGHOUSE HANFORD COMPANY JOB HO. ER3415/241-T

FILE HO. 241 TAY

$\cos T$

CODE/HBS

DESCR IPTIOH

OOO ENGINEERING

112000 WHC ENGINEERIHG

TOTAL 000 ENGINEERIHG

700 SPECIAL EQUIP/PROCESS SYSTEMS

330002 HHC CONSTRUCTION

TOTAL 700 SPECIAL EQUIPIPROCESS SYSTEM 900 HHC "OTHER COST"

500001 HHC "OTHER PROJECT COST" TOTAL 900 HHC "OTHER COST"

PROJECT TOTAL
* IEST - INTERACIIVE ESTIMATIHg * *

ALTERHATIVES FOR SINGLE SHELL TAHK 241-T-101

STUDY ESTIMATE - OPTION \#1 PUMP OUT-EXISTING PIPING

DOE_RO4 - COST CODE ACCOUNT SUMMARY

\begin{tabular}{|c|c|c|c|c|c|c|}
\hline $\begin{array}{l}\text { STIRATE } \\
\text { UBTOTAL } \\
=======\end{array}$ & $\begin{array}{l}\text { ONS ITE } \\
\text { INDIRECTS } \\
========\end{array}$ & $\begin{array}{c}\text { SUB } \\
\text { TOTAL } \\
=\approx=\approx=\approx=\Sigma=\end{array}$ & $\begin{array}{c}\text { ESCALATIOH } \\
\% \text { TOTAL } \\
=z=z x=z==z==z\end{array}$ & $\begin{array}{c}\text { SUB } \\
\operatorname{TOTAL} \\
==\approx===x=\end{array}$ & $\begin{array}{l}\text { CONTINGENCY } \\
z \text { TOTAL } \\
z=z=z \quad=z=z=z==\end{array}$ & $\begin{array}{c}\text { TOTAL } \\
\text { DOLLARS } \\
=== \pm= \pm=x\end{array}$ \\
\hline
\end{tabular}

$\begin{array}{lllllllll}607100 & 20 & 607120 & 0.00 & 0 & 607120 & 20 & 121424 & 728544 \\ 607100 & 20 & 607120 & 0.00 & 0 & 607120 & 20 & 121424 & 728544 \\ 356500 & 20 & 356520 & 0.00 & 0 & 356520 & 20 & 71304 & 427824 \\ 356500 & 20 & 356520 & 0.00 & 0 & 356520 & 20 & 71304 & 427824\end{array}$

$\begin{array}{lllllllll}1015900 & 20 & 1015920 & 0.00 & 0 & 1015920 & 20 & 203184 & 1219104 \\ 10.15900 & 20 & 1015920 & 0.00 & 0 & 1015920 & 20 & 203184 & 1219104\end{array}$

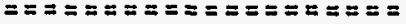

$1,979,500$
$1,979,560 \quad 20$
395,912
PAGE 4 OF 7

BY GDR
DATE $03 / 22 / 93 \quad 09: 48: 47$ 
KAISER ENGINEERS HANFORD HESTINGHOUSE HANFORD COMPANY JOB HO. ER3415/241.T

FILE HO. 24 ITAI

\section{CSI DESCRIPTIOH}

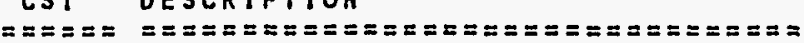

ENGINEERING

OO TECHNICAL SERVICES

TOTAL ENGINEERING

COHSTRUCTION

15 HECHANICÁL

20 OTHER COST

TOTAL CONSTRUCTION

PROJECT TOTAL
* IEST - IHTERACTIVE ESTIHATING **

ALTERNATIVES FOR SINGLE SHELL TANK 241-T-101 STUOY ESTIHATE - OPTION \#I PUMP OUT-EXISTING PIPING

DOE ROS - ESTIMATE SUMMARY BY CSI DIVISIOM
PAGE 5 OF 7

DATE 03/22/93 09:48:50

BY

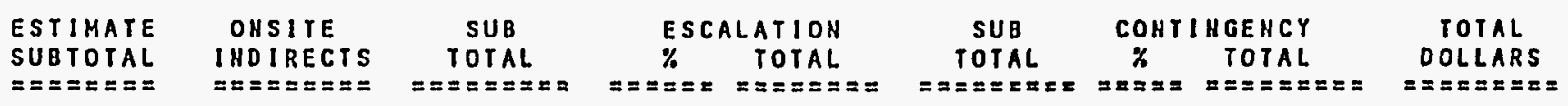

$== \pm==$ $=z== \pm=z==$ $== \pm=\approx \approx=a$

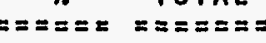
$=\equiv=\geq=2 \pm x=$

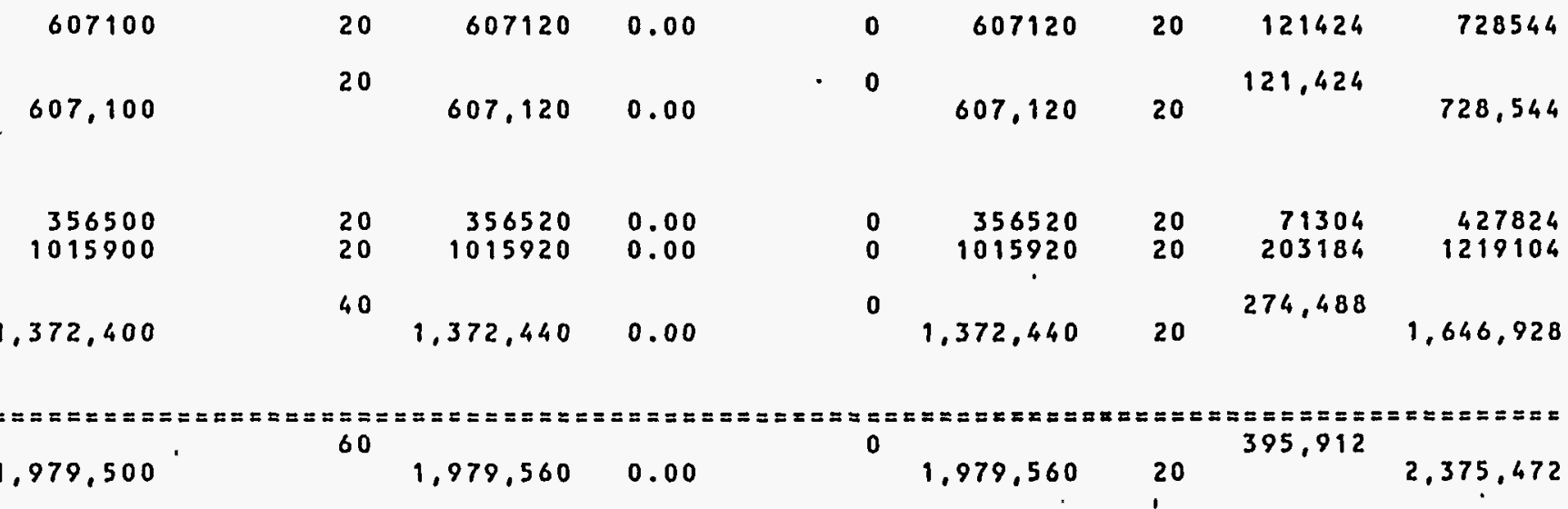


KAISER ENGIHEERS HAHFORD HESTIHGHOUSE HANFORD COMPANY JOB NO. ER3415/241-T

FILE NO. 241 TA
* IEST - INTERACTIVE ESTIMATING * * ALTERNATIVES FOR SINGLE SHELL TANK 241-T-101 STLDY ESTIMATE. OPTION HI PUMP OUT EXISTING PIPING DOE RO6 - CONTINGENCY ANALYSIS BASIS SHEET
PAGE 6 OF 7

DATE $03 / 22 / 93 \quad 07: 25: 31$

BY GDR

$\begin{array}{lll}\text { REFERENCE: } & \text { ESTIMATE BASIS SHEET } & \text { PAGE } 3 \text { OF } 7 \\ & \text { COST CODE ACCOUHT SUMMARY } & \text { PAGE } 5 \text { OF } 7\end{array}$

THE U.S. DEPARTMENT OF ENERGY - RICHLAND ORDER 5700.3 "COST ESTIMATING, ANALYSIS AHD STANDARDIZATIOH" DATED 3-27-85, PROVIDES GUIDELIIIES FOR ESTIMATE CONTIMGENCIES. THE GUIDELIME FOR A STUOY ESTIMATE SHOULD HAVE AN OVERALL RANGE OF 20 TO $35 \%$.

CONTINGENCY IS EVALUATED AT THE THIRD COST CODE LEVEL AND SUMMARIZED AT THE.PRIMARY AND SECONOARY COST CODE LEVEL OF THE DETAILED COST ESTIIIATE.

ENGINEERINO

000 HBS 112000 A $20 \%$ CONTINGENCY WAS APPLIED TO ENGINEERING PER HHC.

CONSTRUCTION

700 HAS 330002 A $20 \%$ CONTINGENCY HAS USED ON CONSTRUCTION BY HHC DUE TO THE HORK

BEING PERFORMED IS IN A HAZARDOUS ZONE.

HHC "OTHER COST"

900 HBS 500001 A $20 \%$ CONTINGENCY HAS APPLIED TO "OTHER PROJECT COST" PER HHC. 
KAISER ENGINEERS HANFORD WESTINGHOUSE HANFORD COMPANY JOB HO. ER3415/241-T

FILE HO. 24 ITA

YBS

WBS

112000 HHC ENGIHEERING

330002 HHC CONSTRUCTION

500001 HHC "OTHER PROJECT COST"

PROJECT TOTAL
* * IEST - INTERACTIVE ESTIMATING * *

ALTERHATIVES FOR SINGLE SHELL TAHK 241-T-101

STUDY ESTIMATE - OPIION \#I PUMP OUT-EXISTIHG PIPING

DOE ROT - ONSITE INDIRECT COSTS BY HBS

\begin{tabular}{|c|c|c|}
\hline $\begin{array}{l}\text { ESTIMATE } \\
\text { SUBTOTAL } \\
====== \pm\end{array}$ & $\begin{array}{r}\text { CONTRACT } \\
\% \\
=====\end{array}$ & $\begin{array}{c}\text { ADMINISTRATION } \\
\text { TOTAL } \\
=x=x=x=\end{array}$ \\
\hline $\begin{array}{r}607100 \\
356500 \\
1015900\end{array}$ & $\begin{array}{l}0.00 \\
0.00 \\
0.00\end{array}$ & $\begin{array}{l}0 \\
0 \\
0\end{array}$ \\
\hline
\end{tabular}

BID PACK

PREP.

$======2$

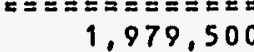

0
PAGE 7 OF 7

DATE $03 / 22 / 9309: 48: 56$

BY GDR

OTHER

I HDIRECTS

TOTAL

I NDIRECTS $z=z=z==\approx$

\section{20}

20
20

20

20
60 
KAISER ENGINEERS HAHFORD

HESTI HGHOUSE HANFORD COMPANY

JOB HO. ER3415/241-T

FILE HO. ZOSISABI
* IEST - INTERACTIVE ESTIHATIHG * ALTERNATIVES FOR SINGLE SHELL TAHK 241-T-101 STUDY ESTIMATE - OPTION \#2 PUMP OUT-HEH PIPIHG DOE_RO1 - PROJECT COST SUMMARY
PAGE 1 OF 7

DATE $03 / 23 / 93 \quad 10: 37: 52$

BY GDR

\begin{tabular}{|c|c|}
\hline $\begin{array}{l}C O D E \\
=x=2\end{array}$ & 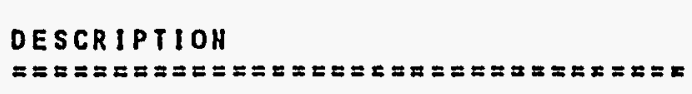 \\
\hline 000 & ENGINEER ING \\
\hline 700 & SPECIAL EQUIP/PROCESS SYSTEMS \\
\hline 900 & HHC "OTHER COST" \\
\hline
\end{tabular}

PROJECT TOTAL

\begin{tabular}{|c|c|c|c|}
\hline $\begin{array}{l}\text { ESCALATED } \\
\text { TOTAL COST } \\
=\approx==\approx=\approx z=z\end{array}$ & $=x^{\cos }$ & $\begin{array}{l}\text { GENCY } \\
\text { TOTAL } \\
========2=\end{array}$ & $\begin{array}{c}\text { TOTAL } \\
\text { DOLLARS } \\
=x=x=x=x=z=\end{array}$ \\
\hline $1,640,000^{\circ}$ & 26 & 420,000 & $2,060,000$ \\
\hline $2.690,000$ & 29 & 770,000 & $3,460,000$ \\
\hline $2,230,000$ & 22 & 500,000 & $2,730,000$ \\
\hline$+40,000$ & & $+10,000$ & $+50,000$ \\
\hline
\end{tabular}
$6,600,000$
26
$1,700,000$
$8,300,000$

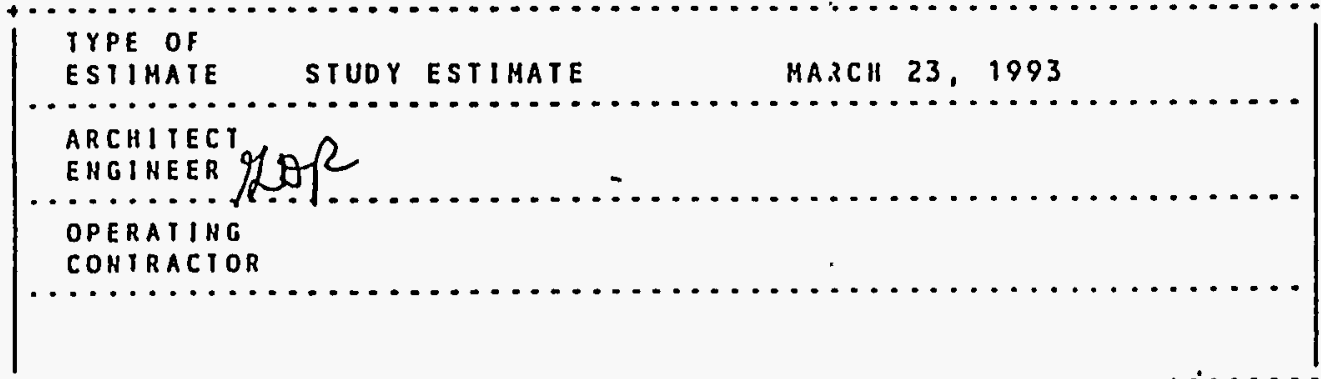

REMARKS :

LIOUID RETRIEVAL ALTERNATIVES

OPIION \#2-PUHP OUT-USING HEH PIPE 
KAISER ENGINEERS HANFORD

HESTIHGHOUSE HANFORD COMPAHY

JOB HO. ER3415/241.T

FILE HO. 203ISAB

HBS DESCRIPTIOH

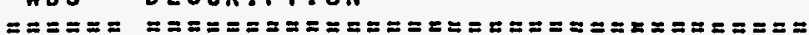

110000 DEFIHITIVE DESIGH (OHSITE)

111000 CONCEPTUAL DESIGN (OHSITE)

112000 HHC ENGINEERING

120000 ENGINEERING INSPECTION (ONSITE)

SUBTOTAL 12 ENGR/IHSPECTION (ONSITE)

SUBTOTAL 1 ENGINEERING

310001 TRANSFER LINE TO $244-T X$ VAULT

SUBTOTAL 31 FA CONST-ONSITE E/C

330009 HHC CONSTRUCTION

SUBTOTAL 33 CONSTRUCTION-O/C

SUBTOTAL 3 CONSTRICTION

500001 HHC OTHER PROJECT COST

500003 WHC "OTHER COST" FOR KEH COHST.

SUBTOTAL 5 OTHER PROJECT COST

PROJECT TOTAL
* * IEST - INTERACTIVE ESTIMATING *

ALTERHATIVES FOR SINGLE SHELL TAHK 241-T-101 \$TUDY ESTIHATE - OPIION \#2 PUMP OUT-HEH PIPING DOE RO2 - HORK BREAKDOHH STRUCTURE SUMHARY
PAGE 2 OF 7

DATE $03 / 23 / 93 \quad 10: 37: 56$

BY GDR

\begin{tabular}{|c|c|c|c|c|c|c|c|c|}
\hline $\begin{array}{l}\text { ESTIMATE } \\
\text { SUB TOTAL } \\
=======\end{array}$ & $\begin{array}{l}\text { ONSITE } \\
\text { INDIRECTS } \\
===\approx====\end{array}$ & $\begin{array}{c}\text { SUB } \\
\operatorname{TOYAL} \\
=z=z=z=z\end{array}$ & $=\underset{X}{E S C A}$ & $\begin{array}{l}\text { ILATION } \\
\text { TOTAL } \\
=x==x=x=\end{array}$ & $\begin{array}{c}\text { SUB } \\
\text { TOTAL } \\
===x= \pm x=x\end{array}$ & $\begin{array}{l}\text { COHTI } \\
x \\
=x=2=\end{array}$ & $\begin{array}{l}\text { I HGENCY } \\
\text { TOTAL } \\
=========\end{array}$ & $\begin{array}{c}\text { TOTAL } \\
\text { DOLLARS } \\
==\approx x==\approx=\end{array}$ \\
\hline $\begin{array}{l}515000 \\
135000 \\
607100 \\
200000\end{array}$ & $\begin{array}{r}0 \\
0 \\
121420 \\
0\end{array}$ & $\begin{array}{l}515000 \\
135000 \\
728520 \\
200000\end{array}$ & $\begin{array}{r}6.68 \\
2.46 \\
0.00 \\
13.11\end{array}$ & $\begin{array}{r}34402 \\
3321 \\
0 \\
26220\end{array}$ & $\begin{array}{l}549402 \\
138321 \\
728520 \\
226220\end{array}$ & $\begin{array}{l}30 \\
30 \\
20 \\
30\end{array}$ & $\begin{array}{r}164821 \\
41496 \\
145704 \\
67866 .\end{array}$ & $\begin{array}{l}714223 \\
179817 \\
874224 \\
294086\end{array}$ \\
\hline 200000 & 0 & 200000 & 13.11 & 26220 & 226220 & 30 & 67866 & 294086 \\
\hline 1457100 & 121420 & 1578520 & 4.05 & 63943 & 1642463 & 26 & 419887 & 2062350 \\
\hline 2058772 & 0 & 2058772 & 9.79 & 201554 & 2260326 & 30 & 684067 & 2944392 \\
\hline 2058772 & 0 & 2058772 & 9.79 & 201554 & 2260326 & 30 & 684067 & 2944392 \\
\hline 356500 & 71300 & 427800 & 0.00 & 0 & 427800 & 20 & 85560 & 513360 \\
\hline 356500 & 71300 & 427800 & 0.00 & 0 & 427800 & 20 & 85560 & 513360 \\
\hline 2415272 & 71300 & 2486572 & 8.11 & 209554 & 2688126 & 29 & 769627 & 3457752 \\
\hline $\begin{array}{r}1015900 \\
945000\end{array}$ & $\begin{array}{r}203180 \\
0\end{array}$ & $\begin{array}{r}1219080 \\
945000\end{array}$ & $\begin{array}{l}0.00 \\
7.49\end{array}$ & $\begin{array}{r}0 \\
70781\end{array}$ & $\begin{array}{l}1219080 \\
1015781\end{array}$ & $\begin{array}{l}20 \\
25\end{array}$ & $\begin{array}{l}243816 \\
253945\end{array}$ & $\begin{array}{l}1462896 \\
1269726\end{array}$ \\
\hline 1960900 & 203180 & 2164080 & 3.27 & 70781 & 2234861 & 22 & 497761 & 2732622 \\
\hline
\end{tabular}


KAISER ENGIHEERS HANFORD HESTINGHOUSE HAHFORD COMPANY JOB 10 OR $3415 / 241-T$

FILE NO. 24 ITA2
* * IEST - INTERACTIVE ESTIMATING * * ALTERNATIVES FOR SINGLE SHELL TANK $249-T \cdot 101$ STUDY ESTIMATE - OPTION HZ PUMP OUT-HEN PIPING DOE_RO3 - ESTIMATE BASIS SHEET
PAGE 3 OF 7

DATE $03 / 22 / 93 \quad 13: 36: 15$ BY GDR

1. DOCUMENTS AND DRAHINGS

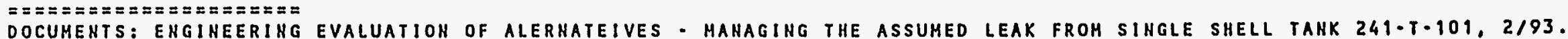
DRAWINGS: SKETCHES

2. MATERIAL PRICES. $==\equiv=======\equiv===$ UNIT COSTS REPRESENT CURRENT PRICES FOR SPECIFIED MATERIAL.

3. LABOR RATES

$==\Sigma====\Sigma=\Sigma$

CURRENT KEH' BASE CRAFT RATES, AS ISSUER BY KEH FINANCE (EFFECIIVE 10-01-92), INCLUDE FRINGE BENEFITS, LABOR INSURANCE, TAXES AND TRAVEL HHERE APPLICABLE. PER HANFORD SITE STABILIZATION AGREEMEHT, APPENDIXA (EFFECTIVE Q-2-91). NON CRAFT

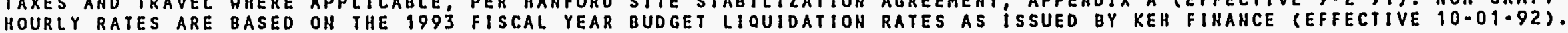

4. GENERAL REQUIREMEHTS/TECHNICAL SERVICES/OVERHEADS A

A.) ONSITE CONSTRUCTION FORCES GENERAL REQUIREMENTS, TECHNICAL SERVICES AHD CRAFT OVERHEAD COSTS ARE IHCLUDED AS A COMPOSITE PERCENTAGE BASED ON THE KEH ESTIMATING FACTOR/BILLING SCHEDULE, REVISIOH 14, DATED OCTOBER OI, 1992. THE TOTAL COMPOSITE PERCENTAGE APPLIED TO ONSITE CONSTRUCTIOH FORCES LABOR, FOR THIS PROJECT, IS $93 \%$ FOR SHOP HORK AND $134 \%$ FOR FIELO WORK, HHICH IS REFLECTED IN THE "OH\&P/B\&I" COLUMH OF THE ESTIMATE DETAIL.

B.) WHC COST INCLUDED ALL ADDERS - ORG, G A, AND CSP.

5. ESCALATION

$==\Sigma======$

ESCALATION PERCENTAGES HERE CALCULATED BY THE IIANFORD MATERIAL \& LABOR ESCALATION STUDY, DATED FEBRUARY I992.

6. ROUNDING

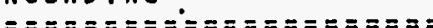

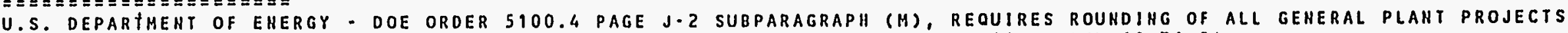
(GPP.S) AND LIHE ITEM (LI) COST ESIIMATES. REFERENCE: DOE 5100.4, FIGURE 1-11, DATED 10.31-84.

7. REMARKS

$=\Sigma= \pm==$

A.) WESTINGHOUSE ENGIMEERING, CONSTRUCTION, AND PROJECT OIHER COST HERE FURNISHED BY HESTINGHOUSE.

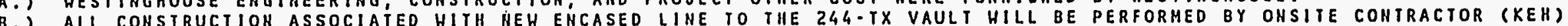

C.) HBS 500003 "OTHER COST" EOR THE. HHC COST ASSOCIATED HITH THE HEH ENCASED LINE TO 244 -TX VAULT IS BASED OH $35 \%$ DF KEH ENGIHEERIHG AND COHSTRUCTIOH BASIS COST BY HHC ON SIMILAR PROJECT (C-106).

D. KEII DEFINITIVE DESIGN IS.BASED ON $25 \%$ OF DIRECT ONSITE CONSTRUCTION

E ) KEH ENGINEERING AND INSPECTION IS BASED ON IO\% OF DIRECT ONSITE CONSTRUCTION

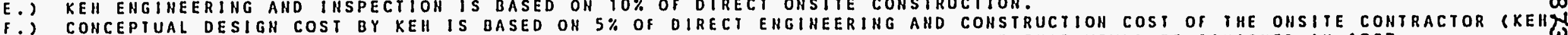

G.) ESCALATION WAS HOT APPLIED TO EHGINEERING, CONSTRUCIION, AND HHC OTHER COST THAT HOULD BE FINISHED IN I993. 
KAISER ENGINEERS HANFORD

HESTINGHOUSE HANFORD COMPANY

JOB NOER3415/241-T

FILE HO. ZOSISABI

$\cos T$

CODE/HBS

DESCR IPTION

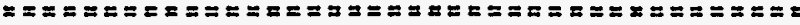

OOO EHGINEERING

110000 DEFINITIVE DESIGN (ONSITE)

111000 CONCEPTUAL DESIGN (ONSITE)

112000 HHC ENGIHEERIHG

120000 EHGINEERING INSPECTION (ONSITE)

TOTAL OOO ENGINEERING

700 SPECIAL EQUIP/PROCESS SYSTEHS

310001 TRAHSFER LINE TO 244-TX VAULT

330001 HHC CONSTRUCTIOH

TOTAL 700 SPECIAL EQUIPIPROCESS SYSYEM

900 HHC "OTHER COST"

500001 HHC OTHER PROJECT COST

500003 HHC "OTHER COST" FOR KEII CONST.

TOTAL 900 HHC "OTHER COST"

PROJECT TOTAL
* IEST - IHTERACTIVE ESTIMATIHG * *

ALTERHATIVES FOR SINGLE SHELL TAHK 249-T-101 DTITE - OPTIOH \#2 PUHP OUTDOE_RO4 - COST CODE ACCOUNT SUMHARY
PAGE 4 OF 7

DATE 03/23/93 10:38:01

BY GDR

\section{ESTIMATE \\ SUBTOTAL}

$z==z=\Sigma==$

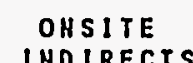

INDIRECTS

SUB
TOTAL

ESCALATION

$=\Xi \approx=\pi=\Xi=$ TOTAL

$=\Sigma=\Sigma= \pm x \approx$
SUB

CONTIRGEHCY

$X$ TOTAL

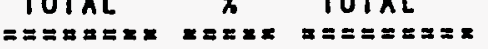

TOTAL DOLLARS

$==x=x=x$.

\section{0}

135000

607100

200000

0
0
121420
0

515000

135000

728520

200000

$6.68 \quad 34402$

2.46

0.00

13.11

1457100

121420

1578520

4.05

3321
26220

549402
138321

728520

226220

30

30
20

30

63043

1642463

26

164821

49496

145704

67866

419887

714223

9817

874224

294086

2062350

2058772
356500

2415272

$\begin{array}{rr}0 & 2058772 \\ 71300 & 427800 \\ 71300 & 2486572\end{array}$

9.79
0.00

201554

226032

8.11201554

427800

2688126

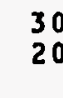

30
20

684067

85560

769627

2944392

513360

.

1015900
945000

$203180 \quad 1219080$

0.00

1960900

$203180 \quad 2164080$

7.49

7078

70781

1219080

1015781

2234869

20

25

243816

253945

497761

3457752

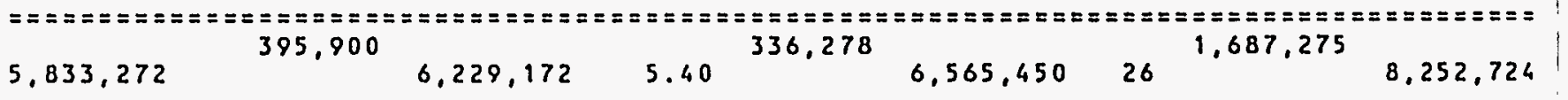


KAISER ENGINEERS HANFORD HESTINGHOUSE HAHFORD COMPANY JOB NO. ER3415/241-T

FILE HO. ZOSISABI

\section{CSI OESCRIPTION}

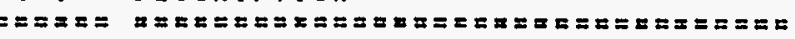

\section{ENGINEERING}

OO TECHHICAL SERVICES

TOTAL EHGIHEERING

\section{CONSTRUCTION}

\section{I5 MECHANICAL \\ 20 HHC OTHER COST}

TOTAL CONSTRUCTION

PROJECT TOTAL
* IEST - INTERACTIVE ESTIMATIHG * *

ALTERNATIVES FOR SINGLE SHELL TANK 249-T-101 STUDY ESTIMATE - OPTION HZ PUMP OUT-NEH PIPING

DOE ROS - ESTIMATE SUMHARY BY CSI DIVISION
PAGE 5 OF 7

DATE 03/23/93 10:38:06

BY GDR

\begin{tabular}{|c|c|c|c|c|c|c|c|c|}
\hline $\begin{array}{l}\text { ESTIMATE } \\
\text { SUB TOTAL } \\
=====x=2\end{array}$ & $\begin{array}{l}\text { ONSITE } \\
\text { INDIRECTS } \\
=\approx== \pm=x=\end{array}$ & $\begin{array}{c}\text { SUB } \\
\operatorname{TOTAL} \\
=\approx==\varepsilon=x=x\end{array}$ & 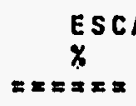 & $\begin{array}{l}\text { ALATION } \\
\text { TOTAL } \\
=x=x=x=x\end{array}$ & $\begin{array}{c}\text { SUB } \\
\text { TOTAL } \\
x=x=x=x=x\end{array}$ & $\begin{array}{l}\text { CONT } \\
x= \pm=\pi\end{array}$ & $\begin{array}{l}\text { I HGEHCY } \\
\text { TOTAL. } \\
z=z=z==x=\end{array}$ & $\begin{array}{c}\text { TOTAL } \\
\text { DOLLARS } \\
=x=x=x=x=\end{array}$ \\
\hline 1457100 & 121420 & 1578520 & 4.05 & 63943 & 1642463 & 26 & 419887 & 2062350 \\
\hline $1.457,100$ & 121,420 & $1,578,520$ & 4.05 & 63,943 & $1.642,463$ & 26 & 419,887 & $2,062,350$ \\
\hline $\begin{array}{l}2415272 \\
1960900\end{array}$ & $\begin{array}{r}71300 \\
203180\end{array}$ & $\begin{array}{l}2486572 \\
2164080\end{array}$ & $\begin{array}{l}8.11 \\
3.27\end{array}$ & $\begin{array}{r}201554 \\
70781\end{array}$ & $\begin{array}{l}2688126 \\
2234861\end{array}$ & $\begin{array}{l}29 \\
22\end{array}$ & $\begin{array}{l}769627 \\
497761\end{array}$ & $\begin{array}{l}3457752 \\
2732622\end{array}$ \\
\hline $4,376,172$ & 274,480 & $4.650,652$ & 5.86 & 272,335 & $4,922,987$ & 26 & $1,267,388$ & $6,190,374$ \\
\hline
\end{tabular}

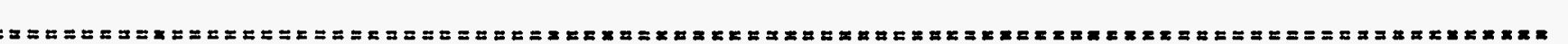

\begin{tabular}{|c|c|c|c|c|}
\hline $5,833,272$ & 6.229 .172 & 5.40 & $6,565,450$ & $8,252,724$ \\
\hline
\end{tabular}


KAISER EHGINEERS HAHFORD WESTIHGHOUSE HAHFORD COMPANY JOB HO. ER3415/241.

FILE NO. $241 T$ TA2
* IEST - INTERACTIVE ESTIMATING * *

ALTERNATIVES FOR SIHGLE SHELL TAHK 241-T-101

STUDY ESTIMATE - OPTIOH HZ PUHP OUT-NEY PIPING.

DOE ROG - CONTINGENCY AHALYSIS BASIS SHEET
PAGE 6 OF 7

DATE $02 / 23 / 93 \quad 13: 36: 23$

BY GDR
REFERENCE: ESTIMATE BASIS SHEET

COST CODE ACCOUNT SUMMARY
PAGE 3 OF 7

PAGE 5 OF 7

THE U.S. DEPARTMENT OF ENERGY - RICHLAHD ORDER STOO.3 "COST ESTIMATING, AHALYSIS AHD STAHDARDIZATIONI DATED 3-27-85, PROVIDES GUIDELIHES FOR ESTIMATE CONTINGENCIES. THE GUIOELINE FOR A STUDY ESTIMATE SHOULD HAVE AN OVERALL RANGE OF 20 TO $35 \%$

CONTINGENCY IS EVALUATED AT THE THIRD COST CODE LEVEL AND SUMHARIZEO AT THE PRIHARY AHD SECONDARY COST CODE LEVEL OF THE DETAILED COST ESTIMATE.

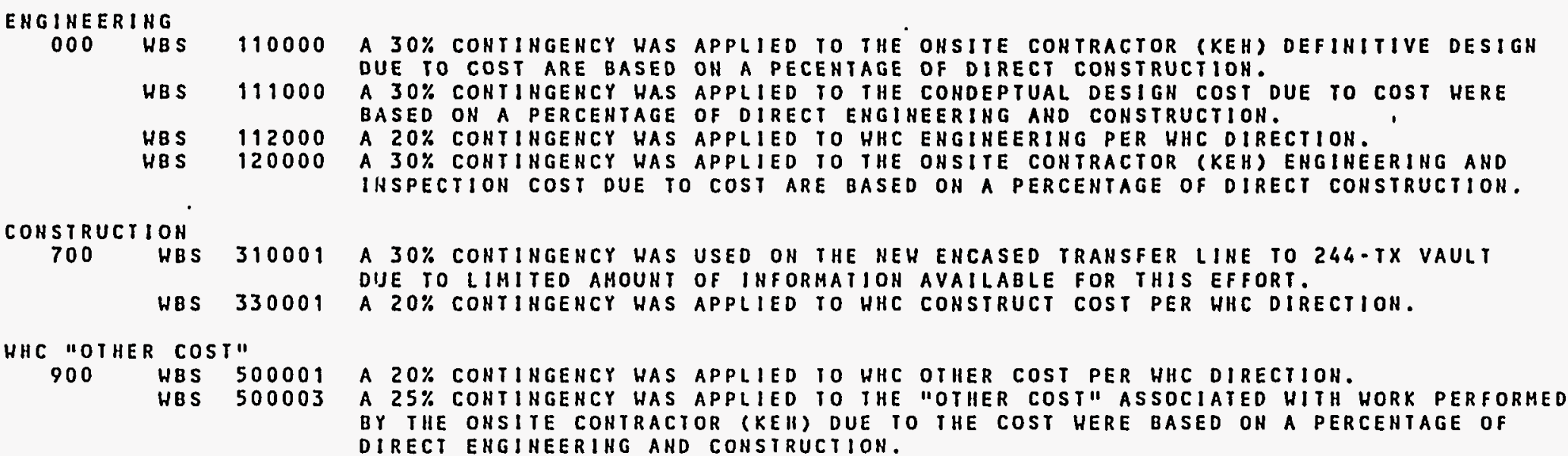

AVERAGE PROJECT CONTINGENCY $23 \%$ 
KAISER ENGINEERS HANFORD

HESTINGHOUSE HANFORD COMPANY

JOB HO. ER3415/241-T

FILE HO. ZOSISAB

\section{HBS}

OESCR IPT ION

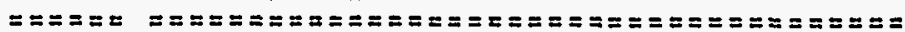

110000 DEFINITIVE DESIGH (OHSITE)

111000 CONCEPTUAL DESIGH (ONSITE)

12000 HHC ENGINEERINO

120000 ENGINEERIHG INS SCTION (ONSITE

310001 TRANSFER LINE TO 244 -TX VAULT

330009 HHC CONSTRUCTIOH

500001 HHC OTHER PROJECT COST

500003 HHC "OTHER COST" FOR KEH CONST.

PROJECT TOTAL
* IEST - INTERACTIVE ESTIMATING * * ALTERHATIVES FOR SINGLE SHELL TANK 241.T-101 STUDY ESTIMATE - OPTIOH \#2 PUMP OUT-HEH PIPING DOE_RO7 - ONSITE INDIRECT COSTS BY HBS

\begin{tabular}{|c|c|c|c|}
\hline $\begin{array}{l}\text { ESTIMATE } \\
\text { SUBTOTAL } \\
==\approx==\approx==\end{array}$ & $\begin{array}{c}\underset{\%}{\text { CONTRACT }} \\
====z\end{array}$ & $\begin{array}{c}\text { RDMINISTRATION } \\
\text { TOTAL } \\
===x===x=\end{array}$ & $\begin{array}{l}\text { BID PACK } \\
\text { PREP. } \\
======\equiv=\end{array}$ \\
\hline $\begin{array}{r}515000 \\
135000 \\
607100 \\
200000 \\
2058772 \\
356500 \\
1015900 \\
945000\end{array}$ & $\begin{array}{r}0.00 \\
0.00 \\
20.00 \\
0.00 \\
0.00 \\
20.00 \\
20.00 \\
0.00\end{array}$ & $\begin{array}{r}0 \\
0 \\
121420 \\
0 \\
0 \\
71300 \\
203180 \\
0\end{array}$ & $\begin{array}{l}0 \\
0 \\
0 \\
0 \\
0 \\
0 \\
0 \\
0\end{array}$ \\
\hline
\end{tabular}

PAGE 7 OF 7

DATE O3/23/93 10:38:10

BY GDR

OTHER
INDIRECTS
$x=x=x=x=$
0
0
0
0
0
0
0
0

TOTAL.

I HD IRECTS

$=\Sigma=\Sigma \Sigma=2 \approx x$

121420

1420
0
0

71300

203180

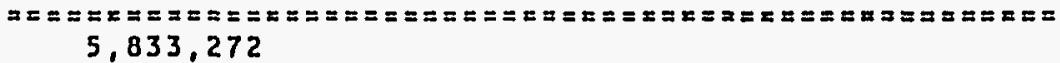

385,900
0

395,900 
KAISER EHGINEERS HAHFORD HESTIHGHOUSE HAHFORD COMPANY JOB NO. ER3415/241-T

FILE HO. ZO31SACI
* IEST - INTERACTIVE ESTIHATING * ALTERNATIVES FOR SIHGLE SHELL TAHK 241-T-109 STUDY ESTIMATE - OPTION \#3 PUMP OUT TAHK TRUCK DOE_RO1 - PROJECT COST SUMMARY
PAGE 1 OF 7

DATE $03 / 23 / 93 \quad 10: 48: 08$

BY GDR

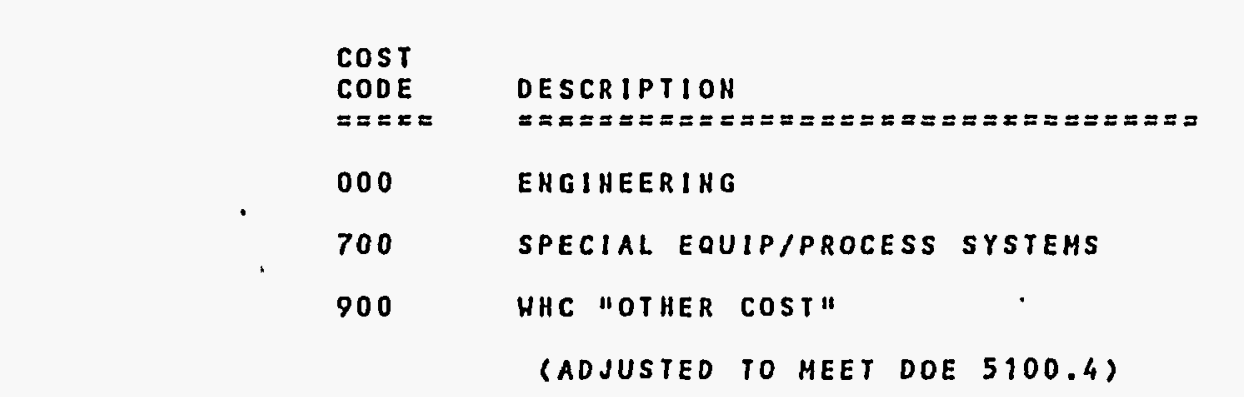

\begin{tabular}{|c|c|c|c|}
\hline $\begin{array}{l}\text { ESCALATED } \\
\text { TOTAL COST } \\
=========\end{array}$ & $=x^{\mathrm{COH}}$ & $\begin{array}{l}\text { IGEHCY } \\
\text { TOTAL } \\
=z===z====\end{array}$ & $\begin{array}{c}\text { TOTAL } \\
\text { DOLLARS } \\
==\equiv===\equiv=x==\end{array}$ \\
\hline $1,340,000$ & 25 & 330,000 & $1,670,000$ \\
\hline $1,900,000$ & 32 & 600,000 & $2,500,000$ \\
\hline $1,990,000$ & 20 & 380,000 & $2,290,000$ \\
\hline$+50,000$ & & $-10,000$ & $+40,000$ \\
\hline \multicolumn{4}{|c|}{ 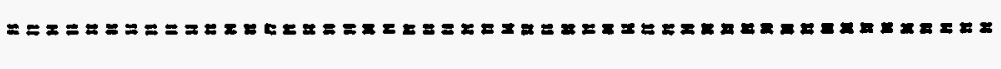 } \\
\hline $5,200,000$ & 25 & $1,300,000$ & $6,500,000$ \\
\hline
\end{tabular}

PROJECT TOTAL

$1,300,000$

$6,500,000$

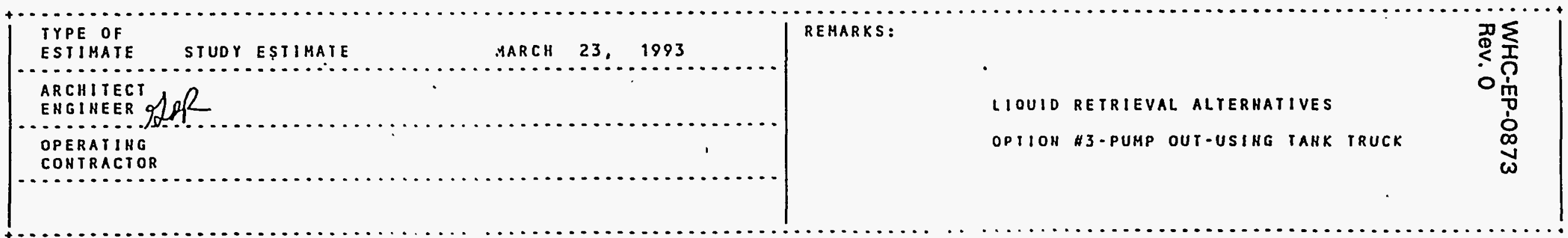

(ROUHDi:)/ADJUSIED IO JHE NEAREST "10,000/100,000" - PERCENIAGES NOI RECALCULATED TO REFLECT ROUHDIHG) 
KAISER ENGIHEERS HAHFORD

HESTINGHOUSE HANFORD COMPANY

JOB NO. ER3415/241-T

FILE NO, ZOSISAC

\section{HBS DESCRIPTIOH}

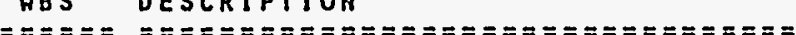

110000 DEFINITIVE DESIGH (ONSITE)

111000 CONCEPTUAL DESIGN (ONSITE)

112000 HHC ENGINEERING

120000 ENGINEERIHG INSPECTION (ONSITE)

SUBTOTAL 12 ENGR/INSPECTION (ONSITE)

SUBTOTAL

ENGINEERING

310001 PUMP OUT HITH TANK TRUCK

SUBTOTAL 31 FA CONST-OHSITE E/C

330001 HHC CONSTRUCTION

SUBTOTAL 33 CONSTRUCTION-O/C

SUBTOTAL 3 CONSTRUCTION

500001 HHC PROJECT OTHER COST

500003 HHC "OTHER COST" FOR KEH CONST.

SUBTOTAL 5

OTHER PROJECT COST

PROJECT TOTAL
* IEST - INTERACTIVE ESTIMATIHG * *

ALTERNATIVES FOR SINGLE SHELL TANK 241-T-101 STUDY ESTIMATE - OPTIOH H3 PUMP OUT TAHK TRUCK DOE_RO2 - HORK BREAKDOHN STRUCTURE SUMHARY

\begin{tabular}{|c|c|c|c|c|c|c|c|c|}
\hline $\begin{array}{l}\text { EST IMATE } \\
\text { SUB TOTAL } \\
=======\end{array}$ & $\begin{array}{l}\text { ONSITE } \\
\text { INDIRECTS } \\
========\end{array}$ & $\begin{array}{c}\text { SUB } \\
\text { TOTAL } \\
====\approx=z=\end{array}$ & $===\begin{array}{l}\text { ESCA } \\
X\end{array}$ & $\begin{array}{l}\text { ALATION } \\
\text { TOTAL } \\
=======\end{array}$ & $\begin{array}{c}\text { SUB } \\
\text { TOTAL } \\
========\end{array}$ & $\begin{array}{c}\text { CONTI } \\
x \\
=== \pm=\end{array}$ & $\begin{array}{l}\text { I NGENCY } \\
\text { TOTAL } \\
=========\end{array}$ & $\begin{array}{c}\text { TOTAL } \\
\text { DOLLARS } \\
===\approx= \pm \approx=\Sigma\end{array}$ \\
\hline $\begin{array}{r}350000 \\
95000 \\
607100 \\
140000\end{array}$ & $\begin{array}{r}0 \\
0 \\
121420 \\
0\end{array}$ & $\begin{array}{r}350000 \\
95000 \\
728520 \\
140000\end{array}$ & $\begin{array}{l}4.74 \\
1.63 \\
0.00 \\
7.92\end{array}$ & $\begin{array}{r}16590 \\
1549 \\
0 \\
11088\end{array}$ & $\begin{array}{r}366590 \\
96549 \\
728520 \\
151088\end{array}$ & $\begin{array}{l}30 \\
30 \\
20 \\
30\end{array}$ & $\begin{array}{r}109977 \\
28965 \\
145704 \\
45326\end{array}$ & $\begin{array}{l}476567 \\
125513 \\
874224 \\
196414\end{array}$ \\
\hline 140000 & 0 & 140000 & 7.92 & 11088 & 151088 & 30 & 45326 & 196414 \\
\hline 1192100 & 121420 & 1313520 & 2.23 & 29227 & 1342747 & 25 & 329972 & 1672718 \\
\hline 1390872 & 0 & 1390872 & 5.77 & 80253 & 1471125 & 35 & 514894 & 1986019 \\
\hline 1390872 & 0 & 1390872 & 5.77 & 80253 & 1471125 & 35 & 514894 & 1986019 \\
\hline 356500 & 71300 & 427800 & 0.00 & 0 & 427800 & 20 & 85560 & 513360 \\
\hline 356500 & 71300 & 427800 & 0.00 & 0 & 427800 & 20 & 85560 & 513360 \\
\hline 1747372 & 71300 & 1818672 & 4.41 & 80253 & 1898925 & 32 & 600454 & 2499379 \\
\hline $\begin{array}{r}1015900 \\
665000\end{array}$ & $\begin{array}{r}203180 \\
0\end{array}$ & $\begin{array}{r}1219080 \\
665000\end{array}$ & $\begin{array}{l}0.00 \\
3.98\end{array}$ & $\begin{array}{r}0 \\
26467 \\
.\end{array}$ & $\begin{array}{r}1219080 \\
.691467\end{array}$ & $\begin{array}{l}20 \\
20\end{array}$ & $\begin{array}{l}243816 \\
138293\end{array}$ & $\begin{array}{r}1462896 \\
829760\end{array}$ \\
\hline 1680900 & 203180 & 1884080 & 1.40 & 26467 & 1910547 & 20 & 382109 & $\begin{array}{c}2292656 \\
.\end{array}$ \\
\hline & 395,900 & & & 135,947 & & & $1,312,535$ & \\
\hline $4.620,372$ & & $5,016,272$ & 2.71 & & $5,152,219$ & 25 & & 6.464 .753 \\
\hline
\end{tabular}

PAGE 2 OF 7

OATE $03 / 23 / 93 \quad 10: 48: 1$

BY GDR 
1. DOCUMEHTS AND DRAHINGS

DOCUMENTS: ENGINEERIHG EVALUATION OF ALTERHATEIVES - MANAGING THE ASSUMED LEAK FROM SINGLE SHELL TANK $241-T-1012 / 93$. DRANINGS : SKETCHES

2. MATERIAL PRICES $==E Z Z Z Z Z Z Z Z Z=Z Z$
UHIT COSTS REPRESEHT CURRENT PRICES FDR SPECIFIED MATERIAL.

3. LABOR RAT.ES

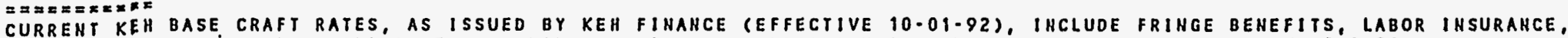
TAXES AND TRAVEL HHERE APPLICABLE, PER HANFORO SITE STABILIZATIOH AGREEMENT, APPENDIX A (EFFECTIVE Q-2-Q1). NON CRAFT HOURLY RATES ARE BASED OH THE 1993 FISCAL YEAR BUDGET LIQUIDATION RATES AS ISSUED BY KEH FIHANCE (EFFECTIVE IO-OI-92).

4. GENERAL REQUIREMENTS/TECHNICAL SERVICES/OVERHEADS

QENERAL REQUIREHENTSVTECHMICAL SERVICES/OVERHEADS

A.) ONSITE CONSTRUCTION FORCES GENERÁL REQUIREMENTS, TECHNICAL SERVICES AHO CRAFT OVERHEAD COSTS ARE IHCLUDED AS A

COMPOSITE PERCENTAGE BASED ON THE KEH ESTIMATING FACTOR/BILLIHG SCHEDULE, REVISION 14, DATED OCTOBER OI, 1992. THE TOTAL COMPOSITE PERCENTAGE APPLIED TO ONSITE CONSTRUCTION FORCES LABOR, FOR THIS PROJECT, IS $93 \%$ FOR SHOP HORK AHD $134 \%$ FOR FIELD HORK, HHICH IS REFLECTED IN THE NOH\&P/B\&IN COLUMN OF THE ESIIMATE DETAIL.

B.) HHC EHGINEERING, CONSTRUCTION, AND OTHER PROJECT COST INCLUDE ALL ADDERS. (ORG,G \& A, AND CSP).

ESCLLC:

ESALATIOA PERCENTAGES HERE CALCULATED GY THE HAHFORD MATERIAL \& LABOR ESCALATION STUDY, DATED FEBRUARY I992.

6. ROUNDING

U.S. DEPARTMENT OF ENERGY DOE ORDER 5100.4 PAGE J-2 SUBPARAGRAPH (H), REQUIRES ROUNDING OF ALL GENERAL PLANT PROJECTS (GPPIS) AHD LINE ITEM (LI) COST ESIIMATES. REFERENCE: DOE 5900.4, FIGURE I-11, DATED 10-3I.B4.

7. REMARKS

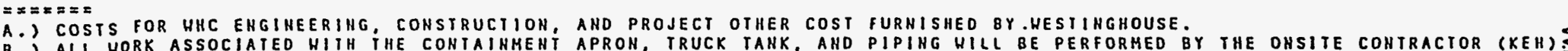

B) ALL "OTHER COST" FOR THE HHC COST ASSOCIATED HITH THE WORK PERFORMED BY THE OHSIIE CONTRACTOR (KEH), IS BASED OH $35 \%$ OF THE ONSITE ENGINEERING AND CONSTRUCTION COST.

D.) COST IOR KEH DEFINIIIVE DESIGN IS $3 A$ SED ON $25 \%$ OF DIRECT CONSTRUCTION.

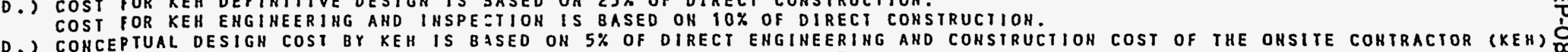
E.) NO ESCALATION HAS APPLIED TO HHC COST ON HORK PERFORHED IN 1993. 
KAISER ENGINEERS HANFORD

WESTINGHOUSE HANFORD COMPANY

JOB NO. ER3415/241-T

FILE NO. ZO3ISAC

$\cos T$

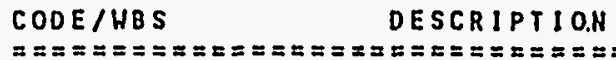

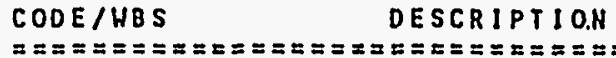

\section{OOO EHGIHEERIHG}

110000 DEFINITIVE DESIGN (ONSITE)

111000 CONCEPTUAL DESIGN (ONSITE)

112000 HHC ENGINEERIHG

120000 ENGINEERIHG INSPECTION (ONSITE)

TOTAL OOO EHGIHEERING

700 SPECIAL EQUIP/PROCESS SYSTEMS

310001 PUMP OUT HITH TANK TRUCK

330001 HHC CONSTRUCTION

TOTAL 700 SPECIAL EQUIP/PROCESS SYSTEM

900 HHC "OTHER COST"

500001 HHC PROJECT OYHER COST

500003 HHC "OTHER COST" FOR KEH CONST.

TOTAL 900 HHC "OTHER COST"

PROJECT TOTAL
* \# IEST - INTERACTIVE ESTIMATING * *

ALTERNATIVES FOR SINGLE SHELL TANK $241-T-101$

STUDY ESTIMATE - OPIION \#3 PUHP OUT TAHK TRUCK

DOE_RO4 - COST CODE ACCOUNT SUMMARY

EST IMATE

SUBTOTAL

ONSITE
INDIRECTS

INDIRECTS
$==\approx=\approx===$

$=\underset{\operatorname{TOTAL}}{\operatorname{SUB}}==x===$

\% TOTAL

$==\Sigma= \pm=\Sigma$

$z=z=z=0=z=x=z=$

SUB
TOTAL

TOTAL

$z= \pm 2$

PAGE 4 OF 7

DATE $03 / 23 / 93 \quad 10: 48: 15$

BY GDR

350000

95000

607100

140000

1192100

121420

350000

95000

728520

$4.74 \quad 16590$

4.63
$0.00 \quad 1549$

0.00

154
11088

366590
96549

728520
150

151088

121420

1313520

2.23

29227

$1342747 \quad 25$

HTINGENCY

TOTAL

DOLLARS

$=z=\geq x=\geq z$

1390872
356500

71300

1390872

5.77

1747372

71300

1818672

4.41

80253

1471125
427800

35
20

80253

1898925

32

514894
85560

600454

109977.

28965

45326

329972

125513

874224

672718

1015900

665000

$\begin{array}{rr}203180 & 1299080 \\ 0 & 665000\end{array}$

0.00

26467

203180

1884080

1.40

26467

1219080
691467

1
20
20

243816

138293

$1910547 \quad 20$

382109

1462896

829760

2292656

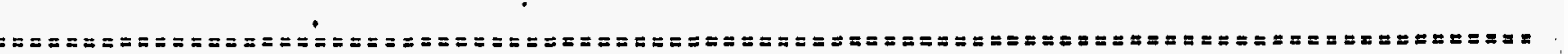

\begin{tabular}{|c|c|c|c|c|}
\hline $4.620,372$ & $5,016,272$ & 2.71 & $5,152,219$ & 6.464 .753 \\
\hline
\end{tabular}


HESTINGHOUSE HAHFORD COMPANY JOB HO. ER3415/241-T

FILE NO. ZOSISAC

CSI DESCRIPTIOH

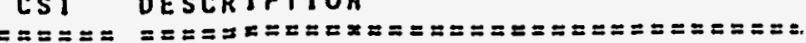

\section{ENGINEERINO}

OO TECHHICAL SERVICES

TOTAL EHGIHEERING

CONSTRUCTION

15 MECHANICAL D
20 HHC "OTHER COST"
IOTAL CONSTRUCTION

PROJECT TOTAL
- LS, - INIERACIIVE ESTIMATING ** ALTERHATIVES FOR SINGLE SHELL TAHK 241-T-101 STUDY ESTIMATE - OṔTION \#3 PUMP OUT TAHK TRUCK DOE_ROS. ESTIMATE SUMMARY BY CSI DIVISION
PAGE 5 OF 7

DATE $03 / 23 / 93 \quad 10: 48: 19$

BY

\begin{tabular}{|c|c|c|c|c|c|c|c|c|}
\hline $\begin{array}{l}\text { ESTIMATE } \\
\text { SUBTOTAL } \\
========\end{array}$ & $\begin{array}{l}\text { ONSITE } \\
\text { IND IRECTS } \\
========z\end{array}$ & 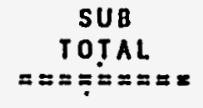 & $=x==x=$ & $\begin{array}{l}\text { ATION } \\
\text { TOTAL. } \\
======x=\end{array}$ & $\begin{array}{c}\text { SUB } \\
\text { TOTAL. } \\
=x=x==x=x\end{array}$ & $\begin{array}{c}\operatorname{CONT} \\
=2 x=2\end{array}$ & $\begin{array}{l}\text { I HGENCY } \\
\text { TOTAL } \\
=x=x=x=z=\end{array}$ & $\begin{array}{c}\text { TOTAL } \\
\text { OOLLARS } \\
===x=x=x\end{array}$ \\
\hline 1192100 & 121420 & 1313520 & 2.23 & 29227 & 1342747 & 25 & 329972 & 167271 \\
\hline $1,192,100$ & 121,420 & $1,313,520$ & 2.23 & 29.227 & $1,342,747$ & 25 & 329,972 & $1,672,71$ \\
\hline $\begin{array}{l}1747372 \\
1680900\end{array}$ & $\begin{array}{r}71300 \\
203180\end{array}$ & $\begin{array}{l}1818672 \\
1884080\end{array}$ & $\begin{array}{l}4.41 \\
1.40\end{array}$ & $\begin{array}{l}80253 \\
26467\end{array}$ & $\begin{array}{l}1898925 \\
1910547\end{array}$ & $\begin{array}{l}32 \\
20\end{array}$ & $\begin{array}{l}600454 \\
382109\end{array}$ & $\begin{array}{l}249937 \\
229265\end{array}$ \\
\hline $3,428,272$ & 274,480 & $3,702,752$ & 2.88 & 106,720 & $3,809,472$ & 26 & 982,563 & $4.792 .03 !$ \\
\hline \multicolumn{9}{|c|}{ 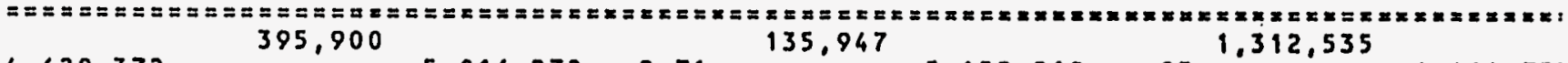 } \\
\hline $4,620,372$ & & $5,016,272$ & 2.71 & & $5,152,219$ & 25 & & $6,464,75$ \\
\hline
\end{tabular}


KAISER EHGINEERS HANFORD HEST INGHOUSE HANFORD COMPANY JOB NO. ER3415/241-T

FILE NO. 241 TA3
* IEST - INTERACTIVE ESTIMATING * * ALTERHATIVES FOR SINGLE SHELL TAHK 241-T-101 STUDY ESTIMATE - OPTION \#3 PUHP OUT TAHK TRUCK DOE_RO6 - CONTINGENCY ANALYSIS BASIS SHEET
PAGE 6 OF 7

DATE $03 / 22 / 93 \quad 13: 36: 23$

BY
GDR
REFERENCE:

ESTIMATE BASIS SHEET

COST CODE ACCOUNT SUMMARY
PAGE 3 OF 7

PAGE 6 OF 7 
KAISER ENGINEERS HAHFORO

HESTIHGHOUSE HANFORD COMPAHY

JOB NO. ER3415/241.

FILE NO ZO31SACI

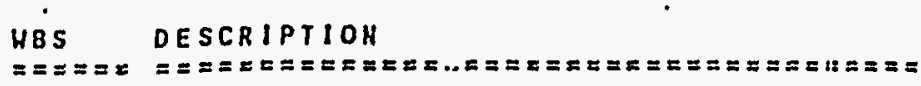

110000 DEFINITIVE DESIGH (ONSITE)

111000 CONCEPTUAL DESIGH (ONSITE)

112000 HHC ENGINEERING

120000 ENGINEERING INSPECTION (ONSITE)

310001 PUMP OUT HITH TANK TRUCK

330001 HHC CONSTRUCTIOH

500009 HHC PROJECT OTHER COST

500003 HHC "OTHER COST" FOR KEH COHST.

PROJECT TOTAL

* IEST - INTERACTIVE ESTIMATING * *

ALTERNAIIVES FOR SINGLE SHELL TAHK 241-T-101 STUOY ESTIMATE - OPTIOH HI PUHP OUT TANK TRUCK

DOE_RO7 - ONSITE IHDIRECT COSTS BY UBS
ESTIHATE
SUBTOTAL

$x=z=\Sigma=\equiv x$

350000

95000

607100

140000

1390872

356500

1015900

665000

\section{CONTRA \\ IHISTRATION}

CONTRAC

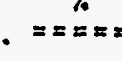

0.00

0.00

20.00

0.00

0.00

20.00

20.00

0.00 TOTAL

$x x x x \geq \pm x \geq x$

0
0

121420

0
0

71300

203180
PAGE

DATE

BY

7 OF 7

$3 / 23 / 93 \quad 10: 48: 23$

\begin{tabular}{|c|c|}
\hline $\begin{array}{l}B I O P A C K \\
\text { PREP } \\
==\approx=\approx=\approx=\end{array}$ & $\begin{array}{l}\text { OTHER } \\
\text { INDIRECTS } \\
\approx \approx \approx \approx=z \approx \approx z\end{array}$ \\
\hline $\begin{array}{l}0 \\
0 \\
0 \\
0 \\
0 \\
0 \\
0 \\
0\end{array}$ & $\begin{array}{l}0 \\
0 \\
0 \\
0 \\
0 \\
0 \\
0 \\
0\end{array}$ \\
\hline
\end{tabular}

TOTAL IHDIRECTS $=x=2 x=x$ 0
0 21420 71300 203180 $\begin{aligned} z=x= & =x=z=x=x=2 \\ & 4,620,372\end{aligned}$
395,900 
KAISER ENGINEERS HANFORD HESTINGHOUSE HANFORD COMPANY JOB HO. ER3415/241-T

FILE NO. $2031 S A D I$
* IEST - INTERACTIVE ESTIHATIHG * * ALTERHATIVES FOR SINGLE SHELL TANK 241-T-101 STUDY ESTIMATE - OPTION \#3A PUMP OUT RAILCAR DOE_RO1 - PROJECT COST SUMHARY
PAGE 1 OF 7

DATE 03/23/93 11:07:48

BY GDR

$\begin{array}{ll}\text { COST } & \\ \text { CODE } & \text { DESCRIPIIOH } \\ ===== & ============================== \\ 000 & \text { ENGIHEERING } \\ 700 & \text { SPECIAL EQUIP/PROCESS SYSTEMS } \\ 900 & \text { HHC "OTHER COST" }\end{array}$

(ADJUSTED TO MEET DOE 5100.4 )

\section{PROJECT TOTAL}

$\begin{array}{rrrr}\begin{array}{c}\text { ESCALATED } \\ \text { OTAL COST } \\ ========\pi\end{array} & \begin{array}{c}\text { CONTINGENCY } \\ \text { TOTAL }\end{array} & \begin{array}{c}\text { TOTAL } \\ \text { DOLLARS }\end{array} \\ 2,450,000 & 27 & 660,000 & 3,110,000 \\ 4,640,000 & 34 & 1,560,000 & 6,200,000 \\ 3,170,000 & 23 & 730,000 & 3,900,000 \\ +40,000 & & -50,000 & -10,000\end{array}$

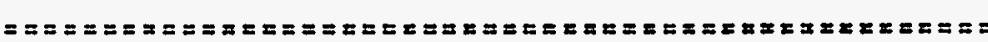

$10,300,000$

29

$2,900,000$

$13,200,000$
LIQUID RETRIEVAL ALTERHATES

OPIION \#3A-PUHP OUT-USING RAILCAR
-

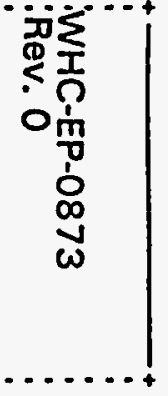


KAISER ENGINEERS HAHFORD

HEST I HGHOUSE HANFORD COMPANY

JOB NO. ER3415/241-T

FILE HO. ZOZISADI

WBS DESCRIPTION

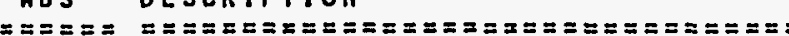

110000 DEFIHITIVE DESIGN (ONSITE)

111000 CONCEPTUAL DESIGN (ONSITE)

112000 HHC ENGIHEERIHG

SUBTOTAL 11 DEFINI-IVE DESIGN

120000 EHGINEERIHG IHSPECTION (ONSITE)

SUBTOTAL 12 ENGR/INSPECTION (ONSITE)

SUBTOTAL 1

ENGINEERING

310001 PUHP OUT RAILCAR \& TAHK

SUBTOTAL 31 FA CONST-ONSITE E/C

330001 HHC CONSTRUCTION

SUBTOTAL 33 CONSTRUCTIOH-O/C

SUBTOTAL 3 CONSTRUCTIOH

500001 HHC PROJECT OTHER COST

500003 HHC "OTHER COST",FOR KEH CONST.

SUBTOTAL 5 OTHER PROJECT COST

PROJECT TOTAL

\begin{abstract}
* IEST - INTERACTIVE ESTIMATIHG **
MLTERHATIVES FOR SINGLE SHELL TAHK 241-T-101

ITUDY ESTIMATE - OPTION \#3A PUMP OUT RAILCAR

DOE ROZ - HORK BREAKDOHH STRUCTURE SUMMARY
\end{abstract}

PAGE 2 OF 7

DATE $03 / 23 / 93 \quad 11: 07: 52$

BY GDR

\begin{tabular}{|c|c|c|c|c|c|c|c|c|}
\hline $\begin{array}{l}\text { EST IMATE } \\
\text { SUB TOTAL } \\
=======\end{array}$ & $\begin{array}{l}\text { ONSITE } \\
\text { IHOIRECTS } \\
==\approx=\approx=\approx\end{array}$ & $\begin{array}{c}\text { SUB } \\
\text { TOTAL } \\
=z=z=z=z=\end{array}$ & $======$ & $\begin{array}{l}\text { ALATION } \\
\text { TOTAL } \\
=\approx===\approx=\end{array}$ & $\begin{array}{c}\text { SUB } \\
\text { TOTAL } \\
=z=\approx z=z==\end{array}$ & $\begin{array}{c}\text { COHT } \\
=x \\
=x=x\end{array}$ & $\begin{array}{l}\text { I HGENCY } \\
\text { TOTAL } \\
==\approx=\approx==\approx\end{array}$ & $\begin{array}{c}\text { TOTAL } \\
\text { DOLLARS } \\
====\approx=\approx\end{array}$ \\
\hline $\begin{array}{l}960000 \\
260000 \\
607100\end{array}$ & $\begin{array}{r}0 \\
. \quad 1290 \\
\quad 120\end{array}$ & $\begin{array}{l}960000 \\
260000 \\
728520\end{array}$ & $\begin{array}{l}6.68 \\
2.46 \\
0.00\end{array}$ & $\begin{array}{r}64128 \\
6396 \\
0\end{array}$ & $\begin{array}{r}1024128 \\
266396 \\
728520\end{array}$ & $\begin{array}{l}30 \\
30 \\
20\end{array}$ & $\begin{array}{r}307238 \\
79919 \\
145704\end{array}$ & $\begin{array}{r}1331366 \\
346315 \\
874224\end{array}$ \\
\hline 1827100 & 921420 & 1948520 & 3.62 & 70524 & 2019044 & 26 & 532861 & 2551905 \\
\hline 384000 & 0 & 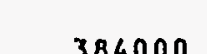 & 13,19 & 50343 & 434342 & 30 & 130303 & 564645 \\
\hline 384000 & 0 & 384000 & 13.11 & 50342 & 434342 & 30 & 130303 & 564645 \\
\hline 2211100 & 121420 & 2332520 & 5.18 & 120866 & 2453386 & 27 & 663164 & 3116550 \\
\hline 3836642 & 0 & 3836642 & 9.79 & 375607 & 4212249 & 35 & 1474288 & 5686536 \\
\hline 3836642 & 0 & 3836642 & 9.79 & 375607 & 4212249 & 35 & 1474288 & 5686536 \\
\hline 356500 & 71300 & 427800 & 0.00 & 0 & 427800 & 20 & 85560 & 513360 \\
\hline 356500 & 71300 & 427800 & 0.00 & 0 & 427800 & 20 & .85560 & 513360 \\
\hline 4193142 & 71300 & 4264442 & 8.81 & 375607 & 4640049 & 34 & 1559848 & 6199896 \\
\hline $\begin{array}{l}1015900 \\
1813000\end{array}$ & $\begin{array}{r}203180 \\
0\end{array}$ & $\begin{array}{l}1219080 \\
1813000\end{array}$ & $\begin{array}{l}0.00 \\
7.49\end{array}$ & $\begin{array}{r}0 \\
135794\end{array}$ & $\begin{array}{l}1219080 \\
1948794\end{array}$ & $\begin{array}{l}20 \\
25\end{array}$ & $\begin{array}{l}243816 \\
487198\end{array}$ & $\begin{array}{l}1462896 \\
2435992\end{array}$ \\
\hline 2828900 & 203180 & 3032080 & 4.48 & 135794 & 3167874 & 23 & 731014 & 3898888 \\
\hline
\end{tabular}

$9,233,142$

395,900

9.629 .042

6.57

632,267
$2,954,026$

$13,215,334$ 
KAISER ENGIHEERS HAHFORD HESTINGHOUSE HAHFORD COMPANY JOB HO. ER3415/241-T

FILE HO. 241 TA3A
* * IEST - IHTERACTIVE ESTIMATING ** ALTERNATIVES FOR SINGLE SHELL TANK 241-T-101 STUDY ESTIHATE - OPTIOH \#3A PUMP OUT RAILCAR DOE_RO3 - ESTIMATE BASIS SHEET
PAGE 3 OF 7

DATE O3/22/93 13:36:15 $G D R$

1. DOCUMENTS AND DRAHINGS

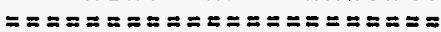

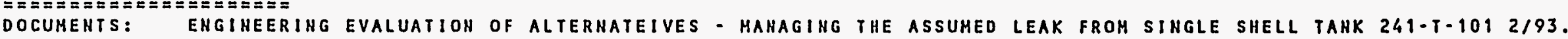
DRAHINGS: SKETCHES

2. MATERIAL PRICES

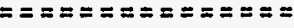
UNIT COSTS REPRESENT CURRENT PRICES FOR SPECIFIED MATERIAL.

3. LABOR RATES $==z========$

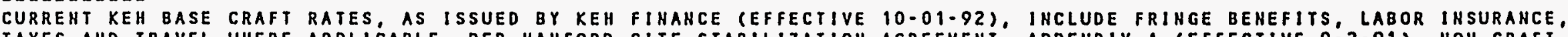
TAXES AHD TRAVEL HHERE APPLICABLE, PER HANFORD SITE STABILIZATION AGREEMENT, APPENDIX A.(EFFECTIVE Q-2-9I). HON CRAFT

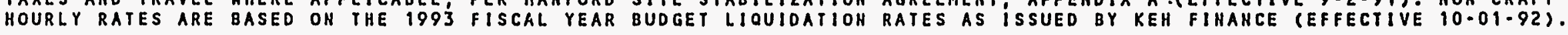

4. GENERAL REQUIREMENTS/TECHNICAL SERVICESTOVERHEADS

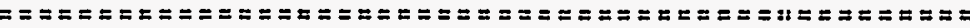

A.) OHSITE CONSTRUCTION FORCES GENERAL REQUIREMENTS. TECHHICAL SERVICES AHO CRAFT OVERHEAD COSTS ARE IHCLUDED AS A

COMPOSITE PERCENTAGE BASED ON THE KEH ESTIMATING FACTOR/BILLING SCHEDULE, REVISION 14, DATED OCTOBER OI, 1992. THE

TOTAL COMPOSITE PERCENTAGE APPIIIED TO ONSITE CONSTRUCTIOH FORCES LABOR FOR THIS PROJECT, IS $93 \%$ FOR SHOP HORK AHD

$134 \%$ OROR

B.) COST FOR HHC ENGINEERING, CONSTRUCTION, AND OTHER PROJECT COST ADDERS ARE IHCLUDED. (ORG, G\&A, CSP). A

5. ESCALATION

$=========$

ESCALATION PERCENTAGES HERE CALCULATED BY THE HANFORD MATERIAL \& LABOR ESCALATIOH STUDY, DATED FEBRUARY IO92.

6. ROUNDING

$==================$

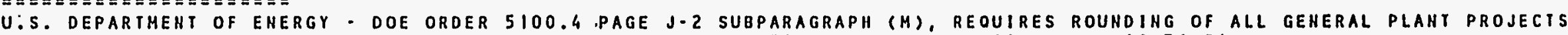
(GPPIS) AND LINE ITEM (LI) COST ESTIMATES. REFEREHCE: DOE 5100.4, FIGURE I.11, DATED 10-31-B4.

7. REMARKS

$== \pm== \pm=$

A.) COSTS HHC EHGIHEERING CONSTRUCIIOV, AND OTHER PROJECT COST HERE FURNISHED BY HESTIHGHOUSE

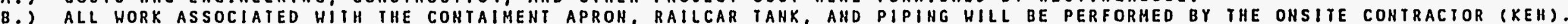

C.) HBS 500003 "OTHER COST"FOR THE HHC COST ASSOCIATED HITH THE HORK PERFORMED BY ONSITE CONTRACTOR (KEH). IS BASED ON $35 \%$ PERCENT OF DIRECT ONSITE ENGINEERING AND CONSIRUCTION COST.

D.) KEH DEFINITIVE DESIGH COST ARE BASED OH $25 \%$ OF DIRECT CONSTRUCTION COST.

E.) KEH ENGINEERING AND INSPECIION ARE BASED ON $10 \%$ OF DIRECT CONSTRUCTION COST.

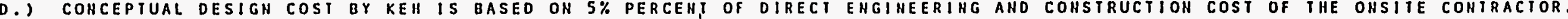

E.) NO ESCALAIIOH HAS APPLIED IO HIIC COST ON HORK PERFORHED IN 1993. 
KAISER ENGINEERS HANFORD

WEST I HGHOUSE HAHFORD COMPAHY

JOB NO. ER3415/241-T

FILE HO. ZO31SAD

\section{$\cos t$}

CODE/WBS

DESCRIPTIOH

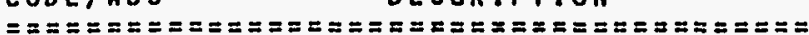

DOO ENGINEERING

110000 DEFINITIVE DESIGN (ONSITE)

111000 CONCEPTUAL DESIGN (OHSITE)

112000 HHC ENGINEERIHG

120000 ENGINEERIHG INSPECTION (ONSITE)

TOTAL OOO ENGINEERING

700 SPECIAL EQUIP/PROCESS SYSTEMS

330001 HHC COHSTRUCTIIAN

TOTAL 700 SPECIAL EQUIPIPROCESS SYSTIEM

900 HHC "OTHER COST"

500001 HHC PROJECT OTHER COST

500003 . HHC "OTHER COST" FOR KEH CONST.

TOTAL 900 WHC "OTHER COST"

PROJECT TOTAL
* IEST - INTERACTIVE ESTIMATING *

ALTERNATIVES FOR SINGLE SHELL TANK 241-T-101

STUDY ESTIMATE - OPTION \#3A PUMP OUT RAILCAR

DOE_RO4 - COST CODE ACCOUNT SUMMARY
PAGE 4 OF 7

DATE 03/23/93 11:07:56

BY GDR

ESTIMATE ONSITE SUB ESCALATION SUB COHTIHGENCY TOTAL

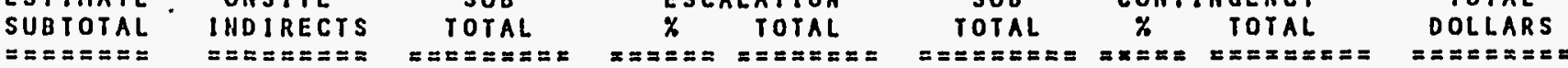

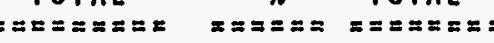
$== \pm= \pm= \pm$ $== \pm=\approx==$ $==\approx=\approx=\Sigma \approx$ $\begin{array}{rrr}64128 & 1024128 & 30 \\ 6396 & 266396 & 30\end{array}$

72852020

434342

2453386

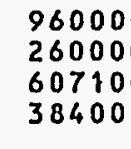

2211100

3836642

356500

4193142

71300

71300

3836642
427800

4264442

9.79
0.00

8.8

1015900

1813000

$203180 \quad 1219080$

1219080
1813000

0.00
7.49

3032080

4.48

135794

135794

120866

203180

2828900
307238
79919

130303

663164

395,900

$9.629,042$

6.57

632,267

$10,261,309$

29

$2,954,026$

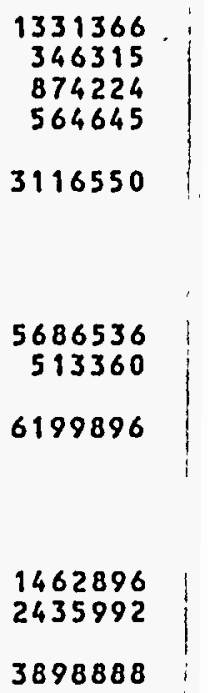


KAISER EHGINEERS HAMFORD HEST INGHOUSE HANFORD COMPANY

JOB NO. ER3415/241.T

FILE HO. ZOSISADI

\section{CSI DESCRIPTION}

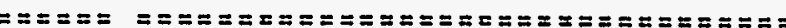

\section{ENGINEER ING}

OO TECHHICAL SERVICES

TOTAL ENGINEERING

\section{CONSTRUCTION}

\section{MECHANICAL \\ 20 HHC "OTHER COST" \\ TOTAL CONSTRUCTION}

PROJECT TOTAL
** IEST - INTERACTIVE ESTIMATIHG **

ALTERNATIVES FOR SINGLE SHELL TAHK $241-T-101$ STUDY ESTIMATE - OPTION \#3A PUMP OUT RAILCAR DOE_ROS - ESTIMATE SUMHARY BY CSI DIVISION
PAGE 5 OF 7

DATE 03/23/93 11:08:00

BY GDR

\begin{tabular}{|c|c|c|c|c|c|c|c|c|}
\hline $\begin{array}{l}\text { EST IMATE } \\
\text { SUBTOTAL } \\
=======\end{array}$ & $\begin{array}{l}\text { ONSITE } \\
\text { IND I REC TS } \\
========\end{array}$ & $\begin{array}{c}\text { SUB } \\
\text { TOIAL } \\
===z====\end{array}$ & $==z=z=z$ & $\begin{array}{l}\text { ALATION } \\
\text { TOTAL } \\
======z\end{array}$ & $\begin{array}{c}\text { SUB } \\
\text { TOTAL. } \\
z=z=z==x\end{array}$ & $\begin{array}{c}\text { CONT } \\
=x \\
=x=x=\end{array}$ & $\begin{array}{l}\text { NGENCY } \\
\text { TOTAL } \\
=========\end{array}$ & $\begin{array}{c}\text { TOTAL } \\
\text { DOLLARS } \\
========\end{array}$ \\
\hline 2211100 & 121420 & 2332520 & 5.18 & 120866 & 2453386 & 27 & 663164 & 3116550 \\
\hline $2,211,100$ & 121,420 & $2,332,520$ & 5.18 & 120,866 & $2,453,386$ & 27 & 663,164 & $3,116,550$ \\
\hline $\begin{array}{l}4193142 \\
2828900\end{array}$ & $\begin{array}{r}71300 \\
203180\end{array}$ & $\begin{array}{l}4264442 \\
3032080\end{array}$ & $\begin{array}{l}8.81 \\
4.48\end{array}$ & $\begin{array}{l}375607 \\
135794\end{array}$ & $\begin{array}{l}4640049 \\
3167874\end{array}$ & $\begin{array}{l}34 \\
23\end{array}$ & $\begin{array}{r}1559848 \\
.731014\end{array}$ & $\begin{array}{l}6199896 \\
3898888\end{array}$ \\
\hline $7,022,042$ & 274.480 & $7,286,522$ & 7.01 & 511,401 & $7,807,923$ & 29 & $2,290,862$ & $10,098,784$ \\
\hline
\end{tabular}

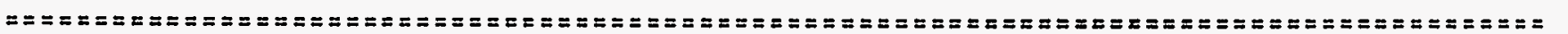

\begin{tabular}{|c|c|c|c|c|}
\hline $9,233,142$ & $9,629,042$ & 6.57 & $10,261,309$ & $29 \quad 13,215,334$ \\
\hline
\end{tabular}


KAISER EHGINEERS HAHFORD HEST I NGHOUSE HANFORD COMPANY JOB NO. ER3415/241-T

FILE HO. $241 T$ TA2
* * IEST - interactive estimating * * ALTERNATIVES FOR SINGLE SHELL TANK 241-T-101 STUDY ESTIMATE - OPTION \#2 PUMP OUT RAILCAR DOE_ROG - CONTINGENCY AHALYSIS BASIS SHEET
PAGE 6 OF 7 DATE 03/22/93 $13: 36: 23$

REFERENCE: ESTIHATE BASIS SHEET COST CODE ACCOUNT SUMMARY

THE U.S. DEPARTHENT OF ENIERGY - RICHLAND ORDER 5700.3 "COST ESTIMATIHG, AHALYSIS AHD STANDARDIZATIOH" DATED 3-27-85, PROVIDES GUIDELIIIES FOR ESTIMATE CONTINGENCIES. THE GUIDELIHE FOR A STUDY ESTIMATE SHOULD HAVE AH OVERALL RANGE OF 20 TO $35 \%$.

COHTINGEHCY IS EVALUATED AT THE THIRD COST CODE LEVEL AND SUMMARIZED AT THE PRIMARY AND SECONDARY COST CODE LEVEL OF THE DETAILED COST ESTIHATE.

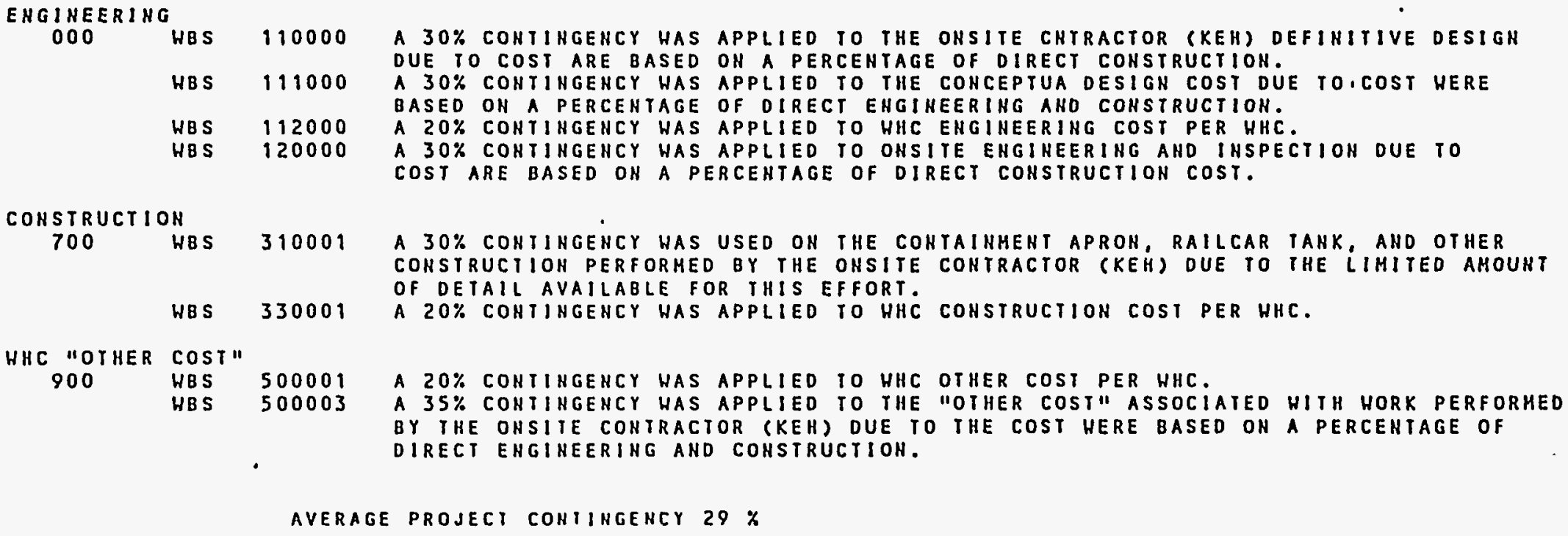

AVERAGE PROJECT CONIIHGENGY $29 \%$ 
KAISER EHGIHEERS HANFORD

WESTINGHOUSE HANFORD COMPANY JOB NO. ER3415/241-T

FILE HO. ZOSISADI

\section{HBS DESCRIPTIOH}

VI:

110000 DEFINITIVE DESIGN (ONSITE)

11000 CONCEPTUAL DESIGN COHSITE

112000 WHC ENGINEERING

120000 ENGINEERING INSPECTION (ONSITE)

310001 PUMP OUT RAILCAR \& TAHK

330001 HHC CONSTRUCTIOH

500001 HHC PROJECT OTHER COST

500003 WHC "OTHER COST" FOR KEH CONST.

PROJECT TOTAL
* IEST - INTERACTIVE ESTIMATING * *

ALTERNATIVES FOR SINGLE SHELL TAHK 249-T-101 STUOY ESTIMATE - OPTION \#3A PUMP OUT RAILCAR

DOE_ROT - OHSITE INDIRECT COSTS BY HBS

\section{ESTIMATE}

SUBTOTAL

$=x=x=x=z$

\section{CONTRACT ADMINISTRATION \\ TOTAL}

960000

260000

607100

384000

3836642

356500

1813000
$\%$

0.00

0.00

0.00
0.00
20.00

20.00

0.00

0.00

20.00

20.00

20.00
0.00

0
0
121420
0
0
71300
203180
0

BID PACK

PREP.

$== \pm== \pm==$

OTHER

INOIRECTS

$x x x=x x x=x$

TOTAL

PAGE 7 OF 7

OATE 03/23/93 11:08:04

BY GDR

NOIRECTS

$3==$

$\begin{array}{lr}0 & 0 \\ 0 & 0 \\ 0 & 121420 \\ 0 & 0 \\ 0 & 0 \\ 0 & 71300 \\ 0 & 203180 \\ 0 & 0\end{array}$


KAISER EHGINEERS HAHFORD

KAISER ENGIHEERS HAHEORDPANY

JOB NO. ER3415/24i-1

FILE HO. 241 TAL
* * IEST - INTERACTIVE ESTIHATING * *

ALTERHATIVES FOR SINGLE SHELL TAHK 241-1-101

STUDY ESTIMATE. OPTION \#L PUHP OUT-BLADDER

DOE_ROI - PROJECT COST SUHMARY
PAGE 1 OF 7

DATE $03 / 23 / 93 \quad 10: 23: 16$ BY

\begin{tabular}{|c|c|}
\hline$==x=$ & 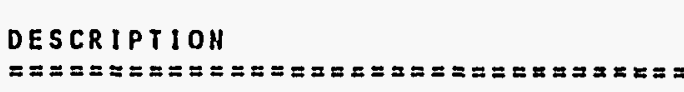 \\
\hline 000 & EHGIHEER ING \\
\hline 700 & SPECIAL EQUIPIPROCESS SYSTEHS \\
\hline 900 & $\begin{array}{l}\text { WHC OTHER PROJECT COST } \\
\text { (ADJUSTED TO MEET DOE } 5100.4 \text { ) }\end{array}$ \\
\hline
\end{tabular}

PROJECT TOTAL

\begin{tabular}{|c|c|c|c|}
\hline $\begin{array}{l}\text { ESCALATED } \\
\text { TOTAL COST } \\
========x==\end{array}$ & $=x^{c 01}$ & $\begin{array}{l}\text { IGENCY } \\
\text { TOTAL } \\
=x=z=z=x=z=z\end{array}$ & $\begin{array}{c}\text { TOTAL } \\
\text { DOLLARS } \\
x=x=x=x=x=x\end{array}$ \\
\hline $1,140,000$ & 35 & 400,000 & $1,540,000$ \\
\hline $3,910,000$ & 35 & $1,370,000$ & $5,280,000$ \\
\hline $1,170,000$ & 35 & 410,000 & $1,580,000$ \\
\hline$-20,000$ & & $+20,000$ & \\
\hline
\end{tabular}
$6,200,000$
35
$2,200,000$
$8,400,000$

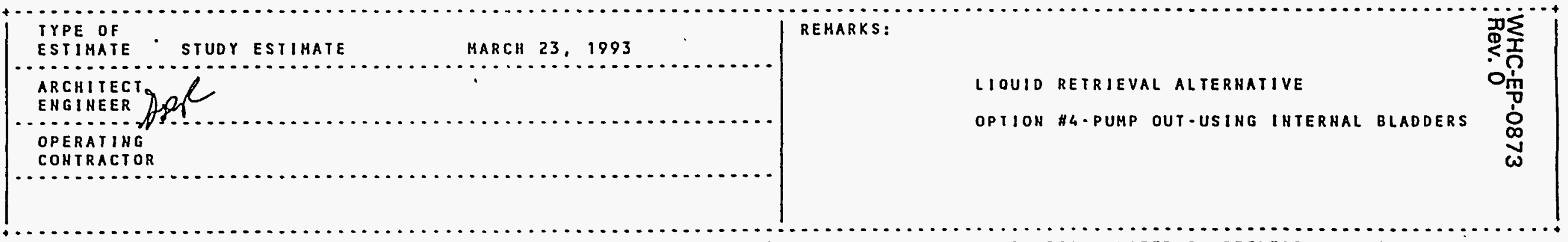

(ROUNDED/AOJUSTED IO THE NEAREST"10,000/100,000" - PERCENTAGES HOI RECALCULATED TO REFLECT ROUHDIHG) 
KAISER ENGINEERS HANFORD

WESTINGHOUSE HANFORD COMPANY

JOB NO. ER3415/241-T

FILE NO. 241 TA4

HBS OESCRIPTIOH

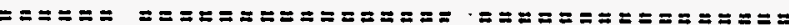

110000 KEH DEFIHITIVE DESIGN

111000 KEH CONCEPTUAL DESIGN

SUBTOTAL 11 DESIGN ENGINEERING

120000 KEH ENGR/INSPECTION

SUBTOTAL 12 ENGINEERINGIINSPECTION

SUBTOTAL 1 ENGINEERING

310001 NEH RISER PITS

310002 INSTALL HEH RISERS

390003 IHSTALL PUHPS

310004 INSTALL BLADOERS

310005 BURN OUT

310006 STEP OFF PADS

SUBTOTAL 31 ONSITE CONTRACTOR

330000 BURIAL FEE

SUBTOTAL 33 CONSTRUCTION-O/C

SUBTOTAL 3 CONSTRUCTION

SO00OY HHC OTHER PROJECT COST

SUBTOTAL 5. OTHER PROJECT COSI

PROJECT TOTAL
* IEST - INTERACTIVE ESTIMATIHG **

ALTERHATIVES FOR SINGLE SHELL TANK 241-1-101 STUDY ESTIMATE - OPTION \#4 PUMP OUT-BLADDER DOE_RO2 - HORK BREAKDOHH STRUCTURE SUMHARY

\begin{tabular}{|c|c|c|c|c|c|c|c|c|}
\hline $\begin{array}{l}\text { ESTIHATE, } \\
\text { SUBTOTAL. } \\
========\end{array}$ & $\begin{array}{l}\text { ONSITE } \\
\text { INDIRECTS } \\
========\end{array}$ & $\begin{array}{c}\text { SUB } \\
\operatorname{TOTAL} \\
========\end{array}$ & $=== \pm= \pm=$ & $\begin{array}{l}\text { ILATION } \\
\text { TOTAL } \\
=======\end{array}$ & $\begin{array}{c}\text { SUB } \\
\text { TOYAL } \\
=z===\geq z=z\end{array}$ & $\begin{array}{l}\text { CONTI } \\
x \underset{X}{x} \\
=x=x=\end{array}$ & $\begin{array}{l}\text { INGENCY } \\
\text { TOTAL } \\
== \pm======\end{array}$ & $\begin{array}{c}\text { TOTAL } \\
\text { DOLLARS } \\
========\end{array}$ \\
\hline $\begin{array}{l}713000 \\
148000\end{array}$ & $\begin{array}{l}0 \\
0\end{array}$ & $\begin{array}{l}713000 \\
148000\end{array}$ & $\begin{array}{l}6.29 \\
2.05\end{array}$ & $\begin{array}{r}44848 \\
3034\end{array}$ & $\begin{array}{l}757848 \\
151034\end{array}$ & $\begin{array}{l}35 \\
35\end{array}$ & $\begin{array}{r}265247 \\
52862\end{array}$ & $\begin{array}{r}1023094 \\
203896\end{array}$ \\
\hline 861000 & 0 & 861000 & 5.56 & 47882 & 908882 & 35 & 318109 & 1226990 \\
\hline 204000 & 0 & 204000 & 13.11 & 26744 & 230744 & 35 & 80761 & 311505 \\
\hline 204000 & 0 & 204000 & 13.11 & 26744 & 230744 & 35 & 80761 & 311505 \\
\hline 1065000 & 0 & 1065000 & 7.01 & 74626 & 1139626 & 35 & 398870 & 1538495 \\
\hline $\begin{array}{r}620505 \\
760544 \\
330262 \\
137937 \\
1516495 \\
187200\end{array}$ & $\begin{array}{l}0 \\
0 \\
0 \\
0 \\
0 \\
0\end{array}$ & $\begin{array}{r}620505 \\
760544 \\
330262 \\
137937 \\
1516495 \\
187200\end{array}$ & $\begin{array}{l}9.79 \\
9.79 \\
9.79 \\
9.79 \\
9.79 \\
9.79\end{array}$ & $\begin{array}{r}60747 \\
74457 \\
32333 \\
13504 \\
148465 \\
18327\end{array}$ & $\begin{array}{r}681252 \\
835001 \\
362595 \\
151441 \\
1664960 \\
205527\end{array}$ & $\begin{array}{l}35 \\
35 \\
35 \\
35 \\
35 \\
35\end{array}$ & $\begin{array}{r}238438 \\
292250 \\
126908 \\
53004 \\
582736 \\
71934\end{array}$ & $\begin{array}{r}919691 \\
1127252 \\
489503 \\
204445 \\
2247696 \\
277461\end{array}$ \\
\hline 3552943 & 0 & 3552943 & 9.79 & 347833 & 3900776 & 35 & 1365270 & 5266048 \\
\hline 11714 & 0 & 11714 & 9.79 & 1147 & 12861 & 35 & 4501 & 17362 \\
\hline 11714 & .0 & 11714 & 9.79 & 1147 & 12861 & 35 & 4501 & 17362 \\
\hline 3564657 & 0 & 3564657 & 9.79 & 348980 & 3913637 & 35 & 1369771 & 5283410 \\
\hline 1085000 & 0 & 1085000 & 7.49 & 81267 & 1166267 & 35 & 408193 & 1574460 \\
\hline 1085000 & 0 & 1085000 & 7.49 & 81267 & 1166267 & 35 & 408193 & 1574460 \\
\hline \multicolumn{9}{|c|}{ 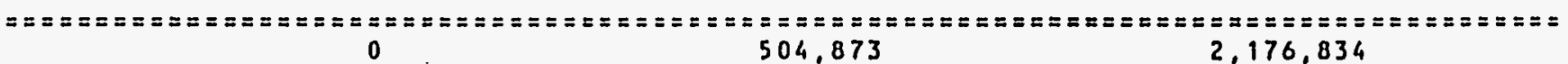 } \\
\hline $5.714,657$ & & 5.714 .657 & 8.83 & & $6,219,530$ & 35 & & $8,396,365$ \\
\hline
\end{tabular}

PAGE 2 OF 7

DATE 03/23/93 10:23:20

BY GOR OR 
KAISER ENGINEERS HAHFORD HESTINGHOUSE HANFORD COMPAHY JOB NO. ER3415/241-T

FILE NO. $241 T A 4$
* * IEST - INTERACTIVE ESTIMATIHG **

ALTERNATIVES FOR SINGLE SHELL TANK $241 \cdot 1 \cdot 10$ STUOY ESTIMATE - OPTIOH \#4 PUHP OUT-BLADDER DOE_RO3 - ESTIHATE BASIS SHEET
PAGE 3 OF 7

$03 / 05 / 93 \quad 10: 35: 28$ BY GDR

1. DOCUMENTS AND DRAHINGS

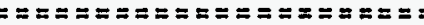

DOCUMENTS: MAHAGIHG the ASSUMED LEAK FROM SINGLE-SHELL TANK 241-T-101, DATED FEBRUARY, 1993.

DRAHINGS: $\quad$ H/A

2. MATERIAL PRICES,

$== \pm===== \pm====$

UNIT COSTS REPRESENT CURREHT PRICES FOR SPECIFIED MATERIAL.

3. LABOR RATES

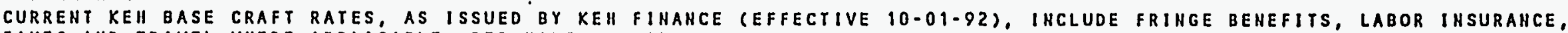
TAXES AHD TRAVEL HHERE APPLICABLE, PER HAHFORD SITE STABILIZATION AGREEMENT, APPENDIX A (EFFECTIVE 9-2-9I). HON CRAFT

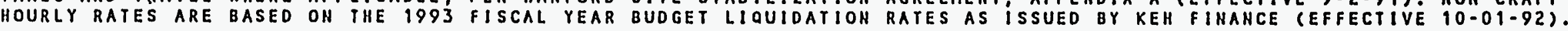

4. GENERAL REQUIREMENTS/TECHHICAL SERVICES;OVERHEAOS

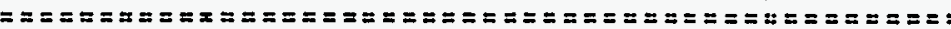

A.) ONSITE CONSTRUCTION FORCES GENERAL HEQUIREMENTS, TECHNICAL SERVICES AHD CRAFT OVERHEAD COSTS ARE IHCLUDED AS A COMPOSITE PERCENTAGE BASED ON THE KEH ESTIMATIHG FACTOR/BILLING SCHEDULE, REVISION 14, DATED OCTOBER OI, I992. THE TOTAL COMPOSITE PERCENTAGE APPLIED OO ONSITE CONSTRUCTION FORCES LABOR, FOR THIS PROJECT, IS $93 \%$ FOR SHOP HORK AND 134\% FOR FIELD HORK, HHICH IS REFLECTED IN THE "OH\&P/B\&I" COLUMH OF THE ESTIMATE DETAIL.

5. ESCALATIOH

$========$

ESCALATION PERCENTAGES HERE CALCULATED BY THE HAHFORD MATERIAL \& LABOR ESCALATION STUDY, DATED FEBRUAR 1992.

6. ROUNDING

$===============$

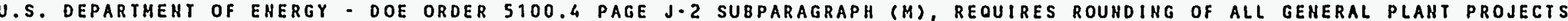
(GPPIS) AND LINE ITEM (LI) COST ESTIMATIS. REFERENCE: DOE 5100.4, FIGURE 1.11, DAIED 10.31.84.

7. REMARKS

$==\Sigma=\Sigma= \pm$

A.) DEFINITIVE DESIGN BY OHSITE ENGINEERING IS BASED ON $35 \%$ OF THE DIRECT COHSTRUCTION COST LESS BURNOUT.

B.) CONCEPTUAL DESIGN BY OHSITE ENGINEERING IS BASED ON $5 \%$ OF TIIE DIRECT EHGIHEERING AND CONSTRUCTION COST LESS BURN-OUT.

C.) OHSITE ENGINEERING AND. INSPECTION IS BASED ON $10 \%$ OF DIRECT CONSTRUCIION COST LESS BURNOUT.

D.) OTHER PROJECT COST BY HHC ARE BASEO ON $35 \%$ OF THE DIRECT ENGINEERING AND CONSTRUCIION COST LESS BURNOUT.

E.) ASSUMED ALL HOP.' TO BE ON MASK.

F.) ASSUHED BURNOUT AT 100 MR.

G.) USED COST PROVIDED BY HHC ON CORE DRILLIHG FOR NEH RISERS, BASED ON IHFORMAIION IROM A SIHILAR JOB. IH HEST VALLEY

H.) ASSUHED PIT SIZE TO BE $8 \cdot \times 8$ 'X 8 .

1.) ESTIMATE DOES HOT INCLUDE AHY REMOVAL OF EOUIPHEHT ARE BLADOERS AFTER IAHK IS PUMPED IHIO THE BLADDERS. 
KAISER ENGIHEERS HAHFORD

HEST INGHOUSE HANFORD COMPAHY

JOB NO. ER3415/241-T

FILE NO 241 TA4

\section{$\cos$}

CODE/HBS DESCR IPT IOH

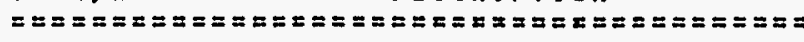

OOO EHGINEERING

110000 KEH DEFINITIVE DESIGH

111000 KEH COHCEPTUAL DESIGN

120000 KEH ENGRIIINSPECTION

TOTAL OOO ENGINEEIIING

700 SPECIAL EQUIP/PROCESS SYSTEMS

310001 NEN RISER PITS

310002 INSTALL NEH RISERS

310003 INSTALL PUMPS

310004 INSTALL BLADDERS

310005 BURN OUT

310006 STEP OFF PADS

330000 BURIAL FEE

TOTAL 700 SPECIAL EQUIP/PROCESS SYSTEH

900 HHC OTHER PROJECT COST

500001 HHC OTHER PROJECT COST

TOTAL 900 WHC OTHER PROJECT COST

PROJECT TOTAL
* * IEST - IHTERACTIVE ESTIHATIHG **

ALTERHATIVES FOR SIHGLE SHELL TAHK 241-1-10

STUDY ESTIMATE - OPTION \#4 PUMP OUT-BLADDER

DOE_ROA - COST CODE ACCOUHT SUMMARY

ESTIHATE

SUBTOTAL

$====\pi==$

\section{ONSITE}

INDIRECTS

$===x== \pm=$

SUB

$== \pm== \pm=2$

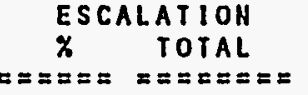

TOTAL

PAGE 4 OF 7

DATE 03/23/93 10:23:26.

BY GDR

713000
148000
204000

1065000

713000
148000
204000

$\begin{array}{rr}6.29 & 44848 \\ 2.05 & 3034 \\ 13.11 & 26744\end{array}$

757848
151034
230744

1065000

7.01

74626

1139626

35

35

5
265247
52862
80761

398870

1023094

203896

311505

1538495

620505

760544

330262

137937

1516495

187200

11714

3564657

\section{5}

760544

760544
330262

330262
137937

137937
1516495

187200

11714

$9.79 \quad 60747$

$9.79 \quad 74457$

9.79

9.79

9.79

9.79
9.79

13504

148465

18327

1147

9.79348980

681252
835001

835001

362595

151441
1664960

205527

12861

3913637

35
35
35
35
35
35
35
35

238438

292250

126908

126908
53004

582736

71934

4501

1369771

919691

1127252

489503

204445

2247696

277461
17362

5283410

108500

1085000

7.49

81267

116626

35

408193

1574460

7.49

31267

1166267

35

408193

.9574460

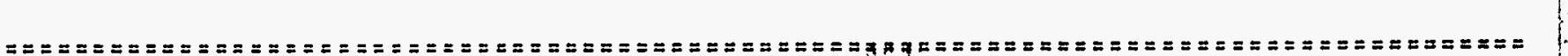

$5,714,657$

$5,714.657$

8.83

504,873 .

$6,219,530$

35

$2.176,834$

$8,396,365$ 
KAISER ENGINEERS HANFORD

HEST I NGIIOUSE HAHFORD COMPANY

JOB NO. ER3415/241-T

FILE NO 24 ITA 4

CSI OESCRIPTION

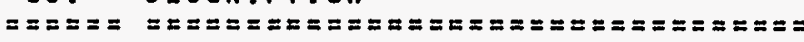

ENGINEERIHG

00 TECHHICAL SERVICES

TOTAL ENGIHEERING

CONSTRUCTION

DO TECHNICAL SERVICES

O1 GENERAL REQUIRMENTS

03 CONCRETE

15 MECHANICAL

TOTAL CONSTRUCTION

PROJECT TOTAL
* * IEST - INTERACTIVE ESTIMATIHG *

ALTERHATIVES FOR SINGLE SHELL TAHK 241-1-101 STUDY ESTIMATE - OPTION HG PUHP OUT - BLADDER DOE_ROS - ESTIMATE SUMMARY BY CSI DIVISION
PAGE 5 OF 7

$10: 23: 3$
$G D$

\section{ESTIMATE}

SUBTOTAL

$==\Sigma=\Sigma==$

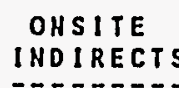

SUB
TOTAL

$z== \pm= \pm=2$

$x$ TOTAL

TOTAL
$=== \pm=$

SUB

TOTAL
$=\approx= \pm==$

CONTIHGEHCY

$x$

TOTAL

TOTAL

DOLLARS

\section{0}

$1,065,000$

$$
\begin{array}{r}
1085000 \\
1715409 \\
1381049 \\
468199
\end{array}
$$

$4,649,657$

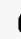

0

$1,065,000$

7.01

74626

1139626

74.626

$1,139,626$

\section{$0 \quad 1085000$}

$0 \quad 1715409$

$\begin{array}{ll}0 & 1381049 \\ 0 & 468199\end{array}$

o

7.01

4.648 .657

7.49

9.79

9.79
9.79
9.79

81267
167939

135204

45837

1166267

1883348

1516253

430,247

9.25

514036

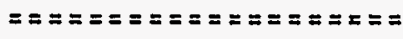

0

5.714 .657

8.83

504,873

$6,219.530$

35

$2,176,83$ 
KAISER ENGINEERS HANFORO HESTINGHOUSE HAHFORD COMPANY JOB HO. ER3415/241-T

FILE NO. $24.1 T A 4$
* IEST - IHTERACTIVE ESTIMATING * ALTERNATIVES FOR SINGLE SHELL TANK 241-1-101 STUDY ESTIHATE - OPTION \#4 PUMP OUT B BLADER DOE_ROG - CONTINGENCY ANALYSIS BASIS SHEET
PAGE 6 OF 7

DATE $03 / 05 / 93 \quad 10: 35: 33$ BY
PAGE 3 OF 7
EST IMATE BASIS SHEET

- THE U.S. DEPARTHENT OF ENERGY - RICHLAND ORDER 5700.3 "COST ESTIMATING. ANALYSIS AND STAHDARDIZATION" DATED 3-27-85, PROVIDES GUIDELINES FOR ESTIHATE CONTINGENCIES. THE GUIDELIHE FOR A STUDY ESTIMATE SHOULD HAVE AN OVERALL RANGE OF 20 TO $35 \%$.

CONTINGENCY IS EVALUATED AT THE THIRD COST CODE LEVEL AND SUMMARIZED AT THE PRIMARY AHD SECONOARY COST CODE LEVEL OF THE DETAILED COST ESTIMATE.

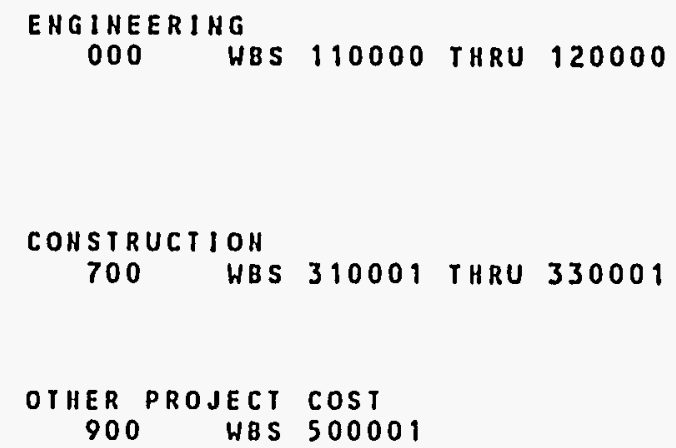

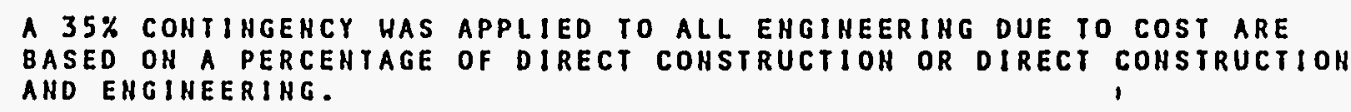

A $35 \%$ CONTINGENCY HAS APPLIED TO ALL COHSTRUCTION AHD BURIAL FEES DUE TO THE LIMITED INFORMATION AVAILABLE FOR THIS ENGINEERING STUDY.

A 35\% CONTINGENCY HAS APPLIED TO OTHER PROJECT COST BY HHC DUE TO THE COST ARE BASED ON A PERCENTAGE OF DIRECT ENGINEERIHG AND CONSTRUCIION. 
KAISER EHGIHEERS HANFORD WESTIHGHOUSE HANFORO COMPANY JOB NO. ER3415/241-T

FILE HO. 241 TAL

\section{HBS DESCRIPTION}

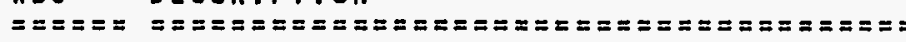

110000 KEH DEFIHITIVE DESIGN

111000 KEH COHCEPTUAL DESIGN

120000 KEH ENGR/INSPECTION

310001 NEH RISER PITS

310002 INSTALL NEH RISERS

310003 INSTALL PUMPS

310004 INSTALL BLADDERS

310005 BURN OUT

310006 STEP OFF PADS

330000 BURIAL FEE

500001 HHC OTHER PROJECT COST

PROJECI TOTAL
* * IEST - INTERACTIVE ESTIMATING * *

ALTERNATIVES FOR SINGLE SHELL TANK 241-1.101 STUDY ESTIMATE - OPTION \#4 PUMP OUT-BLADDER

DOE ROT - ONSITE IHDIRECT COSTS BY HBS
PAGE 7 OF 7

DATE 03/23/93 10:23:35

BY
ESTIMATE
SUBTOTAL

$=\mathbf{z =}=\mathbf{=}$

713000

148000

204000

620505

760544

3.30262

137037

1516495

187200

11714

1085000

CONTRACT ADMINISTRATION

TOTAL

$=z=z=\quad=z= \pm \approx= \pm$

0.00

0.00

0.00

0.00

0.00

0.00

0.00
0.00

0.00

0.00

0.00
0.00
OTHER

IND IRECTS

$x \approx x=\Sigma= \pm==$

BIO PACK
PREP.

$== \pm==$

0
0
0
0
0
0
0
0
0
0
0
TOTAL IHDIRECTS $=\Sigma=z=\Sigma x=2$ 
KAISER ENGINEERS HANFORD HESTIHGHOUSE HANFORD COMPAHY JOB NO. ER3415/241TUHL

FILE NO. 24 ITUNL
* IEST - INTERACTIVE ESTIHATING * *

TAHK 241-T-101 TOTAL REIRIEVAL ALTERHATIVE

STUDY ESTIHATE OPIION \#I UNLIMITED SLUICIHG OOE_ROI. PROJECT COST SUMAARY
PAGE 1 OF 13

DATE $03 / 22 / 93 \quad 14: 33: 10$

DY GDR

\begin{tabular}{|c|c|}
\hline $\begin{array}{l}\text { COST } \\
\text { CODE } \\
=== \pm=\end{array}$ & 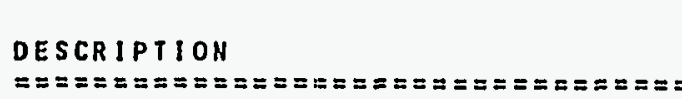 \\
\hline 000 & ENGINEERING \\
\hline 600 & UTILITIES \\
\hline 700 & SPECIAL EQUIP/PROCESS SYSTEHS \\
\hline 810 & DEHOLITION \\
\hline 900 & OTHER COSTS \\
\hline
\end{tabular}

(ADJUSTED TO MEET DOE 5100.4 )

\begin{tabular}{|c|c|c|c|}
\hline $\begin{array}{l}\text { ESCALATED } \\
\text { IOTAL COST } \\
=====\pi==\approx=\end{array}$ & $x===2$ & $\begin{array}{l}\text { IGENCY } \\
\text { TOTAL } \\
=========z\end{array}$ & $\begin{array}{c}\text { TOTAL } \\
\text { DOLLARS } \\
=x=x=x=x=x=2\end{array}$ \\
\hline $25,420,000$ & 34 & $8,580,000$ & $34,000,000$ \\
\hline $1,300,000$ & 35 & 460,000 & $1,760,000$ \\
\hline $37,210,000$ & 30 & $11,200,000$ & $48,410,000$ \\
\hline $4,280,000$ & 36 & $1,540,000$ & $5,820,000$ \\
\hline $24,390,000$ & 30 & $7,320,000$ & $31,710,000$ \\
\hline
\end{tabular}

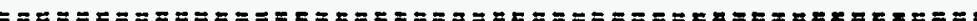

$92,600,000$

31

$29,100,000$

$121,700,000$

PROJECT TOTAL

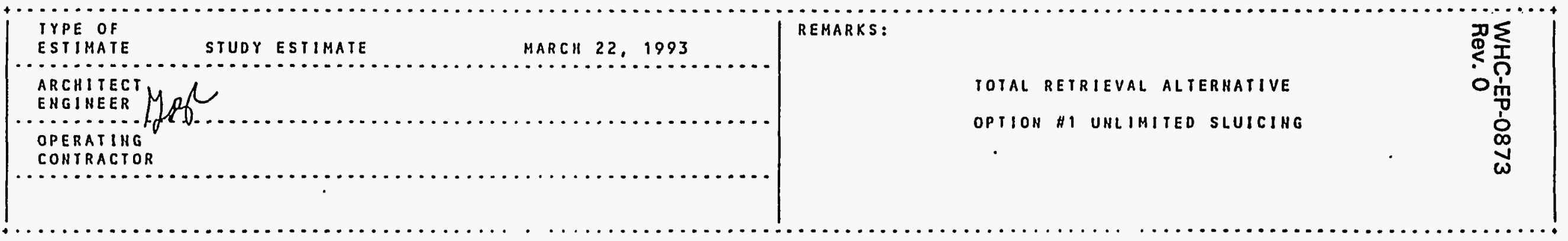


KAISER EHGIHEERS HAHFI D HESTINGHOUSE HAHFORO COMPAHY JOB NO. ER3415/241TURL

FILE NO. 241 TUNL

HBS DESCRIPTION

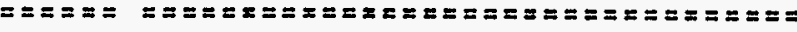

111000 KEH EHGINEERING STUDY

112000 KEH CONCEPTUAL DESIGN

113000 KEH DEFIHITIVE DESIGH

114000 HHC D \& D DESIGN

121000 KEH ENGINEERING/INSPECTIOH

122000 HHC EHGR/INSPEC. D\& D

SUBTOTAL 1 EHGIHEERING

210160 T-101 PROCESS EQUIPMENT

210180 T-101 ELEC EQUIP.

210190 T. 101 HVAC SKIOS

SUBTOTAL 2101 T-10! PROCUREMENT

$210260101 \cdot F Y$ PROCESS EQUIPMENT

SUBTOTAL 2102 103-FY PROCUREMENT

SUBTOTAL 21 KE II PROCUREMENT

SUBTOTAL 2 PROCUREMENT

310110 GREENHOUSE T-101

310120 UPGRADE EXIST.PITS T.101

310140 JUMPERS T-101

310150 MTD.BASE/HASHDOHH/SLIDE VALVE

310160 INSTALL PROCESS EOUIP. I-10

310170 PIPING INSIDE T-101 FARM

310180 ELECTRICAL IN T-101 FARM

310190 HVAC IN T-101 FARM

SUBTOTAL 3101 T-10I SLUICING

310210 GREEN HOUSE 103-FY

310220 UPGRADE EXIST.PITS 103 -FY

310240 JUMPERS $103 \cdot F \dot{Y}$
* IEST - IHTERACT IVE ESTIMATIHG TAHK 241-T-101 TOTAL RETRIEVAL ALTERHATIVE STUDY ESTIAATE OPTION \#1 UNLIMITED SLUICIHO DOE_RO2 - HORK BREAKDOHN STRUCTURE SUMHARY

\begin{tabular}{|c|c|c|c|c|c|c|c|c|}
\hline $\begin{array}{l}\text { ESTIMATE } \\
\text { SUBTOTAL } \\
========\end{array}$ & $\begin{array}{l}\text { ONS ITE } \\
\text { I HD IRECTS } \\
=\approx==\approx=\approx=\approx\end{array}$ & $\begin{array}{c}\text { SUB } \\
\operatorname{TOTAL} \\
=x=x=z==\end{array}$ & $=\underset{x}{\mathscr{X} \text { ECf }}$ & $\begin{array}{l}\text { ILATION } \\
\text { TOTAL } \\
==\approx==E=\end{array}$ & $\begin{array}{c}\text { SUB } \\
\text { TOTAL } \\
=\approx z= \pm z=z=\end{array}$ & $\begin{array}{c}\text { COHTI } \\
\% \\
=x=z=\end{array}$ & $\begin{array}{l}\text { HGEHCY } \\
\text { TOTAL } \\
x=x=x===\end{array}$ & $\begin{array}{c}\text { TOTAL } \\
\text { DOLLARS } \\
=====x=x\end{array}$ \\
\hline $\begin{array}{r}780000 \\
1670000 \\
8000000 \\
1210800 \\
4800000 \\
691900\end{array}$ & $\begin{array}{l}0 \\
0 \\
0 \\
0 \\
0 \\
0\end{array}$ & $\begin{array}{r}780000 \\
1670000 \\
8000000 \\
1210800 \\
4800000 \\
691900\end{array}$ & $\begin{array}{r}0.00 \\
4.74 \\
10.91 \\
10.91 \\
16.43 \\
10.91\end{array}$ & $\begin{array}{r}0 \\
79158 \\
872800 \\
132098 \\
788640 \\
75486\end{array}$ & $\begin{array}{r}780000 \\
1749158 \\
8872800 \\
1342898 \\
5588640 \\
767386\end{array}$ & $\begin{array}{l}35 \\
35 \\
35 \\
35 \\
35 \\
35\end{array}$ & $\begin{array}{r}273000 \\
612205 \\
3105480 \\
470014 \\
1956024 \\
268585\end{array}$ & $\begin{array}{r}1053000 \\
2361363 \\
11978280 \\
1812913 \\
7544664 \\
1035871\end{array}$ \\
\hline 17152700 & 0 & 17152700 & 11.36 & 1948182 & 18100882 & 35 & 6685308 & 25786191 \\
\hline $\begin{array}{r}512050 \\
934879 \\
4005848\end{array}$ & $\begin{array}{l}0 \\
0 \\
0\end{array}$ & $\begin{array}{r}512050 \\
934879 \\
4005848\end{array}$ & $\begin{array}{l}10.91 \\
10.91 \\
10.91\end{array}$ & $\begin{array}{r}55865 \\
101995 \\
437038\end{array}$ & $\begin{array}{r}567915 \\
1036874 \\
4442886\end{array}$ & $\begin{array}{l}35 \\
35 \\
25\end{array}$ & $\begin{array}{r}198770 \\
362906 \\
1110722\end{array}$ & $\begin{array}{r}766685 \\
1399780 \\
5553608\end{array}$ \\
\hline 5452777 & 0 & 5452777 & 10.91 & 594898 & 6047675 & 28 & 1672398 & 7720073 \\
\hline 517440 & 0 & 517440 & 10.81 & 56453 & 573893 & 35 & 200862 & 774755 \\
\hline 517440 & 0 & 517440 & 10.91 & 56453 & 573893 & 35 & 200862 & 774755 \\
\hline 5970217 & 0 & 5970217 & 10.91 & 651351 & 6621568 & 28 & 1873260 & 8494828 \\
\hline 5970217 & 0 & 5970217 & 10.91 & 651351 & 6621568 & 28 & 1873260 & 8494828 \\
\hline $\begin{array}{r}105481 \\
120719 \\
57196 \\
312427 \\
52752 \\
422850 \\
739197 \\
985884\end{array}$ & $\begin{array}{l}0 \\
0 \\
0 \\
0 \\
0 \\
0 \\
0 \\
0\end{array}$ & $\begin{array}{r}105481 \\
120719 \\
57196 \\
312427 \\
52752 \\
422850 \\
739197 \\
985884\end{array}$ & $\begin{array}{l}16.43 \\
16.43 \\
16.43 \\
16.43 \\
16.43 \\
16.43 \\
16.43 \\
16.43\end{array}$ & $\begin{array}{r}17331 \\
19834 \\
9397 \\
51332 \\
8667 \\
69474 \\
121450 \\
161981\end{array}$ & $\begin{array}{r}122812 \\
140553 \\
66593 \\
363759 \\
61419 \\
492324 \\
860647 \\
1147865\end{array}$ & $\begin{array}{l}25 \\
35 \\
35 \\
35 \\
35 \\
35 \\
35 \\
30\end{array}$ & $\begin{array}{r}30703 \\
49194 \\
23308 \\
127316 \\
21497 \\
172313 \\
301226 \\
344359\end{array}$ & $\begin{array}{r}153516 \\
18974 i \\
89901 \\
491074 \\
82916 \\
664631 \\
1161872 \\
1492226\end{array}$ \\
\hline 2796506 & 0 & 2796506 & 16.43 & 459466 & 3255972 & 33 & 1069916 & 4325886 \\
\hline $\begin{array}{l}77844 \\
47864 \\
42897\end{array}$ & $\begin{array}{l}0 \\
0 \\
0\end{array}$ & $\begin{array}{l}77844 \\
47864 \\
42897\end{array}$ & $\begin{array}{l}16.43 \\
16.43 \\
16.43\end{array}$ & $\begin{array}{r}12790 \\
7864 \\
7048\end{array}$ & $\begin{array}{l}90634 \\
55728 \\
49945\end{array}$ & $\begin{array}{l}25 \\
40 \\
35\end{array}$ & $\begin{array}{l}22658 \\
22291 \\
17481\end{array}$ & $\begin{array}{r}11329 i \\
7801 \% \\
67421\end{array}$ \\
\hline & $A-5 i$ & & & & & & & 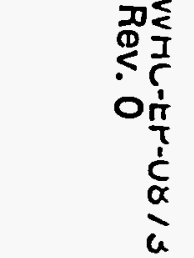 \\
\hline
\end{tabular}
OAE $03 / 22 / 93 \quad 14: 33: 14$ GDR
PAGE 2 OF 13 
KAISER ENGINEERS HANFORD

HESTINGHOUSE HAHFORD COMPANY

JOB NO. ER3415/24ITUHL

FILE HO. 241 TUNL

HBS DESCRIPTIOH

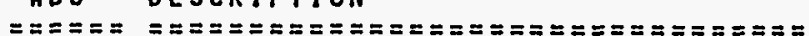

310250 MTD. BASE/HASHDOHH/SLIDE VALVES

310260 INSTALL PROCESS EQUIP. 103-FY

310270 PIPING INSIDE 103-FY FARM

$310280103-F Y$ ELEC EQUIPMENT

SUBTOTAL $3102 \quad 103$ FY TANK FARM

310320 TRANSFER PIPING T-101 TO 103.FY

SUBTOTAL 3103 ENCASED PIPE T-101/103-FY

310400 CONTROL RM/LUNCH RM/CHAHGE RM

SUBTOTAL 3104 CONTROL RM./LUNCH/CHANGE TM

310510 BURH OUT T-101

310520 BURN OUT $103-F Y$

SUBTOTAL 3105 BURN OUT

310600 STEP OFF PAD

SUBTOTAL 3106 STEP OFF PAD SUPPORT

SUBTOTAL 31 KEH CONSTRUCTION

330110 PRE- TRANSFER DEMn. T-101

330120 PRE-TRANSFER DEM: 103-FY

SUBTOTAL 3301 PRE TRAHSFER DEHOLITION

330210 POST-TRANSFER DEMO.T.101

330220 POST-TRANSFER DEMO. 103-FY

SUBTOTAL 3302 POST TRANSFER DEMOLITION
* * IEST - INTERACTIVE ESTIMATING * TANK 241-T-101 TOTAL RETRIEVAL ALTERHATIVE STUDY ESTIHATE OPTION \#I UNLIMITED SLUICIHG DOE_RO2 - HORK BREAKDOWN STRUCTURE SUMMARY

\begin{tabular}{|c|c|c|c|c|c|c|c|c|}
\hline $\begin{array}{l}\text { ESTIMATE } \\
\text { SUB TOTAL } \\
=======\end{array}$ & $\begin{array}{l}\text { OHSITE } \\
\text { INDIRECTS } \\
========\end{array}$ & $\begin{array}{c}\text { SUB } \\
\text { TOTAL } \\
=========\end{array}$ & $======$ & $\begin{array}{l}\text { ILATIOH } \\
\text { TOTAL } \\
=======\end{array}$ & $\begin{array}{c}\text { SUB } \\
\text { TOTAL } \\
===== \pm= \pm E\end{array}$ & $\begin{array}{l}\operatorname{CONTI} \\
x=2 x\end{array}$ & $\begin{array}{l}\text { HGENCY } \\
\text { TOTAL } \\
==== \pm== \pm=\end{array}$ & $\begin{array}{c}\text { TOTAL } \\
\text { OOLLARS } \\
=========\end{array}$ \\
\hline $\begin{array}{r}115949 \\
40849 \\
352308 \\
130650\end{array}$ & $\begin{array}{l}0 \\
0 \\
0 \\
0\end{array}$ & $\begin{array}{r}115949 \\
40849 \\
352308 \\
1306.50\end{array}$ & $\begin{array}{l}16.43 \\
16.43 \\
16.43 \\
16.43\end{array}$ & $\begin{array}{r}19050 \\
6711 \\
57884 \\
21467\end{array}$ & $\begin{array}{r}134999 \\
47560 \\
410192 \\
152117\end{array}$ & $\begin{array}{l}35 \\
35 \\
35 \\
35\end{array}$ & $\begin{array}{r}47250 \\
16646 \\
143567 \\
53241\end{array}$ & $\begin{array}{r}182249 \\
64207 \\
553759 \\
205355\end{array}$ \\
\hline 808361 & 0 & 808361 & 16.43 & 132814 & 941175 & 34 & 323134 & 1264307 \\
\hline 22284725 & 0 & 22284725 & 16.43 & 3661380 & 25946105 & 30 & 7783832 & 33729937 \\
\hline 22284725 & 0 & 22284725 & 16.43 & 3661380 & 25946105 & 30 & 7783832 & 33729937 \\
\hline 238451 & 0 & 238451 & 16.43 & 39178 & 277629 & 40 & 111051 & 388680 \\
\hline 238451 & 0 & 238451 & 16.43 & 39178 & 277629 & 40 & 111051 & 388680 \\
\hline $\begin{array}{l}753152^{\circ} \\
232969\end{array}$ & $\begin{array}{l}0 \\
0\end{array}$ & $\begin{array}{l}753152 \\
232969\end{array}$ & $\begin{array}{l}16.43 \\
16.43\end{array}$ & $\begin{array}{r}123743 \\
38277\end{array}$ & $\begin{array}{l}876895 \\
271246\end{array}$ & $\begin{array}{l}35 \\
35\end{array}$ & $\begin{array}{r}306913 \\
94936\end{array}$ & $\begin{array}{r}1183808 \\
366182\end{array}$ \\
\hline 986121 & 0 & 986121 & 16.43 & 162020 & 1148141 & 35 & 401849 & 1549990 \\
\hline 276108 & 0 & 276108 & 16.43 & 45365 & 321473 & 30 & 96442 & 417914 \\
\hline 276108 & 0 & 276108 & 16.43 & 45365 & 321473 & 30 & 96442 & 417914 \\
\hline 27390272 & 0 & .27390272 & 16.43 & 4500223 & 31890495 & 31 & 9786224 & 41678714 \\
\hline $\begin{array}{l}460343 \\
115885\end{array}$ & $\begin{array}{l}0 \\
0\end{array}$ & $\begin{array}{l}460343 \\
115885\end{array}$ & $\begin{array}{l}4.74 \\
4.74\end{array}$ & $\begin{array}{r}21820 \\
5493\end{array}$ & $\begin{array}{l}482163 \\
121378\end{array}$ & $\begin{array}{l}35 \\
35\end{array}$ & $\begin{array}{r}168757 \\
42483\end{array}$ & $\begin{array}{l}650921 \\
163861\end{array}$ \\
\hline 576228 & 0 & 576228 & 4.74 & 27313 & 603541 & 35 & 211240 & 814782 \\
\hline $\begin{array}{r}1527428 \\
617988\end{array}$ & $\begin{array}{l}0 \\
0\end{array}$ & $\begin{array}{r}1527428 \\
617888\end{array}$ & $\begin{array}{l}28.08 \\
28.08\end{array}$ & $\begin{array}{l}428902 \\
173531\end{array}$ & $\begin{array}{r}1956330 \\
791519\end{array}$ & $\begin{array}{l}35 \\
35\end{array}$ & $\begin{array}{l}684715 \\
277032\end{array}$ & $\begin{array}{l}2641045 \\
1068551\end{array}$ \\
\hline 2145416 & 0 & 2145416 & 28.08 & 602433 & 2747849 & 35 & 961747 & كَ" \\
\hline
\end{tabular}

PAGE 3 OF 13

DATE $03 / 22 / 93 \quad 14: 33: 15$

BY GDR 
KAISER EHGINEERS HAHFORD

HEST IHGHOUSE HAHFORD COHPAHY

JOB NO. ER3415/241TUNL

FILE HO. 241 TUNL

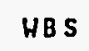

* IEST - INTERACTIVE ESTIMATIHG * * TAHK 241-T-101 TOTAL RETRIEVAL ALTERHATIVE STUDY ESTIMATE OPTION HI UHLIMITED SLUICING DOE_RO2 - HORK BREAKDOHH STRUCTURE SUMMARY
PAGE 4 OF 13

DATE 03/22/93 14:33:15

BY GDR

\begin{tabular}{|c|c|c|c|c|c|c|c|c|}
\hline $\begin{array}{l}\text { ESTIMATE } \\
\text { SUB TOTAL } \\
=======\end{array}$ & $\begin{array}{l}\text { ONSITE } \\
\text { IHDIRECTS } \\
== \pm=====\end{array}$ & $\begin{array}{c}\text { SUB } \\
\text { TOTAL } \\
=z=z=z==\end{array}$ & $\begin{aligned} & E S C A \\
& \% \\
& \%=x==\end{aligned}$ & $\begin{array}{l}\text { ALATION } \\
\text { TOTAL. } \\
====\approx==\end{array}$ & $\begin{array}{c}\text { SUB } \\
\operatorname{TOYAL} \\
== \pm==z=z\end{array}$ & $\begin{array}{l}\text { CONTI } \\
x=x=2\end{array}$ & $\begin{array}{l}\text { HGENCY } \\
\text { TOTAL } \\
====\approx====\end{array}$ & $\begin{array}{c}\text { TOTAL } \\
\text { DOLLARS } \\
=====\approx=\Sigma=\end{array}$ \\
\hline $\begin{array}{l}141120 \\
606875\end{array}$ & $\begin{array}{l}0 \\
0\end{array}$ & $\begin{array}{l}141120 \\
606875\end{array}$ & $\begin{array}{r}4.74 \\
28.08\end{array}$ & $\begin{array}{r}6689 \\
170411\end{array}$ & $\begin{array}{l}147809 \\
777286\end{array}$ & $\begin{array}{l}40 \\
40\end{array}$ & $\begin{array}{r}59124 \\
310914\end{array}$ & $\begin{array}{r}206933 \\
1088200\end{array}$ \\
\hline 747995 & 0 & 747995 & 23.68 & 177100 & 925095 & 40 & 370038 & 1295133 \\
\hline 3469639 & 0 & 3469639 & 23.25 & 806846 & 4276485 & 36 & 1543025 & 5819511 \\
\hline 30859911 & 0 & 30859911 & 17.20 & 5307069 & 36166980 & 31 & 11329249 & 47496225 \\
\hline 5386000 & 0 & 5386000 & 17.25 & 929085 & 6315085 & 30 & 1894526 & 8209611 \\
\hline 5386000 & 0 & 5386000 & 17.25 & 929085 & 6315085 & 30 & 1894526 & 8209611 \\
\hline 20800000 & $\mathbf{0}$ & 20800000 & 17.25 & 3588000 & 24388000 & 30 & 7316400 & 31704400 \\
\hline 20800000 & 0 & 20800000 & 17.25 & 3588000 & 24388000 & 30 & 7316400 & 31704400 \\
\hline
\end{tabular}

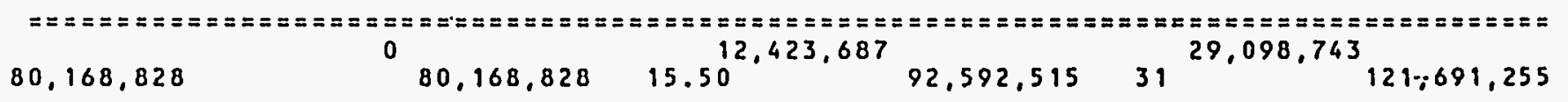


KAISER ENGIHEERS HANFORD HESTINGHOUSE HANFORD COMPAHY JOB HO. ER3415/241TUNL

FILE NO.
* * IEST - INTERACTIVE ESTIHATING *

TAHK 241-T-101 UNLIMITED SLUICING STUDY

DOE_RO3 - ESTIMATE BASIS SHEET
PAGE 5 OF 13

DATE $03 / 22 / 9308: 09: 53$

BY

1. DOCUMENTS AND DRAHINGS

$==================$

DOCUMENTS: ENGINEERING EVALUATION OF ALTERNATEIVES - MANAGING THE ASSUMED LEAK FROM SINGLE SHELL TAHK 241 - $1012 / 93$.

DRAHINGS: IN SAME DOCUMENT AS ABOVE

2. HATERIAL PRICES

$==============$

UNIT COSTS REPRESENT CURRENT PRICES FOR SPECIFIED MATERIAL.

3. LABOR RATES

$===\Sigma==z====$

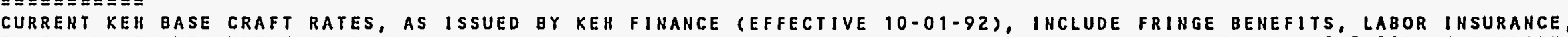

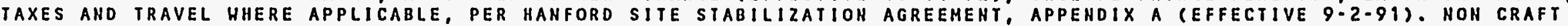

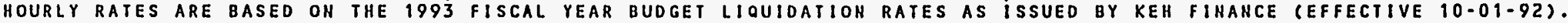

4. GENERAL REQUIREMENTS/TECHNICAL SERVICES/OVERHEADS

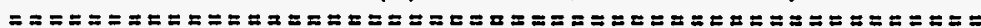

A.) OHSITE CONSTRUCTION FORCES GENERAL REQUIREMENTS, TECHNICAL SERVICES AHD CRAFT OVERHEAD COSTS ARE INCLUDED AS A

COMPOSITE PERCENTAGE BASED ON THE KEH ESTIMATIHG FACTOR/BILLIHG SCHEDULE, REVISION I4, DATED OCTOBER O1, I992. THE TOTAL COMPOSITE PERCENTAGE APPLIED TO ONSITE CONSTRUCTION FORCES LABOR. FOR THIS PROJECT, IS O3\% FOR SHOP HORK AND $134 \%$ FOR FIELD WORK. HHICH IS REFLECTED IN THE "OH\&P/B\&I" COLUHN OF THE ESTIMATE DETAIL.

5. ESCALATION

$=z=\Sigma=\Sigma= \pm=$

ESCALATION PERCENTAGES HERE CALCULATED BY THE HANFORD MATERIAL \& LABOR ESCALATION STUDY, DATED FEBRUARY I992.

6. ROUNDING

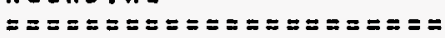

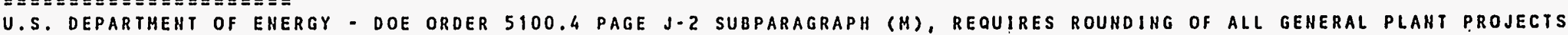
(GPP'S) AND LINE ITEM (LI) COST ESTIMATES. REFERENCE: DOE 5100.4, FIGURE I-11. DATED I0-31-B4.

7. REMARKS

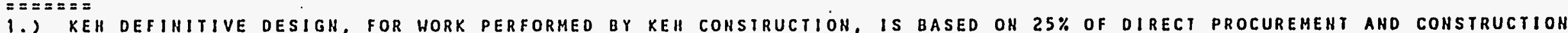
COSTS LESS BURH-OUT COST.

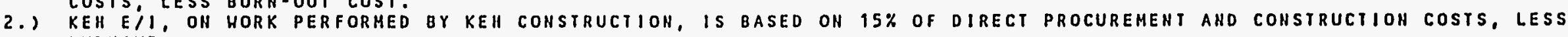
BURNOUT.

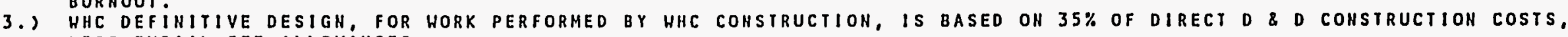
LESS BURIAL FEE ALLOHANCES.

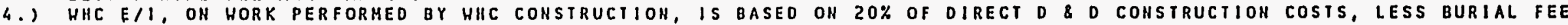
ALL OHANCES.

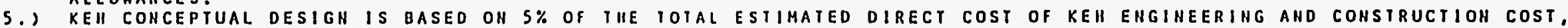
LESS BURN-OUT.

6.) HBS 5 (OTHER COST) COST ARE OASED ON $35 \%$ OF IHE IOIAL DIRECT COST OF ENGINEERING, CONSTRUCIION, PROCUREMENT. AND ARE BASED OH A STUDY ESTIHATE ON C. 106 REIREVIAL. 


\section{REMARKS (CONTIHUEO)}

$====\Sigma=$

7.) ASSUME THAT (2) TRANSFER PUMPS AHD (1) HEEL PUMP HILL HAVE TO BE REMOVED AT T-1O1.

8.) THE EXISTING PITS AT T-101 AHD 103.FY HILL BE UPGRADED PRIOR TO EQUIPMENT INSTALLATIOH. UPGRADING HILL INCLUDE LINING THE PITS HITH AN EPJXY SEALAHT.

9.) HHC D \& D OVERHEAD COSTS HERE APPLIED TO LABOR AT 52\% BASED ON PROJECT H-151. DATED O4/3O/9O.

10$.$) HHC D \& D OVERHEAD COSTS HERE APPLIED TO DIRECT MATERIAL PURCHASES AT 17.4O\%.$

11.) KEH PROCUREMENT COSTS FOR THE HVAC EQUIPHENT ARE BASED ON A VENDOR SUPPLIED BUDGET ESTIHATE. HOHEVER, COSTS FOR SHIELDING HERE NOT INCLUDEDI IN THIS VENDOR QUOTE.

12.) KEH PROCUREMENT COSTS FOR TRANSFER PUMPS, SLUICE MAST AHD SLUICE PUMP HERE ALLOHAHCES EXTRACTED FROM PREVIOUS COST ESTIMATES THAT USED SIMILAR EQUIPMENT.

13.) BURH-OUT ALLOHANCES FOR SEALING OF THE PIT INTERIORS HITHIN T-101 TAHK FARM HERE ASSUMED BY KEH (IOO HR).

14.) BURH-OUT ALLOHANCES FOR SEALIHG OF THE PIT INTERIORS HITHIN $102-F Y$ TANK FARM HERE ASSUMED BY KEH (5O MR):

15.) ALL BURH-OUT ALLOHANCES APPLY TO WORK PERFORMED BY KEH COHSTRUCTIOH OHLY. HORK PERFORMED BY HHC COHSTRUCTION OH THE PRE-TRANSFER \& POST-TRANSFER D\& D DOES NOT HAVE BURN-OUT ALLOHANCES CALCULATED.

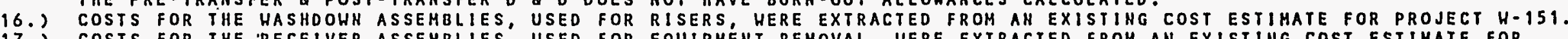

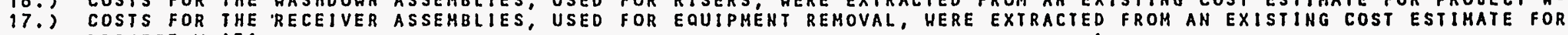
PROJECT H-151.

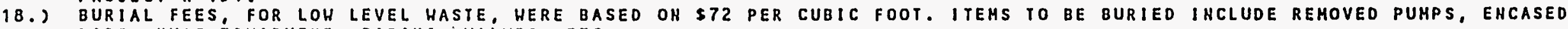
PIPE, HVAC EQUIPMENT, PIPING, VALVES, ETC.

19.) BURIAL FEES, FOR HAZARDOUS HASTE, HERE BASED ON S4Z PER CUBIC YARD. (STEEL SHIELDIHG ONLY)

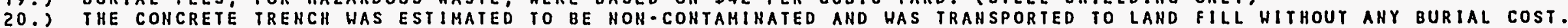

IT HAS ASSUMED THAT A PORTABLE GREENHOUSE/GLOVEBOX HOULD BE USED FOR REMOVAL OF THE ENCASED PIPE.

22.) THE CONCRETE TRENCH WAS ESTIMATED AT 18 "THICK WITH 12OLBS OF REBAR PER CUBIC YARO.

23.) THE USE OF CARBON STEEL, " TIIICK, HAS ESTIMATED FOR SHIELDING REQUIREMEHTS AROUND THE SCRUBBER SKID AMD FILTER HOUSING SKID.

24.) THIS ESTIMATE DID NOT ALLOW FOR SHIELDING AROUHO THE FANS AND FILTER ROOH SKIDS AS REOUESTED BY HHC.

25.) ALL ENCASED PIPING, HITHIN THE TANK FARMS, HAS ROUTED IN THE CONCRETE TRENCH LOCATED ABOVE GRADE.

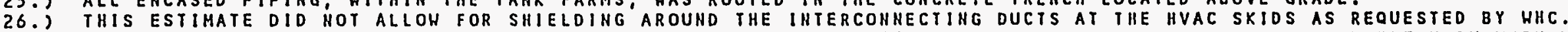

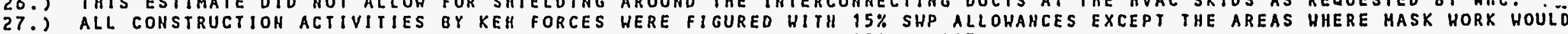
BE REQUIRED AND THE INSTALLATION OF THE ENCASED PIPE FROM T-101 TO 103-FY.

28.) ASSUHPTIONS HERE MADE ON ALL QUAHTITIES WHEH THE ESTIMATE WAS BASED ON FLOH DIAGHRAMS \& SKETCHES.

28.) ASSUMED (2) TRANSFER PUMPS HILL NEEO TO BE REMOVED FROM IO3-FY TANK FARH.

30.) THE T.10I PITS HILL BE SEALED HITK POLYURETHANE FOAM ONCE POST TRAHSFER DEMOLITION HAS BEEN COMPLETED.

31.) THE HVAC PROCURED SKIDS HILL INCLUDE INSTRUMENTAION AND MUX.

32.) ELECTRICAL SKIOS HILL FURHISH POHER TO THE HVAC SKIDS BY SURFACE DUCTS AND CABLE.

33.) THE ESCALATION PERCENTAGES HERE BLSED ON A PRELIMINARY SCHEDULE.

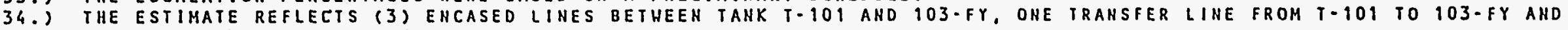
ONE RETURH WITH OLE SPARE. 
KAISER ENGINEERS HANFORD

WEST INGHOUSE HANFORD COMPANY

JOB HO. ER3415/241TUHL

FILE NO. 241 TUNL

$\cos T$

CODE/HBS

DESCRIPTIOH -

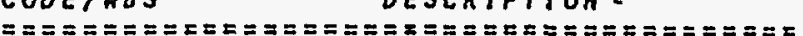

000 EHGINEERING

111000 KEH ENGINEERING STUDY

112000 KEH CONCEPTUAL DESIGN

113000 KEH DEFINITIVE DESIGN

114000 HHC D \& D DESIGN

121000 KEH EHGINEERING/INSPECTION

122000 HHC ENGRIINSPEC. D \& D

400000 HHC PROJECT MANAGEMENT

TOTAL OOO ENGINEERIHG

600 UTILITIES

210180 T-101 ELEC EQUIP.

310180 ELECTRICAL IN T.101 FARM

310280 103.FY ELEC EQUIPMENT

310400 CONTROL RM/LUNCH RM/CHANGE RM

TOTAL 600 UTILITIES

700 SPECIAL EQUIP/PROCESS SYSTEMS

\begin{tabular}{|c|c|}
\hline $\begin{array}{l}210160 \\
210190 \\
210260 \\
3101100 \\
310120 \\
310140 \\
310150 \\
310160 \\
310170 \\
310180 \\
310190 \\
310210 \\
310220 \\
310240 \\
310250\end{array}$ & 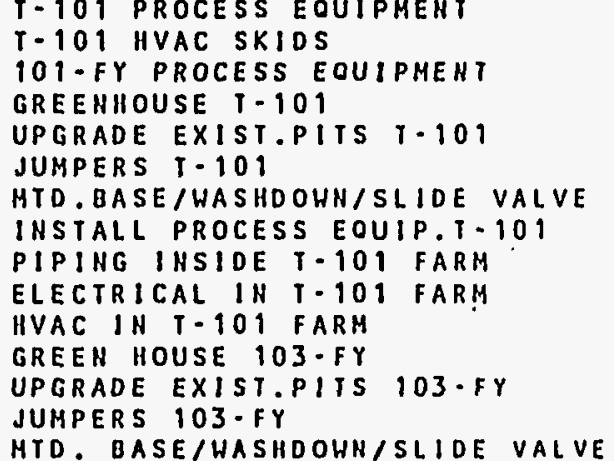 \\
\hline
\end{tabular}

* * IEST - INTERACTIVE ESTIHATING * *

TAHK 241-T-101 TOTAL RETRIEVAL ALTERHATIVE

STUDY ESTIMATE OPTIOH \#I UHLIHITED SLUICING

DOE_ROA - COST CODE ACCOUHT SUMMARY

ESTIMATE SUBTOTAL

OHSITE INDIRECTS $==\Sigma==\pi==$

SUB
TOTAL

SCALATION
TOTAL
$=z===\pi=z$

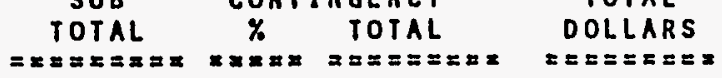

PAGE 7 OF 13

$\begin{array}{ll}\text { DATE } & 03 / 22 / 93 \quad 14: 33: 19 \\ \text { BY } & \text { GDR }\end{array}$

SUB COHTINGEHCY

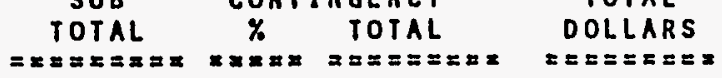

TOTAL

780000

1670000

8000000

1210800

4800000

691900

5386000

22538700

780000
1670000
8000000
1210800
4800000
691900
5386000
22538700

0.00

4.74
10.91

10.91

10.91

16.43
10.91

17.25

12.77

79158
872

872800

132098

788640

75486

929085

2877267

780000

1749158

8872800

1342898

5588640

767386

6315085

$25415967 \quad 34$

35
35
35
35
35
35
30
34

273000 612205
3105480

3105480

470014

1956024

268585

1894526

8579834

1053000

2361363
11978280

1812913

7544664

1035971

8209611

33995802

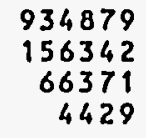

1162021

934879
156342
66371

10.91
16.43

16.43

16.44
101995
25687
10905
728

1036874
182029
77276
5157

\begin{tabular}{l}
35 \\
35 \\
35 \\
40 \\
\hline
\end{tabular}

1162021

11.99

139315

1301336

35
362906
63710
27046
2063

455725
1399780
245739
104322
7219
1757060

512050
4005848
517440
105481
120719
57196
312427
52752
422850
582855
985884
77844
47864
42897
115949

$\begin{array}{rrr}512050 & 10.91 & 55865 \\ 4005848 & 10.91 & 437038 \\ 517440 & 10.91 & 56453 \\ 105481 & 16.43 & 17331 \\ 120719 & 16.43 & 19834 \\ 57196 & 16.43 & 9397 \\ 312427 & 16.43 & 51332 \\ 52752 & 16.43 & 8667 \\ 422850 & 16.43 & 69474 \\ 582855 & 16.43 & 95763 \\ 985884 & 16.43 & 161981 \\ 77844 & 16.43 & 12790 \\ 47864 & 16.43 & 7864 \\ 42897 & 16.43 & 7048 \\ 115949 & 16.43 & 19050\end{array}$

567915

4442886

573893

122812

140553

66593

363759

61419

492324

678618

1147865

97865

90634
55728

55728

49945
134999

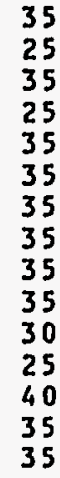

198770
1110722
200862
30703
49194
23308
127316
21497
172313
237516
344359
22658
22291
17481
47250
766685

5553608

774755

153514

189747

89901
491074

82916

664638 :

916133
1492224

1492224

113292

78019

67426

182249 
KAISER ENGINEERS HAHFORD

HESTINGHOUSE HAHFORD COMPANY

JOB NO. ER3415/241TUHL

FILE HO. 241 TUNL

$\cos T$

CODE/WBS

DESCR IPT IOH

310260 INSTALL PROCESS EQUIP. 103-FY

310270 PIPING INSIDE 103-FY FARM

310280 103-FY ELEC EQUIPHENT

310320 TRANSFER PIPING T-101 TO 103-FY

310400 CONTROL RM/LUNCH RM/CHAHGE RM

310510 BURN OUT T-101

310520 BURN OUT $103-F$

310600 STEP OFF PAD

TOTAL 700 SPECIAL EQUIP/PROCESS SYSTI:M

DEMOLITION

330110 PRE-TRANSFER DEMO. T-101

330120 PRE-TRANSFER D.MO,. 103-FY

330210 POST-TRANSFER DEHO. T-101

330220 POST-TRANSFER DEMO. 103-FY

330410 BURIAL FEES - PRE TRANSFER

330420 BURIAL FEES - POST TRANSFER

TOTAL 810 DEMOLITION

900 OTHER COSTS

500010 HHC (OTHER COST)

TOTAL 900 OTHER COSTS

PROJECT TOTAL
* * IEST - IHTERACTIVE ESTIMATIHG * *

TAHK 241-T-101 TOTAL RETRIEVAL ALTERHATIVE STUOY ESTIHATE OPTION HI UNLIHITED SLUICIHG

DOE ROA - COST CODE ACCOUNT SUMMARY
PAGE 8 OF 13

DATE $03 / 22 / 93 \quad 14: 33: 20$
ESTIMATE
SUBTOTAL
$===\approx==x=$
40849
352308
64279
22284725
234022
753152
232969
276108

32198468
ONSITE
INDIRECTS
$==\approx=z=\Omega==$

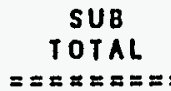

$= \pm 2=2= \pm=$

40849
352308

64279

.22284725

234022

753152

232969
276108

$0 \quad 32198468$

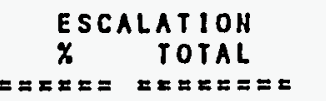

SUB
TOTAL

$a=$

$6.43 \quad 6719$

16.43

16.43

16.43

16.43

16.43

16.43

10562

3661380

38450

123743

38277

45365

$15.57 \quad 5012259$

460343

115885

1527428

617988

141120

606875

3469639

460343

115885

1527428

617988

141120

606875

3469639

4.7
4.7
28.0
28.0
4.74

21820
5493
428902
173531
6689
17041

482163
121378

1956330

791519

147809

777286

8.08

170411

23.25

806846

4276485

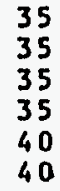

168757
42483
684715

277032

59124
310914

1543025

36

7316400

31704400

20800000

020800000

$17.25 \quad 3588000$

24388000

$0 \quad 20800000$

17.25

3588000
7316400

31704400
TOTAL

64207
553759
101033
33729937
381461
1183808
366182
417914

48414482

65092 163861
2641045 1068551 206933
088200

5819511

$\begin{array}{cccccc} & =5,12,423,687 & & & 29,098,743 & 121,691,255\end{array}$


KAISER ENGINEERS HANFORD HESTINGHOUSE HANFORD COMPANY

JOB NO. ER3415/241TUNL

FILE NO. 241 TUNL

CSI DESCRIPTION

\section{ENGINEERING}

OO TECHHICAL SERVICES

19 HHC PROJECT MANAGEMENT

TOTAL ENGINEERING

\section{CONSTRUCTION}

OI GENERAL REQUIRMENTS
03 CONCRETE
13 SPECIAL CONSTRUCTION
15 HECHANICAL
16 ELECTRICAL
20 OTHER COST
TOTAL CONSTRUCTIOH

PROJECT TOTAL
* IEST - INTERACTIVE ESTIMATING * * TANK 241-T-101 TOTAL RETRIEVAL ALTERHATIVE STUDY ESTIMATE OPTION \#I UNLIMITED SLUICING DOE_ROS - ESTIMATE SUMHARY BY CSI DIVISION
PAGE 9 OF 13

DATE O3/22/93 14:33:24

BY GDR

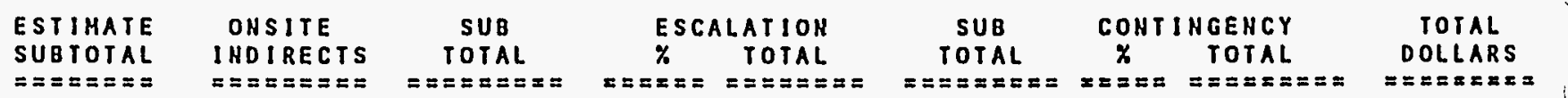

\begin{tabular}{|c|c|c|c|c|c|c|c|c|}
\hline $\begin{array}{r}2426732 \\
5144 \\
368583 \\
32053916 \\
1975753 \\
20800000\end{array}$ & $\begin{array}{l}0 \\
0 \\
0 \\
0 \\
0 \\
0\end{array}$ & $\begin{array}{r}2426732 \\
5144 \\
368583 \\
32053916 \\
1975753 \\
20800000\end{array}$ & $\begin{array}{l}17.54 \\
16.43 \\
16.43 \\
16.27 \\
13.00 \\
17.25\end{array}$ & $\begin{array}{r}425659 \\
845 \\
60558 \\
5214445 \\
256913 \\
3588000\end{array}$ & $\begin{array}{r}2852391 \\
5989 \\
429141 \\
37268361 \\
2232666 \\
24388000\end{array}$ & $\begin{array}{l}35 \\
35 \\
38 \\
30 \\
35 \\
30\end{array}$ & $\begin{array}{r}1007173 \\
2096 \\
164629 \\
11244940 \\
783671 \\
7316400\end{array}$ & $\begin{array}{r}3859562 \\
8085 \\
593770 \\
48513303 \\
3016333 \\
31704400\end{array}$ \\
\hline
\end{tabular}

$57,630,128$

$0 \quad 97,630,128 \quad 966,420$

$67,176,548 \quad 20,518,909$

$39^{20,518,909} 87,695,453$ 1 
KAISER ENGINEERS HANFORD

HESTINGHOUSE HAHFORD COMPANY

JOB HO. ER3415/241TUNL

FILE NO.
* IEST - INTERACTIVE ESTIMATIHG **

TANK 241-T-101 UNLIMITED SLUICING

STUDY ESTIMATE

DOE_ROS - CONTIHGENCY ANALYSIS BASIS SHEET
PAGE 10 OF 13

DATE $02 / 24 / 93 \quad 13: 57: 05$

$\begin{array}{lllll}\text { REFERENCE: } & \text { ESTIMATE BASIS SHEET } & \text { PAGE } & 5 & \text { OF I3 } \\ & \text { COST CODE ACCOUNT SUMMARY } & \text { PAGE } & 7 & \text { OF I3 }\end{array}$

THE U.S DEPARTMENT OF EHERGY - RICHLAND ORDER 5700.3 "COST ESTIMATIHG ANALYSIS AND STANDARDIZATIOH" DATED 3-27-85. PROVIDES GUIDELINES FOR ESTIHATE CONTINGEHCIES. THE GUIDELIHE FOR A STUDY ESTIMATE ASSOCIATED HITH EXPERIMENTAL/SPECIAL CONDITIONS SHOULD HAVE AN OVERALL RANGE OF $20 \%$ TO $50 \%$.

COHIINGENCY IS EVALUATED AT THE THIRD COST CODE LEVEL AND SUMMARIZED AT THE PRIMARY AND SECONDARY COST CODE LEVEL OF THE DETAILED COST ESTIMATE.

ENGINEERING

$\operatorname{COST} \operatorname{CODE} \cdot 000$

HBS $1.1,1,0,0,0$

AH OVERALL AVERAGE OF $12 \%$ CONTIHGEHCY HAS APPLIED TO THE ENGINEERING STUDY ESTIMATE DUE TO THE COST TO DATE AND THE ESTIMATE TO COMPLETE CALCULATIONS.

HBS 1.1 .2 .0 .0 .0 THRU HBS 1.2 .2 .0 .0 .0

A $35 \%$ CONTINGENCY HAS APPLIED TO ALL REMAINING ENGINEERING FUNCTIONS DUE TO THE ALLOHANCES PROVIDED HERE BASED ON A PERCENTAGE OF CONSTRUCTIOH COSTS. ALSO, IT APPEARS THAT THE EVOLUTION OF DESIGN HILL INEYITABLY INCREASE DESIGN AND SCHEDULING COSTS DUE TO UNKHOHHS.

HBS 4.0 .0 .0 .0 .0

A $30 \%$ CONTINGENCY HAS APPLIEO TO THE HHC PROJECT MANAGEMENT PORTION OF THE EHGINEERING ESTIMATE BY WESTINGHOUSE DIRECTION.

CONSTRUCTION

$\operatorname{COST} \operatorname{CODE} 600$

HBS 2.1 .0 .1 .8 .0

A $35 \%$ CONTINGENCY WAS APPLIED IO IHE ELECIRICAL EQUIPMENT PROCUREMENT ITEMS DUE IO IHE LIMITED AMOUHT OF INFORMATION AVAILABLE FOR IIIS EIFORT.

WBS $3.1 .0 .1 .8 .0 \&$ WBS 3.1 .0 .2 .8 .0 A $35 \%$ CONIINGENCY NAS ALSO APPLIEO IO IHE ELECIRICAL EOUIPHENI IMSIALIATIOH DUE IO IHE ASSUHPTIOHS MADE FOR QUANTITIES AND INSIALLAIION HAIERIAL REQUIREHENIS. 
KAISER ENGINEERS HANFORD HEST INGHOUSE HAHFORD COMPANY JOB NO. ER3415/241TUNL FILE NO. 2\&ITUNL

\author{
* * IEST - InTERACTIVE ESTIMATING * \\ TAHK 241-T-101 UNLIMITED SLUICING \\ STUDY ESTIHATE \\ DOE ROG - CONTINGENCY ANALYSIS BASIS SHEET
}

PAGE 11 OF 13

DATE $02 / 25 / 93 \quad 13: 57: 0$

BY GOR

HBS $3.1 \cdot 0.4 \cdot 0.0$

A $40 \%$ CONTINGENCY HAS APPLIEO TO THE CONTROL ROOM, CHANGE ROOM, ANO LUNCH ROOH TRAILER ALLOHAKCES DUE TO THE LIMITED INFORMATION AVAILABLE AT THIS TIME.

$\cos T \operatorname{CODE} 700$

HBS 2.1 .0 .1 .6 .0 AND WBS 2.1 .0 .2 .6 .0

A $35 \%$ CONTINGENCY HAS APPLIED TO THE PUMPS, SLUICE MAST AHD DISTRIBUTOR DISCHARGE SIPHOH, DUE TO THE ALLOHAHCES PROVIDED HERE EXTRACTED FROM PREVIOUS PARAMETRIC COST ESTIMATES FOR SIMILAR ITEMS.

HBS $2.1 \% 0.1 .9 .0$ A $25 \%$ CONTINGENCY HAS APPLIED TO THE IVAC EQUIPHENT DUE TO THE INFORMATION AND BUDGET QUOTE SUPPLIED BY A QUALIFIED VENDER.

HBS 3.1 .0 .1 .1 .0 \& WBS 3.1 .0 .2 .1 .0 A $25 \%$ CONTINGENCY HAS APPLIED TO THE CONSTRUCTION COSTS OF BUILDIHG GREENHOUSEIS OVER THE PITS AHO RISERS BECAUSE OF ASSUMPTIONS ASSOCIATED HITH THE SIZE AND STYLE REQUIRED.

HBS $3,1.0,1,2.0 \&$ HBS $3.1,0.2 .2 .0$ A $35 \%$ \% $40 \%$ CONTINGENCY HAS APPLIED AGAINST THE CONSTRUCTIOH TASKS ASSOCIATED HITH THE UPGRADING OF THE EXISTING PITS BECAUSE OF UNKNOHN COHTAMINATION REOUIREMENTS AHD LIMITED SCOPE DEFINITIOH.

HBS 3.1 .0 .1 .4 .0 \& HBS 3.1 .0 .2 .4 .0 A $35 \%$ CONTINGENCY HAS APPLIED TO THE JUMPER FABRICATION COSTS OUE TO THE ALLOHAHCES PROVIDED HERE EXTRACTED FROM PREVIOUS PARAMETRIC COST ESTIMATES FOR SIMILAR TASKS.

HBS $3.1 .0 .1 .5 .0 \&$ WBS 3.1 .0 .2 .5 .0 A $35 \%$ CONTINGENCY HAS APPLIED TO THE HASHDOHN, MOUNTING BASE, AND SLIDE VALVE ASSEMBLY COSTS DUE TO THE ALLOHANCES PROVIDED HERE EXTRACTED FROM AN EXISTING CONCEPTUAL ESTIMATE HITH SIMILAR TASKS AND DIFFICULTIES.

HBS $3.1 .0 .1 .6 .0 \&$ HBS 3.1 .0 .2 .6 .0 A $35 \%$ CONTINGENCY HAS APPLIED TO THE INSTALLATION OF THE TRANSFER EOUIPHENT DUE TO THE HIGHLY CONTAMIHATED AREA HHERE CONSTRUCTION HILL MOST LIKELY BE DONE WITH REHOTELY OPERATED EQUIPMENT.

HBS 3.1 .0 .1 .7 .0 \& HBS 3.1 .0 .2 .7 .0 A $35 \%$ CONTINGENCY HAS APPLIED TO ALL PIPING INSTALLATION COSTS HITHIN THE TAHK FARH DUE TO THE TAKE-OFF OUANIITIES BEING EXTRACTED FROM FLOW DIAGRAMS HITHOUT DISTANCES REPRESEHTED.

HBS $3.1 .0 .1 .8 .0 \quad 8$ HES 3.1 .0 .2 .8 .0 A $35 \%$ CONTINGENC.Y WAS APPLIED TO ALL ELECTRICAL AND INSTRUMENTATION FUNCTIONS HITHIN THE TANK FARM DUE TO THE LIMITED AMOUNT OF INFORMATION AVAILABLE FOR THIS EFFORT.

H8S $3 \cdot 1 \cdot 0 \cdot 1 \cdot 9 \cdot 0$

A $30 \%$ CONIINGENCY LAS APPLIED TO THE INSTALLATION OF THE HVAC EOUIPMENI SKIDS AND INTERCONNECTING DUCIS DUE IO IHE INSUFFICIENI INFORMATION SUPPLIED FOR SHIELDING REOUIREMEAIS. 
AHISEK LIUUINLLK2 HAURUKU WEST I HGHOUSE HANFORD COMPANY JOB NO.ER3415/241TUNL FILE NO. 24 ITUNL
TAHK $24 \overline{Y-T-10}$ UNLIMITED SLUICING STUDY ESTIHATE

DOE_ROG - CONTIHGENCY AHALYSIS BASIS SHEET
DATE 02/25/93 13:57:0S

BY GDR

HBS 3.1 .0 .3 .2 .0

A 30\% CONTINGENCY HAS APPLIED TO THE INSTALLATION OF ENCASED PIPING DUE TO THE UNKHOHNS ASSOCIATED HITH ROUTING OF PIPING IN EXISING TAHK FARMS.

HBS 3.1 .0 .4 .0 .0

A $40 \%$ CONTINGENCY HAS APPLIED TO THE CONTROL ROOM, CHANGE ROOH, AND LUNCH ROOH TRAILER ALLOHAHCES DUE TO THE LIMITED INFORHATIOH AVAILABLE AT THIS TIME.

HBS $3.1 .0 .5 .1 .0 \&$ HBS 3.1 .0 .5 .2 .0

A $35 \%$ CONTINGENCY HAS APPLIED TO THE. ESTIMATED "BURH-OUT" DOLLARS, DUE TO THE INCONSISTENT AHD . IMITED DETAIL AVAILABLE FOR AREAS THAT ARE CONSIDERED. COHTAMINATED. FUTURE ESTIHATES SHOULD REFLECT INFORMATION DETAILING MR READINGS FOR SPECIFIC CONSTRUCTION AREAS .

HBS $3,1,0,6,0,0$

A $30 \%$ CONTINGENCY WAS APPLIED TO COSTS ASSOCIATED HITH THE "STEP OFF PADS". FOR KEH CONSTRUCTION FORCES DUE TO THE LIMITED IHFORHATION AVAILABLE AT THIS TIME FOR SCHEDULING ACTIVITIES. COSTS FOR "STEP OFF PADS" ARE GEHERALLY CALCULATED BY MAN-LOADING SCHEDULE DURATIONS FOR SPECIFIC TASKS.

$\operatorname{COST} \operatorname{CODE} B 10$

HBS $3.3 .0 .1 .1 .0 \&$ WBS 3.3 .0 .1 .2 .0

A $35 \%$ CONTINGENCY HAS APPLIED TO THE D\&O OF THE EXISTING PRE-TRAHSFER EQUIPMEHT DUE TO THE ALLOHAHCES INCLUDED HITHIN THIS ESTIMATE HERE BASED ON AN EXISTING CONCEPTUAL DESIGH ESTIMATE (H-ISI).

HBS 3.3 .0 .2 .1 .0 \& HBS 3.3 .0 .2 .2 .0

A $35 \%$ CONTINGEHCY WAS APPLIED TO THE D\&D OF IHE POST-TRANSFER EQUIPHENT, CONCRETE TRENCH, AHD ENCASED PIPING, OUE TO THE POTENTIAL PROBLEMS ASSOCIATED HITH CONTAMIHATIOH.

HBS 3.3 .0 .4 .1 .0 \& HBS 3.3 .0 .4 .2 .0 A $40 \%$ CONTINGENCY HAS APPLIED TO THE COST ALLOHANCES FOR BURIAL FEES DUE TO THE UHKHOHHS ASSOCIATED HITH HANDLING COHTAHINATED MATERIAL AHO THE POTENTIAL OF INCREASED VOLUMES OF DISPOSABLE MATERIAL THAT IS NOT REFLECTED HITHIN THIS ESTIMATE.

$\operatorname{COS} T \operatorname{CODE} 900$

HBS 5.0 .0 .0 .1 .0

AN OVERALL AVERAGE $30 \%$ CONTINGENCY HAS APPLIED AGAINST ALL HHC EXPENSE FUNDED ITEMS BY THEIR REQUESI AND BECAUSE THE COST ARE BASED ON A PERCENTAGE OF THE TOIAL ESIIMATED COST. 
KAISER ENGINEERS HANFORD JOB NO. ER3415/241TUKL

FILE HO. 241TUNL HESTINGHOUSE HAHFORD COHPAHY
* * IEST - INTERACTIVE ESTIHATING * * TANK 241-T-101 TOTAL RETRIEVAL ALTERNATIVE DTOY ESTIMATE OPTIOH HI DOE_RO7 - ONSITE INDIRECT COSTS BY HBS

\begin{tabular}{|c|c|c|}
\hline $\begin{array}{l}\text { EST IHATE } \\
\text { SUB TOTAL } \\
==2====z\end{array}$ & $\begin{array}{c}\text { CONTRACT } \\
\% \\
z=z==\end{array}$ & $\begin{array}{c}\text { ADMINISTRATION } \\
\text { IOTAL } \\
========\end{array}$ \\
\hline $\begin{array}{r}780000 \\
1670000 \\
8000000 \\
1210800 \\
4800000 \\
691900 \\
512050 \\
934879 \\
4005848 \\
517440 \\
105481 \\
120719 \\
57196 \\
312427 \\
52752 \\
422850 \\
739197 \\
985884 \\
77844 \\
47864 \\
42897 \\
115949 \\
40849 \\
352308 \\
130650 \\
22284725 \\
238451 \\
753152 \\
232969 \\
276108 \\
460343 \\
115885 \\
1527428 \\
617988 \\
141120 \\
606875 \\
5386000 \\
20800000\end{array}$ & $\begin{array}{l}0.00 \\
0.00 \\
0.00 \\
0.00 \\
0.00 \\
0.00 \\
0.00 \\
0.00 \\
0.00 \\
0.00 \\
0.00 \\
0.00 \\
0.00 \\
0.00 \\
0.00 \\
0.00 \\
0.00 \\
0.00 \\
0.00 \\
0.00 \\
0.00 \\
0.00 \\
0.00 \\
0.00 \\
0.00 \\
0.00 \\
0.00 \\
0.00 \\
0.00 \\
0.00 \\
0.00 \\
0.00 \\
0.00 \\
0.00 \\
0.00 \\
0.00 \\
0.00 \\
0.00\end{array}$ & $\begin{array}{l}0 \\
0 \\
0 \\
0 \\
0 \\
0 \\
0 \\
0 \\
0 \\
0 \\
0 \\
0 \\
0 \\
0 \\
0 \\
0 \\
0 \\
0 \\
0 \\
0 \\
0 \\
0 \\
0 \\
0 \\
0 \\
0 \\
0 \\
0 \\
0 \\
0 \\
0 \\
0 \\
0 \\
0 \\
0 \\
0 \\
0 \\
0\end{array}$ \\
\hline
\end{tabular}

PAGE 13 OF 13

DATE $03 / 22 / 93 \quad 14: 33: 28$ BY

OTHER

INDIRECTS

I0 PACK

$\Sigma \equiv=\Sigma \equiv \pm \approx \Sigma=$

TOTAL I HD IRECTS
$==\approx= \pm== \pm 2$

111000 KEH ENGINEERING STUDY 1.12000 KEH CONCEPTUAL DESIGH

113000 KEH DEFINITIVE DESIGN

114000 HHC D \& D DESIGH

121000 KEH ENGINEERIHG/IHSPECTION

122000 HHC ENGR/IHSPEC. D \& D

$210160 T-101$ PROCESS EQUIPMENT

210180 T-101 ELEC EOUIP.

$210190 T-101$ HVAC SKIDS

$210260101-F Y$ PROCESS EQUIPMENT

310110 GREENHOUSE T - 101

310120 UPGRADE EXIST.PITS T-101

310140 JUMPERS T-101

310150 MTD.BASE/HASHDOHN/SLIDE VALVE

310160 INSTALL PROCESS EQUIP.T-101

310170 PIPING INSIDE T-101 FARM

310180 ELECTRICAL IN T-101 FARM

310190 HVAC IN T-101 FARM

310210 GREEN HOUSE 103-FY

310220 UPGRADE EXIST.PITS 103-FY

310240 JUMPERS 103-FY

310250 MTO. BASE/HASHDOWN/SLIDE VALVES

310260 INSTALL PROCESS EQUIP. 103.FY

310270 PIPIHG INSIDE 103-FY FARM

$310280103-F Y$ ELEC EQUIPMENT

310320 TRANSFER PIPING T-101 TO 103-FY

310400 CONTROL RM/LUNCH RH/CHANGE RM

310510 BURH OUT $T-101$

310520 BURN OUT TO3.

330110 PRE-TRANSFER DEMO. T-101

330120 PRE-TRANSFER DEHO. 103-FY

330210 POST-TRANSFER DEHO. T-101

330220 POST-TRANSEER DEMO. 103-FY

330410 BURIAL FEES - PRE ITRANSFER

330420 8URIAL FEES - POST TRANSFER

400000 HHC PROJECT MAHAGEMENT

500010 HHC (OTHER COST)

PROJECI TOTAL
PREP.

0
0
0
0
0
0
0
0
0
0
0
0
0
0
0
0
0
0
0
0
0
0
0
0
0
0
0
0
0
0
0
0
0
0
0
0
0
0
0
0
0
0
0 $\begin{aligned}== & ========== \\ & 80,168,828\end{aligned}$ 
KAISER ENGINEERS HANFORD HESTINGHOUSE HANFORD COMPAHY JOB HO. ER3415/241TLIM FILE HO. 241 TLIM
* IEST - INTERACTIVE ESTIHATIHG **

TANK 241-T-101 TOTAL RETRIEVAL ALTERHATIVE

STUDY ESTIMATE OPTION \#2 LIMITED SLUICING

DOE ROI - PROJECT COST SUMMARY
PAGE 1 OF 13

DATE 03/22/93 14:12:15

BY GDR

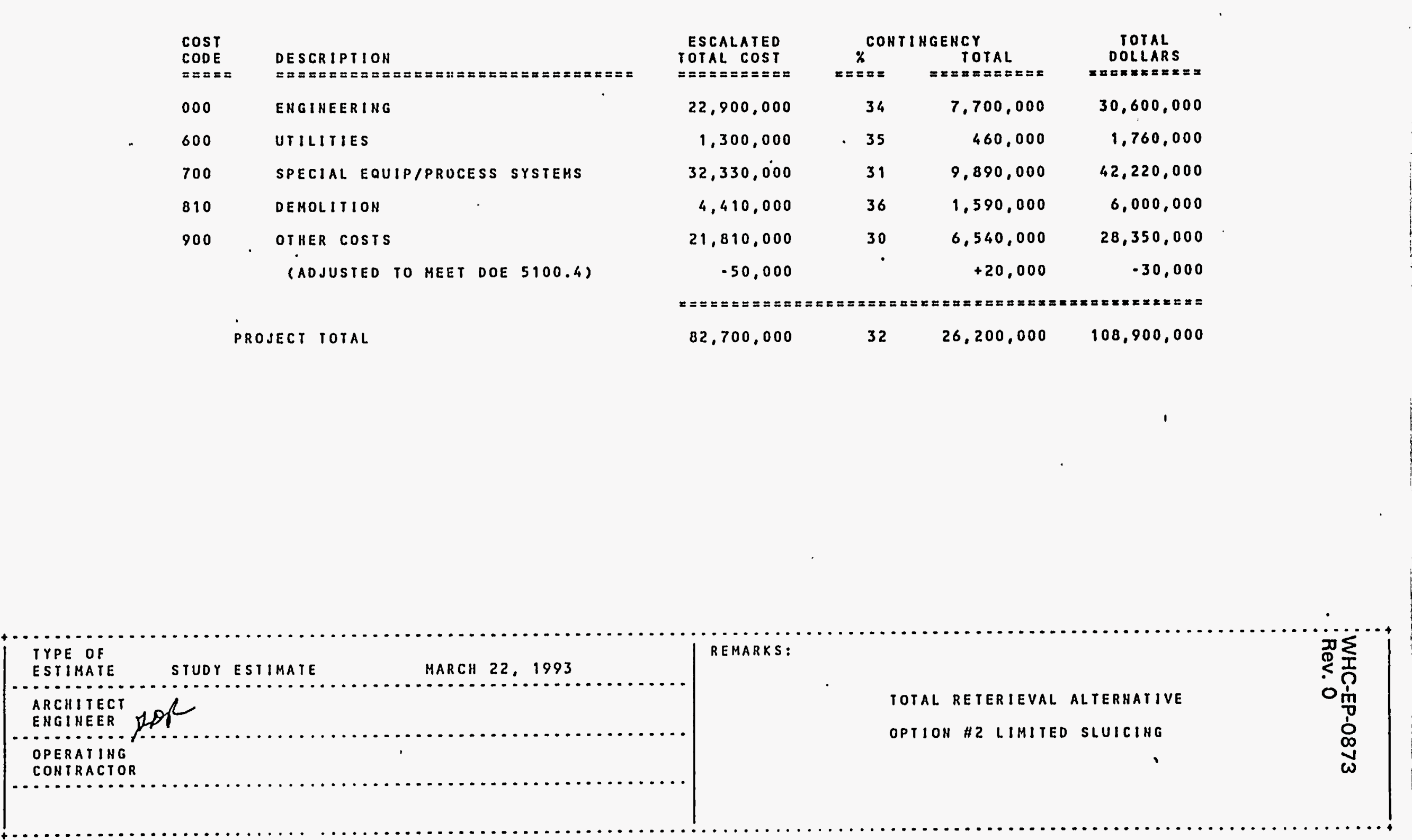


KAISER EHGINEERS HAHFORD

HESTIHGHOUSE HAHFORD COMPANY

JOB NO. ER3415/241TLIM

FILE NO. $241 T L I M$

HBS OESCRIPTION

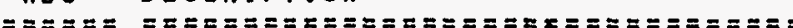

119000 KEH ENGINEERIHG STUDY

112000 KEH COHCEPTUAL DESIG

113000 KEH DEFINITIVE DESIGN

114000 WHC O \& D DESIGN

121000 KEH EHGINEERING/INSPECTION

122000 HHC ENGR/INSPEC. D \& D

SUBTOTAL 1 ENGINEERING

$210160 T-101$ PROCESS EQUIPMENT

$210180 T-101$ ELEC EQUIP.

210190 T-101 HVAC SKIDS

SUBTOTAL 2101 T-101.PROCUREMENT

$210260101-F Y$ PROCESS EOUIPMENT

SUBTOTAL 2102 103-FY PROCUREMENT

SUBTOTAL 21 KEH PROCUREMENT

SUBTOTAL 2 PROCUREMENT

310110 GREENHOUSE T-101

310120 UPGRADE EXIST.PITS T-101

310140 JUHPERS T.101

310150 MTD.BASE/HASHDOWN/SLIDE VALVE

310160 INSTALL PROCESS EOUIP.T.101

310170 PIPING INSIDE T-101 FARM

310180 ELECTRICAL IN T-101 FARM

310190 HVAC IN T.101 FARM

SUBTOTAL 3109 T-101 SLUICING

310210 GREEN HOUSE $103-F Y$

310220 UPGRADE EXIST.PITS $103 \cdot F Y$

310240 JUMPERS $103-8 \dot{Y}$
* * IEST - INTERACTIVE ESTIMATING * *

TAHK 241-T-101 TOTAL RETRIEVAL ALTERHATIVE STUDY ESTIMATE OPTION $\# 2$ LIMITED SLUICING DOE_RO2 - HORK BREAKDOHN STRUCTURE SUHHARY

PAGE 2 OF 13

DATE 03/22/93 14:04:07

BY GDR

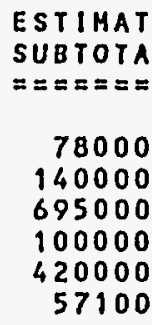

14901000

1104950

934879

4005848

6045677

409640

409640

6455317

6455317

113573

1829902

85794

85794

590727

675292

675292
757769

985884

5154991

77844

47864

42897

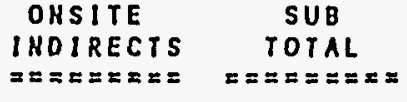

780000

780000
1400000

1400000
6950000

1000000

4200000

571000

14901000

1104950

934879

4.005848

6045677

409640

409640

6455317

6455317

113573

1829902

85794

590727

116050

675292

757769

985884

5154991

77844

77844
47864

47864
42897
ESCALATION

\% TOTAL

$=z z=x=\quad x=z x=z=z$

0.00

4.74
10.91

10.91

16.43

10.91

11.32

10.91

10.91

10.91

10.91

0
66360

65360
758245

109100

690060

62296

1686061

120550

01995

437038

659583

10.91

44692

10.9

44692

10.91

704275

10.91

704275

16.43

16.43

16.43

16.43

16.43

16.43

16.43

16.43

18660

300653

14096

97056

97056

110950

110950

124502

161981

$16.43 \quad 846965$

16.43
16.43

16.43
16.43
12790

7864
7048
SUB

TOTAL

CONTIHGEHCY

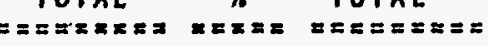

\section{0}

1466360

7708245

1109100

4890060

633296

16587061

1225500

1036874

4442886

6705260

454332

454332

7159592

7159592

132233

2130555

99890

687783

135117

786242

1147865

6001956

90634

55728

55728
49945
35
35
35
35
35
35
35

34
35
25
28

273000

513226

2697886

3881.85

1711521

221654

5805472

418463

362906

1110722

1892091

159016

159016

2051107

2051107

33058

745694

3496

240724

47291

275185

308794

344359

2030066

25
40
35
22658
22291

22291
17481
TOTAL

DOLLARS $=z x=x=z=x$

1053000 1979586 10406131 1497285 6601581

854950

22392533

1643963

1399780

5553608

8597351

613348

613348

9210699

9210699

165291

2876249

134851

928508

182408

1061427

191064

1492224

8032022

113292
78019 78019
67426 
KAISER ENGINEERS HAHFORD

HEST INGHOUSE IIANFORD COMPANY

JOB HO. ER3415/241TLIH

FILE'NO. $241 T L I M$

HBS DESCRIPTION

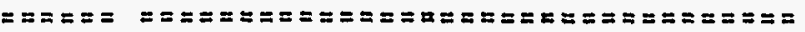

310250 MTD. BASE/HASHDOHN/SLIDE VALVES

310260 INSTALL PROCESS EQUIP. 103-FY

310270 PIPING INSIDE 103-FY FARH

$310280 \quad 103-F Y$ ELEC EQUIPHENT

SUBTOTAL $3102 \quad 103$ FY TANK FARM

310320 TRANSFER PIPING T-101. TO 103-FY

SUBTOTAL 3103 ENCASED PIPE T-101/103-FY

310400 CONTROL RM/LUNCH RH/CHANGE RM

SUBTOTAL 3104 CONTROL RM./LUHCH/CHANGE RM

310510 BURN OUT T-101

310520 BURN OUT $103 \cdot F Y$

SUBTOTAL 3105 BURN OUT

310600 STEP OFF PAD

SUBTOTAL 3106 STEP OFF PAP SUPPORT

SUBTOTAL 31 KEH CONSTRUCTION

330110 PRE - IRANSFER DEMO. T-101

330120 PRE-TRANSFER DEMO. 103-FY

SUBTOIAL 3301 PRE TRANSFER DEMOLITION

330210 POSI-TRANSFER DEMO. T-101

330220 POST-IRANSFER DEMO. 103-FY

SUBIOIAL 3302 POSI TRANSFER DEMOLITION
* * IEST - IHTERACTIVE ESTIMATING * TANK 241-T-101 TOTAL RETRIEVAL ALTERNATIVE STUDY ESTIMATE OPTION \#Z LIMITED SLUICING DOE_RO2 - HORK BREAKDOHH STRUCTURE SUMMARY

\begin{tabular}{|c|c|c|c|c|c|c|c|c|}
\hline $\begin{array}{l}\text { ESTIMATE } \\
\text { SUBTOTAL } \\
========\end{array}$ & $\begin{array}{l}\text { ONSITE } \\
\text { INDIRECIS } \\
========\end{array}$ & $\begin{array}{c}\text { SUB } \\
\operatorname{TOI} \wedge \mathrm{L} \\
=====x===\end{array}$ & $\begin{array}{l}\text { ESCAI } \\
\% \\
=z=z=\end{array}$ & $\begin{array}{l}L A T I O N \\
T O T A L \\
========\end{array}$ & $\begin{array}{c}\text { SUB } \\
\text { TOTAL } \\
====z=z==\end{array}$ & $\begin{array}{c}\text { CONTI } \\
\% \\
=x=x\end{array}$ & $\begin{array}{l}\text { HGEHCY } \\
\text { TOTAL } \\
=====\approx===\end{array}$ & $\begin{array}{c}\text { TOTAL } \\
\text { DOLLARS } \\
====\approx===z\end{array}$ \\
\hline $\begin{array}{r}115949 \\
40849 \\
352308 \\
130650\end{array}$ & $\begin{array}{l}0 \\
0 \\
0 \\
0\end{array}$ & $\begin{array}{r}115949 \\
40849 \\
352308 \\
130650\end{array}$ & $\begin{array}{l}16.43 \\
16.43 \\
16.43 \\
16.43\end{array}$ & $\begin{array}{r}19050 \\
6711 \\
57884 \\
21467\end{array}$ & $\begin{array}{r}134999 \\
47560 \\
410192 \\
152117\end{array}$ & $\begin{array}{l}35 \\
35 \\
35 \\
35\end{array}$ & $\begin{array}{r}47250 \\
16646 \\
143567 \\
53241\end{array}$ & $\begin{array}{r}182249 \\
64207 \\
553759 \\
205355\end{array}$ \\
\hline 808361 & 0 & 808361 & 16.43 & 132814 & 941175 & 34 & 323134 & 1264307 \\
\hline 15270833 & 0 & 15270833 & 16.43 & 2508997 & 17779830 & 30 & 5333949 & 23113780 \\
\hline 15270833 & 0 & 15270833 & 16.43 & 2508997 & 17779830 & 30 & 5333949 & 23113780 \\
\hline 238451 & 0 & 238451 & 16.43 & 39178 & 277629 & 40 & 111051 & 388680 \\
\hline 238451 & 0 & 238451 & 16.43 & 39178 & 277629 & 40 & 111051 & 388680 . \\
\hline $\begin{array}{l}753152 \\
232969\end{array}$ & $\begin{array}{l}0 \\
0\end{array}$ & $\begin{array}{l}753152 \\
232969\end{array}$ & $\begin{array}{l}16.43 \\
16.43\end{array}$ & $\begin{array}{r}123743 \\
38277\end{array}$ & $\begin{array}{l}876895 \\
271246\end{array}$ & $\begin{array}{l}35 \\
351\end{array}$ & $\begin{array}{r}306913 \\
94936\end{array}$ & $\begin{array}{r}1183808 \\
366182\end{array}$ \\
\hline 986121 & 0 & 986121 & 16.43 & 162020 & 1148141 & 35 & 401849 & 1549990 \\
\hline 276108 & 0 & 276108 & 16.43 & 45365 & 321473 & 30 & 96442 & 417,914 \\
\hline 276108 & 0 & 276108 & 16.43 & 45365 & 321473 & 30 & 96442 & 417914 \\
\hline 22734865 & 0 & 22734865 & 16.43 & 3735339 & 26470204 & 31 & 8296491 & 34766693 \\
\hline $\begin{array}{l}460343 \\
115885\end{array}$ & $\begin{array}{l}0 \\
0\end{array}$ & $\begin{array}{l}460343 \\
115885\end{array}$ & $\begin{array}{l}4.74 \\
4.74\end{array}$ & $\begin{array}{r}21820 \\
5493\end{array}$ & $\begin{array}{l}482163 \\
121378\end{array}$ & $\begin{array}{l}35 \\
35\end{array}$ & $\begin{array}{r}168757 \\
42483\end{array}$ & $\begin{array}{l}650921 \\
163861\end{array}$ \\
\hline 576228 & 0 & 576228 & 4.74 & 27313 & 603541 & 35 & 211240 & 814782 \\
\hline $\begin{array}{r}1632411 \\
617988\end{array}$ & $\begin{array}{l}0 \\
0\end{array}$ & $\begin{array}{r}1632411 \\
617988\end{array}$ & $\begin{array}{l}28.08^{\circ} \\
28.08\end{array}$ & $\begin{array}{l}458381 \\
173531\end{array}$ & $\begin{array}{r}2090792 \\
791519\end{array}$ & $\begin{array}{l}35 \\
35\end{array}$ & $\begin{array}{l}731777 \\
277032\end{array}$ & $\begin{array}{l}2822569 \\
1068551\end{array}$ \\
\hline 2250399 & 0 & 2250399 & 28.08 & 631912 & 2882311 & 35 & 1008809 & 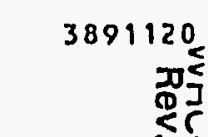 \\
\hline
\end{tabular}

PAGE 3 OF 13

OATE $03 / 22 / 93$ 14:04:08

ar
GD 
KAISER ENGINEERS HAHFORD

WESTINGHOUSE HANFOR

JOB HO. ER3415/24TTLIH

FILE HO. $241 T L I M$

HBS DESCRIPTION

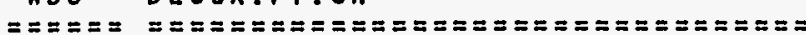

330410 BURIAL FEES - PRE TRANSFER 330420 BURIAL FEES - POST TRANSFER SUBTOTAL 3304 TOTAL BURIAL FEES SUBTOTAL 33 CONSTRUCTION-O/C SUBTOTAL 3 CONSTRUCTION

400000 HHC PROJECT MANAGEMENT

SUBTOTAL 4 PROJECT INTEGRATION

500010 HHC (OTHER COST)

SUBTOTAL 5 OTHER PROJECT COST

PROJECT TOTAL
* IEST - INTERACTIVE ESTIMATING * TAHK 241-T-101 TOTAL RETRIEVAL ALTERHATIVE STUDY ESTIMATE OPTIOH \#2 LIMITED SLUICING DOE_RO2 - WORK BREAKOOHH STRUCTURE SUMHARY

\begin{tabular}{|c|c|c|c|c|c|c|c|c|}
\hline $\begin{array}{l}\text { ESTIMATE } \\
\text { SUBTOTAL } \\
=======\end{array}$ & $\begin{array}{l}\text { ONSITE } \\
\text { I NDIRECTS } \\
=\approx=====\end{array}$ & $\begin{array}{c}\text { SUB } \\
\text { TOTAL } \\
z=\approx==z==\end{array}$ & $==\approx \begin{array}{c}\text { ESCA } \\
X \\
===\end{array}$ & $\begin{array}{l}\text { NLATION } \\
\text { YOTAL } \\
=======\end{array}$ & $\begin{array}{c}\text { SUB } \\
\operatorname{rOr} A L \\
=z=z=z=z\end{array}$ & $\begin{array}{c}\operatorname{con} T \\
\% \\
=\approx===\end{array}$ & $\begin{array}{l}\text { HGEHCY } \\
\text { TOTAL } \\
=======z\end{array}$ & $\begin{array}{c}\text { TOTAL } \\
\text { DOLLARS } \\
=======\end{array}$ \\
\hline $\begin{array}{l}141120 \\
605570\end{array}$ & $\begin{array}{l}0 \\
0\end{array}$ & $\begin{array}{l}141120 \\
605570\end{array}$ & $\begin{array}{r}4.74 \\
28.08\end{array}$ & $\begin{array}{r}6689 \\
170044\end{array}$ & $\begin{array}{l}147809 \\
775614\end{array}$ & $\begin{array}{l}40 \\
40\end{array}$ & $\begin{array}{r}59124 \\
310246\end{array}$ & $\begin{array}{r}206933 \\
1085860\end{array}$ \\
\hline 746690 & 0 & 746690 & 23.67 & 176733 & 923423 & 40 & 369370 & 1292793 \\
\hline 3573317 & 0 & 3573317 & 23.39 & 835958 & 4409275 & 36 & 1589419 & 5998695 \\
\hline 26308182 & 0 & 26308182 & 17.38 & 4571297 & 30879479 & 32 & 9885910 & 40765388 \\
\hline 5386000 & 0 & 5386000 & 17.25 & 929085 & 6315085 & 30 & 1894526 & 8209611 \\
\hline 5386000 & 0 & 5386000 & 17.25 & 929085 & 6315085 & 30 & 1894526 & 8209611 \\
\hline 18600000 & 0 & 18600000 & 17.25 & 3208500 & 21808500 & 30 & 6542550 & 28351050 \\
\hline 18600000 & 0 & 18600000 & 17.25 & 3208500 & 21808500 & 301 & 6542550 & 28351050 \\
\hline
\end{tabular}

PAGE 4 OF 13

DATE $03 / 22 / 93^{14: 04: 08}$ BY GDR

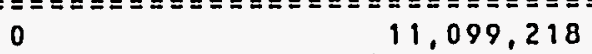

$71,650,499$ 
KAISER ENGINEERS HAHFORD HEST I HGHOUSE HANFORD COMPANY JOB HO. ER3415/241TLIM

FILE NO.
* IEST - INTERACTIVE ESTIMATING * *

TAHK 241-T-101 LIMITED SLUICING STUDY

DOE_RO3 - ESTIMATE BASIS SHEET
PAGE 5 OF 13

DATE 03/22/93 08:09:53

1. DOCUMENTS AHD DRAHINGS $=========z=========$

DOCUHENTS: ENGINEERING EVALUATION OF ALTERHATEIVES - MANAGING THE ASSUHED LEAK FROM SINGLE SHELL TAHK 241 IT $1012 / 93$. DRAHINGS: IN SAME DOCUMEHT AS ABOVE

2. HATERIAL PRICES
$==============$

UNIT COSTS REPRESENT CURRENT PRICES FOR SPECIFIED MATERIAL.

3. LABOR RATES

$======\Sigma===$

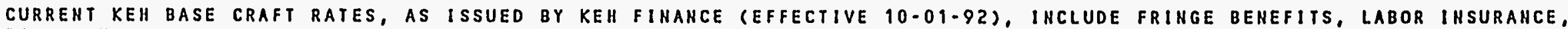

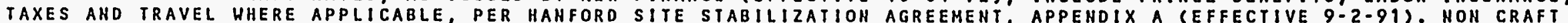

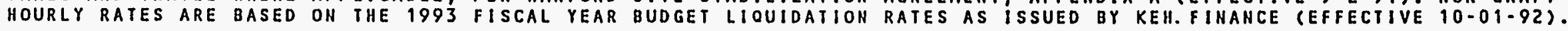

4. GENERAL REQUIREMENTS/TECHNICAL SERVICES/OVERHEADS

A.) ONSITE CONSTRUCTION FORCES GENERAL REQUIREMENTS, TECHNICAL SERVICES AND CRAFT OVERHEAD COSTS ARE IHCLUDED AS A COMPOSITE PERCEMTAGE BASED ON THE KEH ESTIMATIHG FACTOR/BILLIHG SCHEDULE, REVISION 14, DATED OCTOBER OI, I992. THE TOTAL COMPOSITE PERCENTAGE APPLIED TO OHSITE CONSTRUCTION FORCES LABOR, FOR THIS PROJECT, IS 93\% FOR SHOP HORK AND $134 \%$ FOR FIELD HORK, HHICH IS REFLECTED IN TIE "OH\&P/B\&I" COLUMN OF THE ESTIMATE DETAIL.

5. ESCALATION

$========$

ESCALATION PERCENTAGES HERE CALCULATED BY TIIE HAHFORD MATERIAL \& LABOR ESCALATIOH STUDY, DATED FEBRUARY I992.

6. ROUHDING

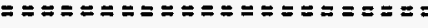

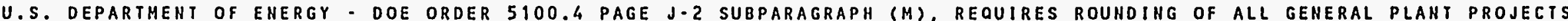
(GPP'S) AND LINE ITEM (LI) COST ESTIMATES. REFERENCE: DOE 5100.4, FIGURE 1.11, DATED 10-31-84.

7. REMA'RKS

\section{$=-2=-==$}

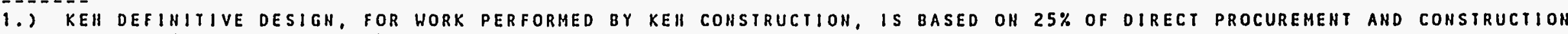
COSTS, LESS BURN-OUT COST.

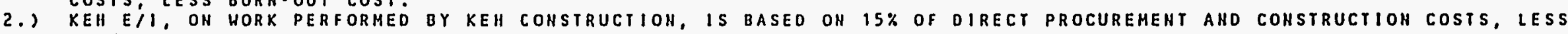
BURHOUT.

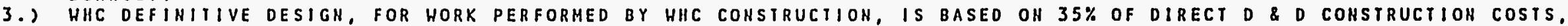

LESS BURIAL FEE ALLOHANCES

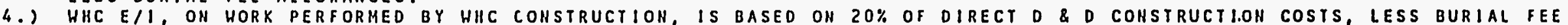
ALLOHANCES

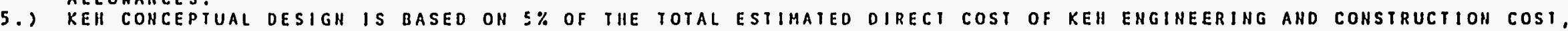

6.) HBS 5 (OTIIER COSI) COST ARE BASED OH $35 \%$ OF THE TOIAL DIRECI COSI OF EHGIHEERIHG. CONSTRUCTION, PROCUREMENI. AND ARE BASED ON A STUDY ESTIMATE CIN C-106 RETREVIAL. 
KAISER ENGINEERS HANFORD HESTINGHOUSE HANFORD COMPANY JOB HO. ER3415/241TLIM FILE NO.
* IEST - INTERACTIVE ESTIHATING * *

TANK 241-T-101 LIMITED SLUICING STUOY

DOE_RO3 - ESTIMATE BASIS SHEET
PAGE 6 OF 13

DATE 02/25/93 08:09:53

\section{REHARKS (COHTINUED)}

$==\mathbf{z =}==$

7.) ASSUHE THAT (2) TRAHSFER PUMPS AHD (1) HEEL PUMP HILL hAVE TO BE REMOVED AT T-101.

8.) THE EXISTIHG PITS AT T-101 AND 103-FY HILL GE UPGRADED PRIOR TO EQUIPMENT INSTALLATIOH. UPGRADIHG HILL

IHCLUDE LINING THE PITS HITH AN EPOXY SEALANT.

9.) HHC D \& D OVERHEAD COSTS HERE APPLIED TO LABOR AT 52\% BASED ON PROJECT H-151. DATED O4/3O/9O.

10.) WHC D \& D OVERHEAD COSTS HERE APPLIED TO OIRECT MATERIAL PURCHASES AT $17.40 \%$.

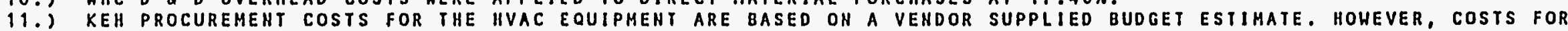
SHIELDING HERE HOT INCLUDED IN THIS VENDOR QUOTE.

12.) KEH PROCUREMENT COSTS FOR TRANSFER PUMPS, SLUICE MAST AHD SLUICE PUMP HERE ALLOHAHCES EXTRACTED FROM PREVIOUS COST ESTIMATES THAT USED SIMILAR EQUIPMENT.

13.) BURN-OUT ALLOHANCES FOR SEALING OF THE PIT INTERIORS HITHIN T-1OI TANK FARM HERE ASSUMED BY KEH (1OO MR).

14.) BURN-OUT ALLOHANCES FOR SEALING OF THE PIT INTERIORS HITHIN 1O2-FY TANK FARM HERE ASSUMED BY KEH (5O HR).

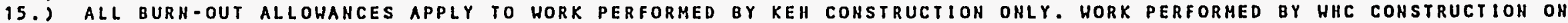
THE PRE-TRANSFER \& POST-TRAHSFER D D DOES NOT HAVE BURH-OUT ALLOHAHCES CALCULATED.

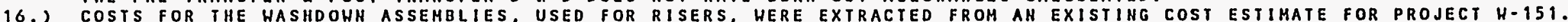

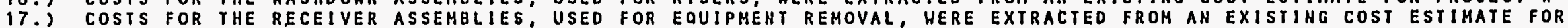
PROJECT H-151.

18.) BURIAL FEES FOR LOH LEVEL HASTE, HERE BASED

19.) BURIAL FEES, FOR HAZARDOUS HASTE, HERE BASED ON \$4Z PER CUBIC YARD. (STEEL SHIELDIHG ONLY)

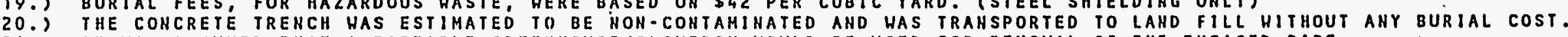

21.) IT HAS ASSUMEO THAT A PORTABLE GREEHHOUSE/GLOVEBOX HOULD BE USED FOR REHOVAL OF THE ENCASED PIPE.

22.) THE CONCRETE TRENCH HAS ESTIMATED AT 18 "THICK HITII 120 LBS OF REBAR PER CUBIC YARD.

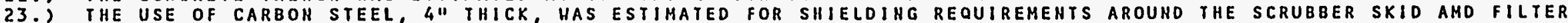
HOUSING SKID.

24.) THIS ESTIMATE DID NOT ALLOH FOR SHIELOING AROUHD THE FANS AND FILTER ROOM SKIDS AS REOUESTED BY HHC

25.) ALL ENCASED PIPING, WITHIN THE TANK FARMS, HAS ROUTED IN THE CONCRETE TRENCH LOCATED ABOVE GRADE.

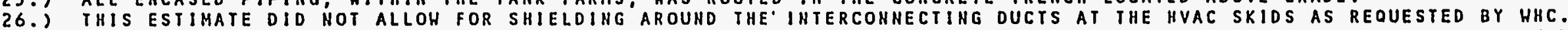

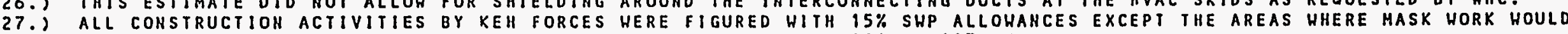
BE REOUIRED AND THE INSTALLATION OF THE ENCASED PIPE FROM T-101 TO 103-FY.

28.) ASSUHPTIONS HERE MADE OH ALL QUANTITIES HHEN THE ESTIMATE WAS BASED ON FLOH DIAGHRAMS 8 SKETCHES.

29.) ASSUHED (2) TRANSFER PUMPS HILL NEED TO BE REMOVED FROM 103-FY TANK FARM.

30.) THE I.101 PITS HILL BE SEALED HITH POLYURETHANE FOAM ONCE POST TRANSFER DEMOLITION HAS BEEN COMPLETED.

31.) THE HVAC PROCURED SKIDS HILL IHCLUDI: INSTRUMENTAION AND MUX.

32.) ELECIRICAL SKIDS HILL FURNISU POHER TO THE HVAC SKIOS BY SURFACE DUCTS AND CABLE.

33.) THE ESCALATION PERCENTAGES HERE BASED ON A PRELIMINARY SCHEDULE.

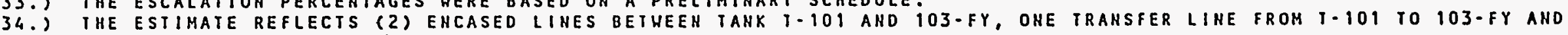
OHE SPARE.

35.) FOUR HEH SLUICE PITS HITH NEH 18" RISERS ARE INCLUDED IN THIS ESTIMATE. 
KAISER EHGIHEERS HANFORD

WEST I HGHOUSE HANFORD COMPANY

JOB HO. ER3415/241TLIM

FILE HO. 241 TLIM

$\cos T$

CODE/HBS

DESCRIPTIOH

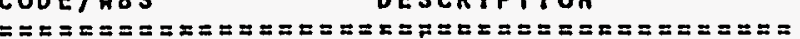

000 ENGINEERING

$\begin{array}{ll}111000 & \text { KEH ENGINEERIHG STUDY } \\ 112000 & \text { KEH CONCEPTUAL DESIGN } \\ 113000 & \text { KEH DEFINITIVE DESIGH } \\ 114000 & \text { HHC D \& D DESIGN } \\ 121000 & \text { KEH ENGINEERIHG/INSPECTION } \\ 122000 & \text { HHC ENGRIINSPEC. D \& D } \\ 400000 & \text { HHC PROJECT HANAGEMENT }\end{array}$

TOTAL OOO ENGINEERING

6OO UTILITIES

$\begin{array}{ll}210180 & \text { T-101 ELEC EQUIP. } \\ 310180 & \text { ELECTRICAL IN T. IOI FARM } \\ 310280 & \text { IOS-FY ELEC EQUIPMENT } \\ 310400 & \text { CONTROL RH/LUNCH RM/CHANGE RM }\end{array}$

TOTAL 600 UTILITIES

700 SPECIAL EQUIP/PROCESS SYSTEMS

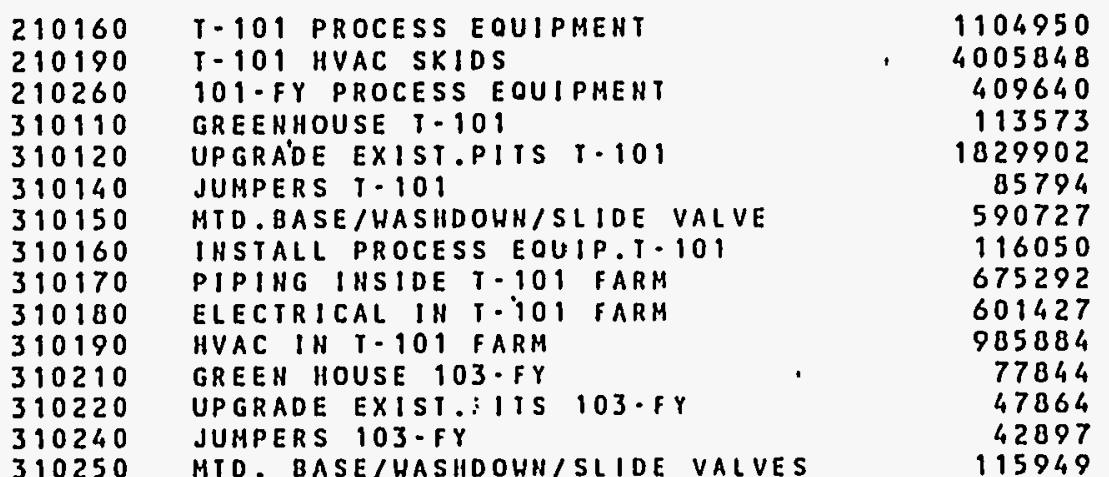

ESTIHATE SUBTOTAL

780000

1400000

100000

4200000

571000

5386000

20287000

156342

66371

4429

1162021
* * IEST - INTERACTIVE ESTIMAIING * * TANK 241-T-101 TOTAL RETRIEVAL ALTERHATIVE STUDY ESTIHATE OPIIOH \#2 LIMITED SLUICING DOE_ROA - COST CODE ACCOUNT SUMMARY ONSITE

NDIRECTS SUB

TOTAL $==z=z=x=$ ESCALATIOH X TOTAL $=z==x==z=x=z=$

TOTAL

TOTAL

$x$ TOTAL

$=x=z== \pm=$

PAGE 7 OF 13

$03 / 22 / 93 \quad 14: 04: 12$

BY GDR

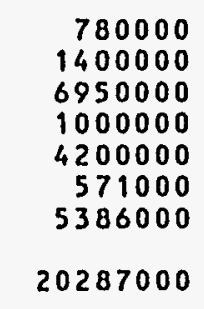

0.00

4.74

10.91

10.91

16.43

10.9

17.25

12.89

2615146

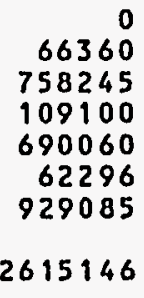

780000
1466360
7708245
1109100
4890060
633296
6315085

35
35
35
35
35
35
30
34

273000

513226

2697886

388185

1711521

221654

1894526

22902146

7699998

1036874

182029

182029

77276

156342

66371
4429

10.91
16.43

101995

25687

0905

16.44

39315

1301336

35
35
35
40

362906

63710

27046

2063

455725

1162021

11.99

139315

1104950
4005848
409640
113573
1829902
85794
590727
116050
675292
601427
985884
77844
47864
42897
115949

10.91

120550

437038

10.9

10.9

44692

4442886

16.43

18660

454332

16.43

300653

132233
2130555

99890

16.43

97056

16.43

19067

687783

135117

110950

98815

16.43

16.43

161981

16.43

16.43

16.43

12790

7864

7048
19050

86242

700242

1147865

90634

55728

49945

134999
418463

1110722

159016

33058

745694

34961

240724

75185

245084

344359

344359

22658

22291

17481

47250
TOTAL LARS
1053000 1979586 10406131

1497285

854950

8209611

30602144

1399780

245739
104322

7219

1757060

1643963 5553608

613348

165291

2876249

134851

928508

182408

1061427

945325

1492224

113292

78019

67426

182249 
KAISER EHGINEERS HANFORO

HESTIHGHOUSE HAHFORD COMPANY

* IEST - IHTERACTIVE ESTIHATIHG * *

TANK 241-T-101 TOTAL RETRIEVAL ALTERNATIVE STUDY ESTIMATE OPTION \#2 LIMITED SLUICING
PAGE 8 OF 13

OATE 03/22/93 14:04:13

BY

GD R
JOB HO. ER3415/241TLLM

FILE. HO. 241TLIM

$\cos t$

CODE/HBS

DESCRIPTIOH

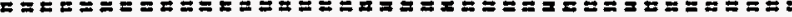

310260 INSTALL PROCESS EQUIP. 103-FY

310270 PIPING INSIDE 103 -FY FARH

310280 103-FY ELEC EQUIPMENT

310320 TRANSFER PIPINA T-101 TO $103-\mathrm{FY}$

310400 CONTROL RH/LUH:H RM/CHANGE RM

310510 BURH OUT T-101

310520 BURH OUT $103-F Y$

STEP OFF PAD

TOTAL $700 '$ SPECIAL EQUIP/PROCESS SYSTEM DOE_RO4 - COST CODE ACCOUNT SUMMARY ESTIHATE
SUBTOTAL $=\Xi \Xi \approx z=\Xi$

40849
352308
64279
15270833
234022
753152
232969
276108

28028161
ONSITE
INDIRECTS

$== \pm== \pm==$

$\begin{array}{lr}0 & 40849 \\ 0 & 352308 \\ 0 & 64279 \\ 0 & 15270833 \\ 0 & 234022 \\ 0 & 753152 \\ 0 & 232969 \\ 0 & 276108\end{array}$

$0 \quad 28028161$

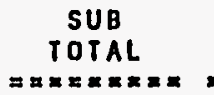

COHTINGENCY TOTAL

TOTAL DOLLARS

$16.43 \quad 6711$

16.43

16.43

16.43

16.43

16.43

16.43

16.43

5788

10562

2508997

38450

123743

38277

45365

$15.34 \quad 4300299$

47560

410192

74841

17779830

272472

876895

271246

321473

32328460

35
35
35
30
40
35
35
30

16646
143567

26195

5333949

108988

108988

306913

94936

96442

9891873

810 DEMOLITIOH

330110 PRE-TRANSFER DEMO. T-10

330120 PRE-TRANSFER DEMO. 103-FY

330210 POST-TRANSFER DEMO. T-101

330220 POST-IRANSFER DEMO. 103-FY

330410 BURIAL FEES - PRE TRANSFER

330420 BURIAL FEES - POST TRAHSFER

IOTAL 810 DEMOLITION

460343

115885

1632411

617988

$141120^{\circ}$

605570

3573317

$\begin{array}{lr}0 & 460343 \\ 0 & 115885 \\ 0 & 1632411 \\ 0 & 617988 \\ 0 & 141120 \\ 0 & 605570\end{array}$

$\begin{array}{rr}4.74 & 21820 \\ 4.74 & 5493\end{array}$

5493
45838

$28.08 \quad 173531$

4.74

$28.08 \quad 170044$

$0 \quad 3573317$

23.39

835958

482163

121378

2090792

791519

147809

775614

4409275

3

35
35
35
35
40
40
36

168757

42483

731777

277032

59124
310246

1589419

-

6420
55375

101033

23193780

381461

183808

366182

417914

42220332

900 OTHER COSTS

500010 HHC (OTHER COST)

TOTAL 900 , OTHER COSTS

- 18600000

$0 \quad 18600000$

$17.25 \quad 3208500$

21808500

30

6542550

28351050

18600000

$0 \quad 18600000$

$17.25 \quad 3208500$
$21808500 \quad 30$

6542550
65092 163861

2822569

1068551
206933

1085860

5998695
PROJECT TOIAL
$71,650,499$
0

$71,650,499$
15.49
$=========$
$11,099,218$
$26,179,565$

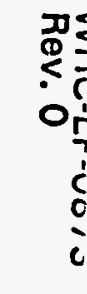


KAISER ENGINEERS HANFORD

WESTINGHOUSE HANFORD COMPAHY

JOB NO. ER3415/24ITLIH

FILE HO. 241 TLIM

\section{CSI DESCRIPTIOH}

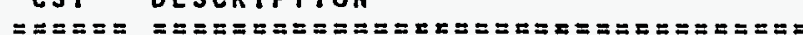

\section{ENGINEERING}

OO TECHHICAL SERVICES

19 HHC PROJECT MAHAGEMENT

TOTAL EHGIHEERIHG

CONSTRUCTION

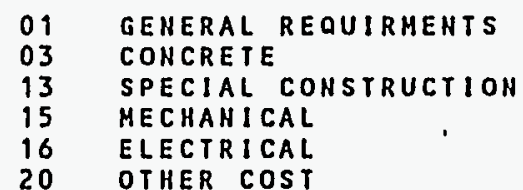

TOTAL CONSTRUCTION

PROJECT TOTAL
* * IEST - INTERACTIVE ESTIMATIHG * *

TAHK 241-T-101 TOTAL RETRIEVAL ALTERHATIVE STUDY ESTIMATE OPTION \#Z LIMITED SLUICING DOE_ROS - ESTIMATE SUMHARY BY CSI DIVISION

\section{ESTIMATE} SUBTOTAL $==z==x=z$

ONSITE $== \pm====$ IHOIRECT

SUB
TOTAL

ESCI $\%$ TOTAL
TOTION $\varepsilon=z=z=z= \pm= \pm=x$
SUB

TOTAL $= \pm= \pm=x=x$
PAGE 9 OF 13

DATE 03/22/93 14:04:17

$B Y$ GDR

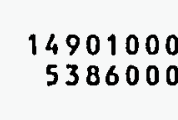

$20,287,000$

$$
\begin{array}{r}
2433519 \\
5144 \\
2077766 \\
26225795 \\
2021275 \\
18600000
\end{array}
$$

$51,363,499$

\section{$\begin{array}{rr}0 & 14901000 \\ 0 & 5386000\end{array}$}

11.32
17.25

$20,287,000$

12.89

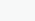

$.615,146$
CONTINGEHCY

\% TOTAL

TOTAL
$=\approx z=\Sigma z=$
TOTAL

DOLLARS $== \pm x=x \geq \Sigma$

$\begin{array}{rrrrrrrr}0 & 2433519 & 17.53 & 426621 & 2860140 & 35 & 1008860 & 3868999 \\ 0 & 5144 & 16.43 & 845 & 5989 & 35 & 2096 & .8085 \\ 0 & 2077766 & 16.43 & 341377 & 2419143 & 36 & 861129 & 3280272 \\ 0 & 26225795 & 16.18 & 4243824 & 30469619 & 30 & 9273693 & 3974316 \\ 0 & 2021275 & 13.01 & 262905 & 2284180 & 35 & 791239 & 307545 \\ 0 & 18600000 & 17.25 & 3208500 & 21808500 & 30 & 6542550 & 28351050 \\ 0 & & & 8,484,072 & & & & \\ 0 & 51,363,499 & 16.52 & & 59,847,571 & 318,479,567 & \end{array}$
$35 \quad 5805472$
1894526
$347,699,998$
22392533
8209611
$0,602,144$

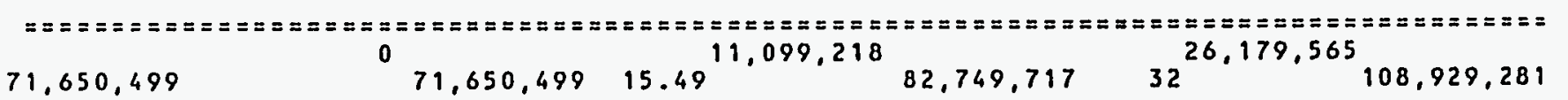


KAISER ENGINEERS HANFORD HESTIHGHOUSE HANFORD COMPANY JOB HO. ER3415/24ITLIM

FILE NO.
* IEST - INTERACTIVE ESTIMATING * *

TAHK 241-T-101 LIMITED SLUICINO

STUDY ESTIMATE

DOE_ROG - CONTINGENCY AHALYSIS BASIS SHEET
PAGE 10 OF 13

DATE 02/24/93 13:57:05

BY GDR
REFERENCE: ESTIHATE BASIS SHEET

COST CODE ACCOUNT SUMMARY $\begin{array}{llll}\text { PAGE } & 5 & \text { OF } & 13 \\ \text { PAGE } & 7 & \text { OF } & 13\end{array}$

THE U.S. DEPARTMENT OF ENERGY - RICHLAND ORDER 5700.3 "COST ESTIMATING, ANALYSIS AND STANDARDIZATIOH" DATED 3-27-85, PROVIDES GUIDELIIIES FOR ESTIMATE CONTIHGEHCIES. THE GUIDELINE FOR A STUDY ESTIMATE ASSOCIATED HITH EXPERIMENTAL/SPECIAL CONDITIONS SHOULD HAVE AN OVERALL RANGE OF $20 \%$ TO $50 \%$.

CONTINGENCY IS EVALUATED AT THE THIRD COST CODE LEVEL AND SUMMARIZEO AT THE PRIMARY ANO SECONDARY COST CODE LEVEL OF THE DETAILED COST ESTIIIATE.

\section{ENGINEERING}

$\cos T$ CODE 000

WBS 1.1 .1 .0 .0 .0

AN OVERALL AVERAGE OF $12 \%$ CONTINGENCY HAS APPLIED TO THE ENGINEERING STUDY ESTIMATE DUE TO THE COST TO DATE AND THE ESTIMATE TO COMPLETE CALCULATIONS.

HBS 1.1 .2 .0 .0 .0 THRU WBS 1.2 .2 .0 .0 .0

A $35 \%$ CONTINGENCY HAS APPLIED TO ALL REMAINIHG ENGINEERING FUNCTIONS DUE TO THE ALLOHANCES

PROVIDED HERE BASED ON A PERCENTAGE OF CONSTRUCTION COSIS. ALSO, II APPEARS THAT THE EVOLUTION OF DESIGH HILL INEVITABLY INCREASE DESIGN AND SCHEOULING COSTS DUE TO UNKNOHNS.

HBS 4.0 .0 .0 .0 .0

A $30 \%$ CONIINGEHCY HAS APPLIEO TO THE HIC PROJECT MAHAGEMENT PORTION OF THE ENGINEERING ESTIMATE BY HESIINGHOUSE DIRECTION.

CONSTRUCTION

$\cos T$ CODE 600

HBS 2.1 .0 .1 .8 .0

A $35 \%$ CONTINGENCY WAS APPLIED TO THE ELECTRICAL EOUIPMENI PROCUREMENT ITEMS DUE TO THE LIMITED AMOUNT OF INFORMATION AVAILABLE FOR THIS EFFORI.

HBS $3.1 .0 .1 .8 .0 \quad 8$ HBS 3.1 .0 .2 .8 .0

A $35 \%$ CONIINGEHCY HAS ALSO APPLIED TO THE ELECTRICAL EOUIPHENI INSIALLATION DUE TO THE ASSUMPIIONS MADE FOR OUANIIIIES AND INSTALLATIOH MATERIAL REOUIREMENTS. 
KAISER ENGINEERS HANFORD WESTINGHOUSE HAHFORD COMPAHY JOB NO. ER3415/241TLIM FILE NO. 241 TUNL

\author{
* IEST - INTERACTIVE ESTIHATING * * \\ TANK 241-T-101 LIMITED SLUICING \\ STUOY ESTIMATE \\ DOE_ROG - CONTINGENCY AHALYSIS BASIS SHEET
}

PAGE 11 OF 13
DATE OR/25/93
BY
GDR

HBS 3.1 .0 .4 .0 .0

A $40 \%$ CONTINGENCY HAS APPLIED TO THE CONTROL ROOM CHAHGE ROOM, AND LUNCH ROOM TRAILER ALLOHANCES DUE TO THE LIMITED INFORHATION AVAILABLE AT THIS TIME.

$\operatorname{COST} \operatorname{CODE} 700$

HBS 2.1 .0 .1 .6 .0 AND HBS 2.1 .0 .2 .6 .0

A $35 \%$ CONTINGENCY HAS APPLIED TO THE PUMPS, SLUICE MAST AND DISTRIBUTOR DISCHARGE SIPHON, DUE TO THE ALLOHANCES PROVIDED HERE EXTRACTED FROM PREVIOUS PARAHETRIC COST ESTIMATES FOR SIMILAR ITEMS.

WBS 2.1 .0 .1 .9 .0 A $25 \%$ CONTINGENCY HAS APPLIED TO THE HVAC EQUIPHENT DUE TO THE INFORHATION AHO BUDGET QUOTE SUPPLIED BY A QUALIFIED VENDER.

HBS 3.1 .0 .1 .1 .0 \& HBS 3.1 .0 .2 .1 .0 A $25 \%$ CONTINGEHCY HAS APPLIED TO THE CONSTRUCTION COSTS OF BUILOING GREENHOUSE SS OVER THE PITS AHD RISERS BECAUSE OF ASSUMPTIONS ASSOCIATED HITH THE SIZE AHD STYLE REQUIRED.

HBS $3.1 .0 .1 .2 .0 \&$ HBS 3.1 .0 .2 .2 .0

A $35 \%$ \& $40 \%$ CONTINGENCY HAS APPLIED AGAINST TIIE CONSTRUCTIOH TASKS ASSOCIATED HITH THE UPGRADING OF THE EXISTING PITS BECAUSE OF UNKNOWN CONTAMINATION REQUIREMENTS AMD LIMITED SCOPE DEFINITIOH.

HOS 3.1 .0 .1 .4 .0 \& HBS 3.1 .0 .2 .4 .0 A $35 \%$ CONTINGENCY HAS APPLIED TO THE JUHPER FABRICATION COSTS DUE TO THE ALLOHANCES PROVIDED HERE EXTRACTED FROM PREVIOUS PARAMETRIC COST ESTIMATES FOR SIMILAR TASKS.

WBS 3.1 .0 .1 .5 .0 \& WBS 3.1 .0 .2 .5 .0 A $35 \%$ CONTINGENCY HAS APPLIED TO THE WASHDOWN, MOUNTING BASE, AND SLIOE VALVE ASSEMBLY COSTS DUE TO THE ALLOWANCES PROVIDED HERE EXTRACIED FROH AN EXISTING CONCEPTUAL ESTIMATE HITH SIMILAR TASKS AND DIFFICULTIES.

HBS 3.1 .0 .1 .6 .0 \& HBS 3.1 .0 .2 .6 .0 A $35 \%$ CONTINGENCY HAS APPLIED TO THE INSTALLATION OF THE TRANSFER,EOUIPMENT DUE TO THE HIGHLY CONIAMINATED AREA WHERE CONSTRUCTION HILL MOST LIKELY BE DONE HITH REMOTELY OPERATED EOUIPMENT.

HBS 3.1 .0 .1 .7 .0 \& HBS 3.1 .0 .2 .7 .0 A $35 \%$ CONTINGENCY HAS APPLIED TO ALL PIPING INSTALLATION COSTS HITHIN THE TANK FARM DUE TO THE TAKE- OFF OUANTITIES BEIHG EXIRACIED FROM FLOW DIAGRAMS HITHOUT DISTANCES REPRESENTED.

HBS $3.1 .0 .1 .8 .0 \&$ HBS 3.1 .0 .2 .8 .0 A $35 \%$ CONTINGENCY HAS APPLIED TO ALL ELECTRICAL AND IHSTRUMENTATION FUNCTIONS HITHIN THE TANK FARM DUE TO TIIE LIMITED AMOUNT OF IMFORMATION AVAILABLE FOR THIS EFFORT.

HBS $3,1,0,1,9.0$

A $30 \%$ CONTIHGENCY WAS APPLIED TO TIIE INSTALLATION OF THE IIVAC EQUIPMENT SKIDS AND INTERCONNECIIHG DUCIS DUE TO TIIE INSUFFICIENI INFORMAIION SUPPLIEO FOR SIIIELDING REQUIREMENTS. 
KAISER ENGINEERS IIANFORD HESTINGHOUSE HANFORD COMPANY JOB NO.ER3415/241TLIM

FILE NO. $241 T$ TUL

\author{
* IEST - INTERACTIVE ESIIMAIING * \\ TANK $241-T \cdot 101$ LIMITED SLUICING \\ STUDY ESTIMATE \\ DOE ROG - CONIIHGEHCY ANALYSIS BASIS SHEET
}

DATE 02/25\%ं93 13:57:05

WBS $3.1,0.3 \cdot 2.0$

A $30 \%$ CONTINGENCY HAS APPLIED TO THE INSTALLATION OF ENCASED PIPIHG DUE TO THE UNKHOHHS ASSOCIATED WITH ROUTING OF PIPING FROH AN EXISTING TANK FARM, C-106, TO TANK FARM 102-AY.

HBS $3 \cdot 1 \cdot 0 \cdot 4 \cdot 0.0$

A $40 \%$ CONTINGEHCY HAS APPLIED TO THE CONTROL ROOM, CHANGE ROOM, AHO LUNCH ROOH TRATLER ALLOHAHCES DUE TO THE LIMITED INFORMATIOH AVAILABLE AT THIS TIHE.

HBS $3.1 .0 .5 .1 .0 \&$ HBS 3.1 .0 .5 .2 .0

A $35 \%$ CONTINGENCY HAS APPLIED TO THE ESTIMATED "BURH-OUT" DOLLARS DUE TO THE INCONSISTENT AHO

LIMITED DETAIL AVAILABLE FOR AREAS IHAT ARE CONSIDERED COHTAMINATED. FUTURE ESTIMATES SHOULD REFLECT

INFORMATION DETAILING MR READINGS FOR SPECIEIC COHSTRUCTION AREAS.

WBS 3.1 .0 .6 .0 .0

A $30 \%$ CONTINGENCY WAS APPLIED TO COSTS ASSOCIATED WITH THE "STEP OFF PAOS", FOR KEH CONSTRUCTION FORCES DUE TO THE LIMITED INFORMATION AVAILABLE AT THIS TIME FOR SCHEDULING ACTIVITIES. COSTS FOR "S.TEP OFF PADS" ARE GENERALLY CALCULATED BY MAN-LOADING SCHEDULE DURATIONS FOR SPECIFIC TASKS.

COST CODE 810

HBS $3.3 .0 .1 .1 .0 \&$ HBS 3.3 .0 .1 .2 .0

- A $35 \%$ CONTINGENCY HAS APPLIED TO THE D\&D OF THE EXISTING PRE-TRANSFER EQUIPMEHT DUE TO THE ALLOHANCES INCLUDED HITHIN THIS ESTIMATE HERE BASED ON AN EXISTING CONCEPTUAL DESIGH ESTIMATE (H. 15I).

WBS $3.3 .0 .2 .1 .0 \&$ HBS 3.3 .0 .2 .2 .0 A $35 \dot{\%}$ CONTINGENCY HAS APPLIED TO THE D\&D OF THE POST-TRANSFER EQUIPMENT, CONCRETE TRENCH, AND ENCASED PIPING, DUE TO THE POIENTIAL PROBLEMS ASSOCIATED HITH CONTAMINATION.

WBS $3.3 .0 .4 .1 .0 \&$ HBS 3.3 .0 .4 .2 .0

- A $40 \%$ CONTINGENCY HAS APPLIED TO THE COST ALLOHANCES FOR BURIAL FEES DUE TO THE UNKNOHNS ASSOCIATED HITH HANDLING CONTAMINATED MATERIAL AND THE POTENTIAL OF INCREASED VOLUMES OF OISPOSABLE MATERIAL THAT IS HOT REFLECTED HITHIN THIS ESTIMATE.

COST CODE 900

HBS $5,0,0,0,1,0$ AN OVERALL AVERAGE $30 \%$ CONTINGENCY HAS APPLIED AGAINST ALL HHC EXPENSE FUNDED ITEMS BY THEIR REQUEST. 


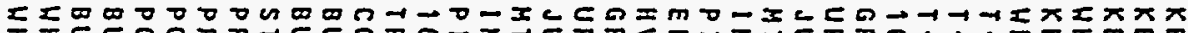

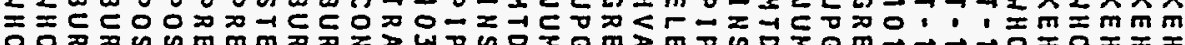

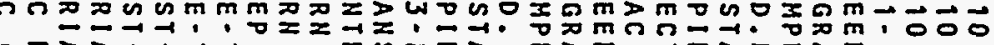

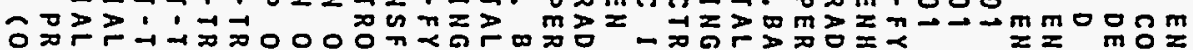

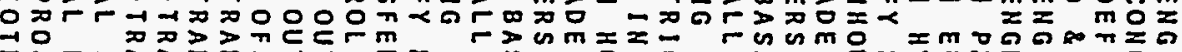

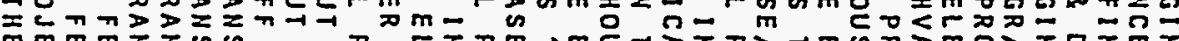

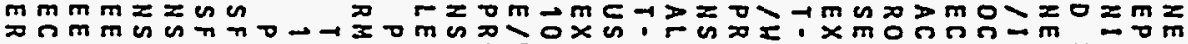

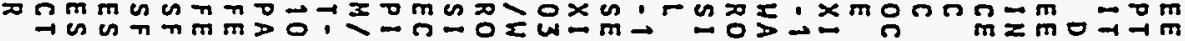

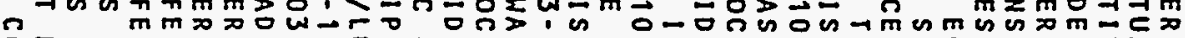

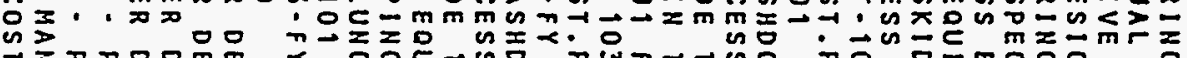

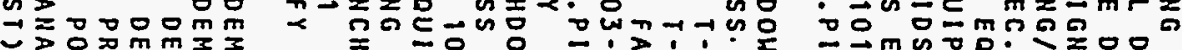

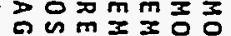
mito.

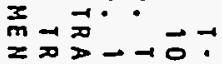

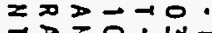

in

is nw: $\overrightarrow{0} \div 0$

mina

$\rightarrow$ 의을

$\infty \cdot x \cdot 0$

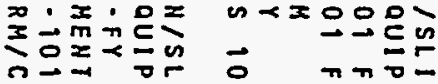

开 $\pi$ 이

$\sum_{0} \overrightarrow{0} \sum_{i=0}^{\pi} \overrightarrow{0}$

m

$\geq 0$

in

x:

$x<$

要要

$\rightarrow$ j

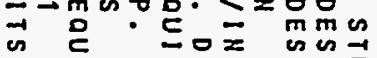

일

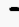

is

92

욛

$\vec{\infty} n$

$\overrightarrow{\mathrm{in}}$

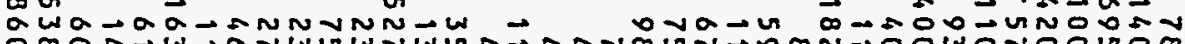

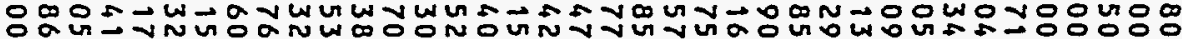

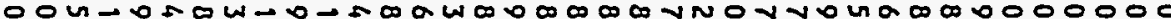

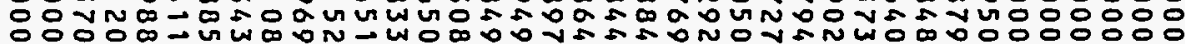

$\operatorname{lin}$

"도요

"ï

$\lim _{\substack{2 \\ i}}$

$\| \vec{m}$

o in

음주

ON

의

$\lim _{n \rightarrow-1} \overrightarrow{-}$

, $=\div$ 向

중

is

$\Rightarrow \overrightarrow{0}=$

옴어 =

- $\rightarrow 5$

주유

징

m $m=$

Ｎ正品

$\rightarrow-\bar{m}$

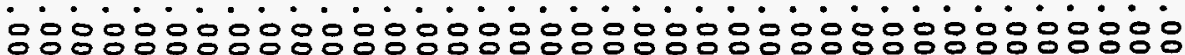

00000000000000000000000000000000000000

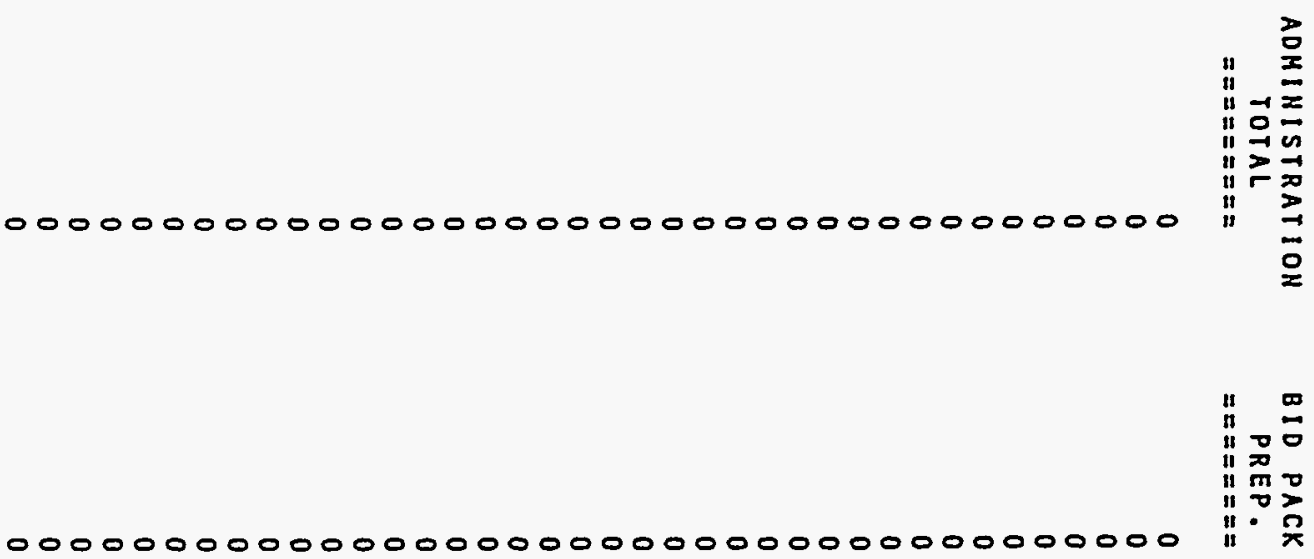

요워

$\overrightarrow{\mathrm{n}} \overrightarrow{\mathrm{m}}>\overline{\mathrm{I}}$

$n m \geq \frac{7}{2}$

ous

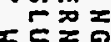

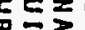

思两

致

00000000000000000000000000000000000000

ס

00000000000000000000000000000000000000

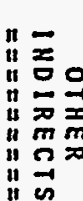

$$
\begin{aligned}
& \text { 뭉요 }
\end{aligned}
$$

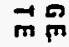

$$
\begin{aligned}
& \text { 운 } \vec{w} \\
& \text { N } \\
& \text { No } \\
& \text { w }
\end{aligned}
$$


KAISER ENGINEERS HANFORD HESTINGHOUSE HANFORD COMPANY

JOB

FILE HO. ZOSISAHI
* * IEST - IHTERACTIVE ESTIMATIHG * *

241-T-101 EXTERNAL TANK STABLIZATION ALTERHATIVE STUDY: OPTIOH 1 -GEOMEMBRANE HALLS/JET GROUTING DOE_ROI - PROJECT COST SUMMARY
PAGE 1 OF 9 DATE O3/22/93 $07: 00: 2$ BY GDR/KDE

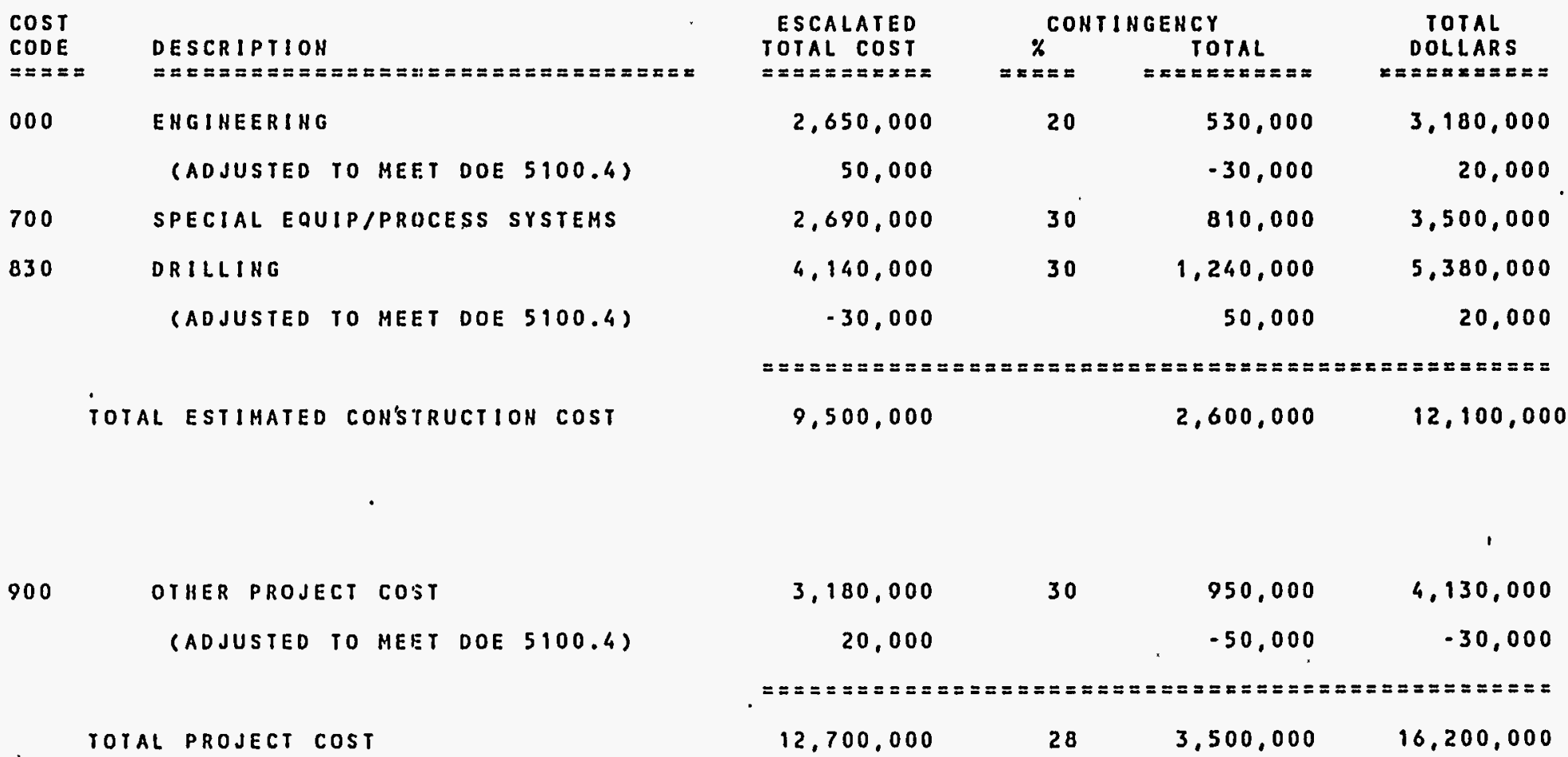

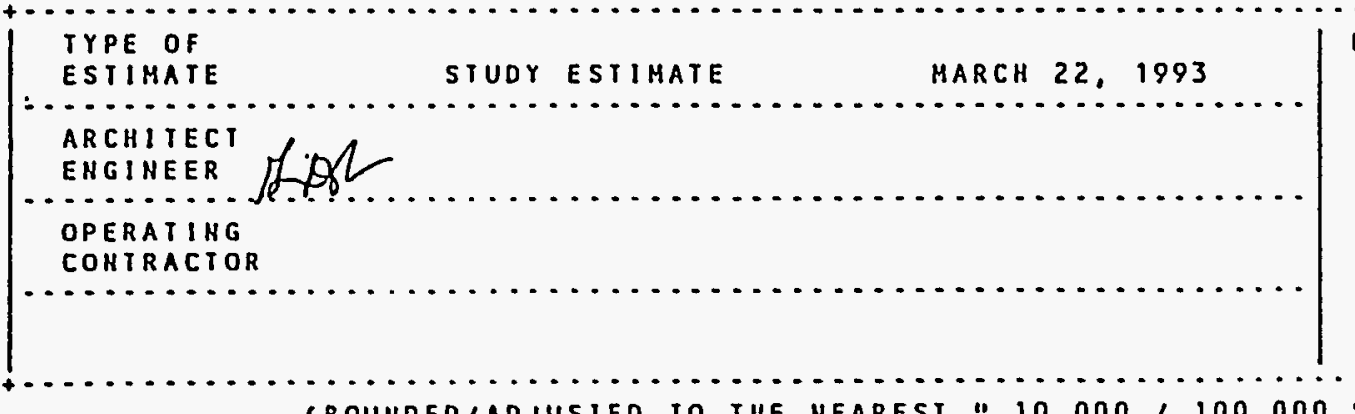

(ROUNDED/AOJUSIED TO TIIE NEAREST" $10,000 / 100.000 "$

PIRCENIACES NOT RECALCULAIEO TO REFLECT ROUNDIHG) 241T101.EEA.1843 
KAISER ENGINEERS HAHFORO HESTI INGHOUSE HANFORD COMPANY JOB NO. ER-3415

FILE NO. ZOS1SAHI

WBS DESCRIPTION

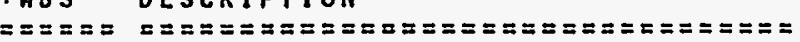

110000 DEFINITIVE DESIGN-ONSITE E/C

111000 CONCEPTUAL DESIGN-ONSITE E/C

120000 ENGINEERING/INSPECTIOH-ONSITE E/C

SUBTOTAL 1 ENGINEERING

210000 PROCUREMENT-ONSITE E/C

SUBTOTAL 2 PROCUREMENT

311000 SITE PREP

312000 JET GROUT CONE - HORIZONTAL HALL

313000 CLEANUP ACTIVITIES

SUBTOTAL 31 FA CONST-ONSITE E/C

321000 VERTICAL HALL INSTALATION

SUBTOTAL 32 CONSTRUCTION-FIXED PRICE

SUBTOTAL 3 CONSTRUCTION

500001 OTHER PROJECT COST

SUBTOTAL 5. OTHER PROJECT COST
* * IEST - INTERACTIVE ESTIMATING * *

241-T-101 EXTERNAL TANK STABLIZATION ALTERHATIVE SIUDY: OPTION T-GEOMEMBRANE WALLS/JET GROUTING DOE_RO2 - HORK BREAXDOHN STRUCTURE SUMMARY

\begin{tabular}{|c|c|c|c|c|c|c|c|c|}
\hline $\begin{array}{l}\text { EST INATE } \\
\text { SUB TOTAL } \\
=======\end{array}$ & $\begin{array}{l}\text { ONSITE } \\
\text { I HDIRECTS } \\
========\end{array}$ & $\begin{array}{c}\text { SUB } \\
\text { TOTAL } \\
========2\end{array}$ & $=z=2==$ & $\begin{array}{l}\text { LATIOH } \\
\text { TOTAL. } \\
====z==z\end{array}$ & $\begin{array}{c}\text { SUB } \\
\text { I } 0 \text { TAL. } \\
==\approx=z=z=\end{array}$ & $\begin{array}{c}\text { CONTI } \\
\% \\
=x==\end{array}$ & $\begin{array}{l}\text { INGENCY } \\
\text { TOTAL } \\
=========\end{array}$ & $\begin{array}{c}\text { TOTAL } \\
\text { DOLLARS } \\
========\end{array}$ \\
\hline $\begin{array}{r}1406820 \\
289364 \\
562728\end{array}$ & $\begin{array}{l}0 \\
0 \\
0\end{array}$ & $\begin{array}{r}1406820 \\
281364 \\
562728\end{array}$ & $\begin{array}{r}17.25 \\
5.52 \\
25.83\end{array}$ & $\begin{array}{r}242676 \\
15531 \\
145353\end{array}$ & $\begin{array}{r}1649496 \\
296895 \\
708081\end{array}$ & $\begin{array}{l}20 \\
20 \\
20\end{array}$ & $\begin{array}{r}329899 \\
59379 . \\
141696\end{array}$ & $\begin{array}{r}1979396 \\
356274 \\
849697\end{array}$ \\
\hline 2250912 & 0 & 2250912 & 17.93 & 403560 & 2654472 & 20 & 530894 & 3185367 \\
\hline 2303200 & 0 & 2303200 & 16.85 & 388089 & 2691289 & 30 & 807387 & 3498676 \\
\hline 2303200 & 0 & 2303200 & 16.85 & 388089 & 2691289 & 30 & 807387 & 3498676 \\
\hline $\begin{array}{r}73485 \\
2701959 \\
88254\end{array}$ & $\begin{array}{l}0 \\
0 \\
0\end{array}$ & $\begin{array}{r}73485 \\
2701959 \\
88254\end{array}$ & $\begin{array}{l}20.33 \\
20.33 \\
20.33\end{array}$ & $\begin{array}{r}14939 \\
549308 \\
17942\end{array}$ & $\begin{array}{r}88424 \\
3251267 \\
106196\end{array}$ & $\begin{array}{l}30 \\
30 \\
30\end{array}$ & $\begin{array}{r}26528 \\
975380 \\
31859\end{array}$ & $\begin{array}{r}114952 \\
4226648 \\
138054\end{array}$ \\
\hline 2863698 & . & 2863698 & 20.33 & 582189 & 3445887 & 30 & 1033767 & 4479654 \\
\hline 460380 & 108784 & 569164 & 21.25 & 120947 & 690111 & 30 & 207033 & 897144 \\
\hline 460380 & 108784 & 569164 & 21.25 & 120947 & 690111 & 30 & 207033 & 897144 \\
\hline 3324078 & 108784 & 3432862 & 20.48 & 703136 & 4135998 & 30 & 1240800 & 5376798 \\
\hline 2757367 & 0 & 2757367 & 15.34 & 422980 & 3180347 & 30 & 954104 & 4134451 \\
\hline 2757367 & 0 & 2757367 & 15.34 & 422980 & 3180347 & 30 & 954104 & 4134451 \\
\hline & 108,784 & & & 917,765 & & & $3,533,185$ & 292 \\
\hline
\end{tabular}

PAGE 2 OF 9

DATE $03 / 22 / 93 \quad 07: 00: 28$

BY GDR/KDE
$10,744,341$

PROJECT TOTAL 
KAISER EHGIHEERS HANFORD HESTINGLIOUSE HANFORD COMPANY JOB NO. ER-3415

FILE NO. ZOSISAHI
* * IEST - INTERACTIVE ESTIMATIHg * * 241-T-101 EXTERHAL TANK STABLIZATION ALTERHATIVE STUDY: OPTION 1-GEOMEMBRANE HALLS/JET GROUIING DOE_RO3 ESTIMATE BASIS SHEET
PAGE 3 OF 9

DATE $03 / 22 / 93$

1. DOCUMENTS AND DRAHINGS

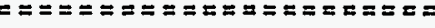
DOCUMENTS: HIC LETTER 9259343 DATED FEBRUARY 4, 1993

DRAHINGS: HONE

2. MATERIAL PRICES

$=======z====$

UNIT COSTS REPRESENT CURRENT PRICES FOR SPECIFIED MATERIAL.

3. LABOR RATES

$== \pm== \pm== \pm=$

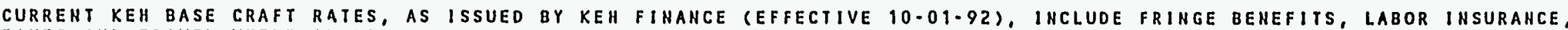
TAXES AND TRAVEL HHERE APPLICABLE, PER HANFORD SITE STABILIZATION AGREEMENT, APPEHDIX A (EFFECTIVE 9-2-91). NON CRAFT

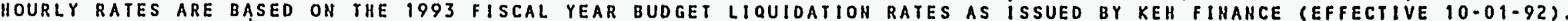

4. GENERAL REQUIREMENTS/TECIINICAL, SERVICES/OVERHEADS

$===z===z==================================0$

A.) ONSITE CONSTRUCTION FORCES GEHERAL REQUIREMENTS, TECHNICAL SERVICES AHD CRAFT OVERHEAD COSTS ARE IHCLUDED AS A COMPOSITE PERCENTAGE BASED ON THE KEH ESTIMATIHG FACTOR/BILLING SCHEDULE, REVISION 14, DATED OCTOBER OI. 1992. THE TOTAL COMPOSITE PERCENTAGE APPLIED TO ONSITE CONSTRUCTION FORCES LABOR, FOR THIS PROJECT, IS 93\% FOR SHOP HORK AND $134 \%$ FOR FIELD HORK, HHICH IS REFLECTED IN THE "OH\&P/B\&I" COLUMN OF THE ESTIHATE DETAIL.

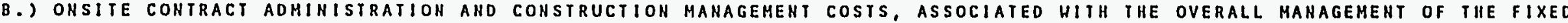
PRICE CONTRACTS, ARE INCLUDED AS A COMPOSITE PERCENTAGE AND LUMP SUM ALLOHANCE (FOR BID PACKAGE PREP) BASED ON THE ESTIMATING FACTOR/BILLING SCHEDULE. THE TOTAL COMPOSITE PERCENTAGE AHD LUMP SUH ALLOWAHCE ARE APPLIED AGAINST THE TOTAL FIXED PRICE CONTRACT AMOUNT WHICH IS REFLECTED ON THE KEH SUMMARY REPORT DOEROT, INCLUDED HITH THIS ESTIMATE. (FINAL ESTIMATES MAY BE PARTIALLY MANLOADED AND IHCLUDED HITHIN THE ESTIMATE DETAIL)

C.) FIXED PRICE CONTRACTOR OVERHEAD, PROFIT, BOND AND INSURANCE COSTS HAVE BEEN APPLIED AT THE FOLLOHING PERCENTAGES AND ARE REFLECTED IN TILE "OHBP/B\&I" COLUMN OF THE ESTIMATE DETAIL: SUBCONTRACTS $20 \%$

5. ESCALATION

$=\Sigma==== \pm==$

ESCALATION PERCENTAGES HERE CALCULATED BY THE HANFORD MATERIAL \& LABOR ESCALATION STUDY, DATED FEBRUARY 1993.

6. ROUNDING

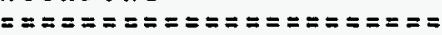

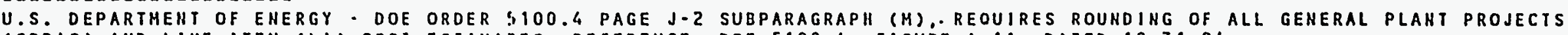
(GPP'S) AND LINE ITEM (LI) COST ESTIMA:ES. REFERENCE: DOE 5100.4, FIGURE I-11, DATED 10-31-84.

7. REMARKS

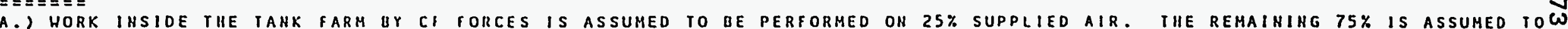
BE IN WHITES.

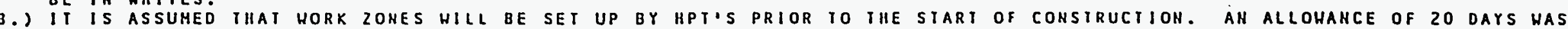
USED FOR THIS ACTIVITY.

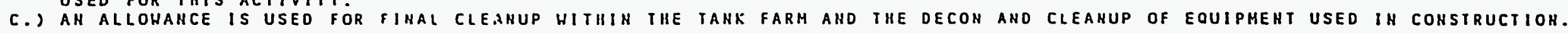


KAISER ENGINEERS HANFORD WESTINGHOUSE HANFORD COMPANY $J O B$ NO. ER-3415

FILE NO. ZOSISAHI
* * IEST - INTERACTIVE ESTIMATING ** 241-T-101 EXTERNAL TAHK STABLIZATION ALTERHATIVE STUDY: OPTION I-GEOMEMBRANE HALLS/JET GROUTING DOE_RO3 - ESTIMATE BASIS SHEET
PAGE 4 OF 9

10:54:27

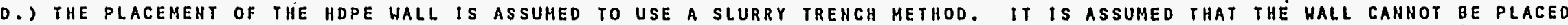
BY THE USE OF VIBRATORY OR HATER JET METHOOS OF INSTALLATIOH. THEREFORE TIIE HALL HILL BE CONSTRUCTED BY PLACING THE HDPE LINER IN A SLURRY TRENCH.

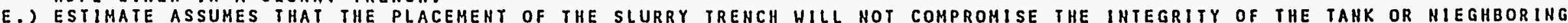
TANKS.

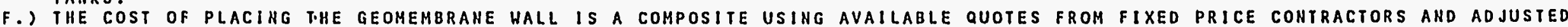
TO REFLECT HORK ON THE HAHFORD SITE.

G.) ESTIMATE ASSUMES THAT THIS HORK HILL BE DONE WITHOUT HINDERANCE FROM CONTAMIHATION. IF SUBSURFACE CONTAMINATION IS ENCOUNTERED AND CF FORCES ARE BROUGHT IN TO DO THE HORK, THE COST OF CONSTRUCTION HILL INCREASE SUBSTAHTIALLY.

II.) ENGINEERING AHD OPC COSTS ARE BASED ON C-106 TOTAL RETRIEVAL ESTIMATE.

1.) OC PROJECT MANAGEMENT COSTS ARE IHCLUDED IN THE OPC COSTS.

J.) AN ALLOHANCE HAS USED FOR PROCUREMEHT OF EQUIPMENT RELATED TO THE INSTALLATIOH OF THE GEOMEMBRANE HALL.

K.) ESTIMATE CONTAINS NO ALLOHANCES FOR CHARACTERIZATION OR MONITORING WELLS.

L.) ESTIHATE HAS NO COST FOR DEMONSTRATION OR TESTING.

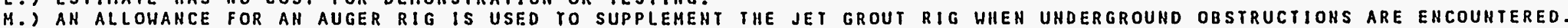

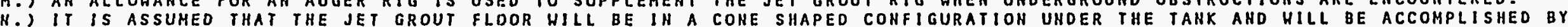
SLANTED GROUT HOLES FOR THE JET GROUTING.

D.) THE GEOHEMBRANE HALL IS ASSUMED TO BE PLACED IN A CIRCULAR CONFIGURATION AROUND THE TANK.

P.) IT IS ASSUMED THAT THE JET GROUT CONE AHD GEOMEMBRANE HALL WILL HAVE A COMPATIBLE IHTERFACE.

Q.) ESTIMATE ASSUMES THAT THE CONSTRUCTION OF THE GEOMEMBRAHE HALL BETHEEN TANKS IS FEASIBLE HITH THE LIMITED SPACE FOR COHSTRUCTION EOUIPMENT.

R.) HO ALLOHANCE FOR ESCORTS. 
KAISER ENGINEERS HAHFORD

HEST I NGHOUSE HANFORD COMPANY

JOB. NO. ER-3415

FILE NO. ZOSISAHI

$\cos 1$

COOE/HBS

DESCRIPTION

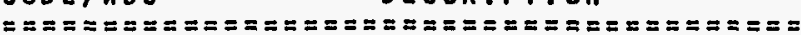

000 ENGINEERING

110000 DEFINITIVE DESIGN-ONSITE E/C 1406820

111000 CONCEPTUAL DESIGH-ONSITE E/C 281364

120000 ENGINEERING/INSPECTION-ONSITE E/C.

TOTAL OOO ENGINEERING.

2250912

700 SPECIAL EQUIP/PROCESS SYSTEMS

210000 PROCUREMENT-ONSITE E/C

TOTAL 700 SPECIAL EQUIPIPROCESS SYSTEM

2303200

2303200

830 DRILLING

\section{SITE PREP \\ JET GROUT CONE - HORIZONTAL HALL \\ 313000 CLEANUP ACTIVITIES \\ 321000 VERTICAL HALL INSTALATION}

TOTAL 830 DRILLIHG

900 OTHER PROJECT COST

500001 OTHER PROJECT COST

TOTAL 900 . OIHER PROJECT COST

PROJECT TOTAL

\section{STIMATE UBTOTAL}

73485

701959
88254

460380

2757367

2757367
* * IEST - INTERACTIVE ESTIMATIHg ** 241-T-101 EXTERHAL TAHK STABLIZATION ALTERHATIVE
STUDY: OPTION T-GEOHEMBRANE HALLS/JET GROUTING DOE_RO4 - COST CODE ACCOUNT SUMMARY
ONSITE INDIRECTS SUB
TOTAL

$== \pm=== \pm==$

$=\approx==\Sigma=\Sigma \Sigma=$

ESCALATIOH

\% TOTAL

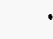

0

1406820

281364

562728

2250912

17.25
5.52
25.83

15531

145353

$17.93 \quad 403560$

$0 \quad 2303200$

$\begin{array}{ll}16.85 & 388089 \\ 16.85 & 388089\end{array}$

$2691289 \quad 30$

$2691289 \quad 30$

807387

3498676

2303200

6.85

\section{2701959}

0
0
0
108784

88254
569164

20.33
20.33

20.33
21.25

14939

549308

549308
17942

120947

108784

3432862

20.48

703136

88424

325126

106196

690111

4135998

30
30
30
30
30

26528
975380

975380

31859

207033

1240800

4226648 897144

5376798

\section{$0 \quad 2757367$}

15.34

422980

$3180347 \quad 30$

$15.34 \quad 422980$
954104

4134451

954104

4134451

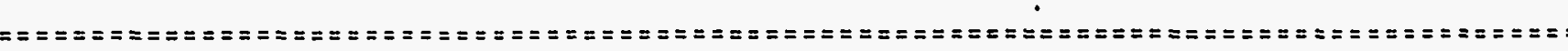

108,784

- 10.744 .34117 .85
$======$
$3,533,185$

$12.662 .106 \quad 28$ 
KAISER ENGIHEERS HANFORD HESTINGHOUSE HAHFORD COMPAHY JOB NO. ER-3415

FILE'NO. ZO31SAHI

\section{CSI DESCRIPTION}

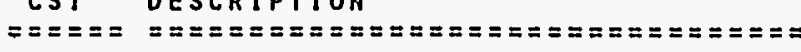

ENG I HEER ING

OO TECHNICAL SERVICES

TOTAL ENGINEERING

CONSTRUCTION

01
02
02 SITEHERAL REQUIRMENTS
15 MECHANICAL
20 OPC

TOTAL CONSTRUCTION

PROJECT TOTAL
* IEST - INTERACIIVE ESTIMATING * *

241-T-101 EXTERNAL TANK STABLIZATION ALTERNATIVE STUDY: OPIION 1-GEOMEMBRANE HALLS/JET GROUTIHG

DOE_ROS ESTIMATE SUMMARY BY CSI DIVISIOH
PAGE 6 OF 9

DATE 03/22/93 07:00:33

\begin{tabular}{|c|c|c|c|c|c|}
\hline $\begin{array}{l}\text { ESTIMATE } \\
\text { SUBTOTAL } \\
========\end{array}$ & $\begin{array}{l}\text { OHS ITE } \\
\text { IND IRECTS } \\
=========\end{array}$ & $\begin{array}{c}\text { SUB } \\
\text { TOTAL } \\
=========\end{array}$ & $\begin{array}{c}\text { ESCALATION } \\
\% \text { TOTAL } \\
==\approx==0======\end{array}$ & $\begin{array}{c}\text { SUB } \\
\text { TOTAL } \\
==\approx======\end{array}$ & $\begin{array}{c}\text { CONTINGENCY } \\
x \text { TOTAL } \\
=x==z========\end{array}$ \\
\hline
\end{tabular}

\section{SUBTOTAL}

$== \pm==2$
$=====$

$=x=$
TOTAL

DOLLARS $==\Sigma==\Sigma==$

$2,250,912$

0

\section{$2250912 \quad 17.93$}

0

$2,250,9 ! 2 \quad 17.93$

403,560

2654472

$2,654,472$

20

530894

530,894

20

$\begin{array}{rrr}0 & 700219 & 20.33 \\ 108784 & 2732643 & 20.52 \\ 0 & 2303200 & 16.85 \\ 0 & 2757367 & 15.34\end{array}$

$\begin{array}{lr}142354 & 842573 \\ 560782 & 3293425 \\ 388089 & 2691289 \\ 422980 & 3180347\end{array}$

30
30
30
30

252773

988027

807387

807387
954104

$3,002,291$

108,784

$8,493.429 \quad 17.83^{1.514,205}$

$10,007,634$

30

$13,009,925$

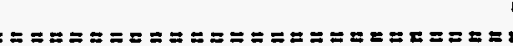

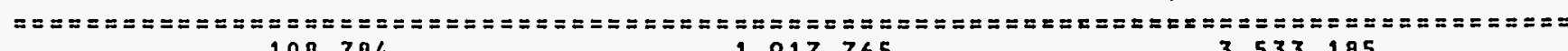

$10,635,557$
108,784

$10,744,341 \quad 17.85$
$1,917,765$

$12,662,106$
$3,533,185$
$16,195,292$

1095345

4281453

3498676

4134451 
KAISER ENGINEERS HANFORD WESTINGHOUSE HANFORD COMPANY JOB NO. ER-3415

FILE" NO. ZOS ISAH
241. * IEST - INTERACTIVE ESTIHATING ** -T-101 EXTERNAL TANK STABLIZATION ALTERHATIVE STUDY: OPTIOH 1-GEOMEMBRANE HALLS/JET GROUTIHO

DOE_ROG - CONTINGENCY AHALYSIS BASIS SHEET
PAGE 7 OF 9 DATE $03 / 22 / 93 \quad 10: 54: 35$ GDR/KDE
REFERENCE: ESTIMATE BASIS SHEET COST CODE ACCOUNT SUMMARY $\begin{array}{llll}\text { PAGE } & 3 & \text { OF } & 9 \\ \text { PAGE } & 5 & \text { OF } & 9\end{array}$

THE U.S. DEPARTHENT OF ENERGY - RICHLAND ORDER 5700.3 "COST ESTIMATING, ANALYSIS AND STANDARDIZATIOH" DATED 3-27-85, PROVIDES GUIDELINES FOR ESTIMATE CONTINGENCIES. THE GUIDELIHE FOR A STUDY ESTIMATE SHOULD HAVE AN OVERALL RANGE OF 20 TO $30 \%$.

CONTINGENCY IS EVALUATED AT THE THIRD COST CODE LEVEL AND SUMMARIZED AT THE PRIMARY AND SECONDARY COST CODE LEVEL OF THE DETAILED COST ESTIMATE.

\section{ENGINEERING}

$\cos T$ coDe 000

WBS 110000 111000 120000

A $20 \%$ CONTINGENCY HAS APPLIED TO THE ENGINEERING BECAUSE OF A LACK OF DETAIL REGARDING THE DESIGN, THE CONSTRUCTION AND THE FACT THAT IT IS BASED ON A PERCENTAGE OF CONSTRUCTION DOLLARS.

AVERAGE ENGINEERING CONTINGENCY

$20 \%$

CONSTRUCT ION

$\cos T \operatorname{CODE} 700$

HBS 210000

A CONTINGENCY OF $30 \%$ HAS APPLIED TO PROCUREMENT AS THERE IS A LACK OF DETAIL CONCERNING THE EOUIPMENT REOUIRED FOR CONSTRUCTION AND THE EQUIPMENT REOUIREMENTS FOR THE OPERATION OF THE BARRIER.

HBS 321000 A $30 \%$ COHIINGENCY HAS APPLIEO TO THE FIXED PRICE CONSTRUCTION TO ACCOUNT FOR THE LACK OAF DETAIL PROVIDED. POSSIBLE INTERUPRIONS DUE TO CONSTRUCTION HITHIN A TANK FARM, UHDEFINED SOIL

CHARACTERISTICS THAT WOULD EFFECT CONSTRUCTION AND THE POSSIBILITY OF SUBSURFACE COHTAMIHATIOH.

$\cos 1 \operatorname{coDE} 830$

HBS 311000 .

312000

A CONTIHLENCY OF $30 \%$ HAS APPLIED TO CF HORK TO ACCOUNT FOR LACK OF DETAIL AND THE POSSIBILITIES OF, 313000

ENCOUHTERING SUBSURFACE CONTAH:HATION.

AVERAIJE COMSIRUCIION COHIIHGEHCY $30 \%$ 
KAISER ENGINEERS HAHFORD

WEST.IHGHOUSE HANFORD COMPANY

JOB NO. ER-3415

FILE NO. ZOSISAHI
* * IEST - INTERACTIVE ESTIMATING * *

241-T-101 EXTERHAL TANK STABLIZATION ALTERHATIVE STUDY: OPTION 1-GEOHEMBRANE HALLS/JET GROUTING DOE RO6 - COHTINGENCY ANALYSIS BASIS SHEET
PAGE 8 OF

DATE $03 / 22 / 93 \quad 10: 54: 35$

BY GDR/KDE

\section{OTHER PROJECT COSTS}

$\operatorname{COST} \operatorname{CODE} 900$

HBS 500001

A CONTIRGENCY OF $30 \%$ HAS PLACED ON OTHER PROJECT COSTS AS IT IS A PERCENTAGE OF CONSTRUCTION ANO IS DRIVEN BY THE SAME UNCERTAINTIES AS THE CONSTRUCTION.

AVERAGE PROJECT COST CONTINGENCY $30 \%$

AVERAGE PROJECT CONTIHGENCY

$28 \%$ 
KAISER ENGIHEERS HANFORD

HESTINGHOUSE HANFORD COMPANY

JO8. HO. ER-3415

FILE NO. ZO3 ISAHI

HBS DESCRIPTION

作

110000 DEFINITIVE DESIGN-ONSITE E/C

111000 CONCEPTUAL DESIGN-ONSITE E/C

120000 ENGINEERING/INSPECTION-ONSITE E/C

210000 PROCUREMENT-ONSITE E/C

311000 SITE PREP

312000 JET GROUT CONE - HORIZONTAL HALL

313000 CLEANUP ACTIVITIES

321000 VERTICAL HALL INSTALATION

500001 OTHER PROJECT COST

PROJECT TOTAL
* * IEST - INTERACTIVE ESTIMATIHG * *

241-T-101 EXTERHAL TANK STABLIZATION ALTERNATIVE STUDY: OPTION 1-GEOMEMBRANE HALLS/JET GROUTING

DOE_RO - ONSITE INDIRECT COSTS BY WBS

\begin{tabular}{|c|c|c|}
\hline $\begin{array}{l}\text { ESTIMATE } \\
\text { SUBTOTAL } \\
=======\end{array}$ & $\begin{array}{c}\text { CONTRACT } \\
=\% \\
====\end{array}$ & $\begin{array}{c}\text { ADMINISTRATIOH } \\
\text { TOTAL } \\
========\end{array}$ \\
\hline $\begin{array}{r}1406820 \\
281364 \\
562728 \\
2303200 \\
73485 \\
2701959 \\
88254 \\
460380 \\
2757367\end{array}$ & $\begin{array}{r}0.00 \\
0.00 \\
0.00 \\
0.00 \\
0.00 \\
0.00 \\
0.00 \\
22.00 \\
0.00\end{array}$ & $\begin{array}{r}0 \\
0 \\
0 \\
0 \\
0 \\
0 \\
0 \\
0 \\
101284 \\
0\end{array}$ \\
\hline
\end{tabular}

7,500

PAGE 9 OF 9

DATE 03/22/93 07:00:36

BY GDR/KDE

OTHER
INOIRECTS
$=\approx \approx=\approx=\approx=$
0
0
0
0
0
0
0
0
0

TOTAL.

INDIRECTS

$=\approx \approx=\approx \Sigma= \pm \approx$

0
0
0
0
0
0
0
0
0

108784
101,284

$10,635,557$
108,784 
KAISER ENGINEERS HAHFORD

HES I INGHOUSE HANFORD COMPANY

JOB NO. ER- 3415

FILE HO. $2031 \mathrm{SAI}$
* IEST - INTERACTIVE ESTIHATING *

241-T-101 EXTERHAL TAHK STABILIZATION ALTERHATIVE

STUDY: OPTION 2 :SLURRY WALLS/JET GROUTING

DOE_ROI' PROJECT COST SUMMARY
PAGE 1 OF 9

DATE 03/22/93 07:01:27

BY GDR/KDE

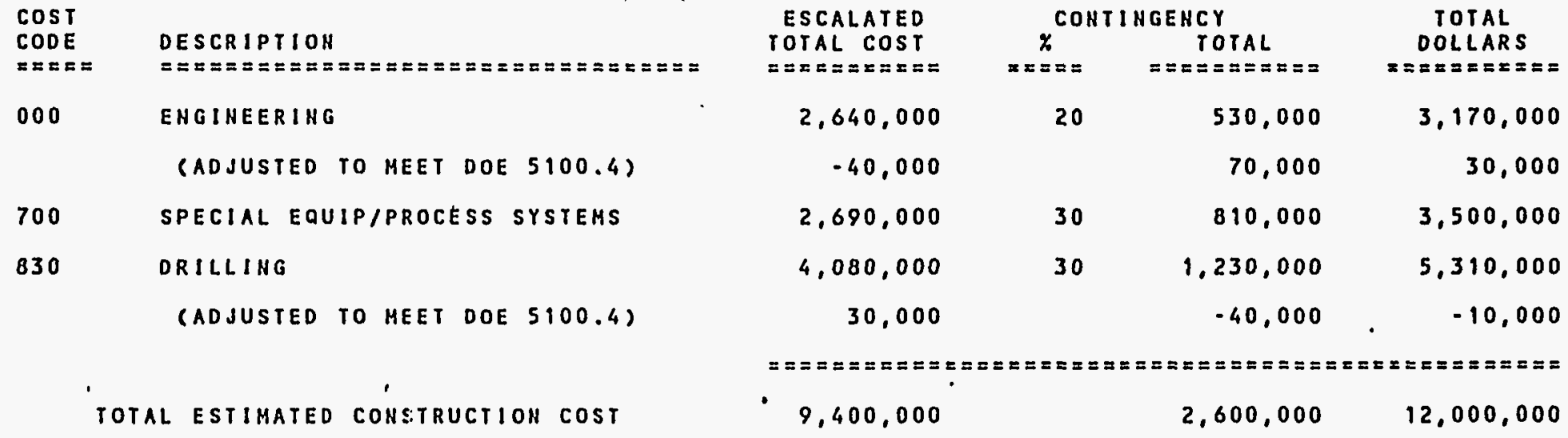

900

OTHER PROJECT COST

(ADJUSTED TO MEET DOE 5100.4)

TOTAL PROJECT COST

\begin{tabular}{|c|c|c|c|}
\hline $3,160,000$ & 30 & 950,000 & $4,110,000$ \\
\hline 40,000 & & $-50,000$ & $-10,000$ \\
\hline
\end{tabular}

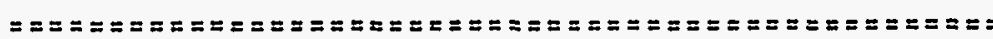

$12,600,000 \quad 28 \quad 3,500,000 \quad 16,100,000$

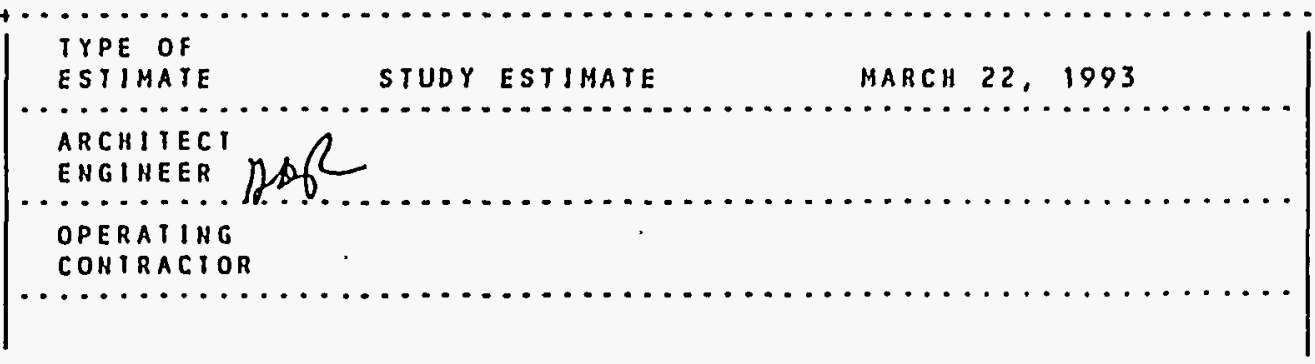


KAISER ENGINEERS IIANFORD WESTINGHOUSE HAHFORD COMPAHY JOB HO. ER-3415

FILE NO. ZOSISAII

\section{HBS DESCRIPTIOH}

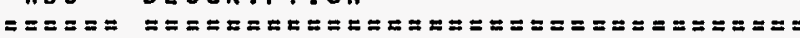

110000 DEFINITIVE DESIGN-ONSITE E/C

111000 CONCEPTUAL DESIGH-ONSITE E/C

120000 ENGIHEERING/INSPECTION-OHSITE E/C

SUBTOTAL 1 ENGINEERING

210000 PROCUREHENT-OHSITE E/C

SUBTOTAL 2 PROCUREMENT

311000 SITE PREP

312000 JET GROUT CONE : HORIZONTAL WALL ,

313000 CLEANUP ACTIVITIES

SUBIOTAL 31 FA CONST-ONSITE E/C

321000 VERTICAL HALL INSTALLATION

SUBTOTAL 32 CONSTRUCTION-FIXED PRICE

SUBTOTAL 3 CONSTRUCTION

500001 OTHER PROJECT COST

SUBIOTAL 5 OTHER PROJECT COST

PROJECT TOTAL
* IEST - INTERACTIVE ESTIMATIHG * *

241-T-101 EXTERHAL TANK STABILIZATIOH ALTERHATIVE STUDY: OPTION 2-SLURRY HALLS/JET GROUTING DOE RO2 - HORK BREAKDOWH STRUCTURE SUMHARY
PAGE 2 OF 9

DATE 03/22/93 07:01:32

\begin{tabular}{|c|c|c|c|c|c|c|c|c|}
\hline $\begin{array}{l}\text { ESTIMATE } \\
\text { SUBTOTAL } \\
=======\end{array}$ & $\begin{array}{l}\text { ONSITE } \\
\text { INDIRECTS } \\
=\approx \equiv=\approx=\equiv\end{array}$ & $\begin{array}{c}\text { SUB } \\
\text { TOTAL } \\
==\approx==\Sigma=z\end{array}$ & 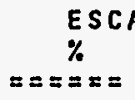 & $\begin{array}{l}\text { LLATION } \\
\text { TOTAL } \\
=======\end{array}$ & $\begin{array}{c}\text { SUB } \\
\text { TOTAL } \\
==\approx=\approx=z==\end{array}$ & $\begin{array}{c}\text { CONTI } \\
=\approx \\
=\approx=z\end{array}$ & $\begin{array}{l}\text { INGENCY } \\
\text { TOTAL } \\
==\approx=====\end{array}$ & $\begin{array}{c}\text { TOTAL } \\
\text { DOLLARS } \\
========\end{array}$ \\
\hline $\begin{array}{r}1398075 \\
279615 \\
559230\end{array}$ & $\begin{array}{l}0 \\
0 \\
0\end{array}$ & $\begin{array}{r}1398075 \\
279615 \\
559230\end{array}$ & $\begin{array}{r}17.25 \\
5.52 \\
25.83\end{array}$ & $\begin{array}{r}241168 \\
15435 \\
144449\end{array}$ & $\begin{array}{r}1639243 \\
295050 \\
703679\end{array}$ & $\begin{array}{l}20 \\
20 \\
20\end{array}$ & $\begin{array}{r}327849 \\
59010 \\
140736\end{array}$ & $\begin{array}{r}1967092 \\
354060 \\
844415\end{array}$ \\
\hline 2236920 & 0 & 2236920 & 17.93 & 401052 & 2637972 & 20 & 527595 & 3165567 \\
\hline 2303200 & 0 & 2303200 & 16.85 & 388089 & 2691289 & 30 & 807387 & 3498676 \\
\hline 2303200 & 0 & 2303200 & 16.85 & 388089 & 2691289 & 30 & 807387 & 3498676 \\
\hline $\begin{array}{r}73485 \\
2701959 \\
88254\end{array}$ & $\begin{array}{l}0 \\
0 \\
0\end{array}$ & $\begin{array}{r}73485 \\
2701959 \\
88254\end{array}$ & $\begin{array}{l}20.33 \\
20.33 \\
20.33\end{array}$ & $\begin{array}{r}14939 \\
549308 \\
17942\end{array}$ & $\begin{array}{r}88424 \\
3251267 \\
106196\end{array}$ & $\begin{array}{l}30 \\
30 \\
30\end{array}$ & $\begin{array}{r}26528 \\
975380 \\
31859\end{array}$ & $\begin{array}{r}116952 \\
4226648 \\
138054\end{array}$ \\
\hline 2863698 & 0 & 2863698 & 20.33 & 582189 & 3445887 & 30 & 1033767 & 4479654 \\
\hline 425400 & 101088 & 526488 & 21.25 & 111879 & 638367 & $30^{\prime}$ & 191510 & 829877 \\
\hline 425400 & 101088 & 526488 & 21.25 & 111879 & 638367 & 30 & 191510 & 829877 \\
\hline 3289098 & 101088 & 3390186 & 20.47 & 694.068 & 4084254 & 30 & 1225277 & 5309531 \\
\hline 2740226 & 0 & 2740226 & 15.40 & 421995 & 3162221 & 30 & 948666 & 4110887 \\
\hline 2740226 & 0 & 2740226 & 15.40 & 421995 & 3162221 & 30 & 948666 & 4110887 \\
\hline
\end{tabular}

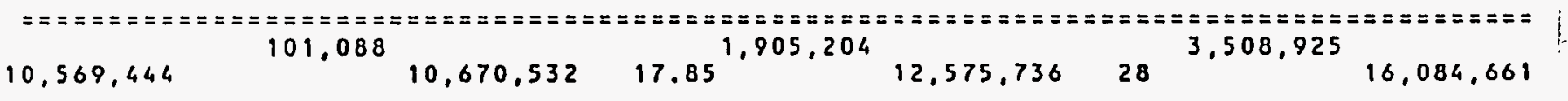


KAISER ENGINEERS IIANFORD HEST INGHOUSE HANFORD COMPANY JOB HO. ER-3415

FILE NO. 203 ISAII
* * IEST - INTERACTIVE ESTIMATING * *
241-T-101 EXTERNAL TANK STABILIZATION ALTERNATIVE
STUDY: OPTION 2-SLURRY HALLS/JET GROUTING
DOE_RO3 - ESTIMATE BASIS SHEET

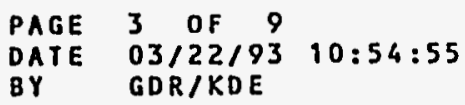

1. DOCUMENTS AHD DRAHIHGS

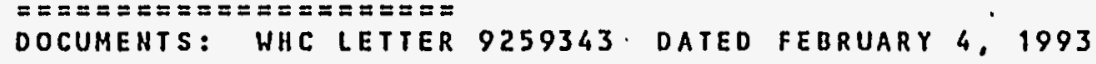

DRAHINGS: HONE

2. MATERIAL PRICES

UNIT COSTS REPRESENT CURRENT PRICES FOR SPECIFIED MATERIAL.

3. LABOR RATES

$=========$

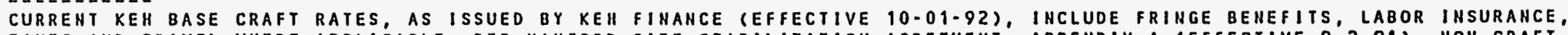

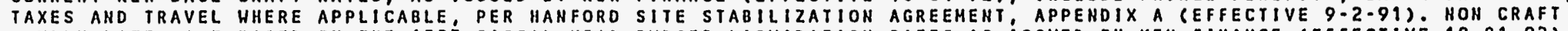

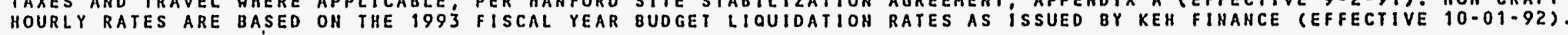

4. GENERAL REQUIREMENTS/TECHNICAL SERVICES/OVERHEADS

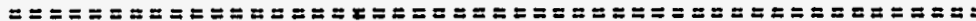

A.) ONSITE CONSTRUCTION FORCES GENERAL REQUIREMENTS, TECHNICAL SERVICES AND CRAFT OVERHEAD COSTS ARE INCLUDED AS A COMPOSITE PERCENTAGE BASED ON THE KEH ESTIMATIHG FACTOR/BILLING SCHEDULE, REVISION I4. DATED OCTOBER O1, 1992. THE TOTAL COMPOSITE PERCEHTAGE APPLIED TO ONSITE CONSTRUCTION FORCES LABOR, FOR THIS PROJECT. IS O3\% FOR SHOP HORK AHD $134 \%$ FOR FIELD HORK, HHICH IS REFLECTED IN THE "OH\&P/B\&I" COLUHA OF THE ESTIMATE DETAIL.

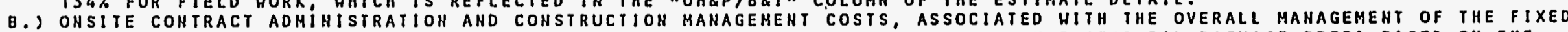
PRICE CONTRACTS, ARE INCLUDED AS A COMPOSITE PERCENTAGE AND LUMP SUM ALLOHANCE (FOR BID PACKAGE PREP) BASED ON THE ESTIMATING FACTOR/BILLING SCHEDULE. THE TOTAL COMPOSITE PERCENTAGE AND LUMP SUM ALLOHANCE ARE APPLIED AGAIHST THE TOTAL FIXED PRICE CONTRACT AMOUNT HHICH IS REFLECTED ON THE KEH SUMHARY REPORT DOEROT, INCLUDED HITH THIS ESTIMATE. (FINAL ESTIMATES MAY BE PARTIALLY MANLOADED AND INCLUDED HITHIN THE ESTIMATE DETAIL)

C.) FIXED PRICE CONTRACTOR OVERHEAO, PROFIT, BOND AND INSURANCE COSTS HAVE BEEN APPLIED AT THE FOLLOHING PERCENTAGES AND ARE REFLECTED IN THE "OH\&P/A\&I" COLUMN OF THE ESTIMATE DETAIL: SUBCONTRACTS $20 \%$

5. ESCALATION

$=========$

ESCALATION PERCENTAGES HERE CALCULATED OY THE HANFORD MATERIAL \& LABOR ESCALATION STUOY, DATED FEBRUARY IQ93.

6. ROUNDING

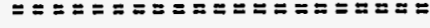

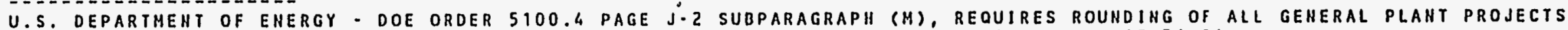
(GPPIS) AND LINE ITEM (LI) COST ESTIMATES. REFERENCE: DOE 5100.4, FIGURE I-11. DATED I0.31.84.

7. REMARKS

$====z==$

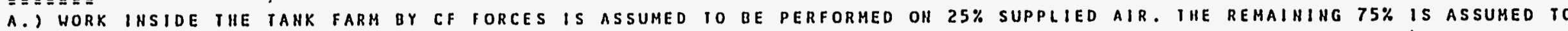
BE IN HHITES.

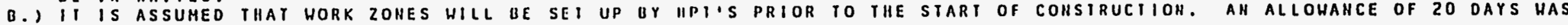
USED FOR TIIIS ACYIVITY. 
KAIS.ER ENGINEERS HANFORD HESIINGHOUSE HANFORD COMPANY JOB HO, ER-3415

FILE NO. ZOS1SAII
* IEST - INTERACTIVE ESTIMATING **

241-T-101 EXTERNAL TANK STABILIZATION ALTERNATIVE

STUDY: OPTION 2-SLURRY WALLS/JET GROUTING

DOE ROZ - ESTIMATE BASIS SHEET
PAGE 4 OF 9

DATE $03 / 22 / 93 \quad 10: 54: 55$

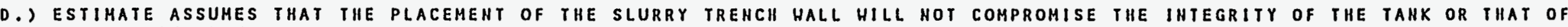
NIEGHBORING TANKS.

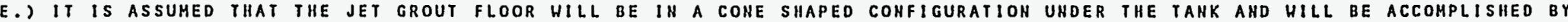
SLANTED GROUT HOLES FOR THE JET GROUTING.

F.) THE SLURRY HALL IS ASSUMED TO BE PLACED IN A CIRCULAR CONGIGURATION AROUND THE TANK.

G.) IT IS ASSUMED THAT THE JET GROUT COHE AND SLURRY HALL WILL HAVE A COMPATIBLE INTERFACE.

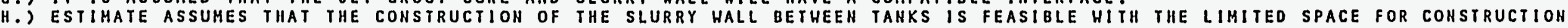
EQUIPHENT.

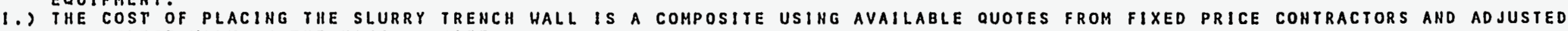
TO REFLECT HORK ON THE HANFORD SITE.

J.) ESTIHATE ASSUMES THAT THIS HORK HILL BE DONE HITHOUT HIHDERANCE FROM COHTAMINATION. IF SUBSURFACE CONTAMINATION IS ENCOUHTERED AND CF FORCES ARE BROUGHT IN TO DO THE HORK, THE COST OF CONSTRUCTION HILL IHCREASE SUBSTAHTIALLY,

K.) ENGINEERING AHD OPC COSTS ARE BASED ON C-106 TOTAL RETRIEVAL ESTIMATE.

L.) OC PROJECT MANAGEMENT COSTS ARE INCLUDEO IN THE OPC COSTS.

M.) AN ALLOHANCE HAS USED FOR PRDCUREMENT OF EQUIPMENT RELATED TO THE INSTALLATION OF THE GEOMEMBRANE HALL.

H.) ESTIMATE CONTAINS NO ALLOHANCES FOR CHARACTERIZATION OR MONITORING HELLS.

0.) ESTIMATE HAS HO COST FOR DEMONSTRATION OR TESTING.

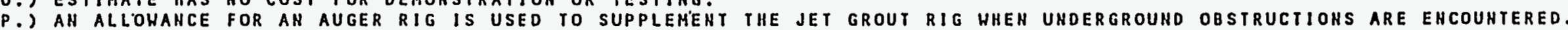

Q.) ESTIHATE CONTAINS NO ALLOWANCE FOR ESCORTS. 
KAISER ENGINEERS HANFORD

HESTINGHOUSE HAHFORD COMPAHY

JOB. HO. ER-3415

FILE HO. $2031 S A 11$

$\cos T$

CODE/WBS

DESCRIPTION

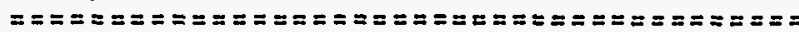

OOO ENGINEERING

910000 DEFINITIVE DESIGH-ONSITE E/C

111000 CONCEPTUAL DESIGN-OHSITE E/C

ENGINEERING/INSPECTION-ONSITE E/C • 559230

TOTAL 000

ENGINEERING

2236920

700 SPECIAL EQUIP/PROCESS SYSTEMS

210000 PROCUREMENT-ONSITE E/C

TOTAL 700

SPECIAL EQUIP/PROCESS SYSTEM

2303200

2303200

830 DRILLING

312000 JET GROUT COHE - HORIZOHTAL HALL

313000 CLEANUP ACTIVITIES

321000 VERTICAL HALL INSTALLATION

TOTAL 830 DRILLING

900 OTHER PROJECT COST

500001 OTHER PROJECT COST

TOTAL 900 OTHER PROJECT COST

PROJECT TOTAL

\section{5}

2701959

88254

425400

3289098

2740226
* * IEST - INTERACTIVE ESTIMATING * * EXIERNAL TANK STABILIZATION ALTERHATIVE TUDY: OPTION 2-SLURRY HALLS/JET GROUTING

DOE_RO4 - COST CODE ACCOUNT SUMMARY

\begin{tabular}{|c|c|c|c|c|c|c|}
\hline $\begin{array}{l}\text { ST IHATE } \\
\text { UB TOTAL } \\
======\end{array}$ & $\begin{array}{l}\text { ONSITE } \\
\text { INDIRECTS } \\
=\approx=\approx \equiv=\approx=\end{array}$ & $\begin{array}{c}\text { SUB } \\
\text { TOTAL } \\
==\approx===\approx=\end{array}$ & $\begin{array}{c}\text { ESCALATION } \\
\text { \% TOIAL } \\
============\end{array}$ & $\begin{array}{c}\text { SUB } \\
\text { TOTAL } \\
===\approx=\Sigma===\end{array}$ & 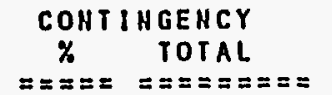 & $\begin{array}{c}\text { TOTAL } \\
\text { DOLLARS } \\
=\approx==\approx===\end{array}$ \\
\hline
\end{tabular}

PAGE 5 OF 9

DATE O3/22/93 07:01:34

BY GOR/KDE

\begin{tabular}{rrrrrrrr|}
0 & 1398075 & 17.25 & 241168 & 1639243 & 20 & 327849 & 1967092 \\
0 & 279615 & 5.52 & 15435 & 295050 & 20 & 59010 & 354060 \\
0 & 559230 & 25.83 & 144449 & 703679 & 20 & 140736 & 844415 \\
0 & 2236920 & 17.93 & 401052 & 2637972 & 20 & 527595 & 3165567
\end{tabular}

$0 \quad 2303200$

$16.85 \quad 388089$

16.85

388089

2691289

2691288

2691288

30

807387

807387

3498676

3498676

101088

0
0
0

73485

2701959

88254

526488

101088

3390186

$20.33 \quad 14939$

$20.33 \quad 549308$

$20.33 \quad 17942$

$\begin{array}{lr}20.33 & 17942 \\ 21.25 & 111879\end{array}$

8842

3251267

3251267
106196

106196
638367

$20.47 \quad 694068$

4084254

694068

2740226

$15.40 \quad 421995$

316222

30

948666

316222130

948666

$0 \quad 2740226 \quad 15.40 \quad 421995$
$1,905,204$

101,088
$10,569,444$

$10,670,532$

17.85

$12,575,736$

28

$3,508,925$

$16.084,66$ 
KAISER ENGINEERS HANFORD HESTINGHOUSE HANFORD COMPANY JOB NO. ER-3415

FILE HO. ZOSISAII

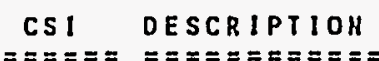

\section{ENG INEERING}

\section{OO TECHNICAL SERVICES}

TOTAL ENGINEERING

CONSTRUCTION

01
02
02 SITEWORK
15
20
20 OPCHANICAL

TOTAL CONSTRUCTION

PROJECT TOTAL
* * IEST - INTERACTIVE ESTIMATING * *

241-T-101 EXTERNAL TANK STUDY: OPTION 2-SLURRY WALLS/JET GROUTING DOE_ROS - ESTIMATE SUMMARY BY CSI OIVISION

\begin{tabular}{|c|c|c|c|c|c|c|c|c|}
\hline $\begin{array}{l}\text { ESTIMATE } \\
\text { SUBTOTAL } \\
=======\end{array}$ & $\begin{array}{l}\text { ONSITE } \\
\text { INDIRECTS } \\
===\approx==\Xi\end{array}$ & $\begin{array}{c}\text { SUB } \\
\text { TOTAL } \\
====\approx===\end{array}$ & $\begin{array}{c}\text { ESC } \\
\% \\
====\end{array}$ & $\begin{array}{l}\text { ALATION } \\
\text { TOTAL } \\
=======\end{array}$ & $\begin{array}{c}\text { SUB } \\
\text { TOTAL. } \\
====\approx=z=\end{array}$ & $\begin{array}{c}\text { CONT } \\
== \pm==\end{array}$ & $\begin{array}{l}\text { INGENCY } \\
\text { TOTAL } \\
=====\equiv=z\end{array}$ & $\begin{array}{c}\text { rOTAL } \\
\text { DOLLARS } \\
==\approx===\approx=\end{array}$ \\
\hline 2236920 & 0 & 2236920 & 17.93 & 401052 & 2637972 & 20 & 527595 & 3165567 \\
\hline $2,236,920$ & 0 & $2,236,920$ & 17.93 & 401,052 & $2,637,972$ & 20 & 527.595 & $3.165,567$ \\
\hline $\begin{array}{r}700219 \\
2588879 \\
2303200 \\
2740226\end{array}$ & $\begin{array}{r}0 \\
101088 \\
0 \\
0\end{array}$ & $\begin{array}{r}700219 \\
2689967 \\
2303200 \\
2740226\end{array}$ & $\begin{array}{l}20.33 \\
20.51 \\
16.85 \\
15.40\end{array}$ & $\begin{array}{l}142354 \\
551714 \\
388089 \\
421995\end{array}$ & $\begin{array}{r}842573 \\
3241681 \\
2691289 \\
3162221\end{array}$ & $\begin{array}{l}30 \\
30 \\
30 \\
30\end{array}$ & $\begin{array}{l}252773 \\
972504 \\
807387 \\
948666\end{array}$ & $\begin{array}{l}1095345 \\
4214186 \\
3498676 \\
4110887\end{array}$ \\
\hline $8,332,524$ & 101,088 & $8,433,612$ & 17.84 & $1,504,152$ & $9,937,764$ & 30 & $2,981,330$ & $12,919,094$ \\
\hline
\end{tabular}

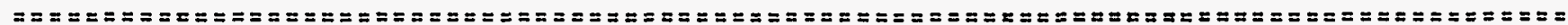
$10,569,444 \quad 101,088 \quad 10,670,532 \quad 17.85 \underbrace{1,905,204} 12,575,736 \quad 283^{3,508,925} 16,084,661$ 
KAISER ENGIHEERS HANFORD HEST INGHOUSE HANFORD COMPANY JOB, NO. ER-3415

FILE HO. ZO3ISAII

\author{
* IEST - INTERACTIVE ESTIMATING * * \\ 241-T-101 EXTERHAL TANK STABILIZATION ALTERNATIVE \\ STUDY: OPTION 2-SLURRY HALLS/JET GROUTING \\ DOE_ROG - CONTINGENCY ANALYSIS BASIS SHEET
}

PAGE 7 OF 9

OATE 03/22/93 10:55:02

BY

THE U.S. DEPARTMENT OF ENERGY - RICHLAND ORDER 5700.3 "COST ESTIMATING, ANALYSIS AND STANOARDIZATION" DATED 3-27-85, PROVIDES GUIDELINES FOR ESTIMATE CONTINGENCIES. THE GUIDELINE FOR A STUOY ESTIMATE SHOULD HAVE AN OVERALL RANGE OF 20 TO $30 \%$

CONTINGENCY' IS EVALUATED AT TIIE THIRD COST CODE LEVEL AND SUMMARIZED AT THE PRIMARY AND SECONDARY COST CODE LEVEL OF THE DETAILED COST ESTIHATE.

\section{ENGINEERING}

COST CODE OOO

HBS 110000 .

111000

120000

CONSTRUCTION

COST CODE 700

HBS 210000

WBS 321000

$\operatorname{COSI} \operatorname{CODE} 830$

HBS 311000 , 312000 , 313000
A $20 \%$ CONTINGENCY HAS APPLIED TO THE ENGINEERING BECAUSE OF A LACK OF DETAIL REGARDIHG THE OESIGN, THE CONSTRUCTION AND THE FACT TIIAT IT IS BASED ON A PERCENTAGE OF CONSTUCTION OOLLARS.

AVERAGE ENGINEERING CONTINGENCY

$30 \%$

A CONTINGENCY OF $30 \%$ HAS APPLIED TO PROCUREMENT AS THERE IS A LACK OF DETAIL CONCERMIHG THE EQUIPMENT REQUIRED FOR CONSTRUCTION AND THE EQUIPMENT REQUIREMENTS FOR THE OPERATION OF THE BARRIER.

A $30 \%$ CONTIMGENCY WAS APPLIEO TO THE FIXED PRICE CONSTRUCTION TO ACCOUNT FOR THE LACK OF DETAIL PROVIDED, POSSIBLE INTERUPIIONS DUE TO CONSTRUCTION HITHIN A TANK FARM. UHDEFINED SOIL CHARACTERISTICS THAT HOULD EFFECI CONSTRUCTION AND THE POSSIBILITY OF SUBSURFACE CONTAHIHATION.

A CONTINGENCY OF $30 \%$ WAS APPLIED IO CF HORK TO ACCOUHT FOR LACK OF DETAIL AND IHE POSSIBILITIES ENCOUNTERING SUBSURFACE CONTAMINAIION. 


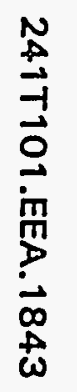

픈도일

m $-\pi$ in

$z=\geq m$

․ ?

m

x등

Nin $=$

나묘

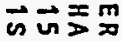

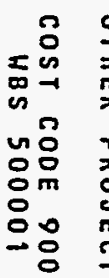

ถู

跤

옹유

중

$\stackrel{\omega}{\omega}$

3
0
0

$\geqslant 0$

学

cᄃ

ñ

$D_{0}$
$=5$
$=5$

$\geq 8$
$-\pi$

is

is

노음

$m$

ס

$=0$

艎是

究祭

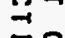

$\overrightarrow{0} 0$

$\geq \frac{\text { u }}{\text { us }}$

is

品

$1 \overrightarrow{1}$

응

ㅈ..

- $\circ \stackrel{m}{x}$

s

용

- I

$\sum_{r}$

m $\mathrm{m}=$

zis

2巨它觉

> क्य

之ख्य

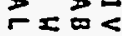

찌

ज正要

जिए人

드른

$>m=z$

너일

政

थ ำ

ma

$m=0$.

즘

鬲

$=$

$=$

$\bar{c}$

$>$

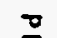

m

20

年

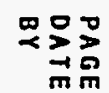

in

욲

웅

刃ำ

$\pi N$

o

$\sum_{n}^{0}$

웅

in

웅

z

- 

JOB .HO. ER-3415

FILE NO. ZOSISAII
KAISER ENGINEERS HANFORD HESTINGHOUSE HAHFORD COMPANY

241-T-101 EXTERHAL TANK STABILIZATION ALTERHATIVE

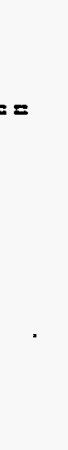

PROJECT TOTAL
* IEST - INTERACTIVE ESTIMATIHG ** STUOY: OPTION 2-SLURRY HALLS/JET GROUTIHG DOE_ROT - ONSITE INDIRECT COSTS BY HBS
1398075

279615

559230

2303200

73485

2701959

88254

425400

2740226
TOTAL

$\begin{array}{rr}0.00 & \\ 0.00 & 0 \\ 0.00 & 0 \\ 0.00 & 0 \\ 0.00 & 0 \\ 0.00 & 0 \\ 0.00 & 0 \\ 22.00 & 0 \\ 0.00 & 93588 \\ & 0\end{array}$

PAGE 9 OF 9

DATE 03/22/93 07:01:39

BY GDR/KDE

OTHER INOIRECTS $z=\Sigma=\Sigma \Sigma= \pm$

QID PACK ID PAC
PREP. $z======$ I HDIRECYS $==== \pm=\Sigma$

$\begin{array}{rr}0 & 0 \\ 0 & 0 \\ 0 & 0 \\ 0 & 0 \\ 0 & 0 \\ 0 & 0 \\ 0 & 0 \\ 7500 & 0 \\ 0 & 0\end{array}$

101088

101088
0

93,588

$10,569,444$
\end{abstract}

$=======2$
101,088

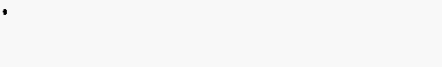


* IEST - INTERACTIVE ESTIMATING * DOE RO1 - PROJECT COST SUMHARY
241-T-101 EXTERHAL TANK STABILIZATIOH ALTERHATIVE STUDY: OPTIOH 3 -GROUND FREEZING
PAGE 1 OF 9

$07: 27: 15$

BY

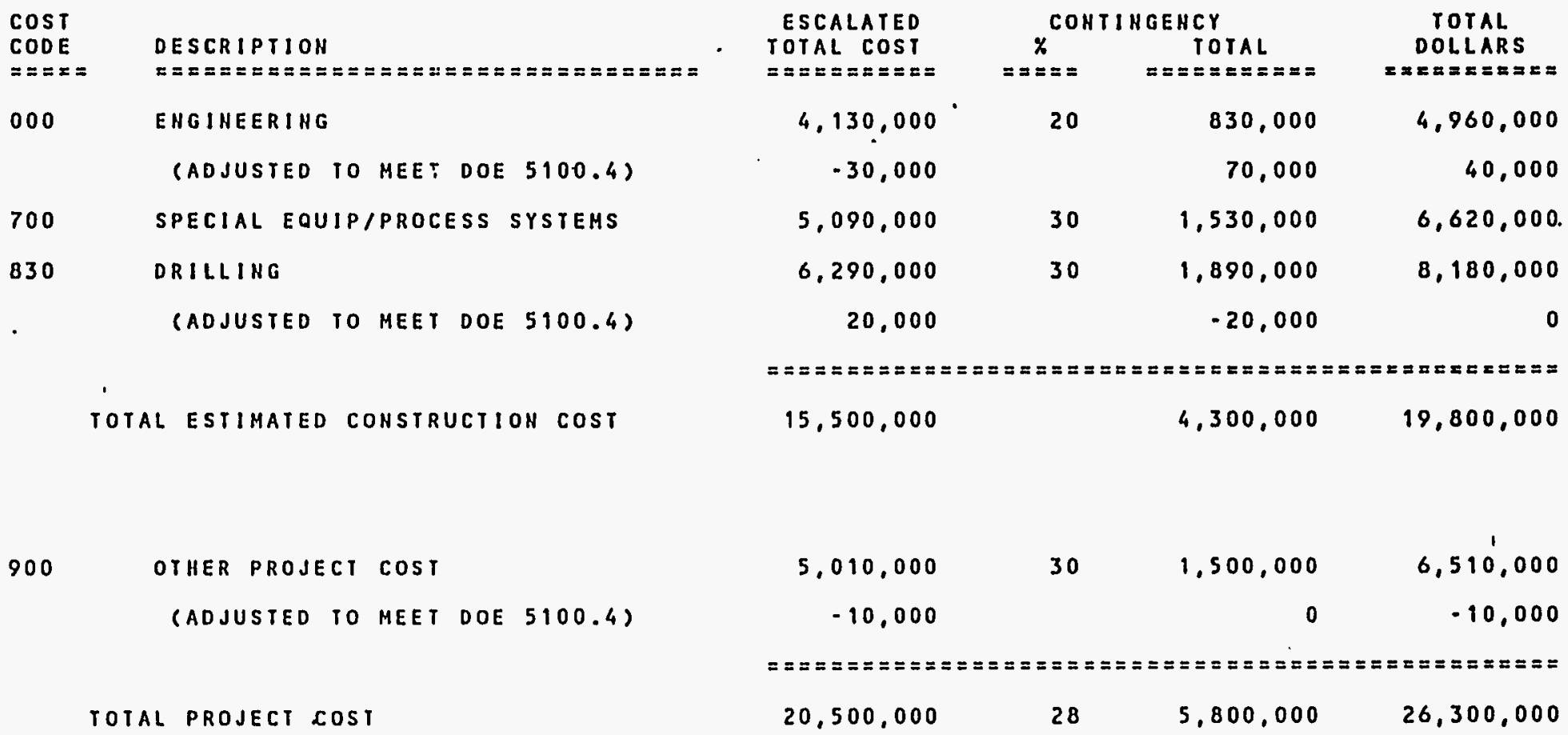

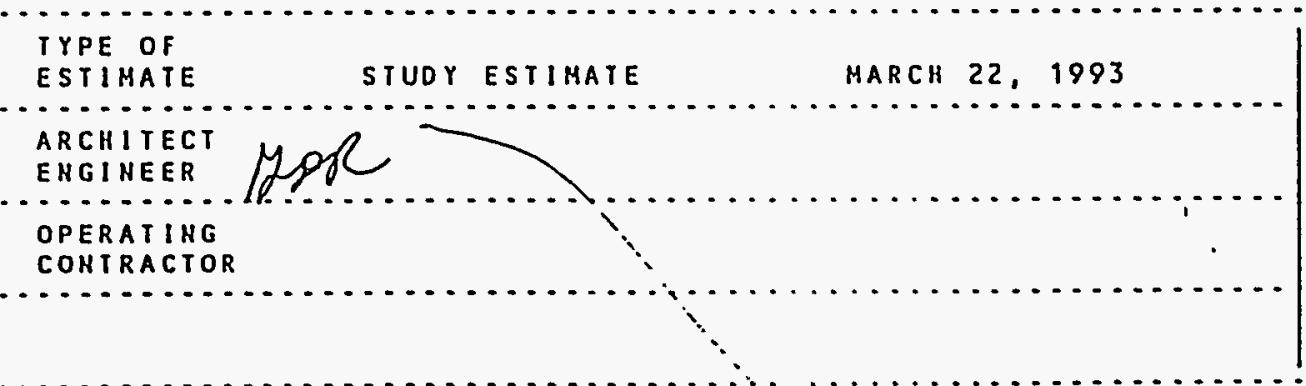

ROUNDEDIADJUSTED 10 IIE NEARES 241T101.EEA.1843
REMARKS :

A-95 
KAISER ENGINEERS HANFORD HESTINGHOUSE HAHFORD COMPAHY JOB.NO. ER-3415

FILE NO 2031 SAJI

HBS DESCRIPTIOH

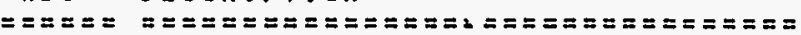

110000 DEFINITIVE DESIGH-ONSITE E/C

111000 CONCEPTUAL DESIGH-ONSITE E/C

120000 ENGINEERING/INSPECTION-ONSITE E/C SUBTOTAL 1 ENGINEERING

210000 PROCUREMENT-ONSITE E/C

SUBTOTAL 2 PROCUREMENT

311000 SITE PREP

312000 PLACE BELOH GRADE PIPING

313000 CLEANUP ACTIVITIES

SUBTOTAL 31 FA CONST-ONSITE E/C

321000 ABOVE GRADE CONSTRUCTION

SUBTOTAL 32 CONSTRUCTION-FIXED PRICE

SUBTOTAL 3

CONSTRUCTION

500001 OTHER PROJECT COSI

SUBTOTAL 5 OTHER PROJECT COST

PROJECT TOTAL
* * IEST - INTERACTIVE ESTIMATING * *

241-T-101 EXTERNAL TAHK STABILIZATION ALTERHATIVE STUDY: OPTION 3-GROUND FREEZING

DOE_RO2 - HORK BREAKDOWN STRUCTURE SUMMARY
PAGE 2 OF 9

DATE $03 / 22 / 93 \quad 07: 27: 19$

BY GDR/KDE

\begin{tabular}{|c|c|c|c|c|c|c|c|c|}
\hline $\begin{array}{l}\text { ESTIMATE } \\
\text { SUB TOTAL } \\
=======\end{array}$ & $\begin{array}{l}\text { ONSITE } \\
\text { INDIRECTS } \\
=======\end{array}$ & $\begin{array}{c}\text { SUB } \\
\text { TOTAL } \\
========\end{array}$ & 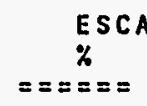 & $\begin{array}{l}\text { ALATION } \\
\text { TOTAL } \\
=======\end{array}$ & $\begin{array}{c}\text { SUB } \\
\text { TOTAL } \\
==\approx=\approx===\end{array}$ & $\begin{array}{c}\text { CONT } \\
\% \\
=====\end{array}$ & $\begin{array}{l}\text { INGENCY } \\
\text { TOYAL } \\
========\end{array}$ & $\begin{array}{c}\text { TOTAL } \\
\text { DOLLARS } \\
=== \pm==\equiv=\end{array}$ \\
\hline $\begin{array}{r}2189177 \\
437835 \\
875671\end{array}$ & $\begin{array}{l}0 \\
0 \\
0\end{array}$ & $\begin{array}{r}2189177 \\
437835 \\
875671\end{array}$ & $\begin{array}{r}17.25 \\
5.52 \\
25.83\end{array}$ & $\begin{array}{r}377633 \\
24168 \\
226186\end{array}$ & $\begin{array}{r}2566810 \\
462003 \\
1101857\end{array}$ & $\begin{array}{l}20 \\
20 \\
20\end{array}$ & $\begin{array}{r}513362 \\
92401 \\
220371\end{array}$ & $\begin{array}{r}3080172 \\
554404 \\
1322228\end{array}$ \\
\hline 3502683 & 0 & 3502683 & 17.93 & 627987 & 4130670 & 20 & 826134 & 4956804 \\
\hline 1698300 & 0 & 1698300 & 16.85 & 286164 & 1984464 & 30 & 595339 & 2579803 \\
\hline 1698300 & 0 & 1698300 & 16.85 & 286164 & 1984464 & 30 & 595339 & 2579803 \\
\hline $\begin{array}{r}73485 \\
5183305 \\
88254\end{array}$ & $\begin{array}{l}0 \\
0 \\
0\end{array}$ & $\begin{array}{r}73485 \\
5183305 \\
88254\end{array}$ & $\begin{array}{l}17.67 \\
17.67 \\
17.67\end{array}$ & $\begin{array}{r}12984 \\
915890 \\
15595\end{array}$ & $\begin{array}{r}86469 \\
6099195 \\
103849\end{array}$ & $\begin{array}{l}30 \\
30 \\
30\end{array}$ & $\begin{array}{r}25949 \\
1829759 \\
31155\end{array}$ & $\begin{array}{r}112410 \\
7928953 \\
135003\end{array}$ \\
\hline 5345044 & 0 & 5345044 & 17.67 & 944469 & 6289513 & 30 & 1886855 & $\therefore 8176366$ \\
\hline 1713363 & 879138 & 2592501 & 19.87 & 515130 & 3107631 & 30 & 932289 & 4039920 \\
\hline 1713363 & 879138 & 2592501 & 19.87 & 515130 & 3107631 & 30 & 932289 & 4039920 \\
\hline 7058407 & 879138 & 7937545 & 18.39 & 1459599 & 9397144 & 30 & 2819144 & 12216286 \\
\hline 4290786 & 0 & 4290786 & 16.78 & 719994 & 5010780 & 30 & 1503234 & 6514014 \\
\hline 4290786 & 0 & 4290786 & 16.78 & 719994 & 5010780 & 30 & 1503234 & 6514014 \\
\hline
\end{tabular}


KAISER ENGINEERS HANFORD HEST INGHOUSE HAHFORD COMPANY JOB NO. ER-3415

FILE HO. ZOSISAJI
* IEST - IHTERACTIVE ESTIMATIHG **

241-T-101 EXTERNAL TAHK STABILIZATION ALTERHATIVE

STUDY: OPTIOH 3-GROUND FREEZIHG

DOE_RO3 - ESTIMATE BASIS SHEET
PAGE 3 OF 9

DATE 03/22/93 10:55:21

BY

1. DOCUMENTS AND DRAHINGS

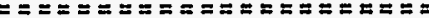

DOCUMENTS: HHC LETTER 9259343 DATED FEBRUARY 4, 1993

DRAWIHGS: NONE

2. MATERIAL PRICES

MATERIAL PRICES

UNIT COSTS REPRESENT CURRENT PRICES FOR SPECIFIED MATERIAL.

3. LABOR RATES

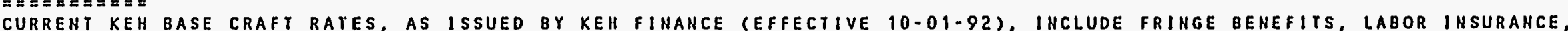

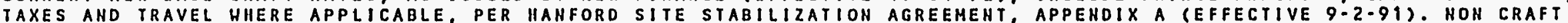

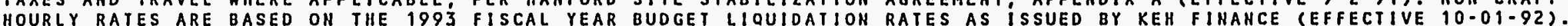

4. GENERAL REQUIREMENTS/TECHNICAL SERVICES/OVERHEADS

A.) ONSITE CONSTRUCTION FORCES GENERAL REQUIREMENTS, TECHNICAL SERVICES AND CRAFT OVERHEAD COSTS ARE INCLUDED AS A COMPOSIIE PERCENTAGE BASED ON THE KEH ESTIMATING FACTOR/BILLING SCHEOULE, REVISION I4, DATED OCTOBER O1, I992. THE TOTAL COMPOSITE PERCENTAGE APPLIED TO ONSITE CONSTRUCTION FORCES LABOR, FOR THIS PROJECT, IS 93\% FOR SHOP HORK AND 134\% FOR FIELD HORK, WHICH IS REFLECTED IN THE "OH\&P/B\&I" COLUMN OF THE ESTIMATE DETAIL.

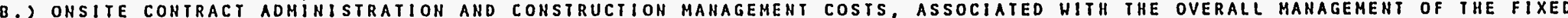
PRICE CONTRACTS, ARE INCLUDED AS A COMPOSITE PERCENTAGE AND LUMP SUM ALLOHANCE (FOR BID PACKAGE PREP) BASED ON THE ESTIMATING FACTOR/BILLING SCHEDULE. THE TOTAL COMFOSITE PERCEHTAGE AND LUMP SUM ALLOHAHCE ARE APPLIED AGAINST THE TOTAL FIXED PRICE CONTRACT AMOUNT WHICH IS REFLECTED ON THE KEH SUMHARY REPORT DOEROT, INCLUDED HITH THIS ESTIMATE. (FINAL.ESTIMATES MAY BE PARTIALLY MPALOADED AND INCLUDED WITHIN THE ESTIHATE DETAIL)

C.) FIXED PRICE CONTRACTOR OVERHEAD, PROFIT, BOND AND INSURANCE COSTS HAVE BEEN APPLIED AT THE FOLLOWING PERCENTAGES AND ARE REFLECTED IN THE "OH\&P/BALI" COLUMN OF THE ESTIMATE DETAIL:

SUBCONTRACTS $15 \%$

5. ESCALATION

$========$

ESCALATION PERCENTAGES HERE CALCULATED UY THE HANFORD MATERIAL \& LABOR ESCALATION STUDY, DATED FEBRUARY I993.

6. ROUNDING

$=================$

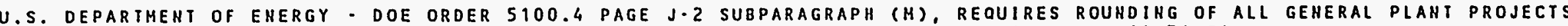
(GPP'S) AND LINE ITEM (LI) COST ESTIMATES. REFERENCE: DOE 5I00.4, FIGURE 1-11, DATED 10-31-84.

7. REMARKS

$==\Sigma===$

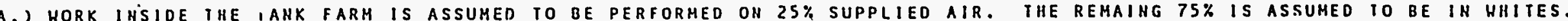

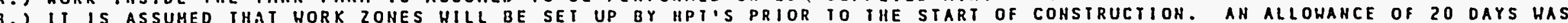
USED IOR IHIS ACTIVITY.

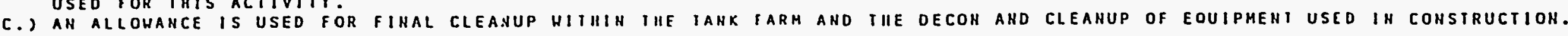


KAISER ENGINEERS HANFORD HESTINGHOUSE HANFORD COMPANY JOB HO. ER - 3415

FILE HO. ZOSISAJI
* IEST - INTERACTIVE ESTIMATING * *

241-T-101 EXTERHAL TANK STABILIZATION ALTERHATIVE

STUDY: OPTION 3-GROUND FREEZING

DOE RO3. ESTIMATE BASIS SHEET
PAGE 4 OF 9

DATE 03/22/93 10:55:21

BY

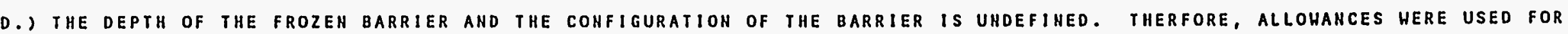
DRILLING DEPTHS, MATERIAL REQUIREMENTS AND REFRIGIRATION NEEDS.

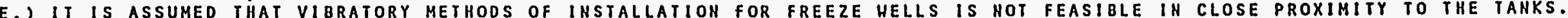
ESTIMATE ASSUMES THAT ALL UNDERGROUND PIPING HILL BE INSTALLED BY R/C AIR ROTARY DRILLING RIGS.

F.) ESTIMATE ASSUMES THE USE OF CARBON STEEL HELL CASING FOR THE FREEZE HELLS.

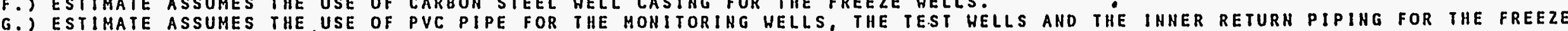
PIPE.

H.) ESTIMATE ASSUMES THE USE OF CARBON STEEL PIPE FOR THE ABOVE GROUNO PIPING SYSTEM.

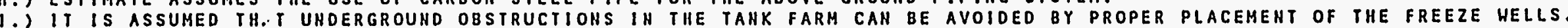

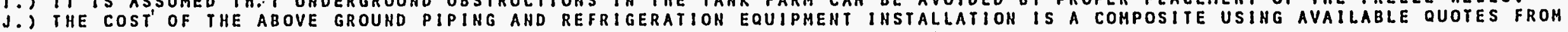
FIXED PRICE CONTRACTORS AND ADJUSTED TO REFLECT HORK ON THE HANFORD SITE.

K.) ESTIMATE ASSUMES THAT THIS HORK HILL BE DOHE HITHOUR HINDERANCE FROM CONTAMIHATIOH. IF SURFACE CONTAMINATION IS ENCOUNTERED AND CF FORCES ARE BROUGHT IN TO DO THE HORK. THE COST OF CONSTRUCTION HILL INCREASE SUBSTANTIALLY.

) ENGINEERIHG AND OPC COSTS ARE BASED ON C. 106 TOTAL RETRIEVAL ESTIMATE.

M.) OC PROJECT MANAGEMEHT COSTS ARE INCLUDED IH TIIE OPC COSTS.

N.) ESTIMATE CONTAINS NO ALLOWANCE FOR CHARACTERIZATION HELLS.

D.) ESTIMATE HAS NO COST FOR DEMONSTRATION OR TESTING.

P.) NO ALLOWANCE FOR ESCORTS IS INCLUDED IN ESTIMATE.

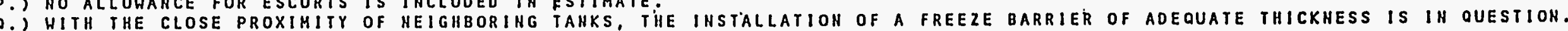
R.) ESTIMATE CONTAINS THE COST FOR THE INITIAL FREEZE DOHH PERIOD OF THE BARRIER.

S.) ESTIMATE DOES NOT INCLUDE THE 30 YEAR POHER COSTS ASSOCIATED HITH MAINTAINING THE BARRIER OVER ITS LIFE SPAN.

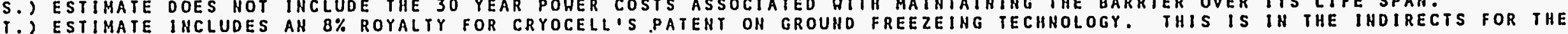
FIXED PRICE CONSTRUCTIOH. THE ROYALTY APPLIES TO CONSTRUCTION COSTS FOR IHSTALLIHG THE BARRIER. 
KAISER EHGINEERS HANFORD

HESTINGHOUSE HANFORD COMPAHY

JOB NO. ER-3415

FILE HO. ZOSISAJ

$\cos T$

CODE/HBS

DESCRIPTION

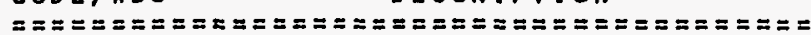

\section{OOO ENGINEERING}

110000 DEFINITIVE DESIGN-ONSITE E/C

111000 CONCEPIUAL DESIGN-ONSITE E/C

120000 ENGINEERING/INSPECTIOH-ONSITE E/C

TOTAL OOO, ENGINEERING

\section{SPECIAL EQUIP/PROCESS SYSTEMS}

210000 PROCUREMENT-ONSITE E/C

321000 ABOVE GRADE CONSTRUCTIOH

TOTAL 700 SPECIAL EQUIP/PROCESS SYSTLM

830 ORILLING

\section{SITE PREP}

312000 PLACE BELOH GRADE PIPING

313000 CLEANUP ACTIVITIES

TOTAL 830 DRILLING

900 OTHER PROJECT COST

500001 OTHER PROJECT COST

TOTAL 900 OTHER PROJECT COST

PROJECT TOIAL
* IEST - IHTERACTIVE ESTIMATING **

241-T-101 EXTERHAL TANK STABILIZATION ALTERNATIVE

STUDY: OPTION 3-GROUHD FREEZING

DOE_ROL COST CODE ACCOUNT SUMMARY

ESTIMATE

SUBTOTAL

ONSITE

I HD I RECTS

SUB

TOTAL

$== \pm=\Sigma==$

$========$

$======= \pm$

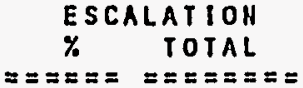

TOTAL.

PAGE 5 OF 9

DATE 03/22/93 07:27:2

BY

GDR/KOE

$======$

TOTAL

TOTAL

DOLLARS

$==\Xi=ニ==$

2189177

437835

875671

3502683

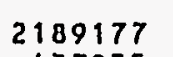

437835

875671

17.25

5.52
25.83

377633

24168

2566810
462003

1101857

20
20

20
20

513362

92401

3080172

$\begin{array}{lll}3502683 & 17.93 & 627987\end{array}$

4130670

20

826134

1322228

4956804

1698300

1713363

$0 \quad 1698300$

16.85

286164

515130

3107631

879138

18.67

801294

5092095

30

59533

932289

1527628

4039920

6619723

\section{5}

5183305

88254

5345044

$$
\begin{aligned}
& 0 \\
& 0 \\
& 0
\end{aligned}
$$

73485
5183305

88254

17.67

17.67
17.67

12984
915890

15890
15595

86469
6090195

6099195
103849

5345044

$17.67 \quad 944469$

6289513

30

30

25941

1829759

829759
31155

7928953

135003

1886855

8176366

4290786

0

4290786

16.78

719994

5010780

4290786

719994

5010780

30

1503234

6514014

4290786 
KAISER ENGIHEERS HANFORO

HESTINGHOUSE HANFORD COMPANY

JOB HO. ER-3415

FILE NO. ZOS1SAJ1

CSI DESCRIPTIOH

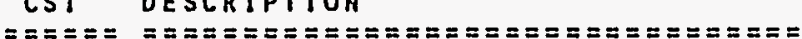

ENG INEERING

OO TECHNICAL SERVICES

TOTAL ENGINEERING

CONSTRUCTION

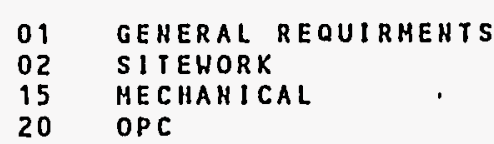

TOTAL CONSTRUCTION

PROJECT TOTAL
* IEST - INTERACTIVE ESTIMATING * *

241-T-101 EXIERHAL TANK STABILIZATIOH ALTERNATIVE STUDY: OPTION 3-GROUND FREEZINC

DOE_ROS. ESTIMATE SUMMARY BY CSI DIVISION
03/22/93 $07: 27: 24$ BY GDR/KDE

\begin{tabular}{|c|c|c|c|c|c|}
\hline $\begin{array}{l}\text { STIHATE } \\
\text { UBTOTAL } \\
:=\approx==\approx=\end{array}$ & $\begin{array}{l}\text { ONSITE } \\
\text { INDIRECTS } \\
========\end{array}$ & $\begin{array}{c}\text { SUB } \\
\text { TOTAL } \\
=======\end{array}$ & $\begin{array}{c}\text { ESCALATION } \\
\% \text { \% TOTAL } \\
==\approx====\approx==\end{array}$ & $\begin{array}{c}\text { SUB } \\
\text { TOTAL } \\
========\end{array}$ & $\begin{array}{l}\text { CONTINGENCY } \\
\% \quad \text { TOTAL } \\
============\end{array}$ \\
\hline
\end{tabular}

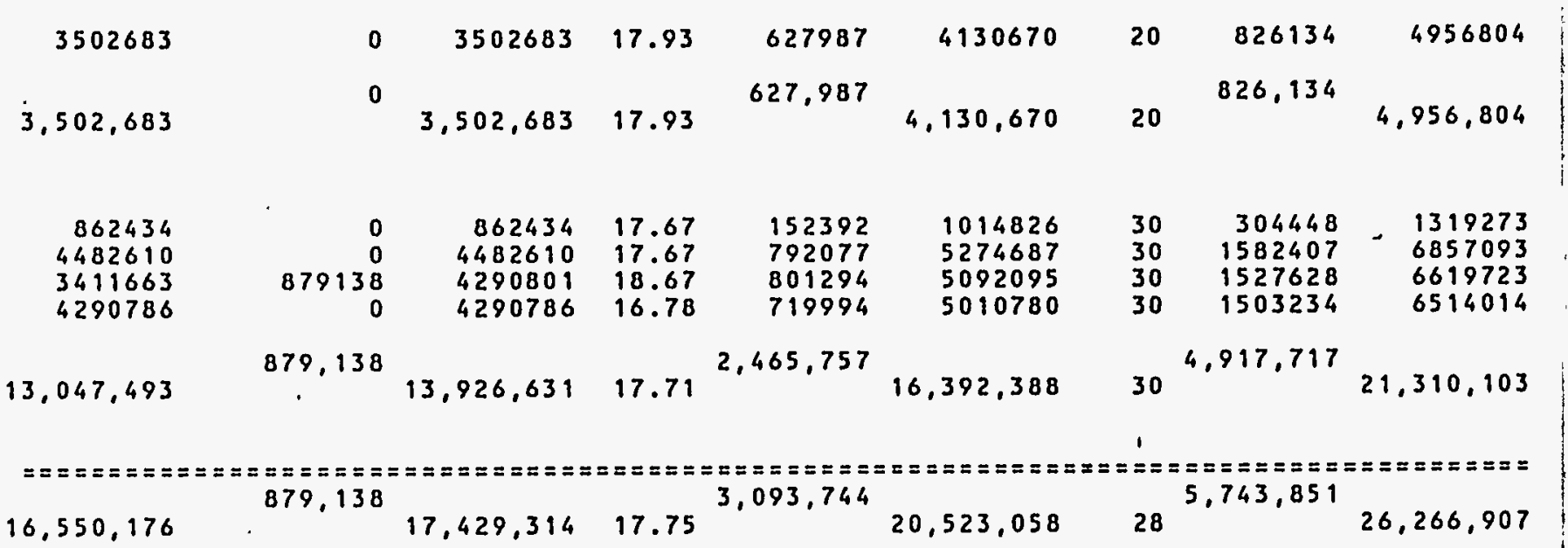


KAISER ENGIHEERS HAHFORD WEST INGHOUSE HANFORD COMPANY JOB HO. ER-3415

FILE NO. ZOSISAJI
241-T-101 IEST - INTERACTIVE ESTIMATING * *

STUDY: OPTIOH 3 -GROUHD FREEZING

DOE_ROG - CONTINGENCY ANALYSIS BASIS SHEET
PAGE 7 OF 9

DATE 03/22/93 10:55:29

BY $\begin{array}{llll}\text { PAGE } & 3 & \text { OF } & 9 \\ \text { PAGE } & 5 & \text { OF } & 9\end{array}$

THE U.S. DEPARTMENT OF ENERGY - RICHLAND ORDER 5700.3 "COST ESTIHATING, ANALYSIS AND STANDARDIZATION" DATED 3-27-85, PROVIDES GUIDELIHES FOR ESTIMATE CONTINGENCIES. THE GUIDELINE FOR A STUDY ESTIHATE SHOULD HAVE AN OVERALL RANGE OF 20 TO $30 \%$.

CONTINGEHCY IS EVALUATED AT THE THIRD COST CODE LEVEL AND SUMMARIZED AT THE PRIMARY AND SECONDARY COST CODE LEVEL OF THE DETAILED COST ESTIHATE.

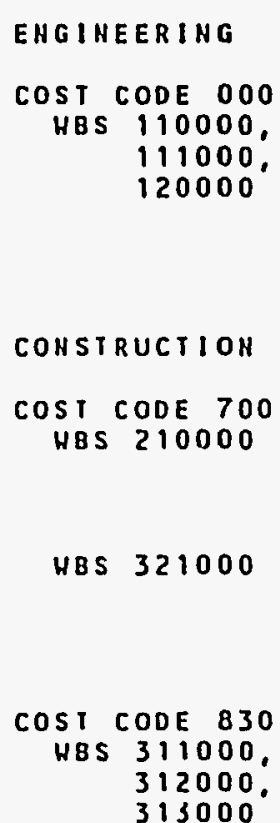

CONSTRUCTION

COST CODE 700

HBS 210000

UBS 321000

$\cos 1$ CODE 830

HBS 311000 .

312000 .

$315000^{\circ}$

AVERAJE ENGINEERING CONTINGENCY $20 \%$

A CONTINGENCY OF $30 \%$ HAS APPLIED IO PROCUREHENT AS THERE IS A LACK OF DETAIL CONCERNING THE EQUIPMENT REOUIRED FOR CONSIRUCIION AND THE EQUIPMENT REQUIREMEHTS FOR IHE OPERATION OF THE BARRIER.

A $30 \%$ CONTINGENCY HAS APPLIED TO THE FIXEO PRICE CONSTRUCTION TO ACCOUHT FOR THE LACK OF DETAIL W PROVIDED, POSSIBLE INTERUPTIONS DUE TO CONSTRUCTION HITHIN A TAHK FARM, UNDEFINED SOIL

CHARACTERISTICS THAT HOULD EFFECT CONSTRUCTION AND THE POSSIBILITY OF SURFACE CONTAMINATION.

A CONTINGENCY OF $30 \%$ WAS APPLIED TO CF HORK TO ACCOUNT FOR LACK OF DETAIL AHD IHE POSSIBILITIES OF ENCOUNTERIHG SUBSURFACE CONIAMINATIOH.

AVERAGE COHSTRUCIION CONIINGENCY $30 \%$ 
KAISER ENGINEERS HANFORD HESTIHGHOUSE HAHFORD COMPANY

JOB NO. ER-3415

FILE NO. ZOS ISAJI
* IEST - INTERACTIVE ESTIMATIHG * *

241-T-101 EXTERNAL TANK STABILIZATION ALTERNATIVE

STUDY: OPTION 3-GROUND FREEZING

DOE_ROG - CONTINGENCY ANALYSIS BASIS SHEET
PAGE 8 OF 9

DATE $03 / 22 / 93 \quad 10: 55: 29$

BY GDR/XOE

OTHER PROJECT COSTS

$\operatorname{COST} \operatorname{coDE} 900$

WBS 500001

A CONTINISENCY OF $30 \%$ WAS PLACED ON OTHER PROJECY COSTS AS IT IS A PERCENTAGE OF CONSTRUCTION AND IS DRIVEN BY THE SAME UHCERTAINTIES AS THE CONSTRUCTION.

AVERAGE * PROJECT COST CONTINGENCY $30 \%$

AVERAGE PROJECT CONTINGENCY

$28 \%$ 
XAISER ENGINEERS HAHFOK.

WESTINGHOUSE HAHFORD COHPAHY

JOB NO. ER-3415

FILE HO. ZOSISAJI
* IEST - INTERACTIVE ESTIMATING **

241-T-101 EXTERHAL TAHK STABILIZATION ALTERHATIVE STUDY: OPTIOH 3-GROUND FREEZIHG

DOE_ROT - ONSITE INDIRECT COSTS BY WBS

\begin{tabular}{|c|c|c|}
\hline $\begin{array}{l}\text { ESTIMATE } \\
\text { SUBTOTAL } \\
=======\end{array}$ & $\begin{array}{c}\text { CONTRACT } \\
\% \\
==z==\end{array}$ & $\begin{array}{c}\text { ADHIHISTRATIOH } \\
\text { TOIAL } \\
=z=z=z==\end{array}$ \\
\hline $\begin{array}{r}2189177 \\
437835 \\
875671 \\
1698300 \\
73485 \\
5183305 \\
88254 \\
1713363 \\
4290786\end{array}$ & $\begin{array}{r}0.00 \\
0.00 \\
0.00 \\
0.00 \\
0.00 \\
0.00 \\
0.00 \\
16.00 \\
0.00\end{array}$ & $\begin{array}{r}0 \\
0 \\
0 \\
0 \\
0 \\
0 \\
0 \\
0 \\
274138 \\
0\end{array}$ \\
\hline
\end{tabular}

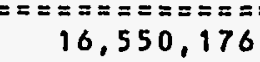

PAGE 9 OF 9

DATE 03/22/93 07:27:26

BY

GR/KDE

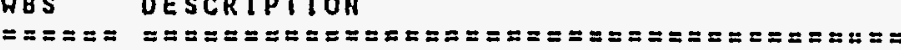

110000 DEFINITIVE DESIGH-OHSITE E/C

111000 CONCEPTUAL DESIGN-ONSITE E/C

120000 ENGINEERING/INSPECTION-ONSITE E/C

210000 PROCUREMENT-ONSITE E/C

311000 SITE PREP

312000 PLACE BELOH GRADE PIPINO

313000 CLEANUP ACTIVITIES

321000 ABOVE GRADE CONSTRUCTION

500001 OTHER PROJECT COST

PROJECT TOTAL

\section{BID PACK \\ PREP.}

$==== \pm=2$

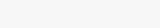

0

0
0
0
0
0
0
5000
0
OTHER
INDIRECTS

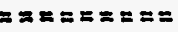

(1)

0
0
0
0
0
0
0
590000
0

NDIRECTS

$====== \pm=$

0
0
0
0
0
0
0
0
0

15,000

274.138

590,000

879,138 . 
WHC-EP-0873, Rev. 0

\section{DISTRIBUTION}

Number of Copies

ONSITE

1

U.S. Department of Energy

Richland Operations office

B. J. Harp \$7-52

8

ICF Kaiser Hanford Company

T. Ambal am

C. H. Brevick

B4-20

L. E. Hall

S3-10

B. K. Rarig

R. T. Steen

B4-40

D. T. VIadimiroff

S3-10

ICF KH Publication

S3-10

R2-80

ICF KH Document Control

E6-63

R1-29

23

Westinghouse Hanford Company

V. C. Boyles

R1-49

J. G. Burton

D. B. Engelman

C. E. Jenkins

S7-01

T. E. Rainey

R1-49

B4-54

R. R. Stickney

R2-54

R2-54

Central Files (2)

A3-88

Tank Chracterization Resource Library

0.S.T.I

(2)

R2-12

G3-11 